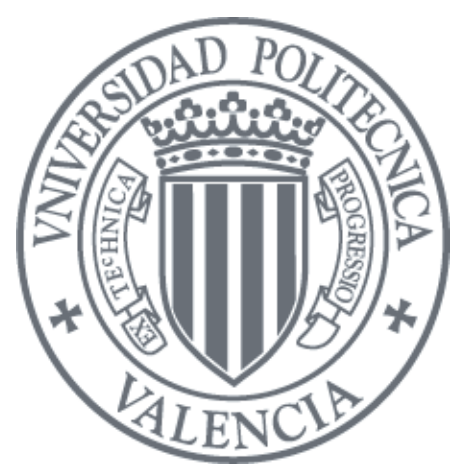

\title{
UTILIZACIÓN DE LAS TECNOLOGÍAS DE LA INFORMACIÓN COMO SOPORTE A LA ESTRATEGIA COMPETITIVA Y SU IMPACTO EN EL DESEMPEÑO EMPRESARIAL
}

\section{TESIS DOCTORAL}

Presentada por: D. David Martínez Simarro

Directores: Dr. D. Carlos Alberto Devece Carañana

Dr. D. Daniel Palacios Marqués 

A Sonia 



\section{Agradecimientos}

Los elementos y las personas que impulsan el desarrollo de un trabajo tan ambicioso, complejo y amplio como es una Tesis Doctoral son muchos y variados. En cierta forma podríamos decir que es un trabajo de equipo, porque aunque es el doctorando el que desarrolla el trabajo de investigación, las circunstancias y las personas que lo rodean tienen mucho que ver en el resultado final. Considero que a todas esas personas que me han rodeado a lo largo de este tiempo les corresponde una parte del mérito de que haya podido llegar al final de este trabajo. Sin su contribución de forma directa o indirecta, probablemente no estaría escribiendo estas líneas.

En primer lugar quisiera agradecer a la Dirección de ainia centro tecnológico, organización en la que desempeño mi actividad profesional, su apoyo y aliento para que pudiera desarrollar este trabajo, particularmente al Dr. Sebastián Subirats y a la Dra. Maria José Peris. Sin su asentimiento y atención a mi propuesta de desarrollar este trabajo hubiera sido imposible abordarlo.

En segundo lugar me gustaría agradecer a mis directores de tesis, Dr. Carlos Alberto Devece y Dr. Daniel Palacios su paciencia, su apoyo y sus recomendaciones, las cuales han sido clave para el correcto desarrollo de esta tesis y especialmente a Carlos su dedicación y apoyo en las últimas fases. Ellos me han ayudado a transitar por este camino donde no siempre se ve la luz al final del túnel. Son personas que, además de estar dotados de excelentes cualidades profesionales y académicas, han demostrado grandes cualidades humanas en su relación conmigo. Cuentan con todo mi respeto profesional y cariño personal.

Por último, y de una forma especialmente efusiva y emotiva, me gustaría agradecer a mi familia, a mis padres Joaquín y Paquita, a mis hermanos Sergio y Estela, y particularmente a Sonia, mi compañera de camino, su apoyo, su comprensión y su cariño. Todos ellos saben la variedad de estados de ánimo de distinta naturaleza que he pasado a lo largo de este periodo y me han soportado cuando las dudas me invadían, las fuerzas desfallecían o el poco tiempo libre que tenía lo dedicaba a desarrollar este trabajo. A todos ellos quiero agradecerles de corazón su paciencia, reconocer su contribución y pedirles disculpas por esos momentos. Ellos saben lo mucho que les quiero. 



\section{ÍNDICE DE CONTENIDOS}

Pág. 3 de 329 
Pág. 4 de 329 


\section{ÍNDICE DE CONTENIDOS}

RESUMEN TESIS DOCTORAL

ABSTRACT DOCTORAL THESIS.......................................................................................................11

RESUM TESI DOCTORAL .........................................................................................................................13

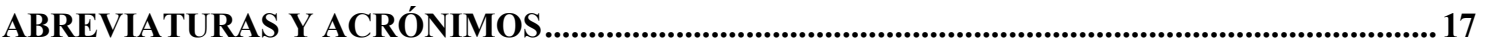

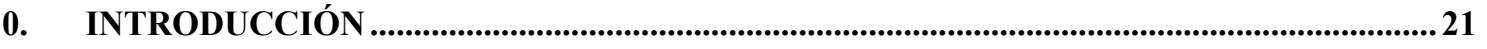

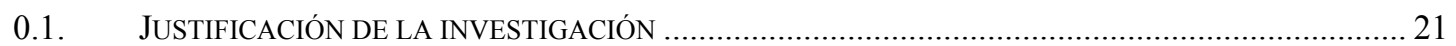

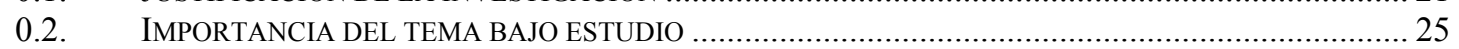

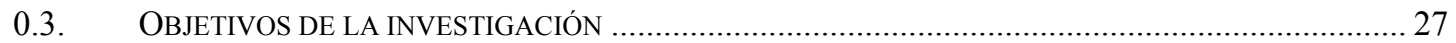

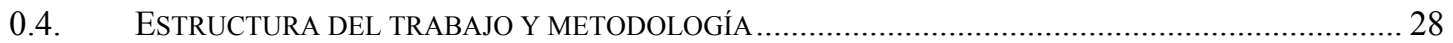

1. LA VENTAJA COMPETITIVA SOSTENIBLE Y LAS TI: UN ENFOQUE BASADO EN

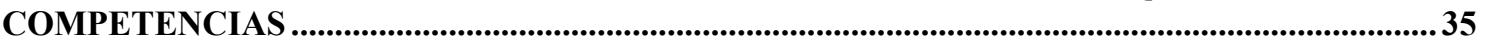

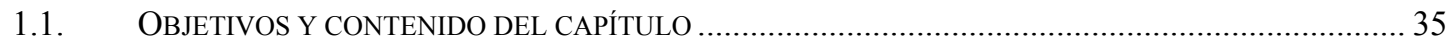

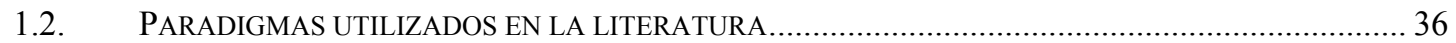

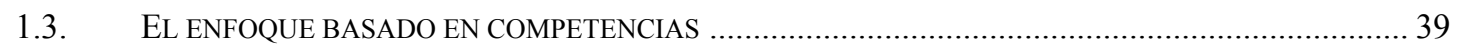

1.3.1. El enfoque basado en recursos..................................................................................... 41

1.3.2. El enfoque basado en las capacidades dinámicas.................................................................. 44

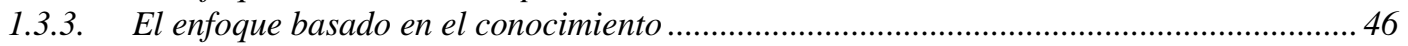

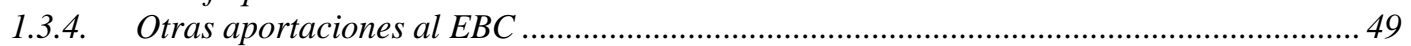

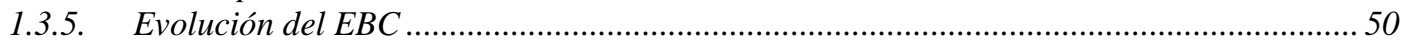

1.3.6. Complementariedad entre el EBC y otros enfoques............................................................5 55

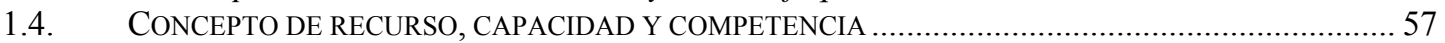

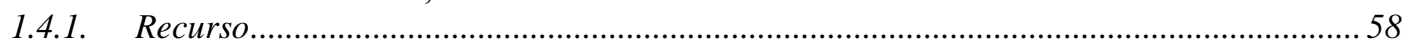

1.4.1.1. Definición de Recurso ……………………………………………………………...5

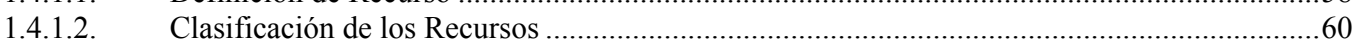

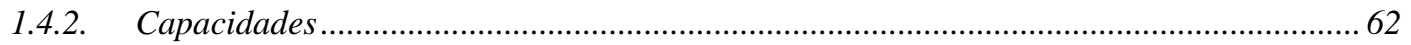

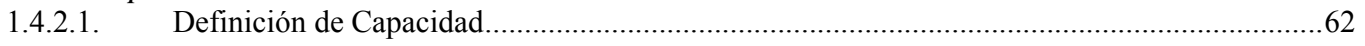

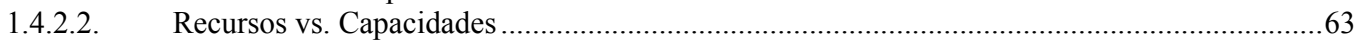

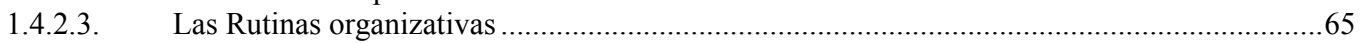

1.4.2.4. Las Capacidades dinámicas ...........................................................................................66

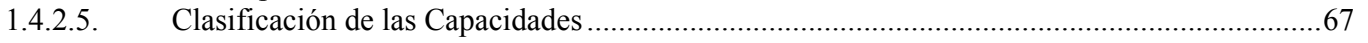

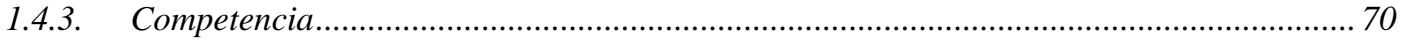

1.5. LAS COMPETENCIAS DISTINTIVAS COMO FUENTE DE VENTAJA COMPETITIVA SOSTENIBLE ........72 72

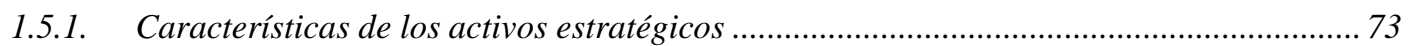

1.5.2. Sostenibilidad de la ventaja competitiva ………................................................................ 75

1.5.3. Apropiabilidad de las rentas .......................................................................................... 79

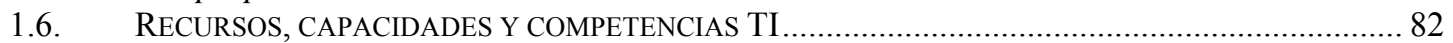

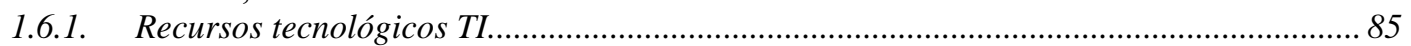

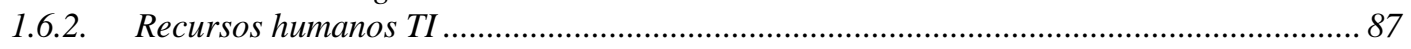

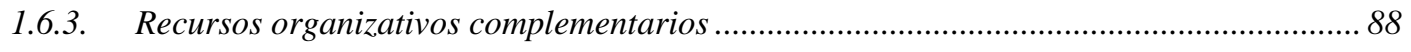

2. UTILIZACIÓN ESTRATÉGICA DE LAS TI...............................................................99

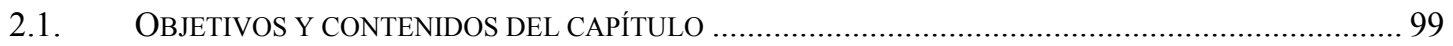

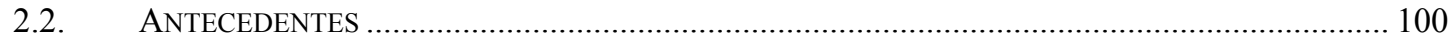


2.3. VALOR DE NEGOCIO DE LAS TI Y SOSTENIBILIDAD DE LA VENTAJA COMPETITIVA ................. 104

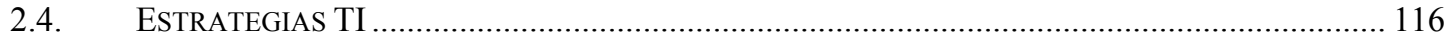

2.4.1. Estrategia TI como utilización de los sistemas de información para soportar la estrategia

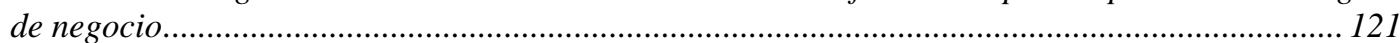

2.4.2. Estrategia TI como el plan maestro de la función SI/TI................................................ 123

2.4.3. Estrategia TI como la visión compartida del rol TI en la organización............................ 125

2.5. VALOR DE LAS TI Y ESTRATEGIA DE NEGOCIO .................................................................. 130

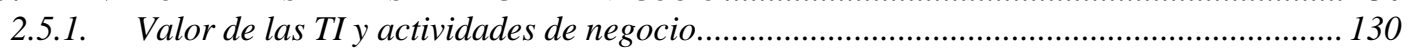

2.5.2. Estrategias de Porter..................................................................................................... 136

2.6. ESTRATEGIA TI COMO MODERADOR DE LA ESTRATEGIA COMPETITIVA EN EL DESEMPEÑO:

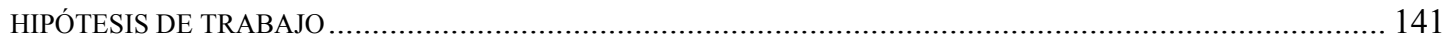

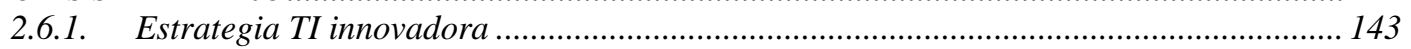

2.6.2. Estrategia TI conservadora ........................................................................................ 144

2.6.3. Estrategia competitiva de diferenciación por innovación ................................................ 145

2.6.4. Estrategia competitiva de diferenciación por marketing ............................................... 149

2.6.5. Estrategia competitiva de liderazgo en costes.............................................................. 150

2.6.6. Resumen de las hipótesis........................................................................................ 153

3. METODOLOGÍA Y DISEÑO DE LA INVESTIGACIÓN ........................................................ 157

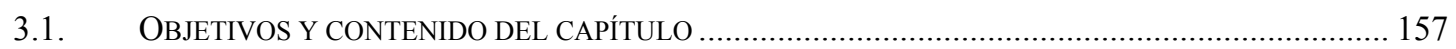

3.2. UNIDADES DE OBSERVACIÓN Y ÁMBITO DEL ESTUDIO................................................... 158

3.3. EL SECTOR AGROALIMENTARIO ESPAÑOL ................................................................ 159

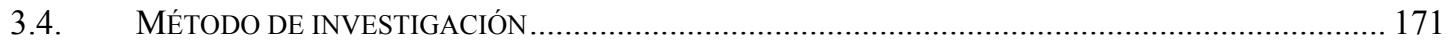

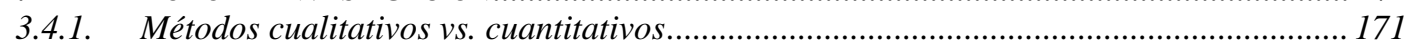

3.4.2. La encuesta como instrumento de investigación ........................................................ 174

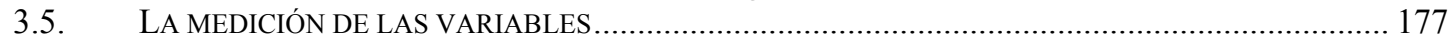

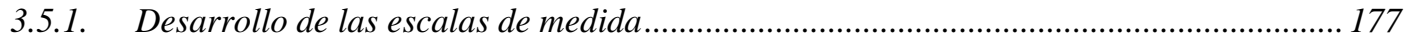

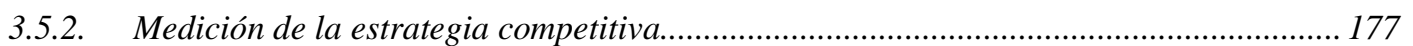

3.5.3. Medición de la estrategia TI.......................................................................................... 180

3.5.4. Diseño del instrumento de medida del desempeño ..................................................... 186

3.6. RECOGIDA DE DATOS Y TRABAJO DE CAMPO ................................................................. 191

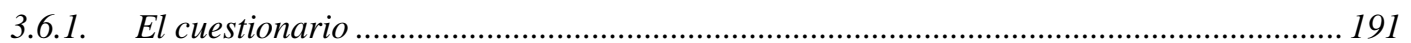

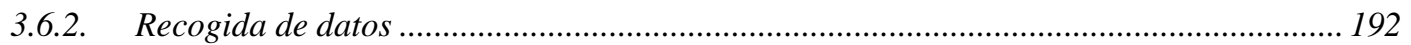

3.7. LA METODOLOGÍA DE LOS MODELOS DE ECUACIONES ESTRUCTURALES ............................. 194

3.7.1. Características de los modelos de ecuaciones estructurales............................................ 194

3.7.2. Etapas para el desarrollo de un modelo de ecuaciones estructurales ................................ 197

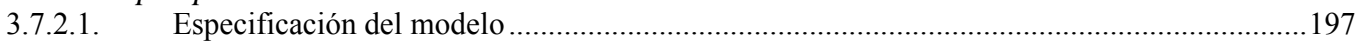

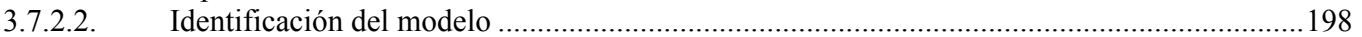

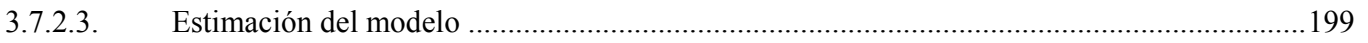

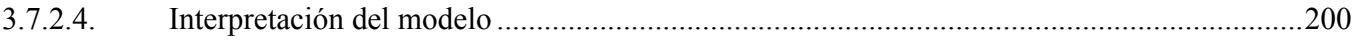

4. ANÁLISIS DE RESULTADOS Y CONTRASTE DE HIPÓTESIS ........................................205

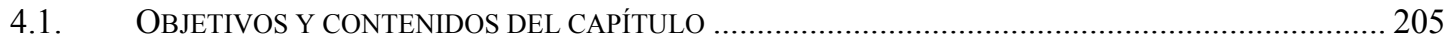

4.2. PROPIEDADES DE LAS ESCALAS E INDICADORES UTILIZADOS EN EL DESARROLLO EMPÍRICO.. 206

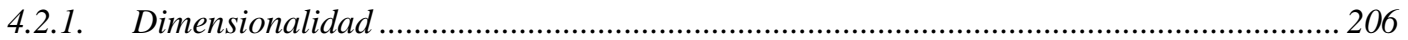

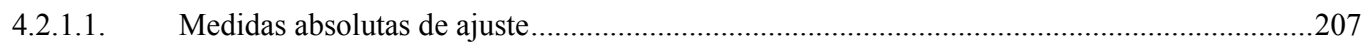

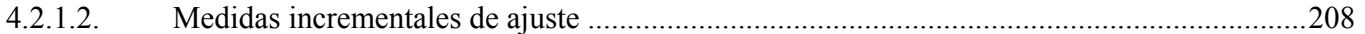

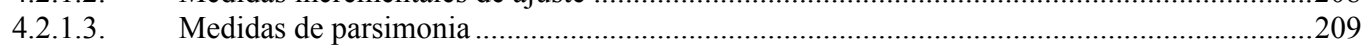

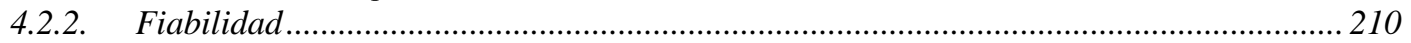

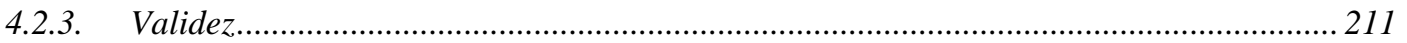

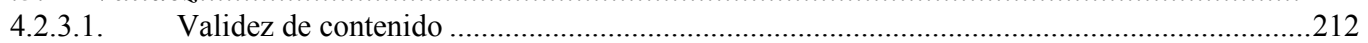

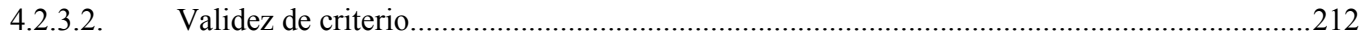

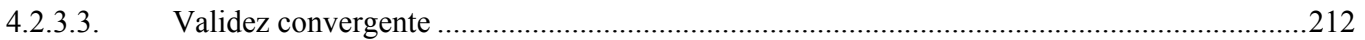

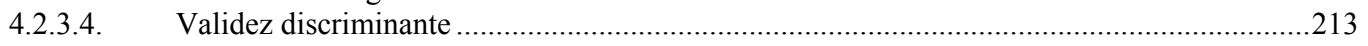

4.3. EVALUACIÓN DE LA ESCALA DE MEDIDA DE LA ESTRATEGIA TI .......................................... 214 
4.3.1. Relación entre ítems de las escalas de estrategia en TI ...................................................217

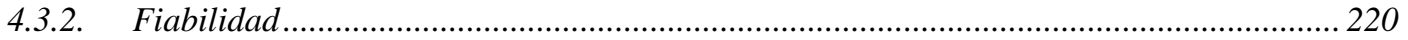

4.3.2.1. Escala estrategia innovadora en TI .................................................................................22

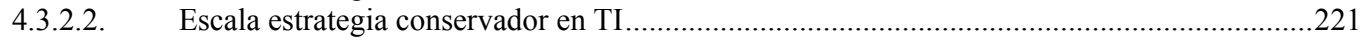

4.3.2.3. Escala falta de estrategia en TI ....................................................................................222

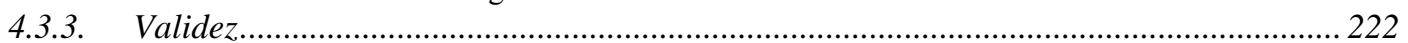

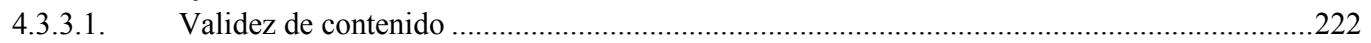

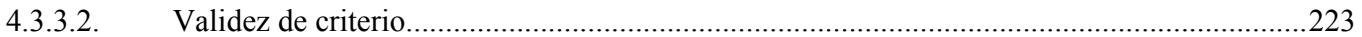

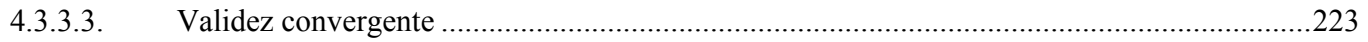

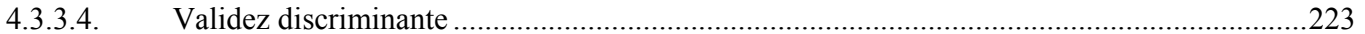

4.4. EVALUACIÓN DE LAS ESCALAS DE MEDIDA DE LA ESTRATEGIA COMPETITIVA ..................... 224

4.4.1. Relación entre ítems de las escalas de estrategia competitiva ....................................227

4.4.2. Fiabilidad ............................................................................................ 231

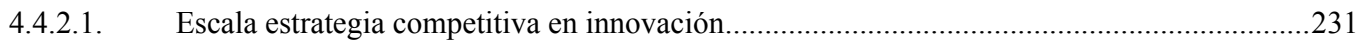

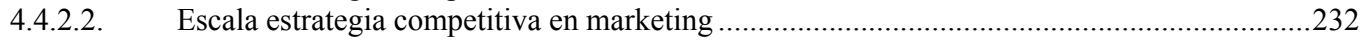

4.4.2.3. Escala estrategia competitiva en costes ..................................................................233

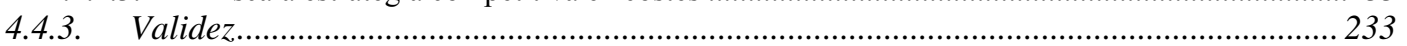

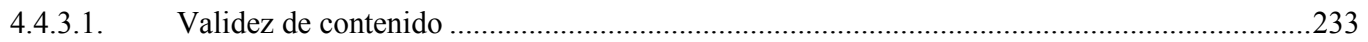

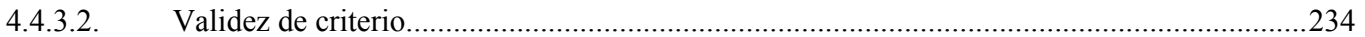

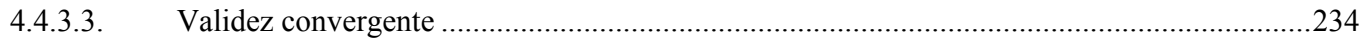

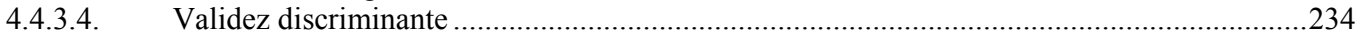

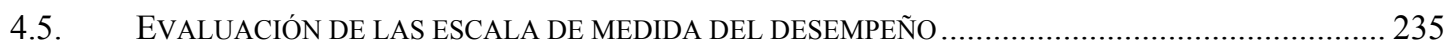

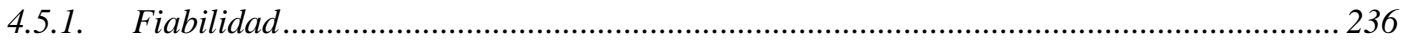

4.5.2. Validez............................................................................................. 237

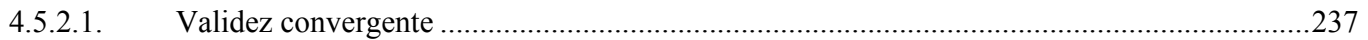

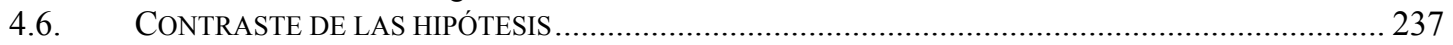

4.6.1. Criterios de evaluación de las hipótesis..................................................................237

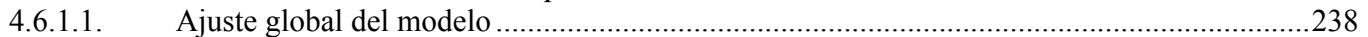

4.6.1.2. Ajuste del modelo de medida....................................................................................238

4.6.1.3. Ajuste del modelo estructural ......................................................................................238

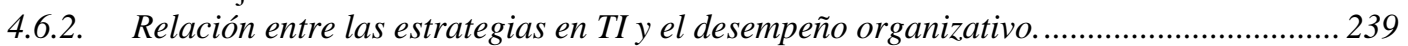

4.6.2.1. Relación estrategia innovadora en TI y desempeño organizativo ......................................239

4.6.2.2. Relación estrategia conservadora en TI y desempeño organizativo ..................................242

4.6.2.3. Relación "sin estrategia en TI" y desempeño organizativo..............................................245

4.6.3. Relación entre las estrategias competitivas y el desempeño organizativo......................248

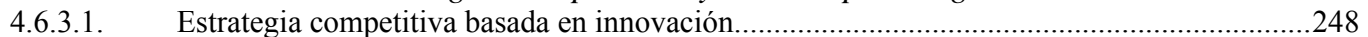

4.6.3.2. Estrategia competitiva basada en marketing ............................................................249

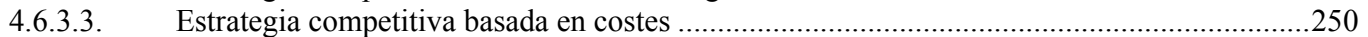

4.6.4. Estadísticos descriptivos de las variables y correlaciones............................................251

4.6.5. Moderación de una estrategia en TI sobre el efecto de las estrategias competitiva sobre el desempeño: verificación de las hipótesis...................................................................254

5. CONCLUSIONES Y LÍNEAS FUTURAS DE INVESTIGACIÓN..........................................261

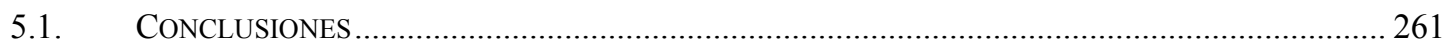

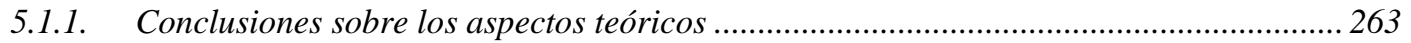

5.1.2. Conclusiones sobre las hipótesis................................................................................... 266

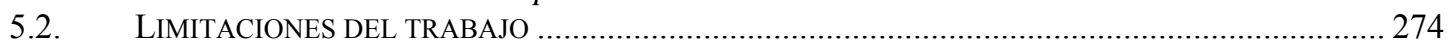

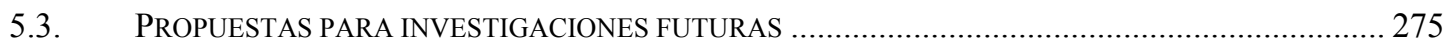

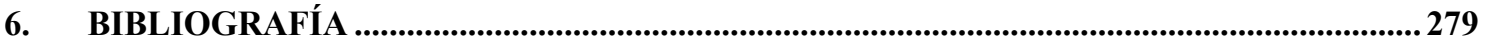

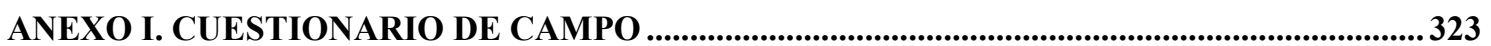

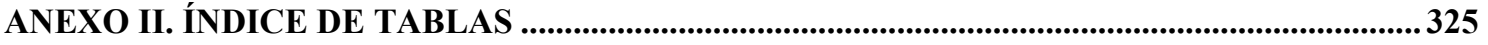

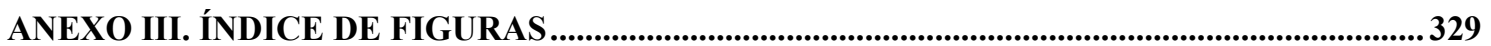


Pág. 8 de 329 


\section{RESUMEN TESIS DOCTORAL}

El objetivo del presente trabajo es, partiendo de la perspectiva del Enfoque Basado en Competencias, analizar el efecto moderador de la estrategia en tecnologías de la información (TI) en la relación entre la estrategia competitiva y el desempeño de una organización. El estudio de esta moderación permite determinar la existencia de una combinación de estrategia TI y estrategia competitiva que arroja mejores resultados que otra en términos de desempeño.

En la primera parte del trabajo, de naturaleza teórica, a partir de la revisión de las principales aportaciones a la cuestión, se ha desarrollado el concepto estrategia TI y se ha analizado la repercusión de los diferentes tipos de estrategias posibles (innovador vs. conservador) en las diferentes estrategias competitivas. En la segunda parte, de naturaleza empírica, se han validado las diferentes hipótesis mediante una muestra de 166 empresas del sector agroalimentario, primer sector industrial español por volumen. Para la validación empírica de las hipótesis se han utilizado métodos cuantitativos con el objetivo de asegurar la objetividad y la extrapolación. En concreto, se ha utilizado el método de la encuesta con escalas Likert para medir variables como estrategia TI y estrategia empresarial. El desempeño organizativo (resultados económicos) se ha extraído de la base de datos SABI. Para la validación de los instrumentos de medida y la contrastación del modelo teórico planteado se han utilizado los modelos de ecuaciones estructurales y el test Z de Fisher.

Las conclusiones son relevantes pues demuestran la eficacia de una estrategia TI innovadora únicamente en la estrategia competitiva basada en costes, vinculada a los procesos de fabricación y relaciones con proveedores. Por el contrario, la estrategia TI innovadora es muy arriesgada en las actividades de marketing y por tanto en estrategias basadas en diferenciación por imagen. La relación con estrategias de diferenciación basadas en $I+D$ es ambigua y únicamente con las variables consideradas no permite extraer conclusiones concluyentes. Por otra parte, una estrategia TI conservadora obtiene siempre mejores resultados, excepto en la estrategia competitiva basada en costes. Las conclusiones obtenidas pueden servir de guía en la toma de decisiones estratégicas en cuanto al desarrollo de las TI en la organización, acorde con sus objetivos de negocio. 
Pág. 10 de 329 


\section{ABSTRACT DOCTORAL THESIS}

The objective of this work is, from the perspective of the Resource-based view to analyze the moderating effect of the strategy on information technology (IT) in the relationship between the competitive strategy developed by an organization and its organizational performance. The study of this moderation allows us to determine the combination of IT strategy and competitive strategy that delivers better results in terms of performance.

In the first part of the work, a theoretical one based on the review of the main contributions to the issue, the concept "IT strategy" has been developed and the impact of different types of possible strategies (innovator vs. Conservative) in different competitive strategies analyzed. In the second part, an empirical one, the hypotheses have been tested using a sample of 166 firms from the food industry, industrial sector Spanish first volume. For the empirical validation of the hypotheses we have used quantitative methods in order to ensure objectivity and extrapolation. Specifically we have used the survey method with a Likert questionnaire to determine variables such as IT strategy and business strategy. Organizational performance has been extracted from the SABI database. Subsequently, for the validation of measuring instruments and the testing of the theoretical model proposed we have used structural equation models and the Fisher's $Z$ test.

The findings are significant because they demonstrate the efficacy of an innovative IT strategy solely on cost-based strategies, linked to manufacturing processes and supplier relationships. By contrast, the innovation in IT strategy is very risky in the marketing activities and therefore in strategies based on image differentiation. The relationship of this IT strategy with strategies based on $R \& D$ differentiation is ambiguous and with only the variables considered in this study no conclusive conclusions can be found. Moreover, conservative IT strategy always obtains best results, excepting the competitive strategy based on costs. The conclusions can provide guidance in making strategic decisions regarding the development of IT in the organization according to its business goals. 


\section{RESUM TESI DOCTORAL}

L'objectiu del present treball és, partint de la perspectiva de l'Enfocament Basat en Competències, analitzar l'efecte moderador de l'estratègia en les tecnologies de la informació (TI) en la relació entre l'estratègia competitiva desenvolupada per una organització i l'acompliment empresarial. L'estudi d'aquesta moderació permet determinar l'existència d'una combinació d'estratègia TI i estratègia competitiva que dona millors resultats que una altra en termes d'acompliment empresarial.

En la primera part del treball, de naturalesa teòrica, a partir de la revisió de les principals aportacions a la qüestió, s'ha desenvolupat el concepte estratègia en TI i s'ha analitzat la repercussió dels diferents tipus d'estratègies possibles (innovador vs. conservador) en les diferents estratègies competitives. En la segona part, de naturalesa empírica, s'han validat les diferents hipòtesis mitjançant 166 empreses del sector agroalimentari, primer sector industrial espanyol per volum. Per a la validació empírica de les hipòtesis s'han utilitzat mètodes quantitatius amb l'objectiu d'assegurar l'objectivitat i l'extrapolació. En concret s'ha utilitzat el mètode de l'enquesta amb escales Likert per determinar variables com a estratègia en TI i estratègia empresarial. L'acompliment organitzatiu s'ha extret de la base de dades SABI. Posteriorment, per a la validació dels instruments de mesura i la validació del model teòric plantejat s'han utilitzat els models d'equacions estructurals i el test $Z$ de Fisher.

Les conclusions són rellevants doncs demostren l'eficàcia d'una estratègia TI innovadora únicament en les estratègies basades en costos, vinculada als processos de fabricació $i$ relacions amb proveïdors. Per contra, l'estratègia TI innovadora és molt arriscada en les activitats de màrqueting i per tant en estratègies basades en diferenciació per imatge. La relació amb estratègies de diferenciació basades en $R+D$ és ambigua i únicament amb les variables considerades no permet extreure conclusions concloents. D'altra banda, una estratègia en TI conservadora obté sempre millors resultats, excepte en la estratègia competitiva basada en costos. Les conclusions obtingudes poden servir de guia en la presa de decisions estratègiques respecte al desenvolupament de les TI en l'organització d'acord amb els seus objectius de negoci. 


\section{ABREVIATURAS Y ACRÓNIMOS}

Pág. 15 de 329 


\section{ABREVIATURAS Y ACRÓNIMOS}

ADF

AIC

ANOVA

APPCC (HACCP)

APQC

BB-NFI

BB-NNFI

BPM o GMP

BSE

CAD

$\mathrm{CE}$

CIAA

DAFO

DOP

E.N

EBC

EBR

EMS

ETG

FIAB

g.1.

GFI

HORECA

IFI

IFS
Método asintóticamente libre de distribución

Akaike Information Criterion

Analysis of Variance

Análisis de Peligros y Puntos Críticos de Control

American Productivity and Quality Center

Bentler-Bonett Normed Fit Index

Bentler-Bonett Non Normed Fit Index

Buenas Prácticas de Producción

Bovine spongiform encephalopathy

Computer Aided Design

Comisión Europea

Confederación Europea de Industrias de Alimentación y Bebidas

Debilidades, Oportunidades, Fortalezas y Amenazas

Denominación de Origen Protegida

Estrategia de Negocio

Enfoque basado en competencias

Enfoque Basado en los Recursos

Enterprise Management Systems

Especialidad Tradicional Garantizada

Federación de Industrias de Alimentación y Bebidas

Grados de libertad

LISREL Goodness Fit Index

Sector hotel, restauración y catering.

Incremental Fit Index

International Food Standard 
IGP

ISO

LS o ULS

MI

MIS

ML

$\mathrm{NC}$

NT-WLS

OCDE

PM

$\mathrm{PpE}$

PYME

RFID

RMSEA

RMSR

ROA

ROI

ROS

SABI

SI

Sig

SQF

TI

TIC

$\mathrm{UNE}$
Indicación Geográfica Protegida

International Standards Organization

Mínimos cuadrados no ponderados

Gestión de la Información

Management Information System

Máxima verosimilitud

Normed Chi-Square

Mínimos cuadrados ponderados bajo normalidad

Organización para la Cooperación y el Desarrollo Económico

Profit Margin

Profit per employee

Pequeña y Mediana Empresa

Radio Frecuency Identification Device

Root Mean Square Error of Approximation

Root Mean Square Residual

Return on Total Assets

Retorno sobre la inversión

Retorno sobre las ventas

Sistema de Análisis de Balances Ibéricos

Sistemas de la Información

Significatividad

Safe Quality Food

Tecnologías de la Información

Tecnologías de la Información y Comunicación

Una Norma Española 


\section{INTRODUCCIÓN}

Pág. 19 de 329 


\section{INTRODUCCIÓN}

\subsection{Justificación de la investigación}

La cuestión de la utilización de las TI como elemento de ventaja competitiva por parte de las empresas ha sido un tema de preocupación por parte tanto de la comunidad científica como de empresas y administraciones públicas. En la década de los 90 y principios del presente siglo una de las principales preocupaciones de las administraciones públicas a escala nacional y europea ha sido la promoción de la utilización de las nuevas tecnologías por parte del tejido industrial, fruto de la convicción de que mejorar en la utilización de estas tecnologías lleva necesariamente a una mejora de la competitividad. Desde hace varios años existen multitud de programas de apoyo por parte de las administraciones públicas (tanto regionales y nacionales como europeas) para el impulso de las Tecnologías de la Información (TI) en las empresas.

Sin embargo, para el caso español, en un reciente informe impulsado por la OCDE (2010), se indica que, aunque se ha convergido sustancialmente a las medias europeas en cuanto a utilización de las TI a lo largo de los últimos años, todavía el país tiene niveles bajos en utilización de las TI para optimizar las operaciones de negocio y las actividades comerciales. Otros informes avalan el evidente retraso en el que se encuentra nuestro país en términos de inversión y uso de TI, como por ejemplo el informe de la Fundación Orange (2008), el del World Economic Forum (2008), el de AETIC-Everis (2009), o los publicados por Fundetec (2010, 2011).

Todos los estudios mencionados desarrollan medidas sobre ciertos indicadores empresariales agregados como son el índice de penetración, utilización de las tecnologías, utilización de Internet, etc. Sin embargo, no es frecuente la existencia de estudios que analicen desde una perspectiva de contenido qué estrategia TI están llevando a cabo las empresas ni en qué medida dicha estrategia tiene efectos en el 
desempeño o en qué medida está correlacionada con su estrategia de negocio. El resultado para los empresarios, sobretodo en la pequeña y mediana empresa, es una desorientación general en cuanto a qué estrategia seguir en este ámbito.

La utilización de las TI es una de las principales preocupaciones de los directivos de empresas desde hace ya algunos años. Una encuesta anual realizada por la Computer Science Corporation en 2001 (CSC, 2001) indicaba que la forma en que las TI podían contribuir a cumplir con los objetivos de negocio era la segunda más importante preocupación de los ejecutivos de TI americanos (la primera era la de extender los servicios de los sistemas de información a toda la compañía). Más recientemente un artículo del Wall Street Journal (Worthen, 2007) indicaba que el $87 \%$ de los altos ejecutivos de las compañías creía que los sistemas de información eran críticos para el éxito de sus negocios.

Debido a la creciente intensidad de utilización de información en las industrias, muchos ejecutivos están elevando el nivel de importancia que dan a las Tecnologías de la Información emergentes (McAfee y Brynholfsson, 2008). A esto hay que añadir que la tendencia del gasto mundial en TI por parte de las organizaciones es creciente. Según Gartner (2012), el gasto mundial en TI será de 3,7 billones de dólares en 2012.

Para el caso de España, en el mencionado estudio AETIC-Everis (2008) se constata una visión positiva en cuanto a rentabilidad para el empresariado español. Un 69,8 \% opina que es rentable invertir en TI mientras que un 27,5\% opina lo contrario. En este mismo estudio aparecen como las principales causas de que no se haga un mayor uso de las TI aspectos como la desconfianza o desconocimiento hacia la tecnología $(36,6 \%)$, los costes de la tecnología $(25,5 \%)$, la escasez de personal con formación adecuada $(23,3 \%)$, la falta de recursos $(19,2 \%)$ o que no se ven suficientes ventajas en el uso de las TI $(12,1 \%)$.

Desde la perspectiva académica, la investigación de los efectos de la utilización de las Tecnologías de la información (TI) para el desarrollo de la estrategia competitiva de la empresa y el impacto que dicha utilización tienen en el desempeño empresarial o la 
adopción de una posición de ventaja competitiva no ha arrojado resultados concluyentes. En términos generales existe un consenso en cuanto al efecto positivo de la utilización de las TI en el desempeño o en la posición en una industria. Trabajos como el de Brynjolfsson y Hitt (1996), Lichtenberg (1995) o el de Dewan y Kraemer (2000) verificaron ya dicho impacto positivo en el desempeño. Trabajos pioneros asociados a la escuela de posicionamiento como los de Porter (1985) o Porter y Millar (1985) consideraron las TI como un medio para que las firmas pudieran obtener ventajas competitiva alterando las fuerzas de la industria contribuyendo, bien a reducir los costes o bien a mejorar la diferenciación. Estos trabajos asentaron las bases para el avance realizado en las últimas décadas.

La importancia que otorga la literatura en Gestión de Sistemas de Información a una estrategia de las TI acorde con la estrategia global de la organización queda reflejada en el gran número de trabajos que abordan el concepto de alineación estratégica. La alineación de las TI con la estrategia de la empresa se ha considerado de manera consistente como uno de los aspectos más importantes a los que se enfrentan tanto los directores generales como los del Departamento de Sistemas de Información de las organizaciones (CSC, 1998). Este persistente interés en la alineación estratégica se debe a que los investigadores consideran la falta de ésta como uno de los factores que impiden la obtención del valor esperado de las inversiones en TI (Henderson y Venkatraman, 1993; Woolfe, 1993). Strassmann (1997: 4) se hace eco de este hecho comentando que "si las consecuencias de los proyectos informáticos individuales están enlazadas nítidamente con la planificación de la empresa y con un compromiso en los presupuestos, entonces, la inversión en informática tiene alguna posibilidad de convertirse en un catalizador del cambio organizativo en lugar de ser un gasto". La mayoría de los trabajos orientados al análisis de la alineación estratégica (Chan y Reich, 2007; Chan et. al, 2006; Croteau y Bergeron, 2001; Oh y Pinsonneault, 2007) utilizan una aproximación de alineación intelectual estática, quedando fuera una visión de perspectiva de la estratégica TI y obviando en consecuencia el carácter dinámico de la alineación. En palabras de Galliers (2006a, p. 227) "la naturaleza dinámica de los entornos competitivos, colaborativos y regulatorios en los que las organizaciones 
dirigen sus actividades dictan la atención cuidadosa y constante que deben tener hacia los continuos cambios en las necesidades de información".

La definición y tipologías de la estrategia TI en el ámbito académico, pese a su importancia para el aprovechamiento del potencial de las TI, todavía es difuso (Chen, 2010), así como su relación con la estrategia empresarial. En la literatura existen diferentes concepciones de la estrategia TI, principalmente desde la literatura emanada del ámbito de la estrategia competitiva general. Por ejemplo, los estudios desde la perspectiva del enfoque basado en competencias han demostrado la importancia de los activos complementarios para que las competencias TI produzcan efecto positivo en el desempeño. También se pone énfasis en la importancia de una buena alineación estratégica (dimensión intelectual de la alineación) para un desempeño superior en las organizaciones. Considerando estas conclusiones es necesario entender la estrategia TI desde una perspectiva holística y global e incorporar la dimensión estratégica de negocio a dicho constructo, como lo ponen de manifiesto trabajos como el de Mata et al. (1995), al hablar de las habilidades de los directivos TI o el de Powell y Dent-Micallef, (1997) al hablar del compromiso de la dirección con las TI. Así, algunos investigadores han afirmado que la estrategia TI puede tanto apoyar como impulsar la estrategia de negocio (Agarwal y Sambamurthy, 2002; Earl, 1989; Galliers, 2004; Preston y Karahanna, 2009). Por ejemplo, Earl (1989) postula que la estrategia TI puede liderar el negocio pero por otra parte esta estrategia también puede cuestionarla. Más allá de esto, Galliers (1991, 1993, 2004) afirma que la estrategia TI puede ser considerada como una parte más de la estrategia integral de negocio que implica el impacto potencial de los sistemas de información en el desempeño organizativo, así como los cambios concomitantes en los aspectos de gestión derivados de las iniciativas de negocio impulsadas por las iniciativas TI. Por tanto, como afirman Chan et al. (2010), limitar la estrategia TI a un subconjunto dependiente de la estrategia de negocio puede resultar en una visión limitada, y exista o no una estrategia de negocio explícita, las organizaciones necesitan de una guía para la toma de decisiones en el ámbito TI no necesariamente supeditadas a la estrategia de negocio. 
La presente investigación estudia la relevancia que tienen las TI como fuente de ventaja competitiva sostenible para la empresa y, desde un punto de vista de estrategia como contenido analiza el efecto moderador de la implementación de un tipo de estrategia TI para una estrategia competitiva dada en términos de desempeño. El estudio empírico se desarrolla en el sector agroalimentario, primer sector industrial en Europa y España en términos de volumen de negocio y número de empleados.

Así pues, el objetivo principal del presente trabajo es responder a la pregunta ¿Para una estrategia competitiva dada, qué estrategia TI arroja mejores resultados en términos de desempeño? ¿Existe alguna estrategia TI mejor que otra para una estrategia competitiva dada en términos de desempeño? O ¿existe alguna vinculación entre la estrategia competitiva de la empresa y la estrategia TI que mejora el desempeño de ésta?

Las organizaciones deben tomar muchas decisiones en cuanto al uso de las TI dada la velocidad de cambio y avance de éstas y la profundidad de los cambios que pueden producir en las actividades de negocio. Ejemplos actuales de importantes decisiones a los que se enfrentan las organizaciones los encontramos en el uso de las redes sociales en el caso de marketing o el "cloud computing" o computación en la nube en el almacenamiento de datos. En estos casos la falta de una estrategia en TI que marque los objetivos y guíe la integración de las TI en los procesos de negocio puede resultar en una falta de coherencia en la implantación de las TI contraproducente.

\subsection{Importancia del tema bajo estudio}

El tema bajo estudio tiene relevancia tanto desde una perspectiva académica como desde una perspectiva empresarial.

Desde la perspectiva académica, el trabajo extiende el conocimiento de la vinculación entre estrategia TI y estrategia competitiva. Muchas explicaciones se han dado al hecho de que la relación entre la integración de sistemas de información en la estrategia 
empresarial no arroje todos los resultados esperados y de una forma evidente. De todo el conjunto de explicaciones, cada vez se impone con más fuerza aquella que postula que las TI per se no permiten en general la consecución de mejoras significativas de la productividad. Su pleno aprovechamiento requiere hacerlo con una orientación estratégica adecuada y en consecuencia, es necesario establecer una complementariedad entre el uso y la estrategia de las TI con una estrategia competitiva alineada. Esta complementariedad es la que conduciría a aumentos de productividad y desempeño. La investigación sobre alineamiento estratégico es útil para explicar cómo las diferencias en la estrategia de negocio afectan a la relación entre las TI y el desempeño. Las TI proporcionarán una mayor contribución al desempeño si éstas se alinean con la estrategia de negocio. Sin embargo, son pocos los trabajos que han tratado el valor para el negocio de las TI de modo que esté vinculado con el tipo de estrategia empleada por una organización (Tallon, 2007).

Otro elemento que incorpora el presente estudio es la concepción de estrategia TI. En la literatura se ha dado multitud de términos para el constructo estrategia TI. Chan et al. (2010) conceptualiza la estrategia, partiendo de la definición de Mintzberg (1987) como una perspectiva organizacional. La novedad del presente estudio radica en la conceptualización de la estrategia TI como una perspectiva organizativa por una parte, y por otra el hecho de que dicha conceptualización no sea dependiente o esté supeditada a la estrategia competitiva de la organización a priori. El interés de la cuestión radica en la vinculación de la estrategia TI con la estrategia competitiva genérica y su impacto en el desempeño de una organización. Este estudio considera la independencia de las estrategias en TI y de negocio, analizando qué combinaciones son deseables.

Las implicaciones empresariales también son relevantes. La investigación permitirá a los directivos de empresas del sector agroalimentario tener una guía para la toma de decisiones estratégicas en cuanto al desarrollo de las TI en la organización acorde con los objetivos de negocio. El presente trabajo busca determinar, a partir de esta concepción de estrategia TI mencionada, qué estrategia TI arroja mejores resultados en término de desempeño para una estrategia competitiva genérica dada. Para la 
determinación de las estrategias se tomará las estrategias genéricas de Porter como referencia.

En este punto, conviene precisar que para conseguir este objetivo deberemos concretar objetivos más específicos, los cuales se desarrollan en el siguiente apartado. Desde el punto de vista teórico, debemos profundizar en el concepto de estrategia competitiva, haciendo una revisión y análisis de los principales paradigmas de estrategia competitiva que han influido en el desarrollo de los modelos de integración de las TI en las organizaciones, así como qué entendemos como estrategia TI y qué estrategias se pueden seguir. Esta revisión teórica nos permitirá crear un modelo hipotético que refleje estas asociaciones.

\subsection{Objetivos de la investigación}

El objetivo del presente trabajo es determinar cómo la elección de una estrategia TI determinada afecta a la relación entre el desempeño empresarial y la estrategia competitiva adoptada por una organización, es decir, si existe alguna combinación de estrategia TI y estrategia de negocio que arroje mejores resultados que otra en términos de desempeño.

El trabajo pretende contribuir a mejorar el conocimiento de las TI como soporte e impulso a la estrategia competitiva de una organización y su contribución al desempeño empresarial y a la mejora del posicionamiento competitivo. La contribución del presente trabajo por tanto es extender la comprensión de la aportación de valor de las TI al negocio como elemento clave y como fuente de ventaja competitiva, así como profundizar en la relación entre estrategia TI y la estrategia de negocio de las organizaciones. 
Para ello es necesario definir claramente el concepto de estrategia TI, que habitualmente ha ido de la mano de las definiciones de estrategia competitiva. Se plantean como objetivos específicos de la presente investigación:

1) Realizar una revisión del Enfoque Basado en Competencias. Este enfoque teórico es uno de los que más ha influido en el estudio de las TI como fuente de ventaja competitiva. Revisar qué recursos, competencias y capacidades TI pueden ser fuente de ventaja competitiva y mejorar el desempeño Dicho análisis nos permitirá adoptar un sólido punto de partida para posteriormente analizar las estrategias TI y abordar el siguiente objetivo.

2) Analizar el efecto moderador de la estrategia TI en la relación entre la estrategia competitiva desarrollada por una organización y el desempeño empresarial. El estudio de esta moderación permite determinar la existencia de una combinación de estrategia TI y estrategia competitiva que arroja mejores resultados que otra en términos de desempeño.

3) Validar empíricamente el modelo en un sector productivo. Para este caso concreto, se ha seleccionado el sector agroalimentario por su importancia económica en España.

\subsection{Estructura del trabajo y metodología}

Para el desarrollo de los objetivos que hemos planteado, el presente trabajo se ha estructurado en dos partes: una primera parte de naturaleza teórica que consta de dos capítulos, donde se ha revisado las principales aportaciones sobre al tema objeto de estudio tanto desde la perspectiva conceptual como desde la operativa, y una segunda de carácter empírico. En la primera parte se ha desarrollado un modelo teórico que relaciona la estrategia competitiva con el desempeño empresarial, donde la variable que modera esta relación es la estrategia TI. 
El primer capítulo está fundamentalmente dedicado al estudio de las TI desde el enfoque basado en competencias como fuente de ventajas competitivas sostenibles. Cabe destacar que se hará posteriormente, en el segundo capítulo, una somera revisión de otro de los grandes enfoques que han influido sustancialmente en la literatura de sistemas de información como es la escuela del posicionamiento (particularmente la teoría de la estrategia competitiva de Porter, 1980, 1985), que complementará el enfoque basado en competencias o EBC. Este enfoque nos permitirá definir las estrategias competitivas posibles para una organización. Ambos marcos teóricos han inspirado la gran mayoría de los trabajos sobre la utilización de las TI para la obtención de ventajas competitivas sostenibles y mejoras de desempeños en las organizaciones.

El segundo capítulo desarrolla cómo las TI pueden producir ventajas competitivas y qué se entiende por estrategia TI. Como colofón a este capítulo de la primera parte, estableceremos un marco para el desarrollo del modelo teórico y la elaboración de las hipótesis propuestas que resumen los objetivos marcados en esta investigación y que serán contrastados en los siguientes capítulos.

La segunda parte del trabajo, de naturaleza empírica, pretende aplicar los conceptos y modos de operativización desarrollados en los capítulos teóricos. Esto nos permitirá seleccionar un instrumento de medida que nos permita contrastar las hipótesis que se desprenden del modelo teórico planteado en el segundo capítulo. La realidad que pretendemos observar en nuestro estudio es el efecto de la estrategia en TI sobre la relación de la estrategia de negocio y el desempeño empresarial. La empresa constituye una entidad organizativa que toma sus propias decisiones en materia de estrategia TI. Existen argumentos y evidencias empíricas en la literatura que sugieren que la adopción de una determinada estrategia tiene efectos positivos sobre el desempeño. Puesto que el objetivo principal de esta investigación es verificar la existencia de esta relación, la unidad de análisis que vamos a considerar es la empresa. Se trata de la unidad de análisis por excelencia de los trabajos empíricos en el campo de la organización de empresas. 
Dentro de la literatura TI existe un gran número de investigaciones que utiliza una metodología de estudio de casos con medidas cualitativas, donde se estudia los efectos particulares de una determinada tecnología en el desempeño (Banker y Kauffman, 1991; Campbell-Kelly, 1996; DeSanctis y Poole, 1994). En estos estudios suele predominar un nivel de análisis de aplicación. Los trabajos cualitativos en este campo aportan una visión en profundidad de los fenómenos y procesos que ocurren en la implantación y el funcionamiento de las TI y los sistemas de información. Las investigaciones de este tipo han mejorado la comprensión de cómo actúan las distintas tecnologías y sistemas en las organizaciones y los cambios que producen. Estos avances han generado nuevas inquietudes entre los investigadores, puesto que comprender dónde reside el valor potencial que puede resultar de la inversión en TI tiene importantes consecuencias tanto académicas como prácticas. En cambio, en otros estudios empíricos como los desarrollados desde el EBC con un nivel de análisis organizativo, existe un predominio de los métodos cuantitativos. En este trabajo se ha optado por la utilización de métodos cuantitativos con el objetivo de asegurar la objetividad y la extrapolación (Henderson y Cockburn, 1994; McEvily y Chakravarthy, 2002). En concreto utilizaremos el método de la encuesta para determinar variables como estrategia en TI y estrategia empresarial (estrategia en costes, marketing, investigación, desarrollo e innovación).

El desarrollo de instrumentos de medida que sean válidos, fiables y precisos es una tarea de importancia crucial en toda investigación. La escala de medición debe ser útil para recoger información sobre el concepto a evaluar y dicha información debe ser obtenida por el procedimiento más exacto y fiel posible. Por tanto, el diseño de instrumentos de medida para aquellas variables que no son directamente observables, como es el caso, debe seguir un procedimiento riguroso que asegure su precisión (Churchill, 1979). Además, debe cumplir con una serie de propiedades sociométricas para su validación. Por tanto, una vez recogidos los datos, se deben verificar las escalas de medida. Esta fase consiste en determinar si los instrumentos de medida seleccionados para evaluar los conceptos teóricos que aparecen en nuestro modelo son adecuados. Para resolver esto utilizaremos los modelos de ecuaciones estructurales que, además, permitirán contrastar el modelo teórico que elaboraremos. 
Esta segunda parte empírica consta de tres capítulos. El primero de esta parte y tercer capítulo de la tesis comienza con la exposición de la metodología y diseño de la investigación empírica, destacando los aspectos metodológicos utilizados. Comprende la descripción del objeto y la selección de las técnicas de observación y tratamiento de datos.

En el capítulo cuarto procedemos al análisis estadístico de los resultados, dedicando un especial interés a la determinación de la fiabilidad y validez de las diferentes escalas de medida utilizadas. Las hipótesis planteadas en el modelo teórico se contrastan aplicando la técnica de modelos de ecuaciones estructurales.

Por último, dedicamos el quinto y último capítulo para exponer de forma resumida las conclusiones obtenidas y las limitaciones de estos resultados, identificando además posibles investigaciones que a partir del trabajo realizado consideramos de interés desarrollar en el futuro. 


\section{LA VENTAJA COMPETITIVA SOSTENIBLE Y LAS TI: UN ENFOQUE BASADO EN COMPETENCIAS}




\section{LA VENTAJA COMPETITIVA SOSTENIBLE Y LAS TI: UN ENFOQUE BASADO EN COMPETENCIAS}

\subsection{Objetivos y contenido del capítulo}

El presente apartado tiene como objetivo analizar los fundamentos de los recursos, capacidades y competencias distintivas en general y las TI en particular como fuente de ventaja competitiva sostenible. El enfoque basado en competencias (EBC) considera que el determinante de la ventaja competitiva sostenible en el tiempo o a largo plazo es la habilidad de una organización para acumular, proteger y desarrollar recursos, capacidades y competencias (Foss, 1996). Este marco teórico es el más frecuentemente utilizado en la literatura para el análisis de los efectos de las TI en el desempeño organizativo.

Para desarrollar los contenidos del presente capítulo, en primer lugar y a modo introductorio (apartado 1.2) se hará una revisión general de los diferentes paradigmas y corrientes de pensamiento que han influido en la literatura relacionada con la investigación de las TI y su papel en las organizaciones, lo que permitirá adoptar un punto de partida sólido para el análisis del valor estratégico que la teoría les atribuye.

En el siguiente epígrafe (apartado 1.3) se desarrollará en profundidad el enfoque basado en competencias, prestando especial atención a las aportaciones recibidas y los elementos comunes que tiene con otros enfoques afines, en concreto el Enfoque Basado en los Recursos (EBR), el Enfoque de las Capacidades Dinámicas y el Enfoque Basado en el Conocimiento.

El EBC explica las diferencias de resultados de una determinada organización a lo largo del tiempo mediante la posesión de ciertos activos estratégicos. Por tanto, los elementos centrales de estudio y la unidad básica de análisis estratégico interno son los recursos, 
las capacidades y las competencias. En el cuarto apartado (1.4) revisamos estos tres conceptos nucleares dentro del EBC.

En el quinto apartado (1.5), analizamos las características que deben tener las competencias para poder convertirse en fuente de ventaja competitiva sostenible, y por tanto, ser consideradas como competencias distintivas. Adicionalmente hacemos una clasificación de las competencias distintivas que nos permitirá categorizar los distintos elementos que componen el modelo propuesto en el segundo capítulo.

En el último apartado (1.6) analizamos qué recursos, capacidades y competencias TI han sido consideradas en la literatura como activos estratégicos.

\subsection{Paradigmas utilizados en la literatura}

Desde hace varias décadas, la dirección de los trabajos de investigación desarrollados en la literatura TI apunta a que éstas pueden ser utilizadas para crear una ventaja competitiva a través de mejoras en la eficiencia, la diferenciación y el control del canal de distribución (Sethi y King, 1994), desarrollándose abundante literatura dedicada a comprender cómo el despliegue de las TI pueden apoyar mejoras en el desempeño de una organización (Brynjolfsson y Hitt, 1996; Hitt et al., 2002). Un importante grupo de investigadores se ha interesado particularmente en la exploración de la magnitud en la que la aplicación innovadora de las TI puede tener el potencial de proporcionar una clara ventaja competitiva a aquellos que las adoptan. La utilización de las TI como una fuente de ventaja competitiva y cómo ésta aporta valor al negocio está directamente relacionada en la literatura con el impacto que puede generar en el desempeño empresarial. El análisis de esta cuestión parte de las diferentes escuelas de pensamiento estratégico. 
La teoría microeconómica proporciona un conjunto de constructos interrelacionados vía modelos y especificaciones matemáticas. La teoría de la producción ha sido especialmente útil para la conceptualización de los procesos de producción y para proporcionar las especificaciones empíricas que permiten estimar el impacto de las TI (Brynjolsson y Hitt, 1995; Dewan y Minn, 1997; Lichtenberg, 1995). La aproximación de la función de la producción relaciona las entradas de la producción como puede ser el trabajo, las TI y otras formas de capital con las salidas vía especificaciones matemáticas derivadas de la teoría microeconómica. Aunque las asunciones de la teoría microeconómica deben ser cuidadosamente enmarcadas en el contexto específico de investigación, ha servido para entender desde una perspectiva global el fenómeno.

Por otra parte, la teoría de la organización industrial también ha sido relevante en el estudio del impacto de las TI en el desempeño. La teoría de juegos se ha utilizado para examinar el rol de la interacción estratégica entre competidores en la captura y generación de valor por parte de las TI (Melville et al., 2004).

Otros investigadores han desarrollado modelos que enlazan las TI con el desempeño organizativo. Por ejemplo, Barua et al. (1995), argumenta que la asociación entre la inversión en TI y el desempeño se atenúa a medida que la distancia entre causa y efecto crece. Los autores desarrollan un modelo de valor de las TI en el que el impacto en el desempeño empresarial está mediatizado por procesos intermedios.

Una perspectiva similar adopta Weill (1992), quien se centra en la habilidad de una firma para transformar elementos TI en desempeño empresarial, identificando factores de efectividad de conversión que median en la relación TI y desempeño. En una síntesis de modelos de procesos, Soh y Markus (1995) desarrollan un marco conceptual que postula que la inversión TI dirige los activos TI (proceso de conversión TI), que los activos TI lideran los impactos TI (proceso de uso de las TI) y que las TI impactan en el desempeño empresarial (proceso competitivo).

La función de la producción y los modelos orientados a procesos han descrito la relación entre inversión TI y desempeño empresarial con una perspectiva de entrada- 
salida que en ocasiones incluyen factores intermedios como pueden ser las decisiones directivas y la estructura de la organización.

Sin embargo los paradigmas que más importancia han tenido en el estudio de las TI son las aproximaciones basadas en Porter (1985), la perspectiva basada en recursos (Penrose, 1959; Wernefelt, 1984; Barney 1991), la perspectiva de capacidades dinámicas (Helfat y Peteraf, 2003), la teoría de competencias dinámicas (Prahalad y Hamel, 1990) y la perspectiva basada en el conocimiento (Grant 1996a), siendo estas últimas corrientes de pensamiento analizadas en el siguiente epígrafe.

El enfoque de la escuela del posicionamiento estratégico considera las TI como un medio para que las firmas pudieran obtener ventajas competitiva alterando las fuerzas de la industria (Porter y Millar, 1985) contribuyendo, bien a reducir los costes o bien a mejorar la diferenciación

Esta perspectiva describe la ventaja competitiva en términos de posicionamiento de una firma en su contexto de industria. Considera las TI como un medio para que las firmas pudieran obtener ventajas competitiva alterando las fuerzas de la industria (Porter y Millar, 1985) contribuyendo cuando se utilizan de forma innovadora, como ya hemos mencionado, bien a reducir los costes o bien a mejorar la diferenciación. Desde esta perspectiva, la aparición de Internet por ejemplo supone alterar el poder de negociación de clientes o proveedores, aumentándolo en la medida que se tiene más información de las posibilidades de compra o venta. Por otra parte, la posibilidad de modificar los costes de las actividades que componen la cadena de valor a través de mecanismos de interoperabilidad de sistemas de información permite a las empresas lograr una ventaja competitiva en términos de costes. Los sistemas de información estratégicos se consideran las herramientas para generar barreras de entrada, incrementar el poder de negociación con proveedores y clientes, ofrecer nuevos productos y servicios o cambiar las reglas de la competencia. Este enfoque será retomado en el siguiente capítulo, en la formulación de las hipótesis, y su relación y complementariedad con el EBC será discutida en el punto 1.3.6. 
El enfoque basado en competencias conceptualiza la empresa como un conjunto de recursos, defendiendo que los recursos únicos de la empresa son los que deben definir la esencia de la estrategia (Spanos y Lioukas, 2001) y que en un contexto TI observa los capacidades TI como una fuente de ventaja competitiva (Bharadwaj, 2000).

El enfoque basado en competencias, dada su relevancia para la presente tesis, se desarrolla a continuación.

\subsection{El enfoque basado en competencias}

El EBC aglutina un conjunto de líneas de pensamiento cuyo denominador común es la importancia de los activos intangibles como fuente de ventajas competitivas sostenibles. Incluye la teoría de los recursos y capacidades así como las extensiones que se han realizado más recientemente, abordando el estudio dinámico de la generación de competencias como son la Teoría de las Capacidades Dinámicas o la Teoría basada en el Conocimiento entre otros. Este enfoque otorga una gran relevancia para la estrategia a los activos que son específicos a la empresa, relacionados con el conocimiento, tácitos, difíciles de comercializar y compartidos en el seno de la organización.

El término competencia distintiva fue utilizado por primera vez por Selznick (1957) para describir el carácter de las organizaciones referido a "aquellas cosas que una organización realiza especialmente bien en comparación con sus competidores". En un trabajo posterior Andrews (1971) consolida el concepto de competencia distintiva de una organización señalando que es mucho más que lo que una empresa puede hacer, "es el conjunto de cosas que la empresa hace especialmente bien". De esta forma define la competencia distintiva como un agregado de varias actividades específicas que la organización tiende a realizar mejor que sus competidores dentro de un mismo entorno. 
Sin embargo, pese a estas primeras aportaciones, no es hasta el principio de la década de los 90, especialmente tras los trabajos de Hamel y Prahalad (1989) y Prahalad y Hamel (1990), que las competencias y la competitividad basada en las competencias se popularizan (Hart and Dowell, 2011).

Otros trabajos más recientes han seguido desarrollando el concepto de competencia y su importancia para conseguir ventajas competitivas (Hamel, 1994; Hamel y Prahalad, 1993, 1994; Stalk, Evans y Schulman, 1992; Newbert, 2008, Kraaijenbrink, 2010). Estos estudios consideran las competencias específicas de la empresa como base de la estrategia y el éxito empresarial, especialmente aquellas con características intangibles. Sánchez, Heene y Thomas (1996) destacan la importancia de las competencias para las organizaciones afirmando que éstas constituyen el eje central de su competitividad, ya que hacen posible el desarrollo conjunto de productos individuales gracias a los cuales la empresa obtiene sus ingresos.

Esta concepción de la empresa como un repertorio de competencias y la consideración de la acumulación y el desarrollo de competencias como generador de las ventajas competitivas constituye la esencia de lo que Foss (1996) denomina el Enfoque basado en las Competencias. El autor entiende que este enfoque "implica una consistente conceptualización de las empresas en términos de competencias, las empresas son esencialmente un repertorio de competencias" y continúa afirmando que "es la habilidad de las empresas para acumular, proteger y finalmente desarrollar competencias lo que se considera el determinante de la ventaja competitiva a largo plazo".

Como hemos mencionado, el EBC recoge diferentes aportaciones de otros enfoques que han contribuido a su desarrollo. Camisón (2002a) destaca las aportaciones realizadas por el Enfoque Basado en los Recursos, el Enfoque de las Capacidades Dinámicas y el Enfoque Basado en el Conocimiento que pasamos a describir brevemente. 


\subsubsection{El enfoque basado en recursos}

La teoría o Enfoque Basado en los Recursos (EBR) explica las diferencias en los resultados de una determinada organización empresarial en base a sus recursos estratégicos. El énfasis se centra en el interior de la empresa, en sus recursos y su relación con la estrategia, como se recoge en las aportaciones pioneras de Selznick (1957), Penrose (1959) y Andrews (1971). Para este enfoque, los recursos de una organización son todos sus activos, capacidades, procesos organizacionales, atributos, información y conocimiento que son controlados por la organización para concebir e implementar estrategias que promuevan la efectividad y eficiencia. La ventaja competitiva se produce en la industria cuando se implementa una estrategia creativa de valor que no está siendo implementada simultáneamente por cualquier competidor.

En una de las primeras aportaciones a este enfoque, Penrose (1959) concibe la empresa como un conjunto de recursos productivos, cuyo valor para el crecimiento no descansa en sí mismos, sino en los servicios que producen esos recursos o la forma en que son utilizados (servicios directivos). Sin embargo, debido a la dificultad para desarrollar modelos empíricos operativos, estos estudios perdieron protagonismo en la comunidad científica frente a las aportaciones procedentes de la Economía Industrial.

A partir de los años ochenta (Wernerfelt, 1984; Montgomery y Wernerfelt, 1988), y principalmente durante la última década del siglo XX (Prahalad y Hamel, 1990; Barney, 1991; Conner, 1991; Grant, 1991; Rumelt, 1991; Amit y Schoemaker, 1993; Peteraf, 1993), el análisis estratégico interno ha tomado un nuevo impulso.

El EBR explica las ventajas competitivas de las empresas a partir de la dotación de recursos tangibles e intangibles a su disposición. Según Wenerfelt (1984), debe considerarse como recurso todo aquel activo tangible o intangible que se vincule a la empresa durante un periodo de tiempo relevante, como es el caso de las marcas, el conocimiento tecnológico propio, el personal cualificado, los contactos comerciales, la maquinaria, los procedimientos eficientes, etc. El enfoque de recursos se centra en el 
análisis de las características de estos activos estratégicos y de sus procesos de acumulación interna en las organizaciones.

Para d'Aveni y Gunther (1994), el grado de imitabilidad y transferencia de esos recursos idiosincrásicos a la empresa determinan la sostenibilidad de las ventajas competitivas que producen. Por tanto, las características de los recursos que permiten las rentas económicas son: escasez, perdurabilidad en el tiempo, dificultad en la imitación y la no transferibilidad. La empresa se concibe como una cartera heterogénea de recursos y capacidades valiosos, escasos, raros, idiosincrásicos, y de imitabilidad y movilidad imperfectas.

Barney (1991) resume las bases del EBR para explicar la ventaja competitiva en las siguientes dos suposiciones:

- Los recursos estratégicos de las empresas de una misma industria pueden ser heterogéneos.

- La movilidad entre empresas de estos recursos puede no ser perfecta, y por lo tanto, la heterogeneidad de los recursos puede prolongarse en el tiempo. 
Figura 1.1. Esquema teórico perspectiva basada en recursos

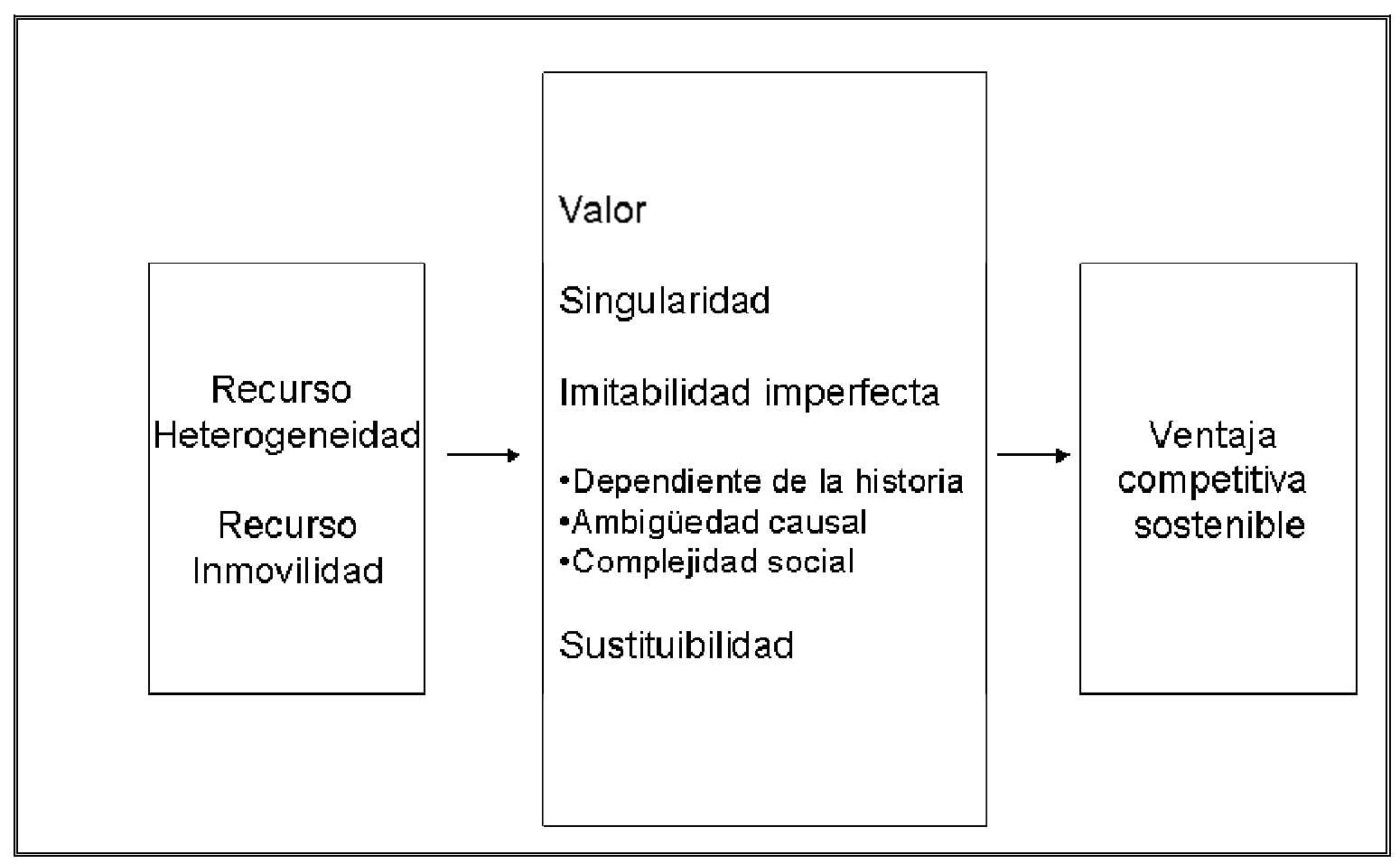

Fuente: Barney (1991)

Basándose en el EBR, Grant (1991) considera más interesante enfocar la estrategia de negocio hacia la búsqueda de rentas ricardianas (cuando una organización tiene factores de producción más productivos que otras que desarrollan la misma actividad), derivadas de los recursos que confieren ventajas competitivas por encima del coste real de esos recursos, que hacia rentas de monopolio, derivadas del poder en el mercado. Para este autor, en entornos turbulentos, los recursos y capacidades de la empresa pueden representar una base mucho más sólida y estable sobre la cual establecer la estrategia que no la definición de ésta en base a las necesidades que el negocio trata de satisfacer (estrategia enfocada al mercado).

Como síntesis, podemos afirmar siguiendo a Siqueira y Cosh (2008) que el EBR adopta dos escuelas de pensamiento: la escuela de contenido estructural, enfocada a las características organizativas para producir rentas ricardianas y la escuela de capacidades 
y procesos, centrada en las capacidades organizativas que producen rentas con eficiencia.

\subsubsection{El enfoque basado en las capacidades dinámicas}

El EBR, al asumir la insustituibilidad de los recursos valiosos como condición para la sostenibilidad de la ventaja competitiva, niega de forma implícita la posibilidad de rápidos cambios en el entorno. Partiendo de esta limitación, Teece, Pisano y Shuen. (1997) desarrollan el concepto de capacidades dinámicas. Éstas se definen como la habilidad para integrar, construir y reconfigurar competencias internas y externas para encarar los rápidos cambios del entorno. La ventaja competitiva se consigue a través del proceso conjunto de desarrollo, acumulación, combinación y protección de las habilidades y capacidades de la empresa. Más recientemente, Helfat et al. (2007) partiendo de trabajos anteriores definen las capacidades dinámicas como "la capacidad de una organización para decididamente crear, extender o modificar su base de recursos"

Este enfoque intenta explicar el por qué algunas empresas son capaces de generar una ventaja competitiva en entornos de cambio continuo (Salunke et al 2011). Las capacidades dinámicas son concebidas como el antecedente organizativo y las rutinas estratégicas a través de las cuales los directivos alteran la base de recursos de la empresa. Éstos, a través de la adquisición, combinación, integración, etc., de recursos pueden generar nuevas estrategias de creación de valor. A diferencia del EBR este enfoque asigna un papel preeminente al liderazgo estratégico de la organización en la alimentación y construcción de capacidades dinámicas críticas para el proceso de generación de valor.

De manera similar, la teoría económica evolutiva (Nelson y Winter, 1982) incide en los procesos de competencia dinámica y en la "creación destructiva" de Schumpeter (1975). El objetivo de estos autores es el de crear los fundamentos necesarios para modelizar una teoría que permita analizar los procesos de competencia dinámica o schumpeteriana. Ya no se analiza el comportamiento de las empresas dentro de una 
estructura de mercado fija, tal como se realizaba en el enfoque neoclásico, sino que se examinan situaciones en las que continuamente se están destruyendo estructuras y creando nuevas.

Schoemaker y Amit (1997) reconocen la importancia de la posición en el mercado de productos, pero no la consideran determinante en un régimen de rápido cambio tecnológico. Partiendo del EBR y la explotación de los recursos a través de rentas ricardianas, el modelo de capacidades dinámicas adopta una visión dinámica y de creación destructiva de tipo Schumpeteriano que estas capacidades producen. Es un intento de llevar el EBR hacia un modelo dinámico. Las rentas que producen las capacidades dinámicas son consideradas schumpeterianas, pues se pone énfasis en la constante innovación que éstas proporcionan. Se trata de un modelo basado en el desequilibrio.

En esta misma línea, Teece et al. (1997) argumentan que la acumulación de recursos no es suficiente para el éxito en un entorno dinámico e innovador, pues estos recursos pueden quedar desfasados con rapidez o no ser aplicados de la manera innovadora necesaria. Para estos autores, las empresas no pueden quedarse solamente en la identificación y explotación de los recursos valiosos específicos a la firma. También critican el EBR por ser un modelo demasiado descriptivo y no normativo. El gran reto es responder a la pregunta de cómo crear esas capacidades dinámicas y establecer una teoría no sólo descriptiva, sino también normativa de cómo desarrollar las competencias y renovarlas siguiendo los cambios del entorno.

Según Zollo y Winter (2002), la respuesta a esta pregunta está en la manera en que la producción está organizada, pues es la fuente de las distintas competencias en los diferentes dominios. Los procesos gerenciales y organizativos con sus tres papeles fundamentales de integración y coordinación, aprendizaje, y reconfiguración, son los responsables de la creación de las capacidades dinámicas. Así pues, ponen como clave estratégica la estructura organizativa y el proceso gerencial. Aquí se incluyen la coordinación e integración de los procesos, el aprendizaje tanto individual como organizativo y la creación de nuevas rutinas. También consideran como esencial la 
capacidad de cambio, entendida como reconfiguración y transformación para adaptarse a los cambios de los mercados.

Desde un punto de vista de capacidades dinámicas, la estrategia también implica la elección de una trayectoria de desarrollo de competencias a largo plazo. Puesto que el aprendizaje se basa en las actividades previas, las nuevas competencias estarán marcadas por la trayectoria seguida, y por tanto, existe un compromiso casi irreversible a ciertos dominios de competencias. La estrategia debe establecer, a parte del posicionamiento de los activos tradicionales y de las capacidades de la empresa, nuevas e innovadoras formas de alcanzar la ventaja competitiva dada la trayectoria y la posición en el mercado.

Al igual que Ghemawat (1991), Teece y Pisano (1998) consideran la trayectoria empresarial determinante en las opciones posibles para el posicionamiento futuro, pero a diferencia del primero, lo achacan al aprendizaje, que está ligado a las actividades previas.

Resumiendo brevemente, el Enfoque Basado en Capacidades Dinámicas centra su atención en el conjunto de conocimientos y habilidades que crean las competencias de la empresa. Las competencias dinámicas actúan como catalizadores en los procesos de generación y renovación de las competencias de la empresa, sobre las cuales se fundamenta su competitividad.

\subsubsection{El enfoque basado en el conocimiento}

El Enfoque Basado en el Conocimiento (considera el conocimiento como el principal recurso propio de la empresa generador de la ventaja competitiva (Grant, 1996a). Esto ha dado lugar a la aparición de nuevas orientaciones en el estudio de las organizaciones. Algunas de ellas llegan a afirmar que la justificación de las empresas es el conocimiento organizativo que se desarrolla y difunde en ella, rompiendo con otras teorías más mercantilistas como puedan ser los ahorros en costes de transacción (Brown y Duguid, 
1998). Tanto es así, que algunos autores definen las empresas como entidades o contextos sociales que sostienen y desarrollan el conocimiento (Kogut y Zander, 1992; Hedlund, 1994).

Lei, Hitt y Bettis (1996) entienden la gestión del conocimiento como la capacidad dinámica preeminente en la empresa, así como el principal impulso del resto de competencias y capacidades. Así, los procesos de generación y adquisición de conocimiento se convierten en un elemento esencial de análisis para comprender el desarrollo y evolución de las estrategias en las empresas.

El trabajo con mayor impacto y reconocimiento dentro de este enfoque ha sido el de Nonaka y Takeuchi (1995). Estos autores abordan la gestión del conocimiento desde una perspectiva completamente dinámica, desarrollando un modelo sobre la creación y la gestión del conocimiento. En este modelo, la creación de conocimiento depende del conocimiento tácito de los individuos, desarrollado a través del aprendizaje mediante la interacción y comunicación entre diferentes agentes dentro del dominio organizativo, que a su vez, permite su transformación en conocimiento explícito (Nonaka, 1994:20).

Para Nonaka y Takeuchi (1995), la generación del conocimiento es esencial para las corporaciones situadas en un entorno cambiante y competitivo. Pero el conocimiento en sí mismo no basta. El nivel de competencia de una empresa no depende sólo de la intensidad de conocimiento de la misma, sino también del grado de utilización de éste en la producción de bienes y servicios. Las organizaciones deben centrarse en el aumento de valor de sus productos mediante el incremento de conocimiento en sus actividades, confiriendo una componente estratégica al proceso de generación del conocimiento. Según Tissen et al. (1998), las empresas buscan esta adición continua de valor mediante el desarrollo de una serie de capacidades. Entre estas capacidades se encuentran las de generación de conocimiento y las de aprendizaje continuo. Pero estas habilidades deben ser combinadas con otras para que realmente aporten valor a las organizaciones, por lo tanto se deben buscar las estructuras y procesos necesarios para la aplicación eficiente del conocimiento existente. Además, estas capacidades deben 
estar orientadas al mercado de manera dinámica, por lo que deben adaptarse a los cambios de éste y ser capaces de anticiparse al futuro.

Resumiendo brevemente los tres enfoques analizados, podemos decir que el enfoque basado en recursos presenta un carácter estático. Una perspectiva más dinámica, donde tengan cabida los procesos de aprendizaje e innovación, la incertidumbre y el impacto de los cambios que se producen en el entorno aportan, sin duda, un mayor realismo y poder explicativo al enfoque. Esto ha producido, como señalan Mahoney y Pandian (1992), la confluencia del enfoque de recursos y el de las capacidades dinámicas en el llamado Enfoque de Recursos y Capacidades. Éste analiza un mismo problema desde dos perspectivas complementarias; la naturaleza de las competencias básicas y su valor como fuente de ventajas competitivas, estática la primera y dinámica la segunda.

Por último, el Enfoque basado en el Conocimiento supone el conocimiento como el recurso más importante dentro de las empresas, considerando la capacidad para generarlo y usarlo de manera eficiente como determinante en la consecución de ventajas competitivas.

Tal y como indica Newbert (2008), los recursos y capacidades no son valiosos per se. Éstos son esencialmente improductivos utilizados de forma aislada. El autor afirma que la clave para obtener una ventaja competitiva es la explotación de una combinación de recursos y capacidades valiosa. Estos tres enfoques, sin embargo, están vinculados y se complementan entre sí. Barney, Wright y Ketchen (2001) reconocen la estrecha relación entre los recursos, las capacidades dinámicas y el conocimiento, y considera como tema crucial para futuras investigaciones profundizar en sus interacciones. Tal y como hemos visto en este epígrafe los recursos y capacidades son fuentes de ventaja competitiva, pero no contribuyen necesariamente a ésta (Bitar y Hafsi, 2007). Para que contribuyan, éstos deben contribuir a generar productos y servicios por los que los clientes estén dispuestos a pagar un precio que genere una renta para la organización (Ambrosini y Bowman, 2009). 


\subsubsection{Otras aportaciones al EBC}

Otras líneas de trabajo que han realizado importantes aportaciones a la conformación del EBC son el Enfoque Evolutivo, el Enfoque de la Competitividad Basada en las Competencias y el Enfoque Basado en el Aprendizaje (Camisón, 2002a). A continuación comentamos brevemente las aportaciones realizadas por estas corrientes de pensamiento:

- Enfoque Evolutivo: la empresa se considera como un conjunto de normas y procedimientos organizativos que se transforman para buscar un ajuste satisfactorio con el entorno. La empresa se adapta al entorno y cambia en el tiempo a través de la búsqueda de nuevas rutinas. Este enfoque concibe el concepto de competencia como la capacidad de aprovechamiento para la producción de un conjunto de recursos en unas circunstancias dadas. Las competencias se manifiestan a través de las rutinas, definidas como un conjunto de secuencias por las que la producción se realiza. Destacan los trabajos de Nelson y Winter (1982), Nelson $(1991,1995)$ y Winter (1995).

- Enfoque de la Competitividad Basada en las Competencias: se centra en los procesos de generación y desarrollo de las competencias. La empresa se interpreta como una cartera de competencias, resultado del aprendizaje colectivo de la organización, utilizadas en distintos campos de actividad vinculadas por un tronco tecnológico común. Aplica el estado de desequilibrio al concepto de ventajas competitivas sostenibles, extendiendo el campo de análisis a los procesos de generación, potenciación y desarrollo de competencias. Destacan los trabajos de Prahalad y Hamel (1990, 1994), Foss (1996), Hamel y Prahalad (1993), y Sánchez, Heene y Thomas (1996).

- Enfoque Basado en el Aprendizaje: considera el conocimiento como el recurso clave en la explicación de la competitividad de las empresas. El aprendizaje 
implica la adquisición y creación de nuevos conocimientos y su aplicación a los procesos de negocio. Es por esto que, desde un punto de vista dinámico, reconoce a la capacidad de aprendizaje como una de las principales fuentes de ventaja competitiva. El proceso de aprendizaje organizativo se considera como resultado de la interacción de los individuos, por lo que la administración de los recursos humanos cobra especial relevancia. Destacan los trabajos de Senge (1990), Brown y Duguid (1991), Lave y Wenger (1991), Blackler (1993), Cook y Yanow (1996) y Heene y Sánchez (1997). Camisón (2002a) señala que, aunque sería deseable la convergencia entre el enfoque basado en el conocimiento y el aprendizaje organizativo, esta aproximación no acaba de progresar, manteniéndose ambas como corrientes de pensamiento paralelas, la primera con una inspiración más económica y la segunda con un carácter más sociológico. Pese a todo, el nivel de solapamiento es elevado, trabajando ambos enfoques en los mismos cuatro niveles (individual, grupal, organizativo e interorganizativo) y estudiando el proceso de renovación de las competencias distintivas de la organización.

\subsubsection{Evolución del EBC}

La línea de pensamiento que sigue el desarrollo del Enfoque Basado en Recursos se centra en estudiar las características que deben poseer los recursos para generar rentas. Los trabajos de Barney $(1986,1991)$ y Amit y Schoemaker (1993) consideran que un recurso es fuente de ventaja competitiva cuando es escaso y valioso y además existe un solapamiento con los factores estratégicos de la industria. Pero estas características no aseguran que la ventaja competitiva sea sostenible. Ésta sólo puede ser considera sostenible si no puede ser copiada, duplicada o neutralizada por los competidores (Barney, 1994). Esto implica que para que la ventaja sea sostenible, los recursos deben, además, tener durabilidad en el tiempo, ser de difícil imitación y no sustituibles (Amit y Schoemaker, 1993). 
Esta visión estática pronto encontró límites en su capacidad para responder a nuevas preguntas, generando una serie de críticas por no abordar el problema de la creación y mantenimiento de estos recursos y poner demasiado énfasis en los recursos individuales (Lockett, Thompson y Morgenstern, 2009). Además, este enfoque estático no explica adecuadamente la forma y el motivo por el cual ciertas empresas logran alcanzar la ventaja competitiva en mercados dinámicos o en situaciones de cambio (Black y Boal, 1994). Así, Fiol (2001) cuestiona que, en un entorno fuertemente competitivo, se pueda alcanzar la ventaja competitiva basándose en una competencia por muy inimitable que sea. Para este autor, los recursos y habilidades de las organizaciones y la manera en que se aplican deben modificarse constantemente y adaptarse para producir ventajas temporales en continua renovación. Por lo tanto, las rentas superiores pueden derivar de la habilidad para destruir y construir recursos o rutinas especializadas e inimitables durante el tiempo.

Estas críticas dieron nacimiento a la vertiente dinámica del EBC donde se aborda el problema del proceso de acumulación de activos que permite la creación y renovación de la ventaja competitiva. Sus estudios consideran las competencias por medio de las cuales se crean nuevos procesos y productos, adaptándose al entorno.

Tomando como base el Enfoque Evolutivo y en el Enfoque Basado en las Capacidades Dinámicas, el EBC evoluciona parar centrar su atención en el conjunto de conocimientos y habilidades que crean las competencias de la empresa. Se analiza el modo en el que las organizaciones desarrollan sus capacidades específicas y regeneran sus competencias para hacer frente a los cambios que aparecen en el entorno. Las capacidades enfatizan "el papel clave de la dirección estratégica en adaptar, integrar y reconfigurar apropiadamente las habilidades organizativas, recursos y competencias funcionales internas y externas" (Teece, Pisano y Schuen, 1997: 515). Según estos autores, las capacidades dinámicas hacen referencia a la "habilidad de la empresa para integrar, construir y reconfigurar competencias internas y externas para tratar con ambientes en constante evolución". 
Si se considera el conocimiento como el recurso clave o estratégico para las empresas, la corriente del Enfoque Basado en el Conocimiento puede englobarse dentro del EBC. Aunque los autores especializados en la gestión del conocimiento hablan de conocimiento y no de capacidades (Kogut y Zander, 1992; Nonaka y Takeuchi, 1995), las capacidades son formas de conocimiento que posee la organización. El desarrollo y generación del conocimiento como recurso entraría dentro del Enfoque Basado en el Aprendizaje. Este desarrollo del conocimiento se realizaría a través del aprendizaje mediante la interacción y comunicación dentro del dominio organizativo (Wang y Raymond, 2010).

En el estado actual del EBC, se intenta conjugar la perspectiva estática, centrada en la naturaleza de los activos estratégico que explican la competitividad a corto plazo, con la perspectiva dinámica, que intenta explicar el proceso de creación y desarrollo de los recursos, capacidades y competencias y que explica la competitividad a largo plazo (Collis y Montgomery, 1995).

Las aportaciones de estos enfoques al EBC se resumen en la siguiente tabla:

Tabla 1.1. Corrientes teóricas en el Enfoque Basado en las Competencias

\section{ENFOQUES ESTÁTICOS}

\section{TRABAJOS PIONEROS EN TEORÍA DE LA ESTRATEGIA}

Referencias básicas

- La empresa se define como una colección de recursos heterogéneos que pueden explicar la diferencia de posición competitiva entre empresas.

Selznick (1957)

Penrose (1959)

- Las competencias se conciben como fortalezas

Andrews (1971) que permiten aprovechar las oportunidades en los mercados.

Ansoff (1965) 


\begin{tabular}{|l|l||}
\hline Enfoque basado en los recursos & Referencias básicas \\
\hline $\begin{array}{l}\text { Los recursos que manejan las empresas en un } \\
\text { determinado sector pueden ser idiosincrásicos, y } \\
\text { por lo tanto, esas empresas podrán ser } \\
\text { heterogéneas. }\end{array}$ & $\begin{array}{l}\text { Wernerfelt (1984) } \\
\text { Dierickx y Cool } \\
(1989)\end{array}$ \\
$\begin{array}{l}\text { La heterogeneidad entre empresas podrá perdurar } \\
\text { en el tiempo puesto que los recursos que } \\
\text { controlan pueden no ser perfectamente móviles. }\end{array}$ & $\begin{array}{l}\text { Barney (1991) } \\
\text { - Emit y Schoemaker } \\
\text { en su relación con la estrategia. } \\
\begin{array}{l}\text { La obtención de rentas, en este caso ricardianas, } \\
\text { depende de las imperfecciones en el mercado de } \\
\text { factores. }\end{array}\end{array}$ Peteraf (1993) \\
\hline
\end{tabular}

\section{ENFOQUES DINÁMICOS}

\begin{tabular}{|c|c|}
\hline Enfoque evolutivo & Referencias básicas \\
\hline $\begin{array}{l}\text { - La empresa se interpreta como un conjunto de } \\
\text { normas y procedimientos organizativos que se } \\
\text { intentan transformar para buscar un ajuste } \\
\text { satisfactorio con el entorno. } \\
\text { - Se analiza cómo la empresa se adapta al entorno y } \\
\text { cambia en el tiempo a través de un proceso } \\
\text { estocástico de búsqueda de nuevas rutinas. La } \\
\text { competitividad de las empresas se explica } \\
\text { mediante las ventajas obtenidas por medio de los } \\
\text { procesos de producción, innovación y aprendizaje } \\
\text { de competencias. }\end{array}$ & $\begin{array}{l}\text { Foss y Harmsen } \\
(1996) \\
\text { Nelson y Winter } \\
(1982) \\
\text { Dosi et al. (1988) } \\
\text { Nelson (1991, 1995) } \\
\text { Winter (1995). }\end{array}$ \\
\hline Enfoque basado en las capacidades dinámicas & Referencias básicas \\
\hline
\end{tabular}




\begin{tabular}{|c|c|}
\hline $\begin{array}{l}\text { - Centra su atención en el conjunto de } \\
\text { conocimientos y habilidades que crean las } \\
\text { competencias. } \\
\text { - La competitividad de las empresas se basa en las } \\
\text { capacidades y habilidades para renovar y generar } \\
\text { las competencias distintivas de la empresa. } \\
\text { - Las competencias ligadas con la competitividad } \\
\text { son las dinámicas, considerándose las rentas } \\
\text { obtenidas schumpeterianas. }\end{array}$ & $\begin{array}{l}\text { Mahoney y Pandian } \\
\text { (1992) } \\
\text { Teece, Pisano y } \\
\text { Shuen (1990, 1997) } \\
\text { Schoemaker y Amit } \\
\text { (1997) } \\
\text { Teece y Pisano (1998) } \\
\text { Eisenhardt y Martin } \\
\text { (2000) } \\
\text { Zollo y Winter (2002) }\end{array}$ \\
\hline Enfoque de la competitividad basada en las competencias & Referencias básicas \\
\hline $\begin{array}{l}\text { - La empresa se visualiza como un conjunto de } \\
\text { competencias aplicables a distintos campos de } \\
\text { actividad vinculadas por un tronco tecnológico } \\
\text { común. } \\
\text { - Se preocupa del estudio de los procesos de } \\
\text { generación, potenciación y desarrollo de las } \\
\text { competencias, resultado del aprendizaje colectivo } \\
\text { de la organización. }\end{array}$ & $\begin{array}{l}\text { Foss (1996) } \\
\text { Prahalad y Hamel } \\
(1990,1994) \\
\text { Hamel y Prahalad } \\
(1993) \\
\text { Sánchez, Heene y } \\
\text { Thomas (1996) }\end{array}$ \\
\hline Enfoque basado en el conocimiento & Referencias básicas \\
\hline $\begin{array}{l}\text { - El conocimiento es el activo clave que explica la } \\
\text { competitividad empresarial. El conocimiento se } \\
\text { acumula como consecuencia del aprendizaje } \\
\text { empresarial. } \\
\text { - Las competencias se consideran como una } \\
\text { colección de formas de conocimiento con distintos } \\
\text { grados de complejidad, especificidad y } \\
\text { codificabilidad. } \\
\text { - Las empresas son entidades heterogéneas } \\
\text { caracterizadas por una única base de conocimiento. }\end{array}$ & $\begin{array}{l}\text { Kogut y } \begin{array}{r}\text { Zander } \\
(1992) \\
(1994)\end{array} \\
\begin{array}{l}\text { Nonaka y } \\
(1995)\end{array} \\
\text { Grant (1996a) } \\
\text { Spender (1996) } \\
\begin{array}{l}\text { Nonaka y Konno } \\
(1998)\end{array}\end{array}$ \\
\hline
\end{tabular}




\begin{tabular}{|l|l|}
\hline Enfoque basado en el aprendizaje & \multicolumn{1}{|c|}{ Referencias básicas } \\
\hline - Se centra en la forma en la que las personas & Senge (1990) \\
interpretan o dan sentido a sus experiencias en el & $\begin{array}{l}\text { Brown y Duguid } \\
\text { trabajo. }\end{array}$ \\
$\begin{array}{l}\text { Wenger (1991) } \\
\text { Los individuos son seres sociales que construyen }\end{array}$ \\
$\begin{array}{l}\text { juntos la comprensión de lo que les rodea y } \\
\text { aprenden de la interacción social dentro de }\end{array}$ & $\begin{array}{l}\text { Blackler (1993) } \\
\text { Cook y Yanow (1996) }\end{array}$ \\
\hline
\end{tabular}

Fuente: Camisón (2002a)

Así pues, el EBC es un enfoque que integra distintas corrientes de pensamiento dentro de un cuerpo común sólido. Sin embargo, existen una serie de inconvenientes que han contribuido a frenar la difusión del EBC como paradigma dominante dentro del pensamiento económico y estratégico y su reconocimiento como "teoría de la empresa". Camisón (2002a) destaca tres deficiencias que han contribuido a frenar la proyección de este enfoque: el propósito ciertamente paradójico de su objetivo científico, "generalizar lo único", que se plasma en la proliferación de métodos para los contrastes empíricos; la ambigüedad terminológica de su marco conceptual y los fallos de operativización.

\subsubsection{Complementariedad entre el EBC y otros enfoques}

Trabajos como el de Spanos y Lioukas (2001) demuestran que el EBC es un enfoque complementario con otros enfoques como el Porter (1980). Los autores demuestran que ambos modelos pueden coexistir y que dan forma al comportamiento organizativo actual, así como que ambas perspectivas se complementan mutuamente en la explicación de los niveles de desempeño de las organizaciones (Amit y Schoemaker, 1993; Peteraf, 1993). Intuitivamente, la creación de valor tiene su raíz en el encaje de las capacidades de una organización para llevar a cabo la estrategia perseguida y de la estrategia hasta el entorno competitivo (Barney y Griffin, 1992; Barney, 1992). Como 
Barney y Zajac (2994) han afirmado, el examen de las capacidades de implementación de la estrategia (es decir, los recursos y capacidades) no pueden ser entendidos de forma independiente del contenido de la estrategia y del entorno competitivo en el que la organización opera.

Es posible argumentar que el enfoque basado en recursos o competencias, dado que pone el acento en los esfuerzos por parte de las empresas en desarrollar y combinar los recursos para conseguir una ventaja competitiva, pone el acento en la parte de Fortaleza/Debilidades de la matriz DAFO, mientras que el análisis industrial permite analizar la parte de Oportunidades/Amenazas de dicha matriz (Foss, 1996). Desde esta perspectiva, ambas visiones son complementarias simplemente porque cubren diferentes dominios de aplicación (Foss, 1997, Barney 1991) en el contexto del análisis DAFO. Los cambios en el entorno "pueden cambiar el significado de los recursos de una firma" (Penrose, 1959:79).

Ambos enfoques en consecuencia tienen similitudes y diferentes sustanciales. Una importante similitud entre ambos enfoques es la visión compartida de que los retornos por encima de la media del sector son posibles y que para que esta situación se produzca, una posición estratégica atractiva es de crucial importancia (Conner, 1991).

Spanos y Lioukas (2001) establecen un modelo de complementariedad basados en las siguientes similitudes:

a) las dos perspectivas son complementarias a la hora de explicar el desempeño de una organización, en el sentido de que uniendo ambas visiones es posible obtener una mayor riqueza y equilibrio a la hora de obtener las fuentes de la ventaja competitiva (integrando determinantes tanto "externos" como internos")

b) ambos enfoques buscan explicar el mismo fenómeno de interés (la ventaja competitiva)

c) la unidad de análisis es la misma en ambos casos 
Sin embargo, como los mismos autores afirman, esto no quiere decir que se puedan obviar los fundamentos teóricos de ambas corrientes de pensamiento, siendo en incluso en ocasiones antagonistas.

\subsection{Concepto de recurso, capacidad y competencia}

En las diferentes aportaciones desarrolladas en el EBC se han utilizado una gran variedad de términos para definir conceptos similares tales como recursos, capacidades, activos intangibles, activos estratégicos, capacidades dinámicas o competencias distintivas. Dado este número de términos, es necesario clarificar los términos que se utilizarán en el resto del trabajo. De hecho, numerosos autores (Fernández y Suárez, 1996; Foss, 1998) consideran el problema terminológico como uno de los principales problemas a los que se enfrentan estos enfoques, ya que lleva en muchos casos a la confusión de los conceptos claves.

Las razones de este elevado número de términos se deben al relativo poco tiempo de desarrollo de este enfoque y a las aportaciones recibidas de múltiples corrientes teóricas, como se ha comentado en el apartado anterior.

Pasamos a continuación a definir y comentar los diferentes conceptos pertenecientes al EBC y que serán relevantes para el problema que trata el presente trabajo. 


\subsubsection{Recurso}

\subsubsection{Definición de Recurso}

Con el propósito de intentar clarificar el controvertido problema conceptual parece interesante, cuando se habla de recursos, diferenciar entre recursos en sentido amplio o en sentido estricto.

Recurso en sentido amplio se entiende como aquel medio que sirve para alcanzar un objetivo marcado de antemano (Palacios, 2002). Por tanto, los recursos serían todos aquellos factores de producción sobre los cuales la empresa puede ejercer un control efectivo, independiente de que tenga sobre ellos derechos de propiedad. De lo anterior se deduce que este concepto de recurso va más allá de la concepción de factor productivo, propia de la teoría económica.

Barney (1991) adopta una visión amplia de recurso y entiende como recurso todos los activos, capacidades, procesos organizativos, atributos empresariales, información, conocimiento, etc. que son controlados por la empresa y que le permiten implantar estrategias que mejoren su eficiencia y eficacia.

Este autor clasifica los recursos de una empresa en tres categorías:

- Recursos físicos: tecnología, equipo productivo, localización geográfica, acceso a materias primas, etc.

- Recursos humanos: formación, experiencia, relaciones y visión, tanto de los directivos como de los empleados.

- Recursos organizativos: estructura formal de la empresa, su planificación formal e informal, sistemas de coordinación y control, etc.

Wenerfelt (1984), al igual que Barney (1991), define los recursos como los activos tangibles e intangibles vinculados a la empresa durante un periodo de tiempo relevante. 
Dentro del concepto de recursos incluye las marcas, el personal cualificado, los contactos comerciales, la maquinaria, el conocimiento tecnológico propio y los procedimientos eficientes.

Más recientemente, para Galbreath y Galván (2004), los recursos se dividen en dos categorías: recursos tangibles y recursos intangibles. Los recursos tangibles incluyen aquellos factores que poseen un valor contable en los libros de contabilidad. Los recursos intangibles, por otra parte, incluyen aquellos factores que no son físicos (o no financieros) y que raramente se incluyen en los libros de contabilidad. Esta conceptuación de recurso como activo también se encuentra en otros trabajos, como los de Dierickx y Cool (1989), Peteraf (1993), Chi (1994) y Galbreath (2005).

Para algunos autores, estas definiciones de recurso en sentido amplio incluyen el concepto de capacidad de una empresa (Camisón, 2002b). No obstante, otros autores diferencian los conceptos de recurso y capacidad. Por ejemplo, Amit y Schoemaker (1993: 35) definen los recursos como "inventarios de factores disponibles que son poseídos o controlados por la empresa y que son convertidos en productos finales utilizando un amplio rango de otros activos y de mecanismos de enlace como la tecnología, los sistemas de información directiva, los sistemas de incentivos, la confianza entre dirección y personal, etc."

De igual manera, Grant (1991) concibe el recurso en sentido estricto y los concibe como las entradas del proceso productivo. Éstos constituyen la unidad básica de análisis, diferenciándolos así de las capacidades. Para este autor, la capacidad depende de la posesión de un conjunto de recursos para desempeñar alguna tarea o actividad. Los recursos constituyen el origen de las capacidades de la empresa, mientras que las capacidades representan la fuente principal de las ventajas competitivas.

Para Hall (1992), los recursos intangibles pueden definirse como activos o capacidades. Si los recursos intangibles es algo que la empresa tiene, puede considerarse como un activo. Si el recurso intangible es algo que la empresa puede hacer, es una capacidad. 


\subsubsection{Clasificación de los Recursos}

Siguiendo con la caracterización de los recursos en sentido estricto, Grant (1991) distingue entre recursos tangibles e intangibles:

- Recursos tangibles: están identificados en los balances y valorados con criterios contables. Son los activos físicos y financieros de la empresa. El principal objetivo en la gestión de estos recursos es conseguir una aplicación más eficiente de los mismos.

- Recursos intangibles: suelen permanecer invisibles en la información contable debido principalmente a la dificultad en su valoración. Estos recursos incluyen los conocimientos, el equipo humano, las tecnologías de las que se dispone, los clientes, la imagen de la empresa y el prestigio de la marca comercial. Una valoración aproximada de los activos intangibles de una empresa se puede deducir, en el caso de que ésta cotice en bolsa, a partir del precio de mercado de las acciones en relación a su precio contable.

Para Itami (1987) estos recursos intangibles son a menudo la única fuente real de ventaja competitiva que puede mantenerse a lo largo del tiempo, pues, para este autor, lo que proporciona una ventaja estratégica a la empresa no es observable ni medible.

Camisón (2002a), tomando como fuente la clasificación de Grant (1996a), hace la siguiente descripción de los recursos (Tabla 1.2): 
Tabla 1.2. Clasificación de los recursos

\begin{tabular}{|c|c|}
\hline \multirow{4}{*}{ Tangibles } & Recursos físicos (capital físico) \\
\hline & $\begin{array}{l}\text { Incluyen el equipamiento productivo, almacenes, inventarios, centros } \\
\text { de aprovisionamiento, equipamiento informático, etc. }\end{array}$ \\
\hline & Recursos financieros (capital financiero) \\
\hline & $\begin{array}{l}\text { Hacen referencia a la estructura de financiación de la empresa que le } \\
\text { permite acometer inversiones en los demás factores. Se restringe a la } \\
\text { tesorería, al capital circulante y a las inversiones financieras en la } \\
\text { empresa. }\end{array}$ \\
\hline \multirow{4}{*}{ Intangibles } & Recursos humanos \\
\hline & $\begin{array}{l}\text { El capital humano hace referencia a los conocimientos adquiridos por } \\
\text { una persona que incrementan su productividad y el valor de su } \\
\text { contribución a la empresa. Incluye los contactos y relaciones } \\
\text { personales, además de otras cualidades individuales como reputación, } \\
\text { lealtad, polivalencia y flexibilidad. El capital humano es el recurso } \\
\text { intangible no separable por excelencia, ya que es indisociable de su } \\
\text { portador. }\end{array}$ \\
\hline & Recursos organizativos \\
\hline & $\begin{array}{l}\text { El capital organizativo de una empresa incluye los acuerdos de } \\
\text { cooperación que tiene con proveedores, distribuidores y socios } \\
\text { tecnológicos, además de su entramado de rutinas organizativas. Estos } \\
\text { elementos pueden considerarse como mecanismos de vinculación y } \\
\text { movilización de los distintos factores productivos empleados, que } \\
\text { facilitan la conversión de las entradas del proceso productivo en bienes } \\
\text { y servicios, creando valor al tiempo que determinan la eficiencia y la } \\
\text { propia capacidad de innovación de la empresa. }\end{array}$ \\
\hline
\end{tabular}




\section{Recursos comerciales}

Es todo aquel activo comercial susceptible de ser objeto de protección legal y cuya propiedad incumbe a la empresa. Normalmente se derivan de contratos de distribución o de abastecimiento privilegiado o en exclusiva.

\section{Recursos tecnológicos}

El stock de capital tecnológico incluye conocimientos relacionados con el acceso, utilización y mejora de las técnicas de producción y las tecnologías de producto. Se amplía y perfecciona a través de las actividades de $\mathrm{I}+\mathrm{D}$ (internas, realizadas en cooperación con otros o contratadas a terceros) y de la adopción y asimilación de las tecnologías desarrolladas por otras empresas, a las que se accede mediante licencias o por la compra de tecnología incorporada a máquinas y equipos de producción.

Fuente: elaborado a partir de Camisón (2002a)

\subsubsection{Capacidades}

\subsubsection{Definición de Capacidad}

Las capacidades resultan de la combinación de activos tangibles y/o intangibles. La esencia de la capacidad es su carácter intangible debido a que su principal componente es el conocimiento subyacente a la hora de desplegar y emplear conjuntamente diferentes activos empresariales para el desarrollo de las actividades organizativas.

Según Amit y Schoemaker (1993: 35), la capacidad sería la facultad de gestionar adecuadamente los recursos para realizar una determinada tarea dentro de la empresa. En este contexto, las capacidades se refieren a la competencia de una empresa para 
desplegar los recursos, usualmente en combinación con procesos organizativos, para producir un fin deseado.

Cuervo (1995: 52) afirma que "el centro de toda estrategia es la obtención de beneficios a partir de los recursos y capacidades que controla la empresa, como son sus activos físicos y financieros, el capital humano, los activos intangibles como marcas, reputación, know-how, experiencia y tecnología. Las capacidades son básicamente consecuencias de la acción de la dirección para movilizar los recursos mediante la generación de un sistema de rutinas organizativas y de una cultura, resultado de un proceso de aprendizaje colectivo". Como se desprende de la definición de Cuervo, las capacidades también serán recursos al alcance de la empresa, de carácter organizativo, que permitirán dinamizar el resto de recursos que posee una organización empresarial

Las capacidades son, por tanto, las habilidades de una empresa para desplegar los recursos, generalmente de forma combinada, utilizando procesos organizativos para llegar a un fin deseado. Se trata de procesos específicos basados en la información, y desarrollados a través del tiempo mediante complejas interacciones entre los recursos de la empresa.

\subsubsection{Recursos vs. Capacidades}

Al analizar la sostenibilidad de las ventajas competitivas que un recurso o capacidad producen, es fundamental clarificar la distinción entre recurso y capacidad. Si tomamos la concepción estricta de recurso, se pueden extraer dos características clave que distinguen a una capacidad de un recurso:

- Una capacidad es específica de la empresa, ya que se encuentra incrustada en la organización y en sus procesos, lo que no ocurre con un recurso ordinario. (Teece, Pisano y Shuen, 1997: 518).

- El principal propósito de una capacidad es el de mejorar la productividad de los otros recursos que la empresa posee (Amit y Schoemaker, 1993). Estos autores 
establecen la analogía de los bienes intermedios, de forma que se puede pensar de forma abstracta en las capacidades como "bienes intermedios" que son generados por la empresa y que mejoran la productividad de sus recursos, así como la flexibilidad estratégica y la protección de su producto o servicio final.

La primera de estas características describe el arraigo de las capacidades en la organización. La propiedad de una capacidad no puede ser transferida fácilmente de una organización a otra sin transferir la organización completa o alguna subunidad. Dado que las capacidades están enraizadas en las empresas, si una empresa desapareciera sus capacidades se perderían con ella, pero sus recursos sobrevivirían en manos de los nuevos propietarios.

Así, si las capacidades no pueden ser adquiridas con facilidad, y tal como señalan Teece, Pisano y Shuen (1997), las capacidades tienen que construirse, el cometido de un directivo debe estar encaminado a impulsar su desarrollo en la organización. En esta línea, Makadok (2001:387) señala dos mecanismos que permiten a los directivos crear rentas económicas en sus empresas: la elección de los mejores recursos y la creación o mejora de las capacidades.

Grant (1991) reconoce que pocos recursos tomados independientemente son productivos, apareciendo el concepto de capacidad. Una capacidad es la habilidad para un equipo de recursos de realizar alguna tarea o actividad. Mientras los recursos son la fuente de las capacidades de la empresa, las capacidades son la principal fuente de sus ventajas competitivas. Pero las capacidades no sólo se limitarán a organizar coordinadamente un conjunto de recursos, sino que incorporan interacciones complejas entre personas y otros recursos que componen la empresa. Aparece aquí el concepto de rutinas organizativas en el sentido de Nelson (1991). Una capacidad es en esencia una rutina o un número de rutinas interactuando (Grant, 1991: 122). 


\subsubsection{Las Rutinas organizativas}

El término "rutina organizativa", como acabamos de comentar, es utilizado por varios autores en la conceptuación de capacidad. Su significado en estas definiciones está cercano a las rutinas organizativas del Enfoque Evolutivo (Nelson y Winter, 1982). Las rutinas organizativas representan las pautas de actividades regulares y predecibles que son desarrolladas mediante una secuencia de acciones coordinadas por individuos.

Se pueden definir como estructuras previsibles y regulares de comportamiento que conducen a esquemas repetitivos de actividad y constituyen la memoria organizativa. Son el producto de procesos de aprendizaje "guiados por los beneficios" deseados. Se podría decir que las rutinas reflejan "lo mejor que sabe y puede hacer" una empresa. Las rutinas incorporan todas las soluciones que han dado buenos resultados en el pasado.

También condicionan las respuestas futuras, definiendo así una trayectoria dependiente. Para el enfoque evolutivo, el conocimiento, recurso clave para la empresa dentro del Enfoque Basado en el Conocimiento, está incorporado en las rutinas y es el elemento que se copia cuando éstas se replican.

Así pues, una capacidad es una rutina o un conjunto de rutinas que interactúan entre sí. Las rutinas determinan los patrones de actividad que guían la acción organizativa. Sin embargo, autores como Chi (1994) consideran recursos a las habilidades humanas y a las rutinas organizativas, lo que para otros es claramente una capacidad. Por su parte, Barney (1991) y Grant (1991) reconocen la existencia de los recursos organizativos, que no serán más que un concepto muy similar al de capacidad.

Siguiendo con el desarrollo de rutina organizativa como capacidad, Grant (1991) señala que las rutinas son para la organización lo mismo que las habilidades para el individuo. De la misma manera que las habilidades individuales se adquieren mediante la práctica continua a lo largo del tiempo, las habilidades de una organización se desarrollan y sostienen únicamente a través de la experiencia. 
Para Nelson y Winter (1982: 112), las rutinas tienen una doble función. Por una parte, son garantía de estabilidad cuando actúan como memoria de la empresa, pero por otra, incorporan elementos de mutación endógena, es decir, pautas que favorecen el cambio y el progreso, introduciendo así una visión dinámica. Ello nos conduce a distinguir entre rutinas estáticas y dinámicas, tal como proponen Dosi, Teece y Winter (1992: 192).

Las rutinas estáticas representan la capacidad para replicar ciertas tareas previamente desarrolladas, aunque puedan mejorar con el tiempo. Desde la Ecología de las Poblaciones, Montgomery (1995: 258) resalta la parte negativa de este tipo de rutinas por considerarlas como un indicador de inercia que impide el cambio.

A diferencia de las rutinas estáticas, las rutinas dinámicas están relacionadas con las capacidades dinámicas.

\subsubsection{Las Capacidades dinámicas}

Las Capacidades dinámicas son el conjunto de conocimientos y habilidades que crean las competencias de la empresa. Se analiza el modo en el que las organizaciones desarrollan sus capacidades específicas y regeneran sus competencias para hacer frente a los cambios que aparecen en el entorno.

Las empresas deben establecer las estrategias para desarrollar nuevas capacidades (Wernerfelt, 1984). Las capacidades dinámicas reflejan la habilidad para alcanzar formas nuevas e innovadoras de ventaja competitiva. Estas nuevas capacidades dependerán de la trayectoria seguida por la empresa a lo largo de su historia y de la posición que ocupa en el mercado (Leonard-Barton, 1995).

Por lo tanto, las capacidades dinámicas enfatizan "el papel clave de la dirección estratégica en adaptar, integrar y reconfigurar apropiadamente las habilidades organizativas, recursos y competencias funcionales internas y externas" (Teece, Pisano y Schuen, 1997: 515). Según estos autores, las capacidades dinámicas hacen referencia 
a la "habilidad de la empresa para integrar, construir y reconfigurar competencias internas y externas para tratar con ambientes en constante evolución”.

Similar a la definición anterior, Eisenhardt y Martin (2000: 1107) definen las capacidades dinámicas como rutinas organizativas y estratégicas mediante las cuales las empresas obtienen nuevas configuraciones de recursos cuando los mercados emergen, colisionan, se dividen, evolucionan y mueren.

El concepto de capacidades dinámicas de Eisenhardt y Martin (2000) es similar al concepto de "competencia arquitectónica" propuesto por Henderson y Cockburn (1994) o al de "capacidades combinadas" de Kogut y Zander (1992). Otros autores son menos específicos y utilizan el término capacidad también en este sentido (Amit y Schoemaker, 1993).

\subsubsection{Clasificación de las Capacidades}

Existen varias formas de clasificar las capacidades. La primera de ellas es según el tipo de activos intangibles que utilice en su configuración. En esta clasificación, las capacidades de una empresa se pueden dividir según estén formadas por activos intangibles vinculados a las personas que las sustentan (directivos, empleados, clientes, proveedores, etc.) o vinculados a la empresa como organización. En todo caso, la protección legal es muy difícil y en algunos casos imposible.

Utilizando el mismo criterio, Camisón (2002a) clasifica las capacidades de la siguiente manera:

- Capacidades humanas: están formadas por los conocimientos, habilidades, experiencia, formación y la capacidad de aprendizaje de los miembros de una organización. No están depositadas en la organización, por lo que ésta no puede ejercer ningún control sobre ellas. 
- Capacidades organizativas: engloban la cultura de la organización, su estructura organizativa, las relaciones informales entre sus diferentes miembros y sus sistemas de planificación y control.

- Capacidades comerciales: este tipo de capacidades comprende las relaciones de la empresa con agentes externos (clientes, proveedores, distribuidores, etc.), así como el grado de conocimiento del mercado, siempre que no esté codificado en la organización. La reputación empresarial también se puede concebir como una capacidad comercial, aunque Grant (1991: 119) la concibe como un recurso. También se incluirían la capacidad para obtener información de los clientes, la habilidad para diseñar y lanzar nuevos productos al mercado, la eficacia del proceso de evaluación y el control de las actividades de marketing, etc.

- Capacidades tecnológicas: comprenden la inversión y la utilización y mejora de las tecnologías que utiliza la empresa con el fin de mejorar sus procesos y los productos y servicios que ofrece. También se incluye la capacidad para obtener información del estado de la ciencia y las tecnologías relevantes, la habilidad para generar tecnologías de proceso avanzadas, la concienciación por parte de la empresa de la importancia de sus competencias en innovación, especialmente respecto a las tecnologías clave, etc.

- Capacidades financieras: se refieren a las capacidades en la gestión del capital. Como ejemplo podemos citar la capacidad para obtener información sobre mercados financieros nacionales e internacionales, la habilidad para obtener información creadora de valor en tiempo real procedente del sistema contable, la capacidad para aprovechar la legislación con el fin de optimizar la gestión financiera, la eficacia para incrementar las reservas vía autofinanciación, la capacidad de acrecentar el capital vía ampliaciones, la habilidad para obtener financiación a un coste medio bajo, etc.

- Capacidades directivas: son las que se despliegan con el fin de coordinar y dar una identidad a todo el proceso de creación de valor. Incluyen la capacidad de los líderes para articular una visión estratégica, así como la capacidad de 
interpretar efectivamente el entorno en relación a posibles oportunidades y amenazas.

Otra forma de clasificación de las capacidades sería la utilizada por Grant (1996a). Este autor considera la existencia de una jerarquía de capacidades, agrupadas en los siguientes tres niveles:

- Nivel 1: Capacidades estáticas. Están asociadas con las actividades funcionales de la empresa.

- Nivel 2: Capacidades dinámicas.

- Nivel 3: Capacidades de aprendizaje. Relacionadas con el aprendizaje organizativo, permiten aprender con mayor rapidez que la competencia.

El tercer y último criterio que proponen los autores para realizar la clasificación de las capacidades es la complejidad. Las capacidades resultan de la combinación de activos tangibles e intangibles. García, Ortiz y Vargas (2001) establecen cuatro grupos de capacidades en función de la composición y relación de los recursos y capacidades que las forman. Los diferentes grados de complejidad hacen que sea necesario establecer una tipología atendiendo al valor estratégico. Los recursos y capacidades pueden clasificarse según su grado de tangibilidad. En el extremo inferior se sitúan los recursos tangibles, mientras que en el superior se hallan las capacidades más complejas. Puesto que los recursos intangibles son más difíciles de imitar, tendrán mayor valor estratégico aquellas capacidades situadas en el nivel jerárquico superior.

- Capacidad I: hace referencia a la combinación de recursos tangibles que posee la empresa.

- Capacidad II: son las que se forman resultado de la combinación de recursos tangibles e intangibles. 
- Capacidad III: tienen lugar cuando nacen de la combinación de recursos intangibles. el nivel de complejidad es superior respecto a las de nivel inferior.

- Capacidad IV: provienen de la combinación de capacidades de cualquiera de los otros tipos anteriores. Son las que tienen mayor relevancia para el análisis estratégico, pero, en cambio, son el grupo de capacidades más difíciles de estudiar, ya que plantean mayores problemas en su definición y delimitación.

Una vez identificado el dominio de capacidad, procedemos a la definición del término competencia.

\subsubsection{Competencia}

Los términos capacidad y competencia suelen utilizarse indistintamente y se les puede atribuir el mismo significado (Prahalad y Hamel, 1990), aunque existe literatura que los diferencia (Stalk, Evans y Shulman 1992; Javidan, 1998).

Al igual que existe un debate abierto entre la diferencia entre recurso y capacidad, las mismas argumentaciones se aplican para diferenciar recurso y competencia. Hofer y Schendel (1978: 25-26) definen las competencias de la organización como "el nivel y patrones de despliegues de recursos y habilidades pasados y presentes que ayudarán a la organización a alcanzar sus metas y objetivos", diferenciándolas de los recursos porque se trata de "recursos obtenidos y desplegados de modo que no puedan ser duplicados fácilmente por otros".

Las competencias pueden ser tomadas, al igual que las capacidades, como habilidades para hacer bien y ejecutar sistemáticamente una actividad gracias al trabajo conjunto de una serie de recursos. En este sentido, Teece et al. (1994) entienden por competencia el conjunto de habilidades tecnológicas diferenciadas, activos complementarios, rutinas organizativas y capacidades que posibilitan la base para la competitividad de la 
empresa. De manera similar, Foss (1996) define las competencias como un capital de conocimiento idiosincrásico que permite a quien lo posee desarrollar actividades de una cierta forma y hacerlo de manera más eficiente que otros.

Por otro lado, las competencias pueden entenderse como actividades desarrolladas por la empresa, yendo más allá de entenderlas solamente como la capacidad para realizarlas. Así, Hamel (1994) entiende las competencias como aquellas operaciones que la empresa es capaz de realizar a través de la integración de un conjunto de activos.

Un término semejante al de competencia, entendida como actividades desarrolladas por la empresa, es el concepto de "oficio" (métier). Este término, oficio, se utiliza en trabajos básicamente de origen francés (Anastassopoulos y Ramanantsoa, 1982; Bommensath, 1987; De Bodinat y Mercier, 1979). En esta corriente de la literatura, el oficio de una empresa se define como la vocación y el conjunto de competencias específicas (individuales y colectivas) acumuladas en la empresa que la hacen capaz de desarrollar determinadas actividades. El oficio es un activo dinámico u objeto de aprendizaje y mejora continua, pues se transmite y se fortalece con el tiempo.

Al igual que Escrig (2001), conceptuamos las competencias en sus dos vertientes, como habilidad y como actividad, definiéndolas como "las habilidades y destrezas específicas que posee la empresa en el despliegue de sus recursos, así como sus características cognitivas, las cuales se dirigen hacia la realización de actividades que permitan la consecución de ciertos objetivos".

Sánchez, Heene y Thomas (1996) señalan tres condiciones que deben cumplir las competencias para considerarlas como tales, reflejadas todas en la definición propuesta:

- Organización: deben coordinar y desplegar los activos.

- Intención: es una actividad premeditada.

- Consecución de objetivos: debe tener un fin y conseguir unos objetivos. 
Para concluir este epígrafe, comentar que en este trabajo consideramos las capacidades y las competencias de manera similar, con la distinción de que siempre denominaremos como competencia a aquellas capacidades de nivel III y IV, generadas a partir de capacidades y recursos de nivel inferior, con mayor relevancia estratégica y que proporcionan las ventajas competitivas sostenibles.

A este respecto, utilizaremos la misma denominación, propuesta por Javidan (1998), que jerarquiza los recursos, capacidades y competencias como se muestra en la figura 1.1. En un primer nivel, los recursos son la base de las capacidades. En el siguiente nivel, las capacidades son el resultado de la unión de los recursos de la organización y habilidades de los empleados. Finalmente, las competencias integran distintas capacidades, definiendo lo que la empresa es capaz de hacer y de qué manera puede competir.

Al igual que Morcillo et al. (2002) consideramos que las competencias empresariales afloran si se sabe imbricar tres elementos fundamentales: el reto estratégico que están dispuestos a asumir los miembros de la organización, la disponibilidad de unos recursos tangibles e intangibles distintivos, y el dominio de unas habilidades que son la expresión de un adecuado desarrollo de las capacidades empresariales

\subsection{Las competencias distintivas como fuente de ventaja competitiva sostenible}

El EBC centra su atención en aquellas competencias que proporcionan ventajas competitivas sostenibles, puesto que no todas son capaces de ofrecer estas ventajas y generar rentas. Aquellas que lo consiguen reciben el nombre de competencias distintivas.

Inicialmente, el concepto de competencia distintiva se vincula directamente al de "fortalezas de la empresa" propuesto por el análisis estratégico convencional (Camisón 2002a). Así, en el trabajo clásico de Selznick (1957), se acuña ya el concepto de 
competencia distintiva de una organización, no como lo que puede hacer, sino como lo que puede hacer bien. Ansoff (1965: 110-117) introduce el perfil de las competencias refiriéndose a los puntos fuertes y débiles relativos a áreas específicas de competencias y habilidades. Andrews (1971: 98-108) le da ya una concepción actual al referirla a la experiencia en producir y comercializar una línea de productos, el desarrollo de las capacidades de los individuos que comprende la organización, el grado en que la capacidad individual se aplica a la tarea común, y la calidad de la coordinación del esfuerzo individual y de grupo.

La academia sobre estrategia se ha limitado a señalar que una ventaja competitiva sólida exige que sea duradera y defendible. Sin embargo, en una segunda etapa, el concepto de competencia distintiva se amplia respecto a los puntos fuertes de la empresa. Las competencias distintivas se entienden como recursos y capacidades difícilmente imitables por los competidores. Estos recursos y capacidades determinantes de la ventaja competitiva sostenible de una organización se han venido a denominar recursos críticos (Wernerfelt, 1984), factores estratégicos (Barney, 1986; 1991), activos estratégicos (Amit y Schoemaker, 1993; Schoemaker y Amit, 1994) o stocks de activos estratégicos (Dierickx y Cool, 1989).

En el siguiente epígrafe vamos a establecer las características que deben cumplir los activos estratégicos para poder generar ventajas competitivas sostenibles.

\subsubsection{Características de los activos estratégicos}

Una de las mayores preocupaciones del Enfoque Basado en Competencias ha sido el análisis de las características de debían tener los recursos para tener la consideración de estratégicos (Wernerfelt, 1984; Barney, 1986, 1991; Dierickx y Cool, 1989; Reed y DeFillippi, 1990; Grant, 1991; Mahoney y Pandian 1992; Amit y Schoemaker, 1993; Peteraf, 1993; Collis y Montgomery, 1995). La falta de consenso y el desigual nivel de análisis en la identificación de los recursos y capacidades (Black y Boal, 1994) son una constante en estos modelos (Priem y Butler, 2001). Podríamos citar entre las más 
comunes el carácter valioso de los recursos, su escasez, su durabilidad, la no posesión por parte de sus competidores, su difícil imitabilidad, la insustituibilidad y el no ser comercializables en el mercado.

Barney (1991) señala que podemos considerar un recurso escaso y generador de ventajas competitivas siempre que el número de empresas que lo posea sea menor que el número de empresas necesario para generar una dinámica de competencia perfecta en la industria.

Grant (1991), de forma similar, considera que los recursos tienen posibilidades de generar retornos solamente si son relevantes y escasos.

Amit y Schoemaker (1993: 38) definen los activos estratégicos de la empresa como "el conjunto de recursos y capacidades difíciles de intercambiar, imitar o sustituir, escasos, complementarios, duraderos, apropiables, y que forman parte del conjunto relevante de factores estratégicos de la industria que confieren a la empresa su ventaja competitiva". Este autor relaciona los activos estratégicos de la empresa con los factores estratégicos de la industria, frente a otros autores que sólo se centran en las características propias y particulares de los recursos poseídos por las organizaciones empresariales. Aún cuando los activos disponibles cumplan los requisitos mencionados, su valor competitivo es escaso si no se corresponden con factores claves de éxito en la actividad. La posición competitiva de la empresa debe apoyarse en ventajas competitivas consistentes con estos elementos críticos del entorno competitivo de la industria.

En esta línea, Porter (1991: 103) señala que los activos intangibles no son valiosos en sí mismos, sino que adquieren valor cuando se ajustan a la estructura de la industria y a una estrategia particular seguida por la organización que los posee.

Esta conceptuación de los activos estratégicos se puede extender a las competencias y considerar que éstas se convierten en competencias distintivas cuando se cumple que:

- La organización no comparte su propiedad con la competencia. 
- Permiten producir bienes y servicios que el mercado demanda con mejor desempeño que los competidores.

Una síntesis de las principales aportaciones efectuadas a la hora de explicar las condiciones que deben satisfacer los activos estratégicos se puede encontrar en el modelo desarrollado por Peteraf (1993). Según este autor, las condiciones que deben poseer los recursos y capacidades para ser fuente de ventaja competitiva son:

- Heterogeneidad: la distribución asimétrica de los recursos y capacidades determina los diferenciales de resultados en las empresas. Aquellas empresas con recursos y capacidades superiores alcanzarán mayor nivel de desempeño.

- Límites ex-post a la competencia: deben existir obstáculos que impidan la imitación de los recursos y capacidades propios por parte de la competencia, por lo que hay que introducir obstáculos a la imitación o límites ex-post a la competencia.

- Movilidad imperfecta: la movilidad imperfecta de los activos estratégicos de una empresa impide que su valor extraordinario se convierta en un coste de oportunidad y se vea anulado. Si un activo no tiene valor fuera de la empresa a la cual está asociado será completamente intransferible o inamovible.

- Límites ex-ante a la competencia: evitan que las rentas no sean compensadas por los costes asociados al control de los factores productivos más valiosos. Para ello se requiere la existencia de imperfecciones en los mercados de factores.

\subsubsection{Sostenibilidad de la ventaja competitiva}

El Enfoque Basado en los Recursos identifica los recursos estratégicos como la fuente de ventajas competitivas. Pero no basta con tener una ventaja competitiva, además ésta debe ser sostenible en el tiempo La ventaja competitiva inicial merced a una competencia distintiva puede ser erosionada rápidamente por empresas rivales mediante la imitación. Existen varias características que limitan la igualación ex-post de las rentas 
entre empresas rivales (Peteraf, 1993). Los tres más destacados son la inimitabiliad, la no sustituibilida y la durabilidad.

\section{$\underline{\text { Inimitabilidad }}$}

Distinguimos tres posibles mecanismos de asilamiento que impiden la imitación de las competencias por parte de los rivales: la ambigüedad causal (Reed y DeFillipi, 1990), la dependencia de la historia (Barney, 1991:107) y la complementariedad de los activos (Grant, 1991).

a) La ambigüedad causal es uno de los mecanismos de aislamiento más ampliamente reconocido en la literatura (King, Zeithaml y Carl, 2001). Hace referencia a la ambigüedad que afecta a los agentes económicos, competidores y directivos de empresas, reduciendo su capacidad para establecer cuáles son las causas de la obtención de una ventaja competitiva.

El concepto de ambigüedad causal fue introducido por Lippman y Rumelt (1982) para reflejar la ambigüedad derivada de la naturaleza de las conexiones entre acciones y resultados. Reed y DeFillipi (1990) relacionaron la ambigüedad causal con las barreras a la imitación y el mantenimiento de la ventaja competitiva. Para estos autores, las competencias con ciertas características como la carencia de codificación, la complejidad o la especificidad generan la ambigüedad causal.

La ambigüedad causal es considerada por ciertos autores como necesaria para el mantenimiento de la ventaja competitiva, al actuar como mecanismo de protección contra imitadores (Mosakowski, 1997; Simonin, 1999). Sin embargo, otros investigadores sostienen que dicha incertidumbre, al impedir la identificación de las competencias que conducen a las ventajas competitivas, limitan la transferencia de dichas competencias dentro de la misma empresa (Szulanski, 1996) e impiden la movilidad de los factores (Lippman y Rumelt, 1982). Desde este punto de vista, la ambigüedad causal funciona como barrera a la imitación siempre que los mecanismos 
de creación de las competencias generadoras de ventajas competitivas queden ocultas a la competencia, aunque no sea así para los directivos y personal de la organización. Esto limita la capacidad de aislamiento de la ambigüedad causal, pues si un empleado conocedor del origen de la ventaja competitiva fuese contratado por la competencia, la ambigüedad quedaría mermada seriamente (Grant, 1991).

Además de las características propias del conocimiento, se han identificado otros atributos que reforzarían la ambigüedad causal. Estos atributos serían el contexto y la fuente y el destinatario del conocimiento (capacidad de absorción del receptor) (Von Hippel, 1994; Szulanski, 1996).

b) Otro mecanismo que impediría la imitación de las competencias es la dependencia de la trayectoria. El EBC supone que las empresas son entidades históricas y sociales. La dependencia de la historia de la empresa en su futuro explica dos hechos relevantes relacionados con las barreras a la imitabilidad: la estabilidad de las estrategias y las ventajas de mover primero.

Ghemawat (1991) se cuestiona la razón de la estabilidad de las estrategias en ciclos de 6 años con periodos breves de cambios radicales. Este autor establece cuatro razones fundamentales para explicar la continuidad en la estrategia: la pérdida de los recursos invertidos en un tipo de estrategia si hace un cambio radical (lock-in), la pérdida de oportunidad irrecuperable en un cambio de estrategia que haría perder todo el valor acumulado en la estrategia anterior (lock-out), la falta de competencias que exige la nueva estrategia y que habría que crear (lag), y la inercia debida a la cultura empresarial.

Las ventajas de mover primero implican que aquellas empresas que se adelantan a sus competidores en un mercado pueden aislar su posición de la competencia. No es fácil replicar y construir una cartera de competencias puesto que es costoso en términos de tiempo. Las capacidades y algunos recursos se caracterizan por un prolongado y paulatino período de acumulación, siendo frecuentemente imposible adquirirlos en mercados organizados. Pensemos al respecto en la posesión de un personal altamente 
motivado y dotado de habilidades específicas para las tareas que debe desempeñar, en la reputación de honestidad de una empresa o en las relaciones de cooperación interempresarial basadas en la confianza mutua.

Las ventajas de mover primero están relacionadas con lo que se conoce como eficiencias de masa. Estas eficiencias de masa se deben a la acumulación de una cierta competencia que se realimenta a partir de un volumen crítico, creciendo con mayor rapidez y menor coste que las de otras empresas. Así, el aprendizaje acumulado produce un efecto de experiencia que confiere una ventaja en costes. También aparecerían ventajas en costes conocidas como ventajas por compresión temporal, debido a la imposibilidad, por parte de los competidores, de alcanzar el mismo nivel de competencia en un tiempo reducido (Dierickx y Cool, 1989).

c) Otra razón que dificulta la imitabilidad es la complementariedad de los activos. La acumulación de un cierto recurso puede depender no sólo del nivel de ese activo, sino también del nivel existente de otros activos. Dado que algunos de estos activos pueden ser imperfectamente móviles, y que las competencias se crean a partir de una combinación de recursos y capacidades, su imitabilidad implicaría copiar la totalidad de estos recursos y capacidades. Puesto que el componente principal de las capacidades es intangible, esto complica su réplica fuera de las organizaciones de origen (Grant, 1991).

\section{$\underline{\text { No sustituibilidad }}$}

Todas estas características comentadas en el punto anterior imposibilitan la réplica de las competencias. Sin embargo, a través de la inversión en competencias sustitutivas, los competidores pueden llegar a destruir la ventaja competitiva inicial, por lo que se hace necesario añadir la característica de imperfecta sustituibilidad (Dierickx y Cool, 1989; Barney, 1991; Collis, 1994).

\section{$\underline{\text { Durabilidad }}$}

La durabilidad está relacionada con la velocidad de erosión de un activo e influye en la persistencia de la heterogeneidad (Dierickx y Cool, 1989; Grant, 1991; Amit y 
Schoemaker, 1993; Peteraf, 1993; Collis, 1994; Collis y Montgomery, 1995). De este modo, Grant (1991: 124) sostiene que, para que las ventajas competitivas sean duraderas, las competencias deben depreciarse o hacerse obsoletas en la menor medida posible. Una renovación o inversión en estas competencias puede paliar su grado de depreciación. La durabilidad exige reinversión y renovación de las competencias que se van depreciando.

Así, la distinción realizada por Dierickx y Cool (1989) entre stocks y flujos es de especial relevancia a la hora de analizar la sostenibilidad de la ventaja competitiva. Los autores consideran los stocks como la cantidad de recursos existente en un momento de tiempo determinado, mientras que los flujos se refieren a las inversiones necesarias para mantener y aumentar dicho stock. La ventaja competitiva no depende del flujo de inversiones, sino de los stocks que estén disponibles en un determinado momento. Las repercusiones de las inversiones realizadas en cualquier flujo de la empresa no aparecen inmediatamente en los stocks, sino que es necesario un determinado lapso temporal.

El concepto de durabilidad está relacionado con las capacidades dinámicas, puesto que la renovación de las competencias distintivas se realizará a través de estas capacidades.

\subsubsection{Apropiabilidad de las rentas}

En los epígrafes precedentes hemos analizado los determinantes que permiten a las empresas obtener una ventaja competitiva en primera instancia, así como la posibilidad de sostener o mantener dicha ventaja en segunda. Además de esto, los recursos y capacidades en los que se basan las competencias distintivas deben ser tales que permitan a la empresa apropiarse de las rentas que se derivan de ellos.

Uno de los aspectos necesarios para que se cumpla esta apropiación de rentas hace referencia al precio que la empresa paga por los recursos que adquiere. Este precio, debido a la existencia de un mercado de recursos imperfecto caracterizado por 
asimetrías de información, debe permitir a la empresa obtener recursos a un precio que no refleje sus rentas futuras.

Grant (1991) considera que existen dos factores determinantes en la posibilidad de apropiación de las rentas: la ambigüedad de los derechos de propiedad y el poder de negociación.

Para la apropiación de rentas generadas por un recurso o capacidad es necesario que su control y propiedad sean de la empresa. Las rentas son rara vez imputables a un solo recurso o capacidad, así que es difícil discernir la contribución de cada uno en la generación del valor añadido, lo que crea una ambigüedad de los derechos de propiedad (Dierickx y Cool, 1989; Grant, 1991). Cuanto mayor sea el grado de complejidad de la competencia que genera las ventajas competitivas, más difícil será asignar un valor concreto a los recursos y capacidades que la forman.

Esta ambigüedad en el efecto de un cierto recurso o capacidad (por ejemplo la capacidad de un cierto trabajador) sobre el valor de la competencia global, permite un mayor poder de negociación de las organizaciones frente a los individuos. Además, este poder de negociación aumenta cuando los recursos y capacidades asociados a las competencias son específicos a la organización y disminuya su valor cuando se utilice en un contexto diferente, puesto que los recursos aislados pierden valor si no están integrados en competencias más complejas cuyo control está en manos de la organización.

Por lo tanto, podemos concluir que existirá apropiabilidad de las rentas cuando la obtención de ventajas competitivas se debe, por un lado, a la posesión de ciertos activos estratégicos, y por otro, a las competencias distintivas que permiten aprovechar de forma eficaz dichos activos.

A continuación (tabla 1.3) se muestra un cuadro sinóptico de los requisitos que deben cumplir los recursos y las capacidades para generar competencias distintivas: 
Tabla 1.3.Requisitos de los activos estratégicos para ser fuente de ventaja competitiva

\begin{tabular}{|c|c|c|c|}
\hline $\begin{array}{c}\text { Barney } \\
(1986,1991)\end{array}$ & $\begin{array}{c}\text { Grant } \\
(1991,1995)\end{array}$ & $\begin{array}{l}\text { Amit y Schoemaker } \\
\text { (1993) }\end{array}$ & $\begin{array}{c}\text { Peteraf } \\
(1993)\end{array}$ \\
\hline \multicolumn{4}{|c|}{ REQUISITOS PARA LA GENERACIÓN DE VENTAJA COMPETITIVA } \\
\hline Escasos & Escasos & Escasos & Heterogeneidad \\
\hline $\begin{array}{l}\text { Explotación de las oportunidades } \\
\text { del mercado }\end{array}$ & Relevantes & $\begin{array}{l}\text { Solapamiento con factores } \\
\text { estratégicos de la industria }\end{array}$ & \\
\hline \multicolumn{4}{|c|}{ REQUISITOS PARA LA SOSTENIBILIDAD DE LA VENTAJA COMPETITIVA } \\
\hline & Durabilidad & Durabilidad & \\
\hline No imitables & $\begin{array}{l}\text { Replicabilidad imperfecta } \\
\text { Transparencia imperfecta }\end{array}$ & No imitables & Límites ex-post a la competencia \\
\hline \multirow[t]{2}{*}{ No sustituibles } & & No sustituibles & \\
\hline & Transferibilidad imperfecta & $\begin{array}{c}\text { No comercializables } \\
\text { Complementarios (específicos) }\end{array}$ & Movilidad imperfecta \\
\hline \multicolumn{4}{|c|}{ REQUISITOS PARA LA APROPIABILIDAD DE LA VENTAJA COMPETITIVA } \\
\hline & Apropiabilidad & Apropiabilidad & \\
\hline & & & Límites ex-ante a la competencia \\
\hline
\end{tabular}

Fuente: Devece (2004) 


\subsection{Recursos, capacidades y competencias $\mathbf{T I}$}

Uno de los aspectos controvertidos que se han dado en la literatura TI desde el enfoque basado en competencias es determinar qué recursos, capacidades y competencias TI deben ser consideradas en el análisis estratégico de una organización, ya que muy pocas han sido claramente definidas y examinadas en detalle (Bhatt y Grover, 2005). La teoría muestra algunos intentos de desarrollar un listado de recursos y capacidades TI organizativas (Bharadwaj, 2000; Peppard y Ward, 2004; Ravinchandran y Lertwongsatien, 2005; Bhatt y Grover, 2005), pero estos marcos teóricos no convergen entre sí.

A ello contribuye el hecho de que no existe una clara distinción entre recurso y capacidad TI. Mientras que en numerosas ocasiones los términos "recurso" y "capacidad" han sido intercambiados indistintamente, algunos autores (Amit y Schoemaker, 1993; Makadok, 2001) hacen una clara distinción entre ellos. La falta de una definición común y la proliferación de escalas ad-hoc para medir el concepto han ralentizado el progreso de las investigaciones en este campo. Como señala Melville et al. (2004), las asunciones subyacentes sobre lo que constituyen las TI da forma a nuestro conocimiento acumulado del impacto en el desempeño empresarial.

Una de las primeras aproximaciones a la definición de recurso $\mathrm{TI}^{1}$ es la de Ross et al. (1996). Los autores lo definen como "la habilidad para controlar los costes relacionados con las TI, entregar sistemas donde se requieran y conseguir los objetivos de negocio a través de implementaciones TI". En esta conceptualización los autores distinguen entre activos TI y procesos TI. Los activos estarían integrados por activos humanos, activos tecnológicos y activos relacionales. Los procesos englobarían todo lo referente a la planificación, capacidades como la mejora en el tiempo de entrega, la efectividad en

\footnotetext{
${ }^{1}$ Los términos recurso TI, competencia TI o capacidad TI son usados indistintamente en la literatura. En el presente trabajo, cuando se citan a los autores se mantiene el término de referencia usado por éstos
} 
costes, etc. Así, los autores distinguen tres recursos TI clave, dos factores estrictamente TI y un factor TI complementario: recursos humanos TI altamente competentes, una base tecnológica reutilizable y una fuerte relación de asociación entre las TI y la gestión de la organización.

Powell y Dent-Micallef (1997) agrupan los recursos TI en tres categorías: recursos humanos, recursos de negocio y recursos tecnológicos.

Otros estudios, como el de Feeny y Willcocks (1998) integran los recursos en las áreas de: negocios y visión TI, diseño de arquitecturas TI, entrega de servicios de SI y un conjunto de capacidades fundamentales como el liderazgo en SI. Bharadwaj et al. (1998) miden la capacidad de las TI a través de seis dimensiones: las relaciones entre la TI y los procesos de negocio, la unión de la TI y el ámbito exterior, la TI estratégica, integración de los procesos de negocio de TI y por último la dirección de TI e infraestructura TI. En un trabajo posterior (Bharadwaj, 2000) convierte estas dimensiones en tres grandes áreas: infraestructura TI, recursos humanos TI (comprendiendo tanto capacidades técnicas como directivas) y recursos intangibles habilitados por la TI como pueden ser conocimiento, orientación al cliente y sinergias. Esta tercera dimensión resalta la integración de los recursos TI en las estrategias de negocio, el diseño de la organización, la estructura y otras competencias cuando se analiza la competitividad a largo plazo a través de las TI (Sambamurthy y Zmud, 1994). Así mismo el autor define la capacidad TI de una empresa como la habilidad para movilizar y desplegar recursos TI en combinación con otros recursos y capacidades.

Otros autores (Tippins y Sohi, 2003; Byrd, 2001) prefieren considerar las capacidades TI estrictamente confinadas en el ámbito de las TI y SI. Sin embargo, esta definición restrictiva de las capacidades TI suele tener en cuenta las habilidades y el conocimiento del personal TI y los responsables que generan una fluida y fructífera interacción con el resto de las funciones de la organización. Aunque con algunos matices en cuanto al lenguaje utilizado y las subdivisiones de los recursos (Tippins y Sohi, 2003; Wade y Hulland, 2004; Ray et al., 2005; Tanriverdi, 2006), existe un consenso general en cuanto a los componentes de la definición "restrictiva" de las capacidades TI. Se pueden 
dividir en infraestructura TI (recursos tangibles) y recursos humanos TI (recursos intangibles) (Byrd y Turner, 2000).

Wade y Hulland (2004) hacen una revisión de la literatura relativa al papel del enfoque basado en competencias aplicado a la investigación en Sistemas de Información, identificando ocho capacidades clave agrupadas en tres categorías: aquellas capacidades que son desarrolladas dentro de la empresa en respuesta a las necesidades del entorno (capacidades "inside-out"), aquellas que anticipan las necesidades del entorno ("outsidein") y aquellas que implican un análisis externo e interno integrando las dos capacidades anteriores (spanning).

Si aplicamos la terminología de Makadok (2001), los recursos se consideran los recursos TI físicos, tales como software, aplicaciones e infraestructura, mientras que capacidades son los recursos complementarios intangibles tales como el liderazgo, las relaciones y la cultura necesarios para la aportación de valor desde los recursos tangibles o físicos.

Cuando el concepto de recurso TI es considerado únicamente como equipamiento y software (recursos tangibles), los resultados muestran un poco significativo efecto en el desempeño (Powell y Dent-Micallef, 1997; Ray et al. 2005). Cuando el concepto de recurso TI se amplia a recurso o competencia TI, donde se incluye los recursos intangibles como las habilidades del personal TI, o las competencias de los directivos TI (Mata et al., 1995) o incluso recursos funcionales complementarios habilitados gracias a las TI (Bharadwaj, 2000), los resultados confirman una relación positiva entre las capacidades TI y el desempeño empresarial.

Mata et al. (1995) determina cinco factores clave de TI en su análisis de los efectos de la misma en la consecución de una ventaja competitiva:

- Costes de captura de clientes

- Acceso al capital

- Propiedad tecnológica 
- Habilidades técnicas

- Habilidades de los directivos

Con todo ello podemos hacer la siguiente clasificación de recursos:

\subsubsection{Recursos tecnológicos TI}

Los recursos de capital físico comprenden las plantas y el equipamiento, la localización geográfica, acceso a materias primas y la tecnología física. Un subconjunto de esto último serían los recursos tecnológicos TI. Siguiendo a Melville et al. (2994) dentro de los recursos tecnológicos TI se pueden establecer dos categorías:

- Infraestructura TI: se puede definir como "la base del portfolio TI (incluyendo tanto los recursos humanos y técnicos) compartido a través de la organización en forma de servicios confiables" (Broadbent et al., 1999, p163). Como tal, la infraestructura TI proporciona la base para el desarrollo de aplicaciones y servicios de negocio (Duncan 1995, Byrd y Turner, 2000). Está compuesta de componentes software y hardware que conforman plataformas técnicas y bases de datos compartibles (Ross et al., 1996).

La infraestructura TI varía tanto en alcance (la extensión de la conectividad tanto dentro como fuera de la firma) como en amplitud (la cantidad de servicios que puede soportar) (Keen, 1991). En la medida que dicho recorrido se incrementa, los recursos puestos a disposición gracias a la infraestructura TI y la habilidad para soportar una amplia gama de iniciativas estratégicas se incrementará también (Broadbent et al., 1999).

Según Piccoli y Ives (2005), las infraestructuras TI están sujetas a la dinámica de acumulación de stock de activos. Se define esta dinámica como el proceso por el cual una organización acumula o construye un recurso a lo largo del tiempo como resultado de un "patrón consistente de flujos de recursos". (Dierckx y Cool, 1989). Mientras que 
muchos recursos (por ejemplo ordenadores o mano de obra especializada) pueden ser adquiridos por una firma en el mercado, otros recursos son por definición no comercializables (por ejemplo infraestructura TI especializada, un repositorio de información sobre las preferencias de clientes, etc.) Este tipo de recursos deben ser construidos por la organización a lo largo del tiempo y la capacidad de conseguirlos está condicionada a la disponibilidad de recursos preexistentes (Piccoli y Ives, 2005). Bajo estas condiciones, conocidas como interconexión de stock de activos (Dierckx y Cool, 1989), sólo la organización que ha adquirido o desarrollado recursos previos puede iniciar un proceso de acumulación.

Cuando una firma introduce una iniciativa estratégica que emplea tecnología reutilizable, ésta contribuye al desarrollo de una infraestructura que puede ser mantenida en el futuro por la iniciativa, a través de mejora o mediante otras iniciativas (Barton y Peters, 1992; Ross et al, 1996). Este proceso permite la creación de "opciones de valor" generando la habilidad de expandir la iniciativa original o crear nuevas a un coste menor, de forma más rápida y con menos riesgo inherente que los competidores (Applegate, 2003; Sambamurthy et al. 2003).

- Aplicaciones de negocio: tales como sistemas de información de compras, herramientas de análisis de ventas, etc. (Broadbent y Weill, 1997). Estas aplicaciones utilizan la infraestructura como soporte. Otros autores han denominado a este recurso “repositorio de información” (Piccoli y Yves, 2005). Dicho término lo definen como una colección de datos lógicamente interrelacionados, organizados de una forma estructurada, que son accesibles y utilizables para propósitos de toma de decisiones. En este sentido los autores utilizan el término no como sinónimo de sistema de gestión de bases de datos, sino que hace referencia a los datos o información disponible que puede ser utilizada para crear valor, más que el programa software que lo implementa. Este recurso está también sujeto a la acumulación de stock de activos. 
En términos generales, existe un cierto consenso sobre los elementos primarios que componen los recursos tecnológicos TI (Byrd y Turner, 2000; Lewis y Byrd, 2003; Ray et al., 2005; Ravichandran y Lertwongsatien, 2005) y que se puede estructurar como:

- plataforma de computación (hardware y sistemas operativos)

- redes de comunicación

- datos críticos compartidos

- aplicaciones nucleares de procesos de datos

Al mismo tiempo, la calidad de estos componentes pueden ser asegurados por las siguientes características (Duncan, 1995):

1) compatibilidad de las tecnologías y la información

2) conectividad o la habilidad de añadir nuevos componentes al sistema

3) modularidad o la habilidad de añadir y/o modificar software y hardware

\subsubsection{Recursos humanos $\mathrm{TI}$}

El siguiente recurso es el capital humano de la organización, que se refiere a la experiencia y el conocimiento (Barney, 1991). Este tipo de recursos denotan tanto conocimiento técnico como de gestión. Ejemplos de conocimiento técnico son el conocimiento para el desarrollo de aplicaciones, integración de múltiples sistemas o el mantenimiento de los sistemas de una firma. Ross et al. (1996) lo definen como "el personal TI que de forma consistente resuelve los problemas de negocio y aborda oportunidades a través de las tecnologías de la información". Ejemplos de conocimientos de gestión son la habilidad para identificar los proyectos más apropiados, liderar y motivar equipos de desarrollo para cumplir en tiempo y forma con las especificaciones, etc. Aunque, en general, se puede afirmar que ambos tipos de 
conocimientos suelen estar entrelazados, lo cierto es que conceptualmente es posible diferenciarlos, y tal conceptualización es necesaria para tener una mayor precisión a la hora de describir su impacto en la inversión TI de una compañía.

Lee et al. (1995) clasifica las habilidades del personal TI en cuatro grupos complementarios:

- Conocimiento o habilidades técnicas (por ejemplo sistemas operativos, lenguajes de programación, sistemas de gestión de bases de datos, redes, telecomunicaciones, etc.)

- Conocimiento y habilidades funcionales de negocio (conocimiento funcional del negocio en profundidad)

- Conocimiento y habilidades de gestión de la tecnología (dónde y cómo desplegar TI de forma efectiva y beneficiosa)

- Conocimiento y habilidades interpersonales y de gestión

\subsubsection{Recursos organizativos complementarios}

En general, cuando se aplica de forma exitosa las TI, frecuentemente viene acompañado de cambios organizativos (Brynjolfsson y Hitt, 2000; Brynholfsson et al., 2002; Cooper et al., 2000), incluyendo cambios políticas y reglas, estructuras organizativos prácticas organizativos o cultura organizativos. Cuando las sinergias entre las TI y otros recursos de la organización se dan, entonces estos últimos recursos son los que denominamos recursos organizativos complementarios (Melville et al., 2004). Esta categoría de recursos incluyen los recursos físicos no TI, recursos humanos no TI, estructura organizativa, políticas y reglas, cultura, etc. Destacan la capacidad de rediseño de procesos en función de las TI (Benjamin y Levinson, 1993; Bharadwaj, 2000; Teo y Ranganathan, 2003), la habilidad para gestionar las relaciones con los agentes relativos a la TI (Feeny y Willcoks, 1998; Bharadwaj et al., 1998; Bharadwaj, 2000; Tanriverdi, 
2006), la capacidad para desarrollar sinergias entre los distintos activos TI y entre los mismos activos y otras áreas de negocio (Sher y Lee, 2004; Tanriverdi, 2006) o la existencia de comunicaciones abiertas y consenso organizativo (Powell y Dent-Micallef, 1997).

Los estudios desde el enfoque basado en competencias de forma recurrente enfatizan el valor de los recursos organizativos complementarios que contribuyen a la integración de las TI en las actividades de negocio.

El análisis sistemático de los recursos complementarios involucrados en la integración de las TI en el negocio requiere una clasificación general de recursos y capacidades. Desde un punto de vista genérico, la literatura relacionada con la estrategia competitiva ha estudiado ampliamente los recursos que posibilitan la cohesión y coordinación de las distintas funciones de la organización. Estos recursos están continuamente explorando nuevas combinaciones de recursos y capacidades que posibiliten un mejor encaje con el mercado y mejoren el desempeño (Teece et al. 1994; Teece et al. 1997; Eisenhart y Martin, 2000). Estos recursos de coordinación pueden clasificarse en dos grupos principalmente: capacidades directivas y capacidades organizativas (Camison, 2005):

\section{a) Capacidades directivas}

Las capacidades directivas se derivan del conocimiento técnico y el "know-how" y por otra parte de los valores y atributos personales existentes en la figura de los directivos (Nonaka y Konno, 1998).

Las capacidades directivas de la función TI se ha incluido previamente en la definición de recursos humanos TI que se ha dado previamente. Como se ha comentado anteriormente, la importancia del personal TI deriva no sólo de sus habilidades técnicas, sino también de su conocimiento de la organización y de sus procesos y actividades, así como de sus habilidades interpersonales y de gestión del conocimiento para el desarrollo de una adecuada integración TI-negocio (Bassellier y Benbasat, 2004). 
El segundo conjunto de capacidades directivas que influyen en la integración de las TI son aquellas asociadas a los altos directivos. Esta tipología general de competencias de los directivos, tales como el liderazgo (Ross et al. 1996; Basselier et al., 2003) o la visión de negocio (Westley y Mintzberg, 1989; Basselier et al., 2001) influye en todos los recursos y capacidades de la organización.

\section{b) Capacidades organizativas}

El segundo tipo de recursos de coordinación y cohesión son aquellos que están relacionadas con la cultura, procedimiento, las rutinas organizativas y el diseño de la organización. Este tipo de recursos y capacidades pueden agruparse bajo el término de “capacidades organizativas" (Camison, 2005). Estas capacidades están relacionadas con la coordinación de las capacidades funcionales y la cohesión de los miembros de la organización (Henderson y Cockburn, 1994; Lado et al., 1992; Nelson y Winter, 1982). Están enraizadas en la habilidad de las organizaciones de reconfigurar y recombinar los recursos organizativos (Bhatt, 2000).

Estas capacidades engloban los aspectos como la cultura organizativa (Hall, 1992; Hall, 1993; Hansen y Wernerflet, 1989) tales como el compromiso y participación de los empleados (Cruise y O’Brien, 1995). Las capacidades organizativas están estrechamente ligadas al diseño y arquitectura organizativa que propicia la flexibilidad y la descentralización (Henderson y Cockburn, 1994), así como las rutinas, los sistemas de gestión y los valores y normas corporativos que guían la renovación y la compartición del conocimiento (Leonard-Barton, 1992).

La importancia de las capacidades organizativas para la implementación de sistemas basados en las TI es debido principalmente a la naturaleza disruptiva de estas tecnologías (Brynjolfsson et al. 2002). La capacidad de las TI de provocar cambios radicales explica en parte el fallo en muchos proyectos TI ambiciosos (Brynjolfsson y Hitt, 2002). 
Tabla 1.4. Recursos TI

\begin{tabular}{|c|c|c|c|}
\hline Autores & $\begin{array}{l}\text { Recursos } \\
\text { tecnológicos TI }\end{array}$ & Recursos humanos TI & Recursos complementarios \\
\hline $\begin{array}{l}\text { Benjamin y Levinson } \\
\text { (1993) }\end{array}$ & $\begin{array}{l}\text { Infraestructura } \\
\text { hardware y software }\end{array}$ & Nivel de aprendizaje & $\begin{array}{l}\text { Integración TI y estrategia organizativa; } \\
\text { relación con los clientes, proveedores y } \\
\text { socios, facilitar la adaptación organizativa y el } \\
\text { rediseño de procesos en función de las TI }\end{array}$ \\
\hline Mata et al. (1995) & $\begin{array}{l}\text { Propiedad } \\
\text { tecnológica }\end{array}$ & $\begin{array}{l}\text { Habilidades técnicas del personal TI } \\
\text { Habilidades directivas del personal TI }\end{array}$ & \\
\hline Ross et al. (1996) & $\begin{array}{l}\text { Infraestructura TI } \\
\text { Propiedad de los } \\
\text { proyectos TI }\end{array}$ & $\begin{array}{l}\text { Personal técnico TI } \\
\text { Formación TI } \\
\text { Habilidades técnicas del personal TI } \\
\text { Liderazgo de la dirección en establecer } \\
\text { prioridades TI }\end{array}$ & $\begin{array}{l}\text { Orientación hacia la resolución de problemas } \\
\text { Capacidad para aprovechar las sinergias entre } \\
\text { los distintos activos y capacidades } \\
\text { Capacidad para planificar estratégicamente las } \\
\text { TI }\end{array}$ \\
\hline $\begin{array}{l}\text { Powell y DenMicallef } \\
\text { (1997) }\end{array}$ & $\begin{array}{ll}\text { Infraestructura } & \text { TI } \\
\text { flexible } & \end{array}$ & Formación del personal TI & $\begin{array}{l}\text { Compromiso directivo } \\
\text { Comunicaciones abiertas, consenso } \\
\text { organizativo } \\
\text { Organización abierta } \\
\text { Trabajo en equipo } \\
\text { Rediseño de procesos } \\
\text { Integración TI/estrategia de negocio } \\
\text { Planificación TI } \\
\text { Relaciones con los proveedores } \\
\text { Existencia de prácticas de benchmarking }\end{array}$ \\
\hline $\begin{array}{l}\text { Jarvanpaa y Leidner } \\
\text { (1998) }\end{array}$ & Infraestructuras TI & & $\begin{array}{l}\text { Integración TI/ Estrategia empresarial } \\
\text { Liderazgo de la dirección } \\
\text { Flexibilidad organizativa }\end{array}$ \\
\hline
\end{tabular}




\begin{tabular}{|c|c|c|c|}
\hline & & & Flexibilidad estratégica TI \\
\hline $\begin{array}{l}\text { Feeny y Willcocks } \\
(1998)\end{array}$ & $\begin{array}{lrr}\text { Diseño } & \text { de } & \text { la } \\
\text { arquitectura } & \text { TI }\end{array}$ & $\begin{array}{l}\text { Personal TI } \\
\text { Habilidades técnicas del personal TI } \\
\text { Habilidad para diseñar arquitecturas TI } \\
\text { Capacidad para supervisar contratos de } \\
\text { outsourcing } \\
\begin{array}{l}\text { Capacidad para gestionar los } \\
\text { proveedores TI }\end{array}\end{array}$ & $\begin{array}{l}\text { Integración de las TI con la estrategia } \\
\text { empresarial y resto de áreas de negocio } \\
\text { Liderazgo de la dirección } \\
\text { Habilidades de negocio }\end{array}$ \\
\hline $\begin{array}{l}\text { Bharadwaj et al., } \\
\text { (1998) }\end{array}$ & Infraestructura TI & $\begin{array}{l}\text { Equipos multidisciplinares } \\
\text { Dirección TI }\end{array}$ & $\begin{array}{l}\text { Existencia de relaciones con proveedores TI } \\
\text { Integración TI/estrategia empresarial } \\
\text { Habilidades de los directivos } \\
\text { Capacidad para establecer relaciones con otros } \\
\text { agentes y rediseñar procesos de negocio }\end{array}$ \\
\hline Bharadwaj (2000) & Infraestructura TI & $\begin{array}{l}\text { Personal técnico TI } \\
\text { Directivos TI } \\
\text { Formación TI } \\
\text { Conocimiento acumulado (“know-how") } \\
\text { Habilidades de los recursos humanos TI }\end{array}$ & $\begin{array}{l}\text { Planificación TI } \\
\text { Desarrollo de aplicaciones efectivas en costes } \\
\text { Cultura corporativa } \\
\text { Reputación } \\
\text { Orientación a cliente } \\
\text { Capacidad para el desarrollo de sinergias } \\
\text { entre los distintos activos y capacidades } \\
\text { Comunicaciones abiertas } \\
\text { Capacidad para rediseñar procesos } \\
\text { Orientación hacia la innovación } \\
\text { Orientación de las TI a la anticipación de } \\
\text { futuras necesidades de negocio } \\
\text { Flexibilidad estratégica de las TI } \\
\text { Habilidad para la coordinación de } \\
\text { colaboradores (proveedores, clientes) }\end{array}$ \\
\hline
\end{tabular}




\begin{tabular}{|c|c|c|c|}
\hline $\begin{array}{ll}\text { Dehning } & y \\
\text { Stratopoulos (2003) }\end{array}$ & Infraestructura TI & $\begin{array}{l}\text { Habilidades técnicas TI } \\
\text { Habilidades directivas TI }\end{array}$ & \\
\hline $\begin{array}{l}\text { Teo y } \text { Ranganathan } \\
\text { (2003) }\end{array}$ & $\begin{array}{l}\text { Tecnología TI } \\
\text { Aplicaciones TI }\end{array}$ & Conocimiento de los directivos TI & $\begin{array}{l}\text { Compromiso de la dirección con las TI } \\
\text { Rediseño de procesos basados en TI } \\
\text { Habilidad para desarrollar relaciones } \\
\text { interempresa para el desarrollo de TI } \\
\text { Habilidad para desarrollar flexibilidad } \\
\text { orgnanizacional }\end{array}$ \\
\hline $\begin{array}{lll}\text { Byrd } & \text { y } & \text { Davidson } \\
(2003) & & \end{array}$ & & $\begin{array}{l}\text { Habilidades técnicas del departamento } \\
\text { TI }\end{array}$ & $\begin{array}{l}\text { Capacidad para planificar las TI } \\
\text { Apoyo de la dirección a las TI } \\
\text { Capacidad para aprovechar sinergias de las TI } \\
\text { en la cadena de aprovisionamiento }\end{array}$ \\
\hline \multicolumn{4}{|l|}{$\begin{array}{lll}\text { Wade } & \text { y } & \text { Hulland } \\
(2004) & & \end{array}$} \\
\hline Sher y Lee (2004) & Infraestructura TI & & $\begin{array}{l}\text { Compromiso de la dirección } \\
\text { Capacidad de identificación y } \\
\text { aprovechamiento de sinergias entre TI y la } \\
\text { gestión del conocimiento }\end{array}$ \\
\hline Melville et al. (2004) & $\begin{array}{l}\text { Infraestructura TI } \\
\text { Aplicaciones TI }\end{array}$ & $\begin{array}{l}\text { Habilidades técnicas del personal TI } \\
\text { Habilidades directivas del personal TI }\end{array}$ & $\begin{array}{l}\text { Estructura organizativa } \\
\text { Políticas } \\
\text { Prácticas de trabajo } \\
\text { cultura }\end{array}$ \\
\hline Piccoli e Ives (2005) & $\begin{array}{ll}\text { Infraestructura TI } \\
\text { Depósitos } & \text { de } \\
\text { información } & \end{array}$ & $\begin{array}{l}\text { Habilidades técnicas del personal TI } \\
\text { Habilidades directivas del personal TI }\end{array}$ & Sinergias entre los distintos activos \\
\hline Ray et al. (2005) & $\begin{array}{l}\text { Tecnologías de } \\
\text { información } \\
\text { genéricas }\end{array}$ & Habilidades técnicas del personal TI & Existencia de conocimiento compartido \\
\hline
\end{tabular}




\begin{tabular}{|c|c|c|c|}
\hline & $\begin{array}{l}\text { Flexibilidad de la } \\
\text { infraestructura TI }\end{array}$ & & \\
\hline Tanriverdi (2006) & Infraestructura TI & $\begin{array}{l}\text { Formación TI } \\
\text { Habilidades TI (técnicas y directivas) }\end{array}$ & $\begin{array}{l}\text { Relación con suministradores TI } \\
\text { Integración TI/estrategia empresarial } \\
\text { Cultura favorable a las TI como apoyo del } \\
\text { negocio } \\
\text { Habilidad para la gestión de relaciones con } \\
\text { otros agentes } \\
\text { Sinergias entre activos y capacidades TI } \\
\text { Orientación hacia el aprendizaje y la } \\
\text { acumulación de conocimiento }\end{array}$ \\
\hline $\begin{array}{l}\text { Tarafdar y Gordon } \\
\text { (2007) }\end{array}$ & & & $\begin{array}{l}\text { Gestión del conocimiento } \\
\text { Colaboración } \\
\text { Gestión de proyecto } \\
\text { Gobierno TI/innovación } \\
\text { Integración TI/estrategia empresarial } \\
\text { Modelado de procesos } \\
\text { Balance visión estratégica/excelencia } \\
\text { operacional }\end{array}$ \\
\hline $\begin{array}{l}\text { Bharadwaj et. al. } \\
(2009)\end{array}$ & $\begin{array}{l}\text { Fiabilidad de la } \\
\text { infraestructura TI }\end{array}$ & & $\begin{array}{l}\text { Gestión de proyectos en el desarrollo de } \\
\text { nuevos sistemas }\end{array}$ \\
\hline $\begin{array}{l}\text { Luo, Fan y Zhang } \\
(2012)\end{array}$ & $\begin{array}{ll}\text { Infraestructura TI } \\
\text { Sistemas } \\
\text { información } \\
\text { empresariales } & \\
\end{array}$ & & $\begin{array}{l}\text { Eficiencia operacional } \\
\text { Servicio al cliente } \\
\text { Desarrollo de producto }\end{array}$ \\
\hline
\end{tabular}




\begin{tabular}{|c|c|c|c|}
\hline Chen (2012) & $\begin{array}{l}\text { Redes de } \\
\text { comunicaciones } \\
\text { Aplicaciones } \\
\text { ofimáticas } \\
\text { Bases de datos } \\
\text { ERP } \\
\text { Sistemas soporte a la } \\
\text { decisión } \\
\text { Sistemas de gestión } \\
\text { del conocimiento }\end{array}$ & $\begin{array}{l}\text { Conocimiento de desarrollo de sistemas } \\
\text { Habilidades para desplegar y mantener } \\
\text { los sistemas } \\
\text { Habilidad para liderar y gestionar } \\
\text { proyectos TI } \\
\text { Habilidad para coordinar e interactuar } \\
\text { con otros usuarios } \\
\text { Habilidad para entender las necesidades } \\
\text { de otras funciones de negocio } \\
\text { Habilidad para anticipar necesidades TI } \\
\text { de otras funciones de negocio }\end{array}$ & $\begin{array}{l}\text { Estructura organizativa } \\
\text { Políticas y reglas explícitas que guían el } \\
\text { trabajo de forma efectiva } \\
\text { Cultura corporativa que apoya a las personas } \\
\text { que innovan } \\
\text { Rutinas y procesos de gestión claros y } \\
\text { eficientes } \\
\text { Patentes y propiedad intelectual valiosa } \\
\text { Entorno y prácticas que favorecen la } \\
\text { innovación }\end{array}$ \\
\hline
\end{tabular}

Fuente: elaboración propia 


\section{UTILIZACIÓN ESTRATÉGICA DE LAS TI}




\section{UTILIZACIÓN ESTRATÉGICA DE LAS TI}

\subsection{Objetivos y contenidos del capítulo}

El presente apartado tiene como objetivo desarrollar el modelo de investigación sobre el que se desarrollará la posterior contrastación empírica. El objetivo básico del presente trabajo es analizar el efecto moderador de la estrategia TI en la relación entre la estrategia competitiva desarrollada por una organización y el desempeño empresarial.

Después de analizar el EBC y revisar la literatura que identifica los recursos TI, es necesario analizar si estas tecnologías pueden ser fuente de ventaja competitiva en las diferentes actividades funcionales de una organización en términos de replicabilidad e imitabilidad, y en términos de valor estratégico de estas actividades (valor estratégico de las TI).

La hipótesis básica de esta tesis es que las organizaciones cuyos procesos clave o estratégicos sean susceptibles de mejora a través de las TI, y además, está aplicación de las TI sea difícilmente imitable, podrán obtener ventajas competitivas sostenibles y por tanto una estrategia TI innovadora podría obtener mejor resultados. Esto implica que debemos conocer la estrategia competitiva para identificar aquellas actividades de negocio críticas de la organización.

Una vez clasificadas estas actividades críticas pasaremos a analizar si las TI añaden valor a estas actividades y si son fácilmente imitables o no. Puesto que el objetivo de esta tesis es obtener una mayor generalidad de sus conclusiones, y evitar una revisión demasiado específica de las actividades o procesos, es interesante analizar si se pueden agrupar las actividades de negocio de forma genérica en términos de imitabilidad de las TI. A su vez, habría que vincular esta agrupación de actividades funcionales con el valor que suponen estratégicamente para una organización. Para delimitar este análisis, nos centraremos exclusivamente en analizar las distintas estrategias de negocio, para 
después analizar cómo se aplican las TI a las actividades clave de cada una de las posibles estrategias.

Para desarrollar los contenidos del presente capítulo, en primer lugar (apartado 2.1) se hará una revisión de los antecedentes más relevantes de la literatura que analiza el valor de las TI.

En el segundo epígrafe (apartado 2.2) se analizarán en profundidad las TI como fuente de ventaja competitiva desde el enfoque basado en competencias, prestando especial interés a las condiciones asociadas a su replicabilidad e imitabilidad.

En el tercer epígrafe (apartado 2.3) se analizarán las diferentes concepciones que se han dado en la literatura sobre el concepto de estrategia TI, identificando los estudios más relevantes para cada una de las concepciones identificadas.

En el cuarto epígrafe (apartado 2.4) estableceremos el valor de las TI en función de las actividades de negocio. Para ello nos basaremos en las estrategias de Porter (1985), lo que nos permitirá identificar cuáles son las actividades de mayor valor en función de la estrategia seleccionada por una empresa.

En el quinto y último epígrafe de este capítulo (apartado 2.5) estableceremos el modelo de investigación junto las hipótesis de trabajo y su justificación.

\subsection{Antecedentes}

Aunque a priori la relación entre TI y productividad parece obvia, durante muchos años ha existido un amplio debate entre si esto es así o no. En los primeros años de desarrollo de las TI (fundamentalmente durante los años 60 y principalmente en las grandes firmas) esta relación positiva era incuestionable, puesto que la automatización de tareas se consideraba que tenía impacto directo en la eficiencia de las operaciones de las compañías. 
Sin embargo, durante los años 70 se vivieron momentos de crisis que provocaron profundos recortes de gastos y esto provocó que estas inversiones se pusieran en cuestión. El hecho de que el nivel de inversiones en estas tecnologías hubiera crecido sustancialmente desde los años 60 y el rápido desarrollo de estas tecnologías obligara a una constante actualización, hicieron emerger las dudas sobre la conveniencia de la inversión en este tipo de activos. Así, Roach $(1987,1991)$ observó que durante las décadas de los 70 y los 80, la inversión en TI por trabajador había crecido sustancialmente, mientras que la productividad se mantenía constante. La conclusión que obtuvo es que el incremento de la inversión de la tecnología tenía un efecto casi nulo en la productividad de los trabajadores.

Durante esta época surgieron más estudios en la misma línea, como por ejemplo el trabajo de Loveman (1994) que sugiere una contribución nula de las TI al "output” o el de Cron y Sobol (1983) que va en la misma línea. En este segundo estudio se apunta a que las TI tienden a reforzar las tendencias de gestión preexistentes, aumentando la productividad en organizaciones bien gestionadas, e incrementando los efectos de la mala gestión en aquellas con una gestión ya deficiente de por sí.

Existen varios factores que justifican la existencia de otros trabajos donde la relación entre inversión en TI y desempeño es negativa o no significativa. Una de estas deficiencias es la elección de la inversión en TI como variable independiente, pues se necesita tiempo para que estas inversiones se traduzcan en beneficios, con lo que los estudios transversales no son adecuados (Mitra y Chayam, 1996). Otro problema asociado a las inversiones en TI como variable de entrada es que deben estar acompañadas de una administración correcta para que se conviertan en una infraestructura en TI eficiente. El gasto en TI por sí mismo no asegura una empresa puntera en estas tecnologías, puesto que los beneficios anticipados de la inversión en TI son marginales a menos que existan procesos integrados y dinámicos para administrar activamente y adaptar estas inversiones (Henderson y Lentz, 1995-96).

Los primeros estudios que encontraron una relación negativa entre la inversión en TI y la productividad, y que dieron nacimiento al término "paradoja de la productividad", 
examinaron la contribución de los gastos en TI agregados en medidas de desempeño económico con un nivel de análisis de industria o nación (Baily, 1986; Hackett, 1990; Roach, 1991; Panko, 1991). En este nivel de análisis, los resultados que encuentran una relación negativa son dominantes. Sin embargo no todos los estudios son negativos. Por ejemplo, Oliner y Sichel (2000), en un estudio más reciente utilizando una aproximación contable del crecimiento, han documentado que el rápido aumento de las inversiones en informática en los Estados Unidos ha contribuido significativamente al crecimiento de la producción, especialmente en la segunda mitad de los 90.

En los estudios con un nivel de análisis organizativo, que es el nivel de análisis de esta tesis, suele predominar un efecto positivo de las inversiones en TI sobre el desempeño. Sin embargo, existen algunos estudios donde su relación se encuentra no significativa e incluso negativa (Strassmann, 1990).

Un factor limitador en cuanto a las conclusiones de estos primeros estudios es la falta de variables mediadoras. Si las TI no son un fin en sí mismo, sino que son una herramienta de apoyo a las actividades empresariales y las funciones de la organización, a través de las cuales se obtienen los resultados empresariales, este hecho enmascararía una relación positiva entre las TI y el desempeño, o la reduciría significativamente, si no se tienen en cuenta estas variables intermedias.

A pesar de ello, durante la misma época surgen estudios que sí encuentran un efecto positivo entre la aplicación de las TI y la mejora de la productividad de las empresas. Así, podemos destacar el estudio de Bender (1986) o el de Harris y Katz (1991) ambos sobre empresas de seguros. También el estudio de Alpar y Kim (1990) sobre el sector bancario detecta que la utilización de estas tecnologías contribuye positivamente a la mejora de la productividad a través de la reducción de costes.

Es a partir de mediados de los 90 cuando empieza a surgir un consenso acerca del efecto positivo que la inversión en TI tiene sobre el desempeño empresarial. Este cambio de perspectiva surge en gran medida debido a la disponibilidad de más y mejores datos, de la existencia de datos desagregados a nivel de firma y a la existencia de un mayor 
volumen de inversión acumulada y de experiencia en la gestión TI. El hecho de haber dejado "madurar" estas tecnologías acabará por dar la razón a los defensores del impacto positivo de éstas en la productividad de las compañías.

De esta manera surgen estudios convergentes hacia esta idea, tanto con un nivel de análisis organizativo, como de industria y de país a nivel sector industrial y nivel economía. Estos mismos estudios empiezan a apuntar a las razones que había detrás de dicha paradoja. En esta línea podemos citar los trabajos de Brynjolfsson (1996), Brynjolfsson y Hitt (1996), o Malone (1997). Con un nivel de análisis organizativo surgen trabajos como los de Dewan y Min (1997) o el de Sohal et al. (2001), pero este último encuentra que las empresas no obtienen una ventaja competitiva tanto por utilizar “per sé” dichas tecnologías como por el hecho de utilizarlas adecuadamente. Con un nivel de análisis sectorial o de industria, Prasad y Harker (1997) observan que desagregando las inversiones TI en capital y trabajo, las inversiones en trabajo sí rinden beneficios, pero que no ocurre lo mismo para las inversiones en capital. Destacar también el estudio con nivel de análisis organizativo de Lichtenberg (1995) o Brynjolfsson y Hitt (1996), que apuntan al hecho que las inversiones TI requieren de una serie de cambios en las economías (infraestructura, capital humano, rediseño de procesos, etc.) que son complementarios a tales inversiones y que han ido teniendo lugar poco a poco, lo que habrían terminado por permitir el desarrollo de todas las potencialidades que estas tecnologías permiten. Muy al contrario, las inversiones en capital "no TI" habría alcanzado ya un grado de madurez tal que no les permitirían alcanzar retornos tan apreciables.

En el estudio desarrollo por Brynjolfsson y Hitt (1996) se propusieron analizar la paradoja de la productividad a través del estudio microeconómico del impacto de las Tecnologías de Información en las organizaciones, en lugar de utilizar los datos macroeconómicos sobre inputs y outputs con los que tradicionalmente se mide este indicador. El estudio de 380 empresas grandes norteamericanas entre 1987 y 1994 demostró que existía una relación positiva entre la inversión en PCs y el aumento de la productividad. Sin embargo, se encontró una importante variación en la muestra 
estudiada. Así, mientras algunas empresas tienen grandes retornos de la inversión en TI, otras no rentabilizan esas partidas. La explicación estriba, por una parte, en que los beneficios de las TI no afectan a todas las industrias por igual. Por otra, algunas empresas usan la tecnología de forma más eficiente que otras. Además, el coste inicial de implementación grava el coste de las TI a corto plazo, mientras que se va reduciendo a medio y largo plazo. Finalmente, los autores encontraron una relación positiva entre comportamiento organizativo e inversión en TI. Cuanto más descentralizadas son las funciones y mayor autonomía tiene el trabajador, mejores son los beneficios de la inversión en TI por trabajador. Dewan y Kraemer (2000) confirmarían esto al observar cómo las TI contribuyen significativamente a la productividad en los países desarrollados, mientras que otros tipos de inversión no lo hacen apenas. Para los países en vías de desarrollo la situación sería justamente la contraria.

En definitiva, podemos decir que después de un "boom" inicial en los años 60 en cuanto a la inversión en TI surgen corrientes escépticas que ponen en duda el impacto que estas inversiones tienen en la productividad de las empresas. A partir de mediados de los años 90, empieza a emerger un consenso en cuanto a la ventaja que suponen estas tecnologías, pero se evidencia que deben ir acompañadas de otras medidas complementarias, como puede ser la adecuada formación a los usuarios, una reingeniería de procesos, adaptación de la estrategia competitiva a las nuevas inversiones, etc.

\subsection{Valor de negocio de las TI y sostenibilidad de la ventaja competitiva}

El EBC ha sido considerado un marco conceptual sólido por muchos investigadores para estudiar los efectos de las TI en el desempeño (Wade y Hulland, 2004) desde que por primera vez esta aproximación fuera utilizada por Clemons (1986), Clemons y Row (1991) y Mata et al. (1995). El término valor de negocio de las TI es utilizado comúnmente desde esta perspectiva para referirse al impacto que las TI tienen en el desempeño empresarial, incluyendo la mejora de la productividad, mejora de los 
beneficios, reducción de costes y otras medidas de desempeño (Devaraj y Kholi, 2003; Brynjolfsson y Hitt, 1996). Los investigadores han utilizado dicho término para denotar tanto las medidas intermedias con un nivel de análisis de proceso como las medidas con un nivel de análisis orgaizativo. Por ejemplo, enfatizando esta doble concepción, Barua et al. (1995) desarrolla un modelo incorporando "efectos de primer orden en variables a nivel operacional" como facturación por inventario o "variables de nivel superior" como puede ser la cuota de mercado.

Según Melville et al. (2004), existen dos formulaciones principalmente para el constructo desempeño: eficiencia y eficacia. La eficiencia enfatiza la perspectiva interna de la organización empleando métricas como reducción de costes e incremento de la productividad en el seno de un determinado proceso de negocio, o, dicho de otro modo, la eficiencia está centrada en "hacer las cosas bien" (Drucker, 1996). En contraste, la eficacia denota la consecución de los objetivos organizativos en relación con el entorno externo de la organización y puede ser manifestado por la consecución de una ventaja competitiva, por ejemplo, consiguiendo una estrategia de creación de valor única respecto a los competidores (Barney, 1991). Así pues, definiremos el valor de negocio de las TI como el impacto en el desempeño organizativo tanto a nivel de proceso intermedio como a nivel de la organización y que comprende impacto tanto en la eficiencia como en la eficacia o competitividad de la empresa (Melville et al, 2004).

Otros investigadores han tomado una aproximación alternativa, enfocándose en los atributos de las TI y de otros recursos de la organización que conjuntamente pueden conferir una ventaja competitiva. Han aplicado la perspectiva basada en recursos tanto para determinar las implicaciones de las TI para conseguir una ventaja competitiva (Mata et al., 1995) como para asegurar empíricamente las complementariedades entre las TI y otros recursos de las organizaciones (Powell y Dent-Micallef, 1997). Por otra parte, los investigadores también han empezado a utilizar esta misma perspectiva basada en recursos para profundizar en el entendimiento de la aportación de valor de las TI al negocio (Caldeira y Ward, 1993; Clemons, 1991). 
Como se ha explicado ampliamente en el primer capítulo del presente trabajo, el EBC explica las diferencias de resultados entre las organizaciones por medio de los recursos, capacidades y competencias estratégicas y heterogéneas que poseen las distintas empresas, centrando la atención en el interior de éstas y sus recursos (Prahalad y Hamel, 1991; Grant, 1991).

El EBC subraya la importancia de las capacidades distintivas, particularmente aquellas de naturaleza intangible. De acuerdo a este enfoque, una ventaja competitiva sostenible debe fundamentarse en un conjunto de recursos y capacidades únicos que son valiosos, únicos, difíciles de imitar y no sustituibles por otros recursos (Barney, 1991).

\section{Valor de la infraestructura TI}

No existe un consenso definitivo en cuanto al valor de la infraestructura TI. Algunos autores (Lacity et al. 1995; Carr, 2003) la consideran un recurso fácilmente obtenible en el mercado de factores como hemos comentado, mientras que otros autores no están de acuerdo con esta visión reduccionista.

El primer análisis teórico sobre los atributos tangibles TI que hemos comentado en el epígrafe anterior como son el hardware, redes y aplicaciones software dejan claro que apenas pueden proporcionar una ventaja competitiva (Powell y Dent-Micallef, 1997). Según este análisis, los productos y servicios TI están disponibles para todas las firmas, por lo que no se pueden considerar escasos y la mayoría de las aplicaciones pueden ser fácilmente replicadas por los competidores a través de la contratación de personal cualificado (Clemons y Row, 1991) o la contratación de empresas consultoras. Estos recursos, por tanto, pueden considerarse una "commodity" teniendo en cuenta la facilidad con la que el recurso puede ser copiado o adquirido en el mercado de factores. Adicionalmente, las innovaciones desarrolladas en el seno de las empresas en forma de aplicaciones TI son difíciles de patentar o de mantener en secreto (Mata et al. 1995). 
Una infraestructura TI fuerte se considera un recurso básico para mantener una ventaja competitiva sostenible (Keen, 1991; McKenney, 1995), o lo que otros autores denominan una necesidad estratégica cuya ausencia puede poner en riesgo la supervivencia de las organizaciones. Uno de los trabajos que inauguraron esta corriente fue el de Clemons y Row (1991), donde de forma general la hipótesis plantea dos proposiciones:

a) las TI consiguen un incremento de la eficiencia de las operaciones internas y externas al otorgar un mayor valor a las empresas, por lo que las organizaciones que no adopten tales tecnologías soportarán mayores costes y estarán en desventaja competitiva

b) a pesar de ello, con la implantación TI no se conseguirá una ventaja competitiva sostenible puesto que la tecnología estará disponible en los mercados de factores para el resto de empresas

Para Holland et al. (1992) algunos sistemas basados en TI se han extendido de tal manera que su utilización se ha convertido en obvia, convirtiéndose en una necesidad estratégica. Los sistemas, en este caso, procuran beneficios bajo la forma de una disminución en costes, retrasos administrativos, tratamiento de las órdenes y la reducción de inventario. Pese a estos beneficios, no se pueden procurar ventajas competitivas en tanto los competidores puedan acceder a los mismos sistemas. Por el contrario, los investigadores constatan que la mala utilización de las TI puede conducir a un descenso en el desempeño y disfunciones organizativas.

No obstante existe una clara discrepancia en la literatura sobre si una infraestructura TI es en sí mismo una fuente de ventaja competitiva o simplemente una necesidad estratégica (Holland et al. 1992). No todos los autores están de acuerdo con esta visión de "commodity" y argumentan que la movilidad perfecta de las infraestructuras TI implica una cuantificación de su valor sólo en términos de componentes individuales (Bharadwaj, 2000; Weill et al. 2002). Para estos autores, la suposición de fácil replicación de los sistemas TI ignora la sinergia de los sistemas integrados. 
Bharadwaj (2000) afirma que el proceso de creación de una infraestructura TI integrada requiere un tiempo considerable, conocimiento y aprendizaje a partir de la experiencia. Aunque los componentes individuales de una infraestructura TI puedan ser adquiridos en el mercado, la integración de estos componentes para crear una infraestructura adaptada al contexto de una empresa es un proceso complejo y esta complejidad puede producir ambigüedad causal (Weill y Broadbent, 1998), es dependiente del camino seguido y se desarrolla a lo largo del tiempo (Ray et al. 2005).

Consecuentemente si la infraestructura TI es considerada en su concepto más restringido y de forma aislada, como los avances y las innovaciones de estas tecnologías son completamente exógenas respecto a las organizaciones fuera de la industria del software y la electrónica están más cerca del concepto "commodity" que de un recurso estratégico. Así, desde la perspectiva del EBC y con esta concepción la infraestructura TI difícilmente puede ser considerada como un recurso que genera una ventaja competitiva sostenible puesto que no es escaso y fácilmente imitable (Powell y DentMicallef, 1997; Mata et al. 1995). Las patentes o derechos de autor asociadas a las aplicaciones TI tampoco son consideradas fuente de ventaja competitiva, ya que una aplicación tecnológica es difícil de patentar o proteger intelectualmente e incluso una vez patentada o protegida, las figuras legales existentes ofrecen poca protección a la imitación (Mata et al. 1995).

Sin embargo, es posible explicar el valor de dichos recursos a través del soporte a capacidades y competencias funcionales (variables mediadoras) como el aprendizaje organizativo (Tippins y Sohi, 2003), gestión del conocimiento (Tanriverdi, 2003) u otras competencias clave (Byrd, 2001; Ravichandram y Lertwongsatien, 2005). En estos casos, la integración de las TI en estas funciones de negocio e desarrollan a lo largo del tiempo a través de una serie de decisiones estratégicas enlazadas sobre inversión en TI embebidas con los procesos organizativos (Sambamurthy y Zmud, 1994), lo que dificulta su imitación. 


\section{Valor de los recursos humanos TI}

En los estudios realizados en la literatura MIS, la competencia de los recursos humanos del departamento TI se ha considerado un elemento clave para la competitividad de la empresa y suele ocupar una posición predominante en la atribución de recurso estratégico desarrollado por distintos autores (Ross et al. 1996; Bharadwaj, 2000; Tippins y Sohi, 2003).

Mata el al. (1995) proponen que sólo las habilidades directivas ligadas a la TI son capaces de sustentar una ventaja competitiva sostenible en el tiempo. Éstas se concretan en el entendimiento y apreciación de las necesidades de otras áreas de negocio y de otros agentes, en la habilidad para trabajar con otros agentes en el desarrollo de aplicaciones TI, en la capacidad para coordinar actividades relativas a las TI y en la disposición para anticiparse a las necesidades tecnológicas de la empresa. El autor afirma que las habilidades técnicas podrían originar una ventaja competitiva, pero sólo de carácter temporal debido a la posible movilidad de la mano de obra. Otros autores apoyan estas mismas tesis (Ross et al. 1996; Ray et al. 2005). Sin embargo Melville et al. (2004) extienden este resultado a ventaja competitiva temporal, ya que con la creciente institucionalización y madurez de los mercados de servicios TI, tanto las funciones técnicas como incluso las de gestión y dirección TI pueden ser externalizadas a empresas especializadas. Consecuentemente de esto se colegiría que si una ventaja competitiva se sustenta sobre la existencia de un departamento TI no sería sostenible debido a las posibilidades de imitación.

Dehning y Stratopoulos (2003) establecen que las habilidades de los directivos TI están positivamente relacionadas con la sostenibilidad de la posición competitiva a largo plazo, mientras que esa relación es negativa para el caso de las habilidades y conocimientos que poseen las empresas competidoras. Sin embargo, no encuentra apoyo estadístico para las habilidades técnicas del personal TI.

Ray et al. (2005) en su estudio sobre el desempeño en servicios de atención al cliente determinan que afectarán positivamente al desempeño organizativo aquellos recursos 
específicos de la empresa con un alto grado de complejidad social, como puede ser el conocimiento compartido entre el área TI y las unidades de atención al cliente. La mejora del desempeño basada en las TI se basará en aquellos activos y capacidades que son desarrollados de forma específica dentro de la empresa y sobre las efectivas relaciones entre las TI y los gestores de otras áreas de negocio. Consecuentemente el capital destinado a TI o las habilidades técnicas del departamento TI no son suficientes para alcanzar un desempeño superior.

Dentro de los activos humanos relativos a las TI, la existencia de un departamento específico TI o de un programa de formación en TI no va a sustentar una mejora posición competitiva (Mata el al. 1995).

\section{Valor de los recursos complementarios TI}

Aunque algunos autores consideran que los recursos TI no pueden ser una fuente de ventaja competitiva per se, existe un consenso sobre el considerable potencial que pueden proporcionar combinadas con otras capacidades o como apoyo a otras funciones organizativas. Algunos estudios afirman que las Competencias en TI no pueden conseguir ventajas competitivas sostenibles por sí mismas pero sí pueden activar otros recursos intangibles complementarios que consigan estas ventajas (Powell y DentMicallef, 1997), o aquellos que consideran las competencias en TI como un antecedente en la generación de competencias con un nivel de complejidad mayor (Sambamurthy y Zmud, 1994). Estos resultados vienen respaldados por prácticamente todos los trabajos empíricos publicados desde el marco conceptual del EBC (Devaraj y Coolí, 2003; Ravichandran y Lertwongsatien, 2002; Bruque, Vargas y Hernández, 2003; Luo, Fan y Zhang, 2012).

Para aquellos trabajos en que no se tienen en cuenta variables intermedias, se podría justificar una relación positiva de las Competencias en TI sobre el desempeño. Sin embargo, como comentan Devaraj y Kohli (2003), si bien las TI contribuyen a un 
aumento de los beneficios, éstos son todavía mayores cuando se combinan las TI con procesos de cambio organizativo.

El análisis profundo de la naturaleza de las TI sugiere lo que la investigación empírica ha empezado a demostrar: para explotar el potencial de las TI, éstas deben estar acompañadas de la utilización de recursos complementarios. En uno de los trabajos pioneros a este respecto, tras analizar 14 casos de empresas que han utilizado las TI de manera estratégica, Neo (1988) constata un aumento del desempeño. Entre las razones del éxito de estas empresas se encuentra la alineación estratégica de las TI con la empresa. De manera similar, Kettinger et al. (1994) observan que las empresas que han obtenido una ventaja gracias a las TI habían puesto en marcha mucho antes una infraestructura organizativa que les permitió desarrollar y comercializar las nuevas aplicaciones de las TI.

Estudios empíricos desde el EBC confirman la importancia de algunas capacidades organizativas que moderan el efecto de las TI en el desempeño. Entre ellas destacan organización y comunicación abierta, la flexibilidad organizativa, visión compartida, cultura favorable al cambio, existencia de rutinas y procesos de reconfiguración, equipos multidisciplinares, relaciones con proveedores basados en la cooperación (Powell y Dent-Micallef, 1997) y ausencia de conflicto (Bruque et al. 2004). El valor de negocio sostenible de las TI emerge principalmente de su complementariedad e integración con las estrategias de negocio, diseño organizativo, estructuras, y competencias. Estos resultados vienen respaldados por prácticamente todos los trabajos empíricos publicados desde el marco conceptual del EBC (Devaraj y Coolí, 2003; Ravichandran y Lertwongsatien, 2002; Bruque, Vargas y Hernández, 2003; Chen, 2012).

Teóricamente, el rol primario jugado por las capacidades organizativas complementarias en los procesos de integración de las TI en el negocio pueden suponer diferentes patrones de uso de las TI específica de una firma y difíciles de imitar. Consecuentemente, las ventajas competitivas que emergen de la integración de las TI pueden ser protegidas si son absorbidas en la organización a través de prácticas 
desarrollo idiosincrático, de complementariedad y coespecialización (Tippins y Sohi, 2003; Powell y Dent-Micallef, 1997) que fortalecen su inimitabilidad y escasez, y que al mismo tiempo reducen su valor fuera del contexto de una empresa específica.

En este sentido, Clemons y Row (1991) afirman que sólo es posible que las TI lideren la creación de una ventaja competitiva sostenible cuando es utilizada como palanca para generar diferencias en los recursos estratégicos. Sambamurthy y Zmud (1994) consideran las competencias TI como un antecedente del nivel de acciones competitivas gracias a sus complementariedades y la integración con las estrategias de negocio, los diseños organizativos, las estructuras y otras competencias.

Ross et al. (1996) profundizan en la importancia de las relaciones entre TI y negocio cuando analizan la competitividad a largo plazo a través de las TI. Sin embargo, el proceso por el que las capacidades TI se integran en las actividades de negocio todavía es un tema escasamente comprendido (Ravinchandran y Lertwongsatien, 2005; Wade y Hulland, 2004) y se han dedicado muy pocos trabajos empíricos a esta cuestión.

Uno de estos escasos trabajos empíricos es el Powell y Dent-Micallef (1997), que estudian la importancia de la integración de las TI con el negocio para obtener mejores desempeños a través de la influencia de un conjunto de recursos complementarios como una cultura abierta o una estructura organizativa favorable. De forma similar, Bruque et al. (2004) encuentra una influencia positiva entre las TI en el desempeño organizativo cuando las TI se combina con una comunicación fluida entre los miembros de la organización, baja conflictividad interna y un apoyo de los directivos a estas tecnologías. Ray et al. (2005) confirman la importancia de una cultura de compartir conocimiento entre los directivos TI y los directivos de negocio para desarrollar el potencial de las TI. Todos estos estudios desde el EBC de forma recurrente resaltan el valor de los recursos organizativos complementarios que contribuyen a la integración de las TI en las actividades de negocio.

Bharadwaj (2000) comprueba un efecto positivo de las competencias en TI sobre el desempeño, pero incluye en estas competencias lo que denomina propiciadores 
intangibles de las TI. Estos propiciadores comprenden una orientación al cliente, ciertos activos en conocimiento y las sinergias entre otros recursos y capacidades de la organización.

Ravichandran y Lertwongsatien (2002) encuentran complementariedad entre las capacidades en TI y otros activos no relacionados con las TI en la obtención de desempeños superiores. En este caso, los recursos complementarios a la utilización de las TI pueden ser coespecializados, es decir, que no tienen valor si no se utilizan junto a las TI, como la experiencia gerencial de la organización en materia de TI (Neo, 1988). Otros recursos complementarios no tienen por qué ser coespecializados, pero sí que pueden aumentar su valor cuando se utilizan conjuntamente con las TI. Este es el caso de una estructura organizativa favorable a la innovación (Kettinger et al. 1994) o una cultura organizativa favorable al intercambio de información.

Desde un punto de vista general, la literatura estratégica ha estudiado ampliamente los recursos responsables de cohesión y coordinación de las funciones en las organizaciones (Kogut y Zander, 1994). Estos recursos están continuamente explorando nuevas combinaciones de recursos y capacidades para alcanzar un mejor encaje con el mercado. Las innovaciones TI tienden a requerir profundos cambios organizativos en los procesos de trabajo y los flujos de información o la ubicación de la responsabilidad y el poder de decisión (Venkatraman, 1994), y las estructuras organizativas (Fielder et al. 1995; Sambamurthy y Zmud, 1999). Cuando las incompatibilidades entre los sistemas de información y los procedimientos de negocio emergen, la elevada inercia de las variables organizativas pueden impedir el éxito de la puesta en marcha de una iniciativa TI.

Para mitigar estos problemas, algunos autores han reclamado la necesidad de programas especiales para una efectiva implementación de los sistemas de información (Joshi, 1991; Venkatesh et al., 2003), de forma que los resultados negativos asociados con la falta de comunicación entre los sistemas TI y la organización puedan evitarse. Este tipo de programas, en general, requieren de la participación de los usuarios en el proceso de diseño, planificación y promoción de una comunicación efectiva entre el personal TI y 
los potenciales usuarios (Hunton y Beeler, 1997). Sin embargo, incluso con el ajuste de los sistemas de información a las actividades de negocio y la estructura organizativa de una firma, la capacidad de la organización de adaptarse y ajustarse al nuevo sistema es determinante. La integración técnica demanda una integración funcional que potencie la cooperación, haga circular la información, distribuya y delimite las responsabilidades y sincronice los horizontes temporales. De acuerdo con Venkatraman (1991), la introducción de sistemas de información no puede ser concebida como una solución técnica independiente de un contexto organizativo concreto. Para este autor, las capacidades de comunicación deben estar en el centro de las investigaciones que estudian la relación entre las TI y la ventaja competitiva.

La importancia de lo mencionado anteriormente se refleja en el gran número de autores que han enfatizado los factores organizativos como esenciales para una implementación y utilización exitosa de los sistemas de información (Neo, 1998; Keen, 993; Orlikowsky, 1996; Davenport, 1999; Wade y Hulland, 2004). Melville et al (2004), en relación a los recursos organizativos complementarios (estructura organizativa, reglas y políticas, prácticas de los centros de trabajo y cultura) afirma que son factores internos decisivos que modulan el valor de las TI. 
Figura 2.1. Modelo de valor de negocio de las TI

III. Macroentomo

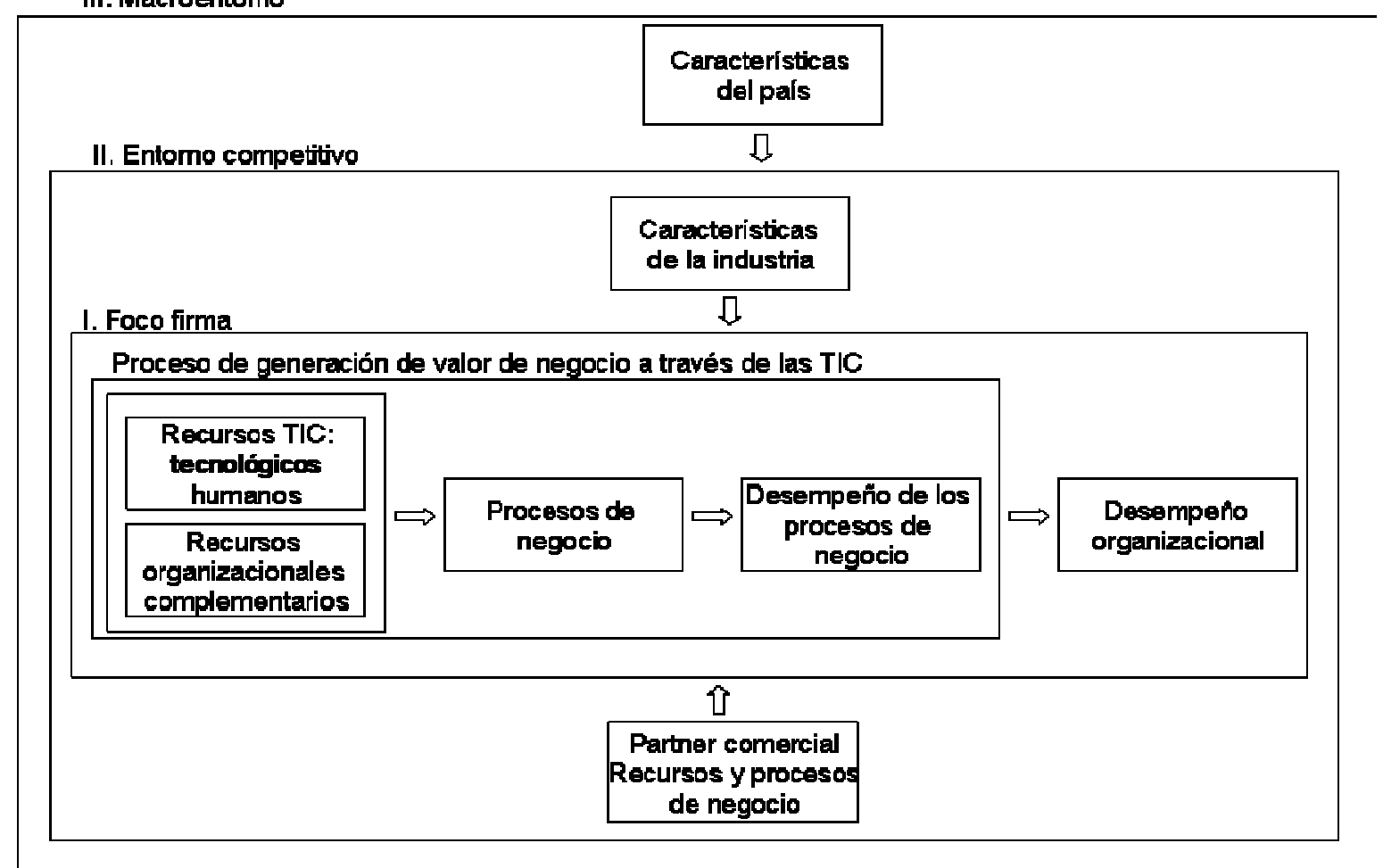

Fuente: Melville et.al., (2004)

Sin embargo, estas perspectivas tiene limitaciones (Melville et al, 2004), ya que asume que los recursos son siempre utilizados de la mejor forma y no se tiene en cuenta de qué manera se aplican. Además, esta perspectiva no es suficiente para ofrecer una visión global del fenómeno, puesto que elementos como los socios comerciales, la estructura de la industria y las condiciones socio-políticas deben ser tenidas también en cuenta. Por otra parte, los autores postulan que la ubicación de la aportación de valor al negocio por parte de las TI está en la organización que invierte y despliega recursos TI. En este sentido, el valor es generado en el despliegue de recursos TI y otros recursos complementarios de la organización en los procesos de negocio. De esta manera, la conjunción de ambos tipos de recursos pueden mejorar los procesos de negocio o habilitar nuevos, lo que en última instancia puede impactar en el desempeño empresarial (Brynjolfsson y Hitt, 2000). 
Así, en función de la consideración de las TI como fuente de ventaja competitiva o no da lugar a un posicionamiento estratégico respecto a éstas por parte de la organización, por lo que es necesario analizar qué estrategias seguir. Es por ello que pasamos a describirlas a continuación.

\subsection{Estrategias TI}

A pesar de la importancia que tienen las TI para las organizaciones y la adecuada implementación de su estrategia para la generación de ventajas competitivas sostenibles, el concepto de estrategia TI todavía es difuso y está inconsistentemente definido y medido (Chen et al. 2010). Mientras el concepto de estrategia ha sido ampliamente estudiado en los trabajos relacionados con estrategia competitiva, el concepto de estrategia TI en sí mismo ha sido escasamente tratado. No obstante, podemos decir que en términos generales la investigación realizada sobre la estrategia en materia de TI y sistemas de información en las organizaciones ha estado muy influenciada por el tratamiento que se ha hecho del concepto estrategia en el ámbito de investigación de la dirección estratégica.

La literatura MIS tradicionalmente se ha enfocado más a determinar cómo conducir la planificación estratégica, cómo alinear la estrategia en sistemas de información para una determinada estrategia de negocio o quién debe estar involucrado en la conformación de la estrategia (Allen y Wilson, 1996; Brown, 2004), obviando en muchas ocasiones la definición del mismo concepto. Por otra parte, según Chan et al. (2010), aplicando el marco teórico de Whittington (1993), la mayoría de las estrategias TI descritas en la literatura existente se encuentran en el cuadrante clásico de estrategia, es decir, aquella concepción en la que la planificación estratégica es un producto de una calculada deliberación cuya meta es la maximización del beneficio. Aunque el concepto de estrategia TI está íntimamente relacionado con el concepto estrategia empresarial, Chen et al (2010), adopta la postura de que la estrategia TI de una empresa debe ser examinada independientemente del análisis de la estrategia de negocio, puesto que la 
estrategia TI puede tanto soportar la estrategia de negocio como liderarla (Agarwal y Samamurthy, 2002).

Sabherwal y Chan, (2001) sugieren hacer una distinción entre estrategia de las TI, y estrategia de los SI: la estrategia de los SI se centra en los sistemas o aplicaciones de negocio de las TI, siendo su objetivo principal su alineación con las necesidades de negocio y su uso para conseguir beneficios estratégicos; las estrategias de las TI se centran en las políticas de la tecnología, incluyendo tales aspectos como la arquitectura, los estándares técnicos, los niveles de seguridad y las actitudes de riesgo; finalmente, las estrategias en la gestión de la información se ocupan de las estructuras y funciones para la administración de los SI y TI, centrándose en cuestiones como las relaciones entre especialistas y usuarios, las responsabilidades de los directivos, los controles de dirección y los procesos de medida de desempeño (Earl, 1989).

Por otra parte nos encontramos con un elevado nivel de ambigüedad, debido a que no existen tipologías establecidas de la misma manera que se produce en el ámbito de la estrategia competitiva. En lugar de esto se pueden encontrar una plétora de términos empleados para representar constructos similares, tales como estrategia TI (Gottschalk, 1996), estrategia SI (Galliers, 1996), estrategia TI/SI (Chan et al., 1997) o estrategia de información (Smits et al., 1997) entre otros: 
Tabla 2.1. Definiciones de estrategia TI y términos relacionados en la literatura

\begin{tabular}{|c|c|c|}
\hline Término usado & Definición proporcionada & Fuente \\
\hline Estrategia $\mathrm{I} / \mathrm{T}$ & Ninguna definición proporcionada & $\begin{array}{l}\text { Henderson } \\
\text { Venkatraman, } 1999\end{array}$ \\
\hline \multirow{2}{*}{$\begin{array}{l}\text { Estrategia de gestión de } \\
\text { la información }\end{array}$} & "reglas a largo plazo para dirigir, implementar y supervisar la gestión de la información" & Reponen, 1994 \\
\hline & $\begin{array}{l}\text { "trata de la función de la gestión completa de los sistemas de información” refiriéndose } \\
\text { a Earl (1989), "el marco de gestión que guía cómo la organización debe realizar las } \\
\text { actividades SI/TI }\end{array}$ & $\begin{array}{l}\text { Ragu-Nathan et al., } \\
2001\end{array}$ \\
\hline Plan de información & Resultados tangibles del proceso de planificación de los sistemas de información & $\begin{array}{l}\text { Brown, 2004; Lederer y } \\
\text { Salmela, } 1996\end{array}$ \\
\hline $\begin{array}{l}\text { Estrategia } \\
\text { información }\end{array}$ & $\begin{array}{l}\text { Complejo de visiones implícitas o explícitas, metas, guías y planes en lo que respecta a } \\
\text { la provisión y demanda formal de información de una organización, aprobado por la } \\
\text { gestión, orientado a apoyar los objetivos de la organización en el largo plazo, mientras } \\
\text { que permite ajustarse al entorno }\end{array}$ & Smits et al., 1997 \\
\hline \multirow[t]{3}{*}{$\begin{array}{l}\text { Estrategia de sistemas } \\
\text { de información, } \\
\text { estrategia SI }\end{array}$} & $\begin{array}{l}\text { Ninguno proporcionado; define únicamente el concepto de "sistemas de información } \\
\text { estratégicos", un término utilizado como sinónimo: "SI utilizados para apoyar y dar } \\
\text { forma a la estrategia competitiva de la organización, su plan para adquirir y mantener } \\
\text { una ventaja competitiva" }\end{array}$ & Chan y Huff, 1992 \\
\hline & Ninguna proporcionada & $\begin{array}{l}\text { Galliers, 1991; Hatten y } \\
\text { Hatten, 1997; Hayward, } \\
1987\end{array}$ \\
\hline & “Aproximación integrada y coordinada de estándares y planes para la provisión y & Hoey, 1998 \\
\hline
\end{tabular}




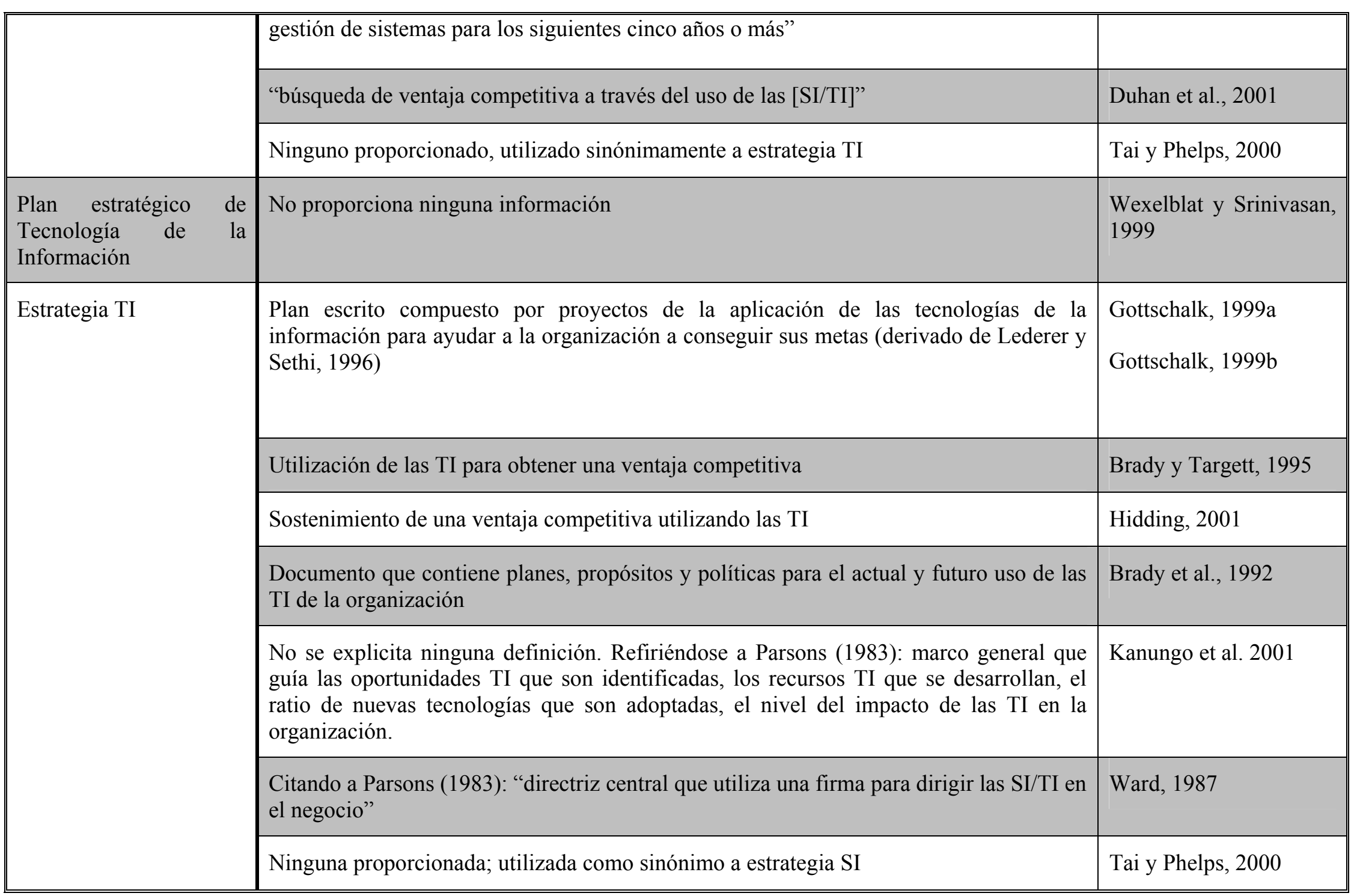




\begin{tabular}{|c|c|c|}
\hline Estrategia SI/TI & $\begin{array}{l}\text { "el modo en que los SI/TI son utilizados para desarrollar una estrategia". Refiriéndose a } \\
\text { Wiseman (1985) "sistemas de información utilizados para apoyar o dar forma a la } \\
\text { estrategia competitiva de la organización" }\end{array}$ & Atkins, 1994 \\
\hline $\begin{array}{l}\text { Documento de } \\
\text { planificación SI a largo } \\
\text { plazo }\end{array}$ & $\begin{array}{l}\text { "planificación estratégica/a largo plazo" como "un proceso que considera tres o más } \\
\text { años en el futuro y engloba el desarrollo de objetivos EDP/MIS y la implementación de } \\
\text { estrategias y políticas para conseguir estos objetivos }\end{array}$ & Conrath et al., 1992 \\
\hline Plan MIS & Los "resultados observables" de "una planificación estratégica SI" & Pyburn, 1983 \\
\hline $\begin{array}{l}\text { Escenario estrategia } \\
\text { MIS }\end{array}$ & Guia el diseño y desarrollo del MIS derivado del escenario de estrategia organizativa & King, 1978 \\
\hline $\begin{array}{l}\text { Plan estratégico de } \\
\text { información }\end{array}$ & $\begin{array}{l}\text { Portafolio de aplicaciones de ordenador que ayudarán a la organización a ejecutar sus } \\
\text { planes de negocio y conseguir sus objetivos de negocio }\end{array}$ & Lederer y Salmela, 1996 \\
\hline $\begin{array}{l}\text { Planificación de los } \\
\text { sistemas de información } \\
\text { estratégicos }\end{array}$ & Identificación e implementación con éxito de los sistemas estratégicos de información & Galliers, 1991 \\
\hline $\begin{array}{l}\text { Plan estratégico para los } \\
\text { sistemas de información }\end{array}$ & Resultado del proceso de planificación SI & Teo y Ang, 2000 \\
\hline Plan estratégico de MIS & No proporciona ninguna & Ein-Dor y Segev, 1978 \\
\hline $\begin{array}{l}\text { Sistemas de información } \\
\text { para las estrategias }\end{array}$ & Utilizado de forma sinónima a estrategia SI & Ward, 1987 \\
\hline Estrategia TI & $\begin{array}{l}\text { Establecimiento de un plan a medio y largo plazo para la introducción SI y para } \\
\text { coordinar las inversiones TI relevantes }\end{array}$ & Yeh et al., 2012 \\
\hline
\end{tabular}

Fuente: adaptado de Chen et al. (2010) 
En términos generales, la conjunción de todos estos términos puede resultar en una confusión para la interpretación de los diferentes trabajos en este campo (Allen y Wilson, 1996). Muchas de los trabajos relacionados con las TI están vinculados con elementos que Chan et al. (2010) catalogan de "tangenciales", tratando aspectos como el aspecto de desarrollo de la estrategia, el impacto de la estrategia SI o el alineamiento entre la estrategia TI y la estrategia de negocio. Según estos autores, es posible diferenciar tres concepciones de estrategia TI/SI en la literatura:

- Concepción I: estrategia TI como utilización de los sistemas de información para soportar la estrategia de negocio

- Concepción II: estrategia TI como el plan maestro de la función SI/TI

- Concepción III: estrategia TI como la visión compartida del rol SI/TI en la organización

\subsubsection{Estrategia TI como utilización de los sistemas de información para soportar la estrategia de negocio}

Esta concepción de estrategia TI responde a la pregunta de en qué manera los sistemas de información pueden ayudar al negocio a obtener y mantener ventajas competitivas sostenibles (Brady y Targett, 1995; Duhan et al., 2001; Hidding, 2001). Earl (1989) propone que la gestión estratégica de los sistemas de información en las organizaciones se divide en tres dominios: qué hay que hacer, cómo tiene que ser hecho y quién debe hacerlo, etiquetando cada dominio como SI, TI y estrategia MI (gestión de la información) respectivamente.

Aplicando el modelo de Earl (1989), esta concepción de la estrategia TI encajaría con el subdominio "qué", aunque no sería idéntica. Por ejemplo, el autor indica que este subdominio también estaría relacionado con el alineamiento del desarrollo de sistemas de información con las necesidades de negocio. 
Esta concepción de estrategia TI sugiere que el inicio de una estrategia debe estar conectada con una estrategia de negocio establecida (Atkins, 1994; Hatten y Hatten, 1997) o lo que Mintzberg (1987) nombró como “posición” cuando definió el concepto de estrategia competitiva en su trabajo. Por ejemplo, si una compañía ha elegido una estrategia de desarrollo de mercado siguiendo la marco estratégico de Ansoff (1965) con un vector de crecimiento, la estrategia TI implicaría a aquellos recursos estratégicos TI que pueden apoyar el desarrollo de mercado (Atkins, 1994). O por ejemplo, si una compañía ha elegido una estrategia de negocio de liderazgo en costes siguiendo el marco de estrategia competitiva genérica de Porter (1980), la estrategia en sistemas de información necesitaría incluir iniciativas que ayudaran a la organización a intensificar su posición de coste bajo (Brady y Targett, 1995).

Dado que la estrategia TI es una derivada de la estrategia de negocio en este caso, esta concepción se puede definir como centrada en el negocio (Chan et al., 2010). Por definición, la estrategia de negocio y de sistemas de información están intrínsecamente ligadas y el alineamiento se ha conseguido ya en la medida que se ha desarrollado la estrategia TI (es decir, está apriorísticamente conseguido). Una contribución de esta concepción es que, dado que la investigación de la gestión estratégica ha establecido unas bases teóricas sólidas, los investigadores en sistemas de información pueden utilizar dichas bases para avanzar en la investigación de la estrategia TI (Chan y Huff, 1992).

No obstante, esta concepción está limitada en cuanto a las implicaciones de la vinculación con la estrategia de negocio. La estrategia TI así concebida no es una estrategia en sí misma. Los trabajos realizados bajo esta concepción de estrategia tiende a asumir que la estrategia TI no existiría sin una estrategia de negocio que apoyar claramente definida o que no existiría si la organización no estuviera buscando una ventaja competitiva sostenible a través de los sistemas de información. Es posible argumentar que una organización necesita articular una estrategia de negocio, la realidad es que en muchas compañías (particularmente en las pequeñas y medianas empresas, ámbito en el que están concentradas las empresas en las que se desarrolla el 
estudio empírico del presente trabajo) no existe una estrategia de negocio explícita (Mintzberg y Waters, 1985). Para estas organizaciones con una estrategia de negocio más implícita que explícita, esta concepción no aplicaría, puesto que la base para diseñar una estrategia TI es mucho menos sólida. Sin embargo, aunque pueda ser complicado interpretar la estrategia de negocio, la estrategia TI puede existir entre estas organizaciones, aunque el desarrollo del proceso estratégico sea más informal.

Más aún, como decíamos al principio del presente capítulo, algunos investigadores han afirmado que la estrategia TI puede tanto apoyar como impulsar la estrategia de negocio (Agarwal y Sambamurthy, 2002; Earl, 1989; Galliers, 2004; Preston y Karahanna, 2009). Por ejemplo, Earl (1989) postula que la estrategia TI puede liderar el negocio pero por otra parte esta estrategia también puede cuestionar la estrategia de negocio. Más allá de esto, Galliers (1991, 1993, 2004) afirma que la estrategia TI puede ser considerada como una parte más de la estrategia integral de negocio que implica el impacto potencial de los sistemas de información en el desempeño organizacional así como los cambios concomitantes en los aspectos de gestión derivados de las iniciativas de negocio impulsadas por las iniciativas TI. Por tanto, como afirma Chan et al. (2010) limitar la estrategia TI a un subconjunto dependiente de la estrategia de negocio puede resultar en una visión limitada, y exista o no una estrategia de negocio explícita, las organizaciones necesitan de una guía para la toma de decisiones en el ámbito TI no necesariamente supeditadas a la estrategia de negocio.

\subsubsection{Estrategia TI como el plan maestro de la función SI/TI}

Esta concepción de la estrategia es una concepción altamente utilizada en la literatura existente (Chan et al., 2010). Proporciona una visión más amplia que la anterior concepción de estrategia TI. Aunque la función SI/TI es una parte esencial de la organización y el objetivo último de esta función es soportar y habilitar el desempeño del negocio, esta segunda concepción está enfocada en la estrategia para hacer funcionar 
la función SI/TI eficazmente y eficientemente. En esta concepción la estrategia TI es un plan (Mintzberg, 1987) que persigue dos objetivos principalmente:

- Identificar los recursos TI necesarios, incluyendo personal (es decir, plantilla y sus capacidades), estructura (es decir, procesos TI), recursos monetarios (es decir, presupuesto TI) y tecnología (infraestructura y aplicaciones TI).

- Ubicar los recursos TI existentes de la forma más efectiva.

Esta concepción cubriría el segundo (estrategia TI) y el tercero (estrategia MI) subdominios del modelo triángulo de Earl (1989). Por ejemplo, Earl (1993) afirma que el propósito de la estrategia TI es dirigir la gestión eficiente y efectiva de los recursos SI y que la estrategia MI es desarrollar la arquitectura y las políticas tecnológicas. En este sentido, esta segunda concepción está centrada en SI/TI, ya que la estrategia TI es un plan a largo plazo para un conjunto de artefactos relacionados con los sistemas de información de la organización (Orlikowski y Iacono, 2001).

Dicho de otra manera, las asunciones que subyacen a esta segunda concepción de estrategia TI está adscrita a un concepto de estrategia funcional, entendiendo la estrategia funcional como aquella que está preocupada en primera instancia con la ubicación de los recursos para conseguir la maximización de la productividad de éstos (Hoffer y Schendel, 1978; Whellen y Hunger, 1986). En consecuencia, parece claro que aunque muchos de los recursos TI están en el núcleo del negocio o complementarios a los recursos de negocio, esta concepción de estrategia, en contraste con la concepción anterior, puede ser examinada de forma independiente a la estrategia de negocio de una organización ya que se enfoca a la gestión efectiva de la función de Sistemas de Información para la mejor ubicación y utilización de los recursos TI (Earl, 1989, 1993).

En los trabajos enfocados desde esta perspectiva, la estrategia TI es en ocasiones vista como la estrategia de negocio asociada a la función SI, que ha sido etiquetada como un “negocio dentro del negocio" (Adler et al., 1992; Ragu-Nathan et al., 2001) que requiere "atención a sus procesos clave, sus recursos y a sus conexiones internas y externas". Como afirma Ragu-Nathan et al. (2001), la función SI “está en proporcionar servicios a 
los usuarios de la organización quien, por otra parte, deben ser observados como clientes" (p. 277). Adicionalmente esto requiere su propia "estrategia [funcional] dirigida a desarrollar un producto final (es decir, sistemas de información) que son buscados por los usuarios" (p.278). Estas afirmaciones sugieren que la unidad funcional SI puede tener una estrategia separada de otras unidades de negocio. En consecuencia, el alineamiento entre la estrategia TI y la estrategia de negocio requiere de una aproximación "ex post" ya que ambas estrategias requieren ser desarrolladas concurrentemente.

Un beneficio de esta concepción de estrategia TI es que proporciona un esquema más comprensivo de la planificación de la función SI que la concepción anterior. Por otra parte esta concepción puede ser aplicada como guía para la toma de decisiones TI en las organizaciones que no tienen claramente definidas la estrategia de negocio o en organizaciones que no necesariamente conciben los Sistemas de Información como una fuente de ventaja competitiva (Duncan, 1995; Hagel y Brown, 2001; Ross et al., 2006). Sin embargo las limitaciones de esta concepción son relevantes: en primer lugar, un énfasis en la función SI puede crear dificultades para que las funciones de negocio puedan comprender la estrategia TI y consecuentemente generar posibles barreras para alinear ambas estrategias. En segundo lugar, la visión de la función SI como una unidad de negocio puede hacer que se tomen decisiones aisladamente y por tanto con riesgo subyacente de que no sean las decisiones óptimas en el presente o futuro respecto a la estrategia de negocio o que no estén en línea con los objetivos organizativos para la mejora del desempeño (Baldwin y Curley, 2007).

\subsubsection{Estrategia TI como la visión compartida del rol TI en la organización}

Esta tercera concepción describe la estrategia TI como una visión compartida atendiendo al rol que los Sistemas de Información juegan en la organización. En este sentido, la estrategia TI es vista desde una perspectiva organizativa (Mintzberg, 1978) que guía el futuro de las decisiones y actividades de negocio relacionadas con los Sistemas de Información más que un plan concreto o un posicionamiento como las dos 
concepciones anteriores. Esta perspectiva refleja la actitud de los directivos de una organización (incluyendo los directivos TI) hacia los Sistemas de Información que puede estar basada en la experiencia previa, las preferencias personales o los requisitos de la industria (Nolan y McFarlan, 2005). Podemos ver un resumen de las diferentes propuestas en relación a los roles que pueden jugar los Sistemas de información en las organizaciones en la siguiente tabla:

Tabla 2.2. Visión de los roles TI en la organización

\section{Visiones de los roles TI en la organización}

\begin{tabular}{|l|l|}
\hline Rol sugerido de las TI en la organización & Fuente \\
\hline $\begin{array}{l}\text { Planificación centralizada, puntera, mercado } \\
\text { libre, monopolio, recursos escasos y mal } \\
\text { necesario }\end{array}$ & $\begin{array}{l}\text { Parsons (1983) } \\
\text { Kanungo et al. (2001) } \\
\text { Ward (1987) }\end{array}$ \\
\hline $\begin{array}{l}\text { Basada en la importancia actual y futura de las } \\
\text { pI para el negocio: estratégicas (alta } \\
\text { importancia presente y futura), factoría (alta en } \\
\text { el presente y baja en el futuro), modo cambio o } \\
\text { respuesta (baja en el presente y alta en el futuro) }\end{array}$ & $\begin{array}{l}\text { Matriz estratégica de } \\
\text { McFarlan (McFarlan et al., } \\
\text { y soporte (baja en el presente y en el futuro) } \\
\text { (1987) Adoptada por Ward }\end{array}$ \\
\hline $\begin{array}{l}\text { Promoción agresiva de las TI; desarrollo de las } \\
\text { TI basadas en el análisis; gestión defensiva de } \\
\text { las TI; gestión proactiva de las TI; gestión } \\
\text { conservadora de las TI }\end{array}$ & $\begin{array}{l}\text { Dimensiones del constructo } \\
\text { estrategia Ragu-Nathan et al. } \\
\text { 2001) }\end{array}$ \\
\hline $\begin{array}{l}\text { Automático; informativa hacia arriba; } \\
\text { informativa hacia abajo; transformadora. }\end{array}$ & $\begin{array}{l}\text { Visiones organizativas de las } \\
\text { Zuboff, 1988); adoptadas por } \\
\text { Tai y Phelps (2000) }\end{array}$ \\
\hline $\begin{array}{l}\text { Del momento; defensiva; desarrollo moderado; } \\
\text { agresiva }\end{array}$ & $\begin{array}{l}\text { Estrategias TI de Szyperski } \\
\text { (Szyperski, 1992); adoptada } \\
\text { por Teubner (2007) }\end{array}$ \\
\hline $\begin{array}{l}\text { Exploración de las TI (innovadora); explotación } \\
\text { ambivalente }\end{array}$ & $\begin{array}{l}\text { Tipología de Chen (2010); } \\
\text { adoptada y ampliada por } \\
\text { Leidner et al. (2011) }\end{array}$ \\
\hline
\end{tabular}

Fuente: adaptado de Chen et al. (2010) 
Esta tercera concepción de la estrategia TI representa un concepto de orden superior a las otras dos concepciones anteriores. Esta concepción no sólo cubre los tres subdominios (es decir, qué, cómo y quién) de la gestión estratégica de los Sistemas de Información propuesto por Earl (1989), sino que sugiere que las decisiones relacionadas con los SI son contingentes con el rol elegido para dichos Sistemas de Información (por ejemplo, si soportan el negocio o lo impulsan) acordado por los altos directivos.

No obstante, esta concepción está centrada en la organización, lo que permite establecerse como puente entre los dos extremos expuestos en las anteriores concepciones: la concepción centrada en el negocio y la concepción centrada en los Sistemas de Información. Una perspectiva organizativa asegura que "todos los miembros de una organización están orientados en la misma dirección" (Tai y Phelps, 2000, p.165). En esta concepción, la estrategia TI no es necesariamente dependiente de una estrategia de negocio en particular. Por ejemplo, tanto si los Sistemas de Información son vistos como un mal necesario como si se ven como un elemento estratégico capaz de liderar el negocio es independiente de si una compañía está ejecutando una estrategia de negocio de diferenciación o una estrategia de liderazgo en costes (Parsons, 1983). Sin embargo, la estrategia TI debe reflejar la visión estratégica de los ejecutivos de negocio en relación al rol que la función TI debe jugar (Armstrong y Sambamurthy, 1999; Earl, 1989; Galliers, 2004).

Conceptualizando la estrategia como una visión compartida del rol TI en la organización es también consistente con la definición de estrategia TI presentada anteriormente. Específicamente, una visión compartida proporciona una base para conformar la perspectiva organizativa de cómo invertir y utilizar las TI para conseguir objetivos estratégicos (Armstrong y Sambamurthy, 1999; Preston y Karahanna, 2009). Debido a la creciente intensidad de utilización de información en las industrias, muchos ejecutivos están elevando el nivel de importancia que dan a las Tecnologías de la Información emergentes (McAfee y Brynholfsson, 2008). Por tanto, es muy posible que a través de la mencionada visión compartida entre los ejecutivos de negocio y de TI el 
impacto potencial de las nuevas tecnologías puedan dar forma a la estrategia de negocio (Galliers, 1995).

Una limitación de esta concepción es que generalmente refleja una perspectiva de arriba a abajo de la estrategia. Sin embargo, algunas organizaciones pueden practicar una perspectiva de abajo a arriba para desarrollar su estrategia. Ciborra (1994) afirma que los sistemas de información estratégicos necesitan evolucionar de abajo a arriba en las organizaciones en lugar de ser implementados de arriba abajo, de tal forma que debido a que su integración está enraizada en la cultura específica de la organización son difícilmente imitables, lo que permitiría crear recursos, competencias o capacidades que generaran ventajas competitivas sostenibles. Smith y Tushman (2005) proponen una estrategia de dentro a afuera, sugiriendo que los ejecutivos de una empresa necesitan constantemente analizar el entorno para descubrir nuevas oportunidades estratégicas.

A pesar de que esta concepción tiene un menor índice de madurez que las anteriores concepciones, ofrece oportunidades de analizar el alineamiento estratégico entre los Sistemas de Información y el negocio a través de una óptica diferente (Chen et al., 2010). Dado que esta concepción asume un conocimiento compartido entre los actores de los dominios negocio y TI en relación al rol de los Sistemas de Información, refleja consecuentemente la dimensión social del alineamiento estratégico TI (Preston y Karahanna, 2009; Reich y Benbasat, 1996, 2000) más que la dimensión intelectual que es la que ha sido predominante en la literatura sobre alineamiento estratégico (Chan y Reich, 2007). Bajo esta concepción, el alineamiento estratégico es entendido como un proceso en marcha dirigido por los ejecutivos de ambos dominios (Preston y Karahanna, 2009) más que un resultado derivado de la conformidad con la estrategia de negocio desarrollada. En este caso, por tanto, la estrategia TI puede desarrollarse tanto para soportar la estrategia de negocio o alternativamente dirigirla, permitiendo así una forma dinámica de alineamiento. 
Partiendo de esta tercera concepción, Chen et al. (2010) conceptualizan el constructo estrategia TI como "la perspectiva organizativa de la inversión, el despliegue, el uso y la gestión de los sistemas de información”. Esta definición, pretende integrar el concepto de sistemas de información desde una perspectiva amplia, cubriendo aspectos tales como los componentes tecnológicos y las actividades de las personas relacionadas con la tecnología y los procesos dentro de la organización. Introduciendo el elemento "perspectiva" los autores pretende poner de relevancia que la estrategia es entendida no necesariamente como una estrategia predefinida y conscientemente implementada y desplegada por una organización, sino que es el resultado de las decisiones que de una forma u otra la organización ha ido tomando en el tiempo en relación con la utilización de los sistemas de información. Esta definición, por otra parte, sugiere que conceptualmente la estrategia no debe ser examinada como una parte de la estrategia de negocio, sino que es una perspectiva independiente de la estrategia de negocio y con alcance a toda la organización y su desempeño global.

Esta definición implica necesariamente que la estrategia debe verse desde el ámbito de organización más que desde un ámbito funcional. Mientras que cada unidad de negocio de una firma o sus directivos pueden tener una visión propia de los Sistemas de Información, la estrategia TI organizativa refleja la visión colectiva compartida en la organización (Mintzberg, 1987).

En el presente trabajo asumiremos esta última concepción de estrategia TI para el desarrollo de la investigación. Esta última concepción de estrategia TI independiza la estrategia TI de la estrategia competitiva elegida por la empresa (asumiendo que en ocasiones apoya y en otras guía a la segunda), además de posibilitar integrar una visión de perspectiva de esta estrategia. Adicionalmente esta última concepción nos posibilita entender la estrategia TI desde una perspectiva holística y global organizativa e integrar la dimensión social a dicho constructo. 


\subsection{Valor de las TI y estrategia de negocio}

\subsubsection{Valor de las TI y actividades de negocio}

Como hemos comentado anteriormente uno de los objetivos principales del presente trabajo es el de contribuir a la comprensión del valor estratégico de las TI para las distintas posibles estrategias adoptadas por la empresa.

Al examinar el efecto moderador de las TI en la estrategia empresarial lo haremos a través del impacto en las actividades a las que se enfoca la empresa, adoptando una perspectiva de proceso. Esta perspectiva de proceso sugiere que el impacto sobre el desempeño organizativo de las TI sólo puede ser medido a través de la contribución de las TI a niveles intermedios, es decir, a través del impacto en los procesos clave (Barua et al., 1995; Mooney et al., 1995; Mukhopadhyay et al., 1997; Sambamurthy, 2001; Tallon et al., 2000; Tallon, 2007). La discusión es que si las TI son implementadas para dar soporte a procesos específicos, consecuentemente el impacto de dichos sistemas deben ser analizados donde sus efectos de primer orden se espera que se produzcan. Esta aproximación es consistente con la aproximación contingente y que sugiere la necesidad de tener en cuenta otras variables que pueden mediar o moderar el retorno de las inversiones TI (Markus y Soh, 1993; Weill, 1992), así como las inversiones organizativas complementarias a las TI (Barua et al. 1996; Brynjolfsson et al. 1998). Ray et al (2004) afirman que examinar la teoría del EBC para examinar las implicaciones económicas a nivel de firma puede llevar a conclusiones erróneas y que el análisis a nivel de procesos o actividades puede ser más apropiado. 
Más recientemente Piccoly e Ives (2005) han llamado a desarrollar estudios sobre el valor de las TI utilizando las "iniciativas estratégicas individuales" ${ }^{2}$ como unidad de análisis, aunque apenas no se han desarrollado estudios en esta línea (Doherty y Terry, 2009).

En términos generales, como denotan Ray et al. (2004) en los estudios que analizaban el impacto competitivo de las inversiones TI se ha utilizado típicamente variables dependientes agregadas con nivel de análisis organizativo, como pueden ser el retorno de ventas, cuota de mercado o nuevos clientes:

${ }^{2}$ En la literatura se ha definido una iniciativa TI como una implementación TI completamente nueva o una revisión mayor de un sistema existente que ha sido ejecutada explícitamente para mejorar la posición competitiva 
Tabla 2.3. Revisión de estudios desde el EBC que examinan el impacto de las TI en la ventaja competitiva

\begin{tabular}{|c|c|c|c|c|c|c|}
\hline Referencia & $\begin{array}{l}\text { Unidad de } \\
\text { análisis }\end{array}$ & $\begin{array}{l}\text { Variable } \\
\text { independiente }\end{array}$ & $\begin{array}{l}\text { ¿Se evalúa la } \\
\text { heterogeneidad } \\
\text { de recursos? }\end{array}$ & Variable dependiente & $\begin{array}{l}\text { ¿Se evalúa la ventaja } \\
\text { competitiva? }\end{array}$ & $\begin{array}{l}\text { ¿Se evalúa la } \\
\text { duración absoluta } \\
\text { de la ventaja? }\end{array}$ \\
\hline $\begin{array}{l}\text { Powell y Dent- } \\
\text { Micallef (1997) }\end{array}$ & La empresa & $\begin{array}{l}\text { Recursos humanos, } \\
\text { tecnológicos y de } \\
\text { negocio }\end{array}$ & No & $\begin{array}{l}\text { TI y desempeño general de la } \\
\text { organización }\end{array}$ & $\begin{array}{l}\text { Si }- \text { comparación con } \\
\text { competidores en un periodo } \\
\text { de tres años }\end{array}$ & No \\
\hline $\begin{array}{l}\text { Bharadwaj } \\
(2000)\end{array}$ & La empresa & Recursos TI & No & $\begin{array}{l}\text { Varias medidas de coste y } \\
\text { rentabilidad }\end{array}$ & $\begin{array}{l}\text { Si - Líderes TI versus grupo } \\
\text { de control }\end{array}$ & No \\
\hline $\begin{array}{l}\text { Santhanam y } \\
\text { Hartono }(2003)\end{array}$ & La empresa & Capacidades TI & No & $\begin{array}{l}\text { Varios ratios de coste y } \\
\text { beneficio }\end{array}$ & $\begin{array}{lrr}\text { Si } \quad \text { comparación } & \text { con } \\
\text { competidores sobre } & \text { un } \\
\text { periodo de dos/tres años } & \end{array}$ & No \\
\hline $\begin{array}{l}\text { Ravichandran y } \\
\text { Lertwongsatien } \\
(2005)\end{array}$ & La empresa & $\begin{array}{l}\text { Competencias } \quad \text { y } \\
\text { capacidades TI }\end{array}$ & No & $\begin{array}{l}\text { Rentabilidad, } \begin{array}{l}\text { productividad, } \\
\text { lanzamiento } \\
\text { productos }\end{array} \\
\text { de nuevos }\end{array}$ & $\begin{array}{llr}\mathrm{Si}-\text { comparación } & \text { con } \\
\text { competidores sobre } & \text { un } \\
\text { periodo de tres años } & \\
\end{array}$ & No \\
\hline $\begin{array}{l}\text { Bhatt y Grover } \\
(2005)\end{array}$ & La empresa & Capacidades TI & No & $\begin{array}{l}\text { Crecimiento de ventas y } \\
\text { desempeño financiero }\end{array}$ & $\begin{array}{llr}\mathrm{Si}-\text { comparación } & \text { con } \\
\text { competidores sobre } & \text { un } \\
\text { periodo de tres años } & \\
\end{array}$ & No \\
\hline $\begin{array}{l}\text { Rivard et al. } \\
(2006)\end{array}$ & La empresa & $\begin{array}{l}\text { Soporte TI para la } \\
\text { estrategia y activos } \\
\text { de la compañía }\end{array}$ & No & $\begin{array}{l}\text { Ingresos, cuota de mercado, } \\
\text { margen de beneficio, ROI, etc. }\end{array}$ & $\begin{array}{llr}\mathrm{Si}-\text { comparación } & \text { con } \\
\text { competidores sobre } & \text { un } \\
\text { periodo de tres años } & \\
\end{array}$ & No \\
\hline Lin (2007) & La empresa & Capacidades TI & No & $\begin{array}{l}\text { ROE, MVA, EVA, Q de } \\
\text { Tobin, etc. }\end{array}$ & $\begin{array}{l}\text { No - utilización de medidas } \\
\text { absolutas de desempeño } \\
\text { organizativo }\end{array}$ & No \\
\hline $\begin{array}{l}\text { Zhang et al. } \\
(2008)\end{array}$ & La empresa & Capacidades TI & No & $\begin{array}{l}\text { Desempeño internacional de } \\
\text { PYMEs chinas orientadas a la } \\
\text { exportación }\end{array}$ & $\begin{array}{l}\text { No - utilización de medidas } \\
\text { absolutas de desempeño } \\
\text { organizativo }\end{array}$ & No \\
\hline Chen (2012) & La empresa & $\begin{array}{l}\text { Recursos } \\
\text { Capacidades TI }\end{array}$ & No & $\begin{array}{l}\text { Retorno sobre capital, retorno } \\
\text { sobre inversión, beneficio neto } \\
\text { sobre ventas, etc. }\end{array}$ & $\begin{array}{l}\text { No - utilización de medidas } \\
\text { absolutas de desempeño } \\
\text { organizativo }\end{array}$ & No \\
\hline Yeh et al. (2012) & La empresa & Capacidades SI & No & $\begin{array}{l}\text { Desempeño general } \\
\text { negocio electrónico }\end{array}$ & $\begin{array}{l}\text { No - utilización de medidas } \\
\text { absolutas de desempeño } \\
\text { organizativo }\end{array}$ & No \\
\hline
\end{tabular}

Fuente: a partir de Doherty y Terry (2009) 
En la literatura existe consenso sobre la dificultad de detectar el impacto en la utilización de las TI, particularmente en términos de ventaja competitiva en medidas de desempeño organizativo (Brynjolfsson, 1993; Cavaye y Cragg, 1993). Contra esta dificultad, muchos investigadores han sugerido que el impacto debe medirse sobre el proceso o las actividades específicas de una organización (Ray et al. 2004; Melville et al. 2004). Algunos autores como Doherty y Terry (2009) han establecido una taxonomía de procesos genéricos para definir dicho impacto:

Tabla 2.4. Taxonomía genérica de procesos de negocio

\begin{tabular}{|c|c|}
\hline Procesos de operación & Referencia \\
\hline Diseño/desarrollo de nuevos productos o servicios & $\begin{array}{l}\text { Simon y Tellier } \\
(2011) \\
\text { APQC, } 2004 \\
\text { Pandya et al., } 1997\end{array}$ \\
\hline $\begin{array}{l}\text { Adquisición y almacenamiento de entradas requeridas para } \\
\text { la producción de productos o servicios }\end{array}$ & $\begin{array}{l}\text { APQC (2004) } \\
\text { Malone et al. (1999) }\end{array}$ \\
\hline Transformación de entradas en producto/servicio & $\begin{array}{l}\text { APQC, } 2004 \\
\text { Pandya et al., } 1997 \\
\text { Flower, } 1998\end{array}$ \\
\hline Marketing y venta de productos y servicios & $\begin{array}{l}\text { Nath et al. (2010) } \\
\text { Trainor et al. (2010) } \\
\text { APQC, } 2004 \\
\text { Pandya et al., } 1997\end{array}$ \\
\hline Entrega de productos o servicios(logística externa) & $\begin{array}{l}\text { Elgazzar et al. (2012) } \\
\text { APQC (2004) } \\
\text { Malone et al. (1999) }\end{array}$ \\
\hline Servicio al cliente y gestión de cuentas & $\begin{array}{l}\text { APQC, } 2004 \\
\text { Pandya et al., } 1997 \\
\text { Ray et al., } 2004\end{array}$ \\
\hline
\end{tabular}




\begin{tabular}{|l|l|}
\hline Procesos de operación & Referencia \\
\hline Procesos de gestión y apoyo & \\
\hline Desarrollo de visión y estrategia & $\begin{array}{l}\text { APQC, 2004 } \\
\text { Pandya et al., 1997 } \\
\text { Flower, 1998 }\end{array}$ \\
\hline Gestión y desarrollo del capital humano & $\begin{array}{l}\text { APQC, 2004 } \\
\text { Pandya et al., 1997 }\end{array}$ \\
\hline Gestión y desarrollo del conocimiento y TI & $\begin{array}{l}\text { Spraggon y Bodolica } \\
(2012)\end{array}$ \\
& $\begin{array}{l}\text { APQC, 2004 } \\
\text { Flower, 1998 } \\
\text { Pandya et al., 1997 }\end{array}$ \\
\hline Gestión de recursos financieros & $\begin{array}{l}\text { Elgazzar et al. (2012) } \\
\text { APQC, 2004 }\end{array}$ \\
\hline Gestión de relaciones externas & $\begin{array}{l}\text { Pandya et al., 1997 } \\
\text { Flower, 1998 }\end{array}$ \\
\hline
\end{tabular}

Fuente: a partir de Doherty y Terry (2009)

La literatura de dirección estratégica muestra que las actividades acometidas por una compañía varía en función de su estrategia de negocio (Tallon, 2007). En función de la estrategia definida por una empresa hará que ésta ponga más énfasis en un tipo de procesos u otros. El modelo de cadena de valor genérico utiliza un argumento similar para identificar cómo las organizaciones crean valor enfocándose a procesos particulares que son esenciales para llevar a cabo la estrategia seleccionada (Porter, 1985). Esto significa que en función de la estrategia seleccionada por una firma, algunos procesos de la cadena de valor serán más importantes que otros. Podemos utilizar este 
argumento para afirmar que el valor de negocio de las TI estará principalmente en dichos procesos (Tallon, 2007).

La hipótesis básica de esta tesis es que las organizaciones cuyos procesos clave o estratégicos sean susceptibles de mejora a través de las TI, y además, esta aplicación de las TI sea difícilmente imitable, podrán obtener ventajas competitivas sostenibles a través de las TI, y por tanto una estrategia TI innovadora podría obtener mejor resultados. Esto implica que debemos conocer la estrategia de negocio para identificar aquellos procesos críticos de la organización.

Una vez conocidos esos procesos críticos asociados a las actividades de mayor valor, habría que analizar si las TI añaden valor a esos procesos y si son fácilmente imitables o no. Puesto que el objetivo de esta tesis es obtener una mayor generalidad de sus conclusiones, y evitar una revisión demasiado específica de algunos procesos determinados, es interesante analizar si se pueden agrupar los procesos de forma genérica en términos de imitabilidad de las TI. A su vez, debemos vincular esta agrupación de procesos con el valor que suponen estratégicamente para una organización. Para delimitar este basto análisis, nos centraremos exclusivamente en analizar las distintas estrategias de negocio, para después analizar cómo se aplican las TI a las actividades clave de cada una de las posibles estrategias.

Si se considera las TI como fuente de ventaja competitiva o no da lugar a un posicionamiento estratégico respecto a las TI por parte de la organización, por lo que es necesario analizar qué estrategias seguir y determinar los procesos clave que, asociados a cada una de las estrategias, pueden ser más o menos imitables desde el punto de vista del enfoque EBC.

La agrupación de las actividades dependiendo de sus características y necesidades en TI no es sencilla. La especialización por actividades que da como resultado una departamentalización de la organización funcional es la clasificación más lógica y una de las utilizadas por los investigadores en TI. Por ejemplo, Chen (2012) utiliza esta clasificación de actividades en su análisis, también desde la perspectiva de recursos y 
capacidades, de la rentabilidad de las inversiones en la cartera de tecnologías en TI. En este estudio, tampoco las TI son consideradas como un fin en sí mismas sino como unas capacidades que activan otros aspectos competitivos. Así, observa como los recursos en TI tecnológicos, humanos y organizativos potencian y encuentran sinergias con otras capacidades, éstas agrupadas en operaciones, I+D y marketing.

Así pues, se pasa a describir dichas estrategias a continuación.

\subsubsection{Estrategias de Porter}

La estrategia es una parte esencial de cualquier plan de negocio efectivo. Utilizando una estrategia competitiva efectiva, una firma encuentra su nicho en la industria y aprende sobre sus clientes (Porter, 1980). Porter (1985) afirma que existen un conjunto de estrategias de negocio básicas (diferenciación, liderazgo en costes, enfoque) y una empresa desarrolla su cometido mejor en tanto en cuanto se enfoca en una de ellas. Sin embargo, muchos investigadores consideran que una combinación de estas estrategias pueden proporcionar la mejor opción para que una organización pueda obtener una ventaja competitiva (Cross, 1999; Karnani, 1984; Miller y Friesen, 1986; White, 1986; Hlavacka et al. 2001). Cualquiera que sea la estrategia escogida por una organización, ésta debe alinearse con las metas y objetivos para obtener una ventaja competitiva (Kippenberger, 1996; Surowiecki, 1999; Ross, 1999).

Aunque se han identificado varias tipologías de estrategias organizacionales a lo largo de las últimas décadas (Miles y Snow, 1978; Chrisman et al., 1988; Porter, 1980), las estrategias genéricas definidas por Porter han sido las más ampliamente tratadas en los libros de textos relacionados con estrategia competitiva (David, 2000; Miller, 1998; Thompson y Stickland, 1998) y en la literatura relacionada (Kim y Lim, 1988; Miller y Dess, 1993). En los trabajos de Porter (1980), el autor afirma que para que una organización asegure una posición de ventaja a largo plazo, ésta debe elegir entre una de las estrategias genéricas decididamente en lugar de "permanecer en el medio". 


\section{Estrategia de diferenciación}

La estrategia de diferenciación es una de las estrategias clave definidas por Porter (Reilly, 2002). Cuando una organización utiliza esta estrategia, se enfoca a proporcionar un servicio o producto único (Hyatt, 2001; Porter, 1980, 1985; Bauer y Colgan, 2001). De acuerdo a esta característica, si el producto o servicio es único, se obtiene una alta lealtad por parte del cliente (Porter, 1985; Cross, 1999).

La estrategia de diferenciación por producto cumple las necesidades del consumidor e incluye la personalización del producto. Esto permite a las organizaciones añadir un cargo adicional al producto. La estrategia de diferenciación está adecuadamente implementada cuando la compañía proporciona un valor único o superior al consumidor a través de la mejora de la calidad del producto, sus características o el soporte postventa. Las firmas que siguen una estrategia de estas características pueden establecer un precio más alto al producto fundamentado en las características del producto, el sistema de entrega del bien, la calidad del servicio o los canales de distribución. La calidad puede ser real o percibida, fundamentada en la moda o imagen o la marca. La estrategia de diferenciación apela a un consumidor sofisticado o con conocimiento interesado en adquirir productos o servicios únicos o de alta calidad y que está dispuesto a pagar por ello un precio más alto.

El paso clave para diseñar una estrategia de diferenciación es determinar qué hace a una compañía diferente de sus competidores (McCracken, 2002; Reilly, 2002; Berthoff, 2002; Tuminello, 2002). Estos factores incluye la calidad del trabajo en el sector, la dimensión de la empresa, la imagen, el grafismo, la involucración de las organizaciones clientes, el producto, el sistema de distribución o la estrategia de marketing (McCracken, 2002; Davidson, 2001). Para ser efectivo, el mensaje de diferenciación debe alcanzar a los clientes (McCracken, 2002), ya que la percepción de la compañía que tiene el cliente es importante (Berthoff, 2002; Troy, 2002). 
Cuando se utiliza la diferenciación, el precio no es el factor principal (Hlavacka et al., 2001). Al percibir los consumidores que el producto o servicio es único, se genera una lealtad hacia la compañía y están dispuestos a pagar un precio más elevado por sus productos (Cross, 1999).

\section{$\underline{\text { Estrategia de liderazgo en costes }}$}

Otras de las estrategias genéricas de Porter es la estrategia de liderazgo en costes. Esta estrategia está enfocada a obtener ventajas competitivas teniendo los costes más bajos de la industria (Porter, 1979, 1987, 1996). Para conseguir esta ventaja, una organización debe mantener una estrategia de costes bajos permanente, una producción de costes bajos y una plantilla comprometida con esta estrategia (Malburg, 2000; Davidson, 2001). Para conseguir un liderazgo en costes, la empresa debe tener una amplia cuota de mercado (Hyatt, 2001).

La consecución de este tipo de liderazgo se puede conseguir a través de la implementación estrategias en diferentes áreas funcionales de la organización: generación de economías de escala, producciones en masa, distribución en masa, utilización de la tecnología para generar eficiencia en los procesos, utilización eficiente de la capacidad, etc. (Malburg, 2000; Davidson, 2001). Porter (1980) postula que sólo una empresa en una industria puede ser la líder en costes.

La disminución de costes y la ventaja en costes es el resultado de procesos de innovación, mejoras en la curva de aprendizaje, economías de escala y reducciones de tiempo y costes de fabricación así como actividades de reingeniería. Una estrategia de este tipo es efectiva cuando la organización es capaz de diseñar, producir y poner en el mercado un producto más eficientemente que sus competidores. El hecho de que una firma tanga acceso a materias primas o tecnología diferencial puede suponer un elemento clave para la consecución o mantenimiento de dicho liderazgo.

La organizaciones que buscan esta estrategia no tienen por qué sacrificar beneficios para serla líder en costes, puesto que los beneficios vienen derivados de la obtención de una 
amplia cuota de mercado (Porter, 1987, 1996). Los precios más bajos supondrán mayor demanda y consecuentemente mayor cuota de mercado (Helms et al., 1997). Como líder en costes, una organización puede generar barreras contra la entrada de nuevos competidores, ya que éstos necesitarían elevadas cantidades de capital para entrar en el mercado (Hyatt, 2001). Sin embargo, esta estrategia tiene inconvenientes, principalmente la escasa lealtad a la marca que se genera en el consumidor y el hecho de que, una excesiva reducción de precios podría suponer un pérdida relevante de ingresos (Cross, 1999).

Muchos estudios concluyen que la estrategia de liderazgo en costes es la que peores resultados arroja en términos de desempeño y requiere ser complementada con otras estrategias como la de diferenciación para ser verdaderamente efectivas (Robinson y Pearce, 1988; White, 1986). Las empresas que persiguen esta estrategia tienden a orientarse hacia la estandarización y la producción en masa y estas acciones pueden ser fácilmente imitadas.

\section{$\underline{\text { Estrategia de enfoque }}$}

En la estrategia de enfoque, la empresa se dirige a un segmento específico de mercado (Davidson, 2001; Porter 1979, 1987,1996). La empresa puede elegir entre enfocarse a un grupo de clientes seleccionados, a un rango de producto, a un área geográfica o a una línea de servicio (Anon, 1998; Hyatt, 2001, McKraken, 2002). La estrategia de enfoque está basada en adoptar un foco estrecho de competencia dentro de una industria. Esta estrategia busca elevar la cuota de mercado a través de la operación en nichos de mercado que no tienen atractivo o que han sido pasados por alto por los grandes competidores el mercado. Estos nichos pueden surgir por diferentes elementos como puede ser la geografía, las características de los compradores o los requisitos o especificaciones del producto. Una estrategia de enfoque exitosa (Porter, 1980) depende de que el segmento elegido sea lo suficientemente amplio como para tener potencial de crecimiento para la organización pero no tanto como para que sea clave para los principales competidores. Estrategias de penetración de mercado o de desarrollo de 
mercado pueden ser estrategias de enfoque. Las empresas de tamaño medio y grande utilizan estrategias de enfoque pero combinándolas con estrategias genéricas de diferenciación y liderazgo en costes. No obstante, las estrategias de enfoque son más efectivas cuando los consumidores o clientes tienen preferencias distintas y cuando el nicho no ha sido explotado por empresas rivales (David, 2000).

\section{Combinación de estrategias}

Una organización puede optar por utilizar una combinación de estrategias utilizando y mezclando las diferentes estrategias genéricas mencionadas. Una organización podría utilizar por ejemplo una estrategia de diferenciación enfocada a un nicho de mercado concreto o bien podría buscar un liderazgo en costes enfocado a un grupo de clientes con necesidades particulares.

Se ha debatido mucho sobre si una organización puede o no tener una estrategia de diferenciación y liderazgo en costes simultáneamente (Helms et al., 1997). Porter consideró que las estrategias de diferenciación y liderazgo en costes son mutuamente excluyentes (Helms et al., 1997; Campbell-Hunt, 2000). Sin embargo, la investigación muestra que no es así (Dess y Miller, 1993; Gupta, 1995; Hlavacka et al. 2001). Kumar et al. (1997), en su estudio de la utilización de las estrategias genéricas utilizadas en la industria hospitalaria encontró que cuando los hospitales siguen una estrategia de liderazgo en costes y de enfoque muestran mejores resultados en términos de desempeño que aquellos que utilizan estrategias exclusivamente de diferenciación o liderazgo en costes. De forma similar, Richardson y Dennis (2003) encontraron que utilizar una estrategia híbrida de enfoque y diferenciación era la mejor opción para segmentos específicos. Spanos et al. (2004) estudió la industria de fabricación griega y encontró que las estrategias híbridas arrojaban mejores resultados que estrategias puras. Este debate todavía está abierto en la literatura. 


\subsection{Estrategia TI como moderador de la estrategia competitiva en el desempeño: hipótesis de trabajo}

La revisión de la bibliografía previa al desarrollo del presente trabajo de investigación nos hizo entender que pueden existir unas estrategias TI que funcionen mejor para unas determinadas actividades, y si estas actividades son clave para una determinada estrategia competitiva, esto se reflejará en un mejor desempeño de esta estrategia competitiva y consecuentemente arrojará mejores resultados. A partir de todo lo expuesto en el presente capítulo, podemos decir que los estudios desarrollados no arrojan resultados concluyentes en cuanto a la pregunta de investigación nuclear del presente trabajo: ¿qué papel moderador tiene la estrategia TI entre la estrategia competitiva y el desempeño? O dicho de otra manera, ¿qué combinación de estrategia TI y estrategia competitiva arroja mejores resultados en términos de desempeño? La justificación de las hipótesis requerirá una reflexión de síntesis. Con esta idea, y en función de lo anteriormente expuesto, que constituye el marco teórico sobre el que se sustenta la presente investigación, vamos a establecer las hipótesis del presente trabajo.

Como ya hemos mencionado anteriormente, la hipótesis básica de esta tesis es que las organizaciones cuyos procesos clave o estratégicos sean susceptibles de mejora a través de las TI, y además, esta aplicación de las TI sea difícilmente imitable, podrán obtener ventajas competitivas sostenibles a través de éstas, y por tanto una estrategia TI innovadora podría obtener mejor resultados. Esto implica que debemos conocer la estrategia de negocio para identificar aquellos procesos críticos de la organización.

Una vez conocidos esos procesos críticos, necesitaremos analizar si las TI añaden valor a esos procesos por un parte y si son fácilmente imitables o no. Puesto que el objetivo de esta tesis es obtener una mayor generalidad de sus conclusiones, y evitar una revisión demasiado específica de determinados procesos, es necesario determinar si se pueden agrupar las actividades de negocio de forma genérica en términos de imitabilidad de las TI. A su vez, será necesario vincular esta agrupación de actividades con el valor que suponen estratégicamente para una organización. Para delimitar este análisis, nos 
centraremos exclusivamente en analizar las distintas estrategias de negocio, para después analizar cómo se aplican las TI a las actividades clave de cada una de las posibles estrategias.

Aunque existen multitud de trabajos en la línea de determinar el impacto de la utilización de las TI en el desempeño empresarial no es tan frecuente encontrar estudios que analicen el impacto de la adopción de una estrategia TI en dicho desempeño (Tallon, 2007; Chen, 2010). Podemos afirmar que en términos generales existe un consenso en cuanto al efecto positivo del valor de las TI en términos de ventaja competitiva y desempeño si tenemos en cuenta los recursos organizativos complementarios. Sin embargo no hay un consenso definitivo en la cuestión del valor de negocio de las TI en función del tipo de actividades de negocio y en su extensión a las estrategias competitivas que estas actividades sustentan.

El EBC proporciona un conjunto de condiciones necesarias para la consecución de ventajas competitivas vía la adquisición de recursos y competencias, pero no especifica los mecanismos que subyacen y por los que éstas son adquiridas. La investigación vinculada a las capacidades dinámicas sugiere que una empresa puede desarrollar capacidades superiores a través de mecanismos de aprendizaje, incluyendo la repetición, la experimentación e incluso el análisis de los errores cometidos (Eisenhardt y Martin, 2000). Consecuentemente, el aprendizaje organizativo es dependiente del camino seguido y en el caso que nos ocupa se generará en presencia de las TI y a través del desarrollo de iniciativas donde las TI sean un elemento estratégico. La generación de barreras competitivas a erosionar y los factores de retrasen su replicabilidad permitirán postular la ventaja de seguir una estrategia TI innovadora o conservadora.

Llegados a esta fase del trabajo, se presenta a continuación el modelo teórico que posteriormente se contrastará empíricamente y que se desprende del análisis efectuado. Para ello, se expondrán a continuación brevemente las principales aportaciones de estudios anteriores a partir de los cuales se ha construido cada una de las hipótesis del modelo: 


\subsubsection{Estrategia TI innovadora}

Las organizaciones que continuamente persiguen las innovación TI es más probable que creen y capitalicen capacidades TI únicas que potencialmente permitan a éstas disfrutar de ventajas competitivas sobre sus competidores (Li et al. 2006).

Sin embargo, mientras que una estrategia TI innovadora es más probable que aporte una ventaja competitiva para una empresa, esta estrategia es más costosa y más arriesgada que una estrategia conservadora (Chen, 2010). Dicho de otra manera, los potenciales riesgos y beneficios para una organización que persigue una estrategia innovadora es contingente con su habilidad para llevarla a cabo con éxito (Galliers, 2004). Una organización que desarrolle una estrategia TI innovadora necesita asegurar que puede desarrollarla con éxito puesto que de otro modo será poco probable que le suponga una ventaja posicional relativa respecto a sus competidores (Cooper, 1979; Day, 1990; He y Wong, 2004). Aunque el objetivo es ganar una ventaja competitiva a través de innovar con las TI los riesgos de fracaso que supone puede revertir en resultados adversos en términos financieros y organizativos (Leidner y Mackay, 2007). De esta manera, las organizaciones que no están bien posicionadas para ser líderes TI se pueden beneficiar de adoptar una estrategia conservadora.

Stratopoulos y $\operatorname{Lim}(2007,2008,2010)$ analizaron la utilización de una estrategia innovadora por parte de las principales firmas americanas y concluyeron que aquellas compañías que mantienen una estrategia TI innovadora y que suele superar a sus competidoras en innovación TI un año, es muy probable que en sucesivos periodos mantenga dicha ventaja y que aquellas que utilizan una estrategia TI innovadora un año es más probable que sean innovadoras el año siguiente que el que una empresa que no ha sido innovadora se convierta en innovadora. Dicho de otra manera, la innovación TI es persistente. En el contexto de la teoría de capacidades dinámicas, esto quiere decir que el mantener una estrategia innovadora TI permite generar una capacidad de innovación TI que es un recurso valioso, heterogéneo y distribuído. El autor concluye 
que las empresas con una estrategia TI innovadora tienen niveles superiores de desempeño que las que no la adoptan. No obstante, remarca el efecto moderador del sector o industria, puesto que para unos sectores la adopción de las TI son la base de la estrategia competitiva mientras que para otros la adopción de las TI es algo menos que una necesidad estratégica.

\subsubsection{Estrategia TI conservadora}

Las empresas que persiguen una estrategia TI conservadora, es decir, que siguen las mejores prácticas establecidas por los líderes de la industria en la que opera limitan su habilidad para crear el conocimiento requerido para responder a los imperativos dictados por el entorno (Galliers, 2006). Consecuentemente, esta aproximación estable y segura hace que la organización que siguiera esta estrategia TI cediera la oportunidad de derivar una ventaja competitiva a través de los Sistemas de Información puesto que es poco probable que pudiera desarrollar recursos y capacidades nuevas y singulares.

Sin embargo, una estrategia TI conservadora no es necesariamente inferior a una estratega TI innovadora en términos de impacto en el desempeño empresarial (Chen et al, 2010). A través de la evaluación de los movimientos competitivos de los competidores que mantienen una estrategia innovadora, las organizaciones que adoptan una estrategia TI conservadora pueden calibrar los éxitos y fracasos de los líderes TI y ajustar su propia estrategia TI de acuerdo a estas observaciones. Por otra parte, a través de una estrategia enfocada en proporcionar unas operaciones TI eficientes y efectivas en costes los conservadores se especializan en reducir los fallos en los sistemas TI y en gestionar la calidad y fiabilidad de los sistemas para la organización, todo lo cual tiene un impacto en el desempeño de la organización (Bharadwaj, 2000; Ross et al., 1996; Wade y Hulland, 2004).

Cegielsky et al (2005) analizaron la estrategia de integración de TI emergentes en las principales firmas norteamericanas. En el estudio desarrollado con los principales 
ejecutivos de estas firmas, concluyeron que, dada la rápida evolución tecnológica en las TI, la utilización de soluciones comerciales en exclusiva puede suponer una rápida obsolescencia de esta estrategia. En este análisis también se pone de manifiesto la importancia de un adecuado alineamiento, tanto desde la perspectiva de negocio como técnica, entre las soluciones a incorporar y las existentes.

\subsubsection{Estrategia competitiva de diferenciación por innovación}

La estrategia de diferenciación por producto o proceso está vinculada a la generación de un producto superior a lo existente en el mercado o "único", bien sea en términos de calidad o de imagen. Miller y Friesen (1986) miden esta estrategia en términos de producto o servicio de calidad superior, imagen de producto y ratio de nuevos productos lanzados.

La estrategia que se enfoca en la innovación también requerirá algún grado de flexibilidad en su estructura organizativa (Blumentritt y Danis 2006). La existencia de canales de comunicación abiertos, la descentralización de la estructura, descripciones de trabajo poco identificadas, la toma de decisiones distribuída o la flexibilidad en los procesos y procedimientos están asociadas con la actividad de innovación (Mintzberg, 1979). Según Tallon (2007), las empresas que tienen un enfoque de diferenciación por innovación obtendrán un mayor valor de negocio de las TI en el desarrollo de nuevos productos y en los procesos de I+D.

Para que una organización pueda desarrollar una capacidad de innovación sostenible en el tiempo, así como incorporar la innovación como un componente clave de su estrategia de diferenciación, debe generar recursos y competencias para la generación de nuevos productos y proporcionar procesos y estructuras colaborativas para resolver problemas de forma creativa y conectar las innovaciones con los negocios existentes (Bhaskaran, 2006). De esta manera, las TI se postulan como un elemento vital para construir esta capacidad (King y Burgess, 2006). Según Frishammar y Hörte (2005), el desempeño se verá mejorado cuando la actividad innovadora de una organización sea 
complementada con iniciativas TI que resulten en la introducción sistemática de nuevos procesos y productos que encajan con los procesos existentes, promoviendo un incremento de la lealtad del cliente y estimulando la demanda para otros productos.

Dibrell et al. (2008) encontraron que una organización que pone énfasis en la innovación está directamente vinculada en la importancia que se le da a las TI. Por otra parte, Song y Song (2010) demuestran que la utilización de las TI reducen el impacto negativo de la separación física, la incongruencia de metas y las diferencias culturales de los equipos de marketing y de $\mathrm{I}+\mathrm{D}$, por lo que puede ser un arma de mejora para la integración de $\mathrm{I}+\mathrm{D}$ y marketing.

Sin embargo Durmusuglu et al. (2006) encuentran que el uso de las TI no tiene un efecto en la velocidad y calidad en el proceso de desarrollo de nuevos productos y apuntan a que las empresas involucradas en el estudio no son capaces de asimilar ${ }^{3}$ las TI que incorporan. Armstrong y Samabamurthy (1999) argumentan que no todas las firmas son capaces de aplicar con igual efectividad las TI en sus procesos de negocio.

Song et al. (2005) encuentran que en las empresas de alta tecnología la aplicación de las TI tiene un impacto positivo directo en la aplicación del conocimiento, pero que sin embargo, la aplicación de estas tecnologías puede resultar costosa. Durmusoglu et al. (2006) encuentran este mismo hecho para empresas manufactureras.

Croteau y Bergueron (2001) analizaron el impacto del desarrollo tecnológico TI a partir de la tipología estratégica de Miles y Snow (1978). En este estudio encontraron que para los prospectores, aun siendo una estrategia orientada a ser los líderes innovadores en su industria en cuanto al desarrollo de nuevos productos y servicios, la tecnología no era el principal contribuyente al desempeño organizacional. La explicación que dan los autores es que las organizaciones desarrollan capacidades orientadas a encontrar nuevas ideas, lanzar nuevos productos y están más abiertas a la adopción de riesgos que a

\footnotetext{
${ }^{3}$ Armstrong y Sambamurthy (1999) definen este concepto como el grado de éxito de una empresa en hacer uso de las capacidades TI y consecuentemente mejorar el desempeño
} 
buscar y aplicar TI para obtener ventajas competitivas. Los autores afirman que es la excelencia en las anteriores actividades estratégicas lo que les permite obtener un mejor desempeño organizativo, no su conocimiento de la tecnología.

Todos estos resultados llevan a una situación ambigua respecto a la mejor estrategia en TI en las actividades de I+D. Por lo general, si se considera un sector en el que las TI son un elemento en el diseño de nuevos productos con una alta componente de integración de éstas, una estrategia innovadora en TI, soportada por el desarrollo de las competencias en TI de la organización acorde a los objetivos, tanto en infraestructura como en el departamento de sistemas de información, es una estrategia generadora de ventajas competitivas. La replicabilidad e imitación está dificultada por la integración de las TI al producto. Sin embargo, estas circunstancias dependen del sector que se considere. En un sector donde las TI funcionen como soporte a la I+D, y no como el núcleo central de la innovación, una estrategia innovadora TI aumenta los riesgos e incertidumbre de los resultados, pudiendo resultar contraproducente. Los riesgos asociados a una doble innovación siempre son más altos.

Respecto a la imitabilidad de las TI, los procesos de soporte a la innovación como las aplicaciones de gestión del conocimiento, tratamiento de información, etc., desde un punto de vista de infraestructura son fácilmente replicables, y dependen más de competencias organizativas para su uso que del propio departamento de sistemas de información. Esto garantiza en cierta manera la dificultad en su réplica, por lo que sí pueden ser fuente de ventaja competitiva las TI, pero no por su innovación, sino por su combinación con otras competencias. Esto supone además que una estrategia innovadora en TI basada en las competencias en TI de la organización por sí sola no garantiza su éxito en actividades de gestión de la información y del conocimiento. Así pues, no existe una conclusión generalizable para todos los sectores respecto a la mejor estrategia TI para las actividades de I+D, aunque para aquellos en que las TI no formen parte del diseño del producto se puede decir que una estrategia en TI innovadora será negativa por acumular riesgos en una actividad ya de por sí compleja, o en todo caso no significativa. 
Esto nos lleva a formular la siguiente hipótesis:

Hipótesis 1: Una estrategia TI innovadora modera negativamente la relación de estrategia competitiva de diferenciación por innovación y el desempeño organizativo.

Como ya se ha comentado, esta hipótesis debe ser tomada con cautela, pues dependen mucho del tipo del sector e integración de las TI en el diseño de productos.

Paradójicamente, una estrategia conservadora TI tampoco tiene por qué tener efectos positivos. En primer lugar, si las TI forman parte del diseño del producto, una estrategia conservadora en TI sería completamente contraproducente. Pero para aquellos sectores donde las TI no están incorporadas a los productos, una estrategia TI conservadora debe estar respaldada por competencias organizativas.

En este tipo de innovaciones, la dificultad de su imitación depende más de las competencias organizativas y cultura de la organización que de las propias competencias en TI de la organización. Puesto que este estudio se centra exclusivamente en la estrategia en TI y no considera otras variables, su moderación en la relación entre la estrategia de negocio basada en innovación y desempeño debe tener una relación ambigua, exceptuando aquellos sectores con alto componente en TI en el diseño del producto. Por lo tanto no se puede formular una hipótesis de mejor estrategia en TI para la estrategia de negocio basada en innovación de manera contundente sin revisar otros aspectos organizativos.

Hipótesis 2: Una estrategia TI conservadora NO modera la relación de estrategia competitiva de diferenciación por innovación y el desempeño organizativo. 


\subsubsection{Estrategia competitiva de diferenciación por marketing}

La estrategia de diferenciación en marketing tiene como objetivo una mayor vinculación con el cliente enfatizando la creación de vínculos de fidelización con éste a través de publicidad, servicios complementarios o adecuados canales de distribución (Miller et al., 1988:549). Consecuentemente, una organización que adopte una estrategia de este tipo, debe crear nuevas capacidades en este ámbito a partir de la combinación de los recursos TI y los recursos de marketing.

Las organizaciones pueden mejorar la adquisición y retención de los clientes integrando las TI en sus prácticas de marketing para fomentar interacciones más ricas y complejas con lo clientes o consumidores (Brodie et al., 2007). Según Trainor et al. (2010), esta asimilación de TI y marketing se ha denominado en la literatura comúnmente como "emarketing". Estas capacidades representan la competencia de utilización de una organización de Internet y otros elementos TI para facilitar interacciones enriquecidas con los clientes. Estas interacciones proporcionan a los clientes acceso a los recursos e información de la organización al mismo tiempo que proporciona a la organización información sobre sus clientes. De acuerdo con Brodie et al. (2007), las TI del emarketing se extienden más allá de las comunicaciones y publicidad basada en Internet para incluir tecnologías que dan soporte a varias funciones del marketing, incluyendo la gestión de la relación con el cliente, la actividad de ventas, el soporte al cliente y la planificación e investigación en marketing (Brady et al., 2002).

En relación a las capacidades vinculadas a esta estrategia, Nath et al. (2010) encuentran que las capacidades de marketing dependen de la habilidad para entender las necesidades del cliente y crear relaciones a largo plazo.

Bharadwaj et al. (2009) encuentran que el mercado responde más negativamente a fallos de implementación en los nuevos sistemas TI que a los fallos operativos asociados a los sistemas existentes. Esto supone un riesgo importante par las empresas que operan asumiendo una estrategia de diferenciación a través de marketing, por lo que en este 
sentido, la asunción de riesgos que supone el adoptar una estrategia TI innovadora puede no compensar el impacto de un fracaso en el desarrollo de estas iniciativas.

Estudios como el de Levis et al., (2003) ponen de manifiesto que una estrategia habilitada por las TI es considerada opaca, en términos de reconocimiento del mercado.

La aplicación de una estrategia TI innovadora a una organización con una estrategia competitiva de diferenciación por marketing en un sector como el industrial agroalimentario, donde los costes de conexión son inexistentes así como las características estructurales del sistema de valor supone asumir riesgos en términos de ventaja competitiva y desempeño es contraproducente. Por otra parte, la visibilidad de estas iniciativas hace que el tiempo de respuesta de los competidores se reduzca para este tipo de iniciativas, siendo más fácil y rápida su replicabilidad.

Estos resultados nos llevan a formular la siguiente hipótesis:

Hipótesis 3: Una estrategia TI innovadora modera negativamente la relación de estrategia competitiva de diferenciación por marketing y el desempeño organizativo.

Hipótesis 4: Una estrategia TI conservadora modera positivamente la relación de estrategia competitiva de diferenciación por marketing y el desempeño organizativo.

\subsubsection{Estrategia competitiva de liderazgo en costes}

Una estrategia de liderazgo en costes persigue la máxima eficiencia en las operaciones, mediante economías de escala, economías de experiencia y de aprendizaje, optimizando la capacidad, con bajos costes laborales o el acceso favorable a materias primas, entre otros aspectos (Grant, 1999: 225-238). Según Porter (1980) esta estrategia requiere de la construcción de un mercado vía precios agresivos para la maximización de dichas economías de escala, el diseño de productos de fácil manufactura, la utilización de equipamiento moderno y la inversión en $\mathrm{I}+\mathrm{D}$ tecnológico asociado a la producción. Las variables consideradas como paradigmáticas son la diferencia de precio (el líder en 
costes puede cargar precios más bajos que sus competidores), la integración vertical (reduciendo los costes indirectos o generales de distribución utilizando distribuidores), la novedad de la planta productiva y su equipamiento (una planta moderna y eficiente reduce los costes de producción), la utilización de la capacidad (una elevada utilización de la capacidad contribuye a la eficiencia), los costes directos y los procesos de I+D o de valor añadido (inversión en asegurar una planta productiva y un equipamiento productivo) (Miller y Friesen, 1988).

Esta estrategia supone un elevado riesgo, siendo el mayor riesgo la caída en un círculo vicioso de bajada de precios y rotura de márgenes, por lo que existe en la literatura un consenso en cuanto a que esta estrategia no es viable por sí misma y necesita ser complementada por otro foco para ser verdaderamente efectiva (White, 1986). Las firmas que persiguen esta estrategia tienden a centrarse en actividades de producción en masas y estandarización que pueden ser fácilmente imitables. Los clientes son muy sensibles al precio y tienen bajos niveles de lealtad a la marca (Krell y Matook, 2009).

Tallon (2007) postuló que para una estrategia de liderazgo en costes, el mayor valor que aportan las TI están en los procesos relacionados con las relaciones con proveedores, la producción y las operaciones.

En este sentido, la incorporación de tecnologías de la información orientadas a estas actividades mejoran la eficiencia del procesamiento de la información y permiten un intercambio de información más rápido con los colaboradores de la organización (Bhardan, 2007).

Wade y Hulland (2004) postulan que los sistemas de información para la gestión de operaciones mejoran las capacidades de las operaciones de las plantas productivas haciendo éstas más efectivas en costes.

Los EMS (Enterprise Management Systems) proporcionan capacidades interorganizacionales para la toma de decisión conjunta con los partners de negocio, bien sean clientes o proveedores, mejorando la involucración de los proveedores en la 
gestión de los pedidos y los procesos logísticos (Mithas et al., 2005; Ramasubbu et al., 2008). Por ejemplo, las aplicaciones de la tecnología RFID (Radio Frecuency Identification Device) permite a las organizaciones trabajar con redes de proveedores y "partners" e impulsar el desarrollo de capacidades para ofrecer una respuesta rápida y flexible que pueda encajar con la volatilidad del mercado (Whitaker et al. 2007).

Otros estudios también avalan esta hipótesis. Por ejemplo, Wu et al. (2006), también desde la respectiva de recursos y capacidades, consideran que las capacidad en TI generadas en la cadena de suministros son específicas a la empresa, y por tanto difíciles de imitar. Estas capacidades, por tanto, pueden servir como catálisis en la transformación de los recursos en TI en un gran valor para la empresa. Por lo tanto, una inversión en capacidad en TI de la empresa para generar las propias aplicaciones es positiva en los procesos de la cadena de suministros.

La generación de iniciativas estratégicas TI innovadoras vinculadas a estas actividades permitirá construir capacidades difíciles de imitar por los competidores. Estas iniciativas generan barreras competitivas y factores de retraso en su replicabilidad elevados, puesto que los costes de conexión, las inversiones co-especializadas tangibles e intangibles son elevadas.

Por todo ello formulamos las siguientes hipótesis:

Hipótesis 5: Una estrategia TI innovadora modera positivamente la relación de estrategia de liderazgo en costes y el desempeño organizativo.

Hipótesis 6: Una estrategia TI conservadora modera negativamente la relación de estrategia de liderazgo en costes y el desempeño organizativo.

Por último, quedaría hacer una reflexión sobre aquellas empresas que no tengan una estrategia en TI definida. Esto implicaría no obtener nunca las ventajas de una estrategia definida, ya sea conservadora o innovadora en TI, mientras que compartirían muchos de 
sus inconvenientes. Por tanto, la moderación de una falta de estrategia en TI es siempre negativa en la relación estrategia competitiva y desempeño.

\subsubsection{Resumen de las hipótesis}

Hipótesis 1: Una estrategia TI innovadora modera negativamente la relación de estrategia competitiva de diferenciación por innovación y el desempeño organizativo

Hipótesis 2: Una estrategia TI conservadora NO modera la relación de estrategia competitiva de diferenciación por innovación y el desempeño organizativo.

Hipótesis 3: Una estrategia TI innovadora modera negativamente la relación de estrategia competitiva de diferenciación por marketing y el desempeño organizativo.

Hipótesis 4: Una estrategia TI conservadora modera positivamente la relación de estrategia competitiva de diferenciación por marketing y el desempeño organizativo.

Hipótesis 5: Una estrategia TI innovadora modera positivamente la relación de estrategia de liderazgo en costes y el desempeño organizativo.

Hipótesis 6: Una estrategia TI conservadora modera negativamente la relación de estrategia de liderazgo en costes y el desempeño organizativo. 
Pág. 154 de 329 


\section{METODOLOGÍA Y DISEÑO DE LA INVESTIGACIÓN}


Pág. 156 de 329 


\section{METODOLOGÍA Y DISEÑO DE LA INVESTIGACIÓN}

\subsection{Objetivos y contenido del capítulo}

Lo expuesto en el apartado anterior mediante las hipótesis planteadas esquematiza de manera sustancial el contenido de los dos capítulos precedentes, que constituyen el cuerpo teórico sobre el que se asienta este trabajo y que trataremos de contrastar con una adecuada investigación empírica. De esta manera, el objetivo principal de este capítulo es abordar las cuestiones relacionadas con el diseño de dicha investigación empírica, investigación que permitirá contrastar las hipótesis planteadas en el anterior capítulo.

El diseño de la investigación puede catalogarse como un plan básico que guía las etapas de recolección de datos y el análisis del proyecto (Kinnear y Taylor, 1993: 127). Este diseño debe ser acorde con los objetivos planteados y con el modelo conceptual. Se debe especificar el tipo de información que se requiere, las fuentes de datos y los procedimientos utilizados para su recolección.

El primer epígrafe (epígrafe 3.2) trata dos cuestiones básicas a abordar en el diseño de la investigación empírica: la delimitación de las unidades de observación y el ámbito de estudio. La determinación del ámbito de estudio debe estar en consonancia con los objetivos propuestos. Por tanto, su elección está condicionada por la necesidad de seleccionar un conjunto de empresas del sector agroalimentario. Posteriormente se hace una descripción de dicho sector (epígrafe 3.3).

En el siguiente epígrafe (3.4) se justifica la elección de un método cuantitativo para esta investigación y la encuesta como método de recogida de datos.

En el epígrafe 3.5 se lleva a cabo una revisión y posterior selección, de las distintas escalas existentes en la literatura de los conceptos utilizados en el modelo. Se analizarán las distintas escalas utilizadas para los conceptos de estrategia competitiva, estrategia TI 
y desempeño, por ser los conceptos claves en este trabajo, haciendo un análisis general sobre el diseño de instrumentos de medida en las ciencias sociales.

En el epígrafe 3.6 se desarrolla el diseño de la encuesta, se definen las características de la muestra y se explica el trabajo de campo.

Para acabar el capítulo, en el epígrafe 3.7, justificamos la metodología analítica empleada (modelos de ecuaciones estructurales) para el contraste de las hipótesis, determinada por los objetivos del trabajo y la naturaleza de los datos.

\subsection{Unidades de observación y ámbito del estudio}

Las unidades de observación se pueden definir como las realidades que se pretende observar, constituyendo el objeto global del estudio, ya que de ellas se obtienen los datos empíricos necesarios para contrastar las hipótesis con la realidad (Sierra, 1995). Estas hipótesis expresan, mediante términos de unión, relaciones entre variables referidas a unidades de observación determinadas (Devece, 2004).

Para describir adecuadamente las unidades de observación, se hace necesario establecer las realidades que se desean observar, y los datos que se desean obtener a partir del estudio empírico. La realidad que pretendemos observar en nuestro estudio es el efecto de la estrategia TI como variable moderadora del efecto de la estrategia competitiva de una organización en el desempeño.

La empresa constituye una entidad organizativa que toma sus propias decisiones en materia de estrategia TI. Como hemos comentado en el segundo capítulo del presente trabajo, existen argumentos y evidencias empíricas en la literatura que sugieren que una adecuada estrategia TI tiene efectos positivos sobre el desempeño. Puesto que el objetivo principal de esta investigación es verificar la existencia de esta relación de moderación, la unidad de análisis que vamos a considerar es la empresa. Se trata de la 
unidad de análisis más frecuente de los trabajos empíricos en el campo de la Dirección Estratégica.

Puesto que con el presente trabajo se busca un elevado impacto y dada el escaso número de trabajos de esta naturaleza en el ámbito industrial, el ámbito del estudio se ha centrado en el primer sector industrial de la economía española (FIAB, 2011) y de Europa (Fundetec, 2010, CIAA, 2008) y tradicionalmente poco estudiado desde el punto de vista de las TI: el sector agroalimentario.

Es usual encontrar este tipo de análisis sectoriales en los trabajos empíricos vinculados con la utilización estratégica de las TI. Adicionalmente, la literatura recomienda el acotamiento sectorial dado que facilita la identificación y la medición de los recursos más críticos de las empresas (Dess, Ireland y Hitt, 1990; Hitt et al., 2001), estableciendo además cierta homogeneidad en cuanto a los indicadores tecnológicos y económicos (Santarelli y Piergiovanni, 1996).

\subsection{El sector agroalimentario español}

En términos generales podemos decir que el sector agroalimentario está compuesto por dos grandes grupos de actividades: por una parte, el sector primario, es decir, el conjunto de actividades formado por la agricultura, la ganadería, la silvicultura y la pesca; por otro lado, la industria agroalimentaria, en la que se incluyen aquellas empresas o actividades en las que se produce una transformación de las materias primas agrícolas o ganaderas, más allá de la mera distribución, incorporando en el proceso un valor añadido y dando lugar a productos elaborados o semielaborados. Es posible añadir también el sector de la distribución en lo que podríamos denominar "hipersector" agroalimentario. 
Considerando únicamente la componente industrial de este sector (sector industrial de alimentación y bebidas), que es donde está centrada la parte empírica del presente trabajo y teniendo en cuenta los datos del informe FIAB (2009), España cuenta con 30.261 empresas, una cifra de ventas global de 81.369 millones de euros y 445.475 empleados, aportando el $17 \%$ del empleo industrial. Es el segundo sector industrial en exportaciones, sólo por detrás del sector de la automoción, exportando un $79 \%$ del total de las exportaciones a la Unión Europea, un 7\% a Latinoamérica, 7\% a Asia, un 6\% a EEUU y Canadá y un 5\% al resto de Europa.

Desde el punto de vista sectorial europeo, España es el quinto país en ventas netas según CIAA de las industrias agroalimentarias, por detrás de Francia, Alemania, Italia y Reino Unido y es el 8\% del PIB español. Un desglose de las principales magnitudes del sector podemos ver en la siguiente tabla: 
Tabla 3.1. Magnitudes económicas del Sector Agroalimentario

\begin{tabular}{|c|c|}
\hline & Magnitudes \\
\hline \multicolumn{2}{|c|}{ Volumen de negocio (millones de euros) } \\
\hline Industria de la alimentación & 76.066 \\
\hline Fabricación de bebidas & 15.463 \\
\hline TOTAL & 91.529 \\
\hline \multicolumn{2}{|l|}{ Número de empresas } \\
\hline Industria de la alimentación & 24.358 \\
\hline Fabricación de bebidas & 4.976 \\
\hline TOTAL & 29.334 \\
\hline \multicolumn{2}{|l|}{ Personal ocupado } \\
\hline Industria de la alimentación & 317.724 \\
\hline Fabricación de bebidas & 47.090 \\
\hline TOTAL & 364.814 \\
\hline
\end{tabular}

Fuente: Libro blanco de las TIC en el Sector Agroalimentario

El sector agroalimentario se enfrenta en la actualidad a numerosos retos que requieren una transformación de muchas de sus prácticas tanto en la producción y comercialización de sus productos como en aspectos relacionados con la cooperación de empresas a lo largo de la cadena alimentaria, las relaciones con empresas en la misma etapa de la cadena, la utilización de las TI. Por otra parte, la influencia de la legislación y las presiones gubernamentales en las actividades de gestión empresarial están actuando como catalizadores de estos cambios. Todo esto obedece a una mayor presión del mercado, a una creciente globalización y competencia, la necesidad de una 
producción cada vez más diferenciada y segmentada, unos requisitos complejos de aseguramiento de la calidad, una fiabilidad y flexibilidad en la provisión del producto, una mejor comprensión del comportamiento del consumidor y sus tendencias, una asunción de prácticas sostenibles, etc.

En Europa, la industria agroalimentaria está integrada por un gran número de empresas. El sector está caracterizado por una gran heterogeneidad de actividades que redunda en distintas estructuras y métodos de explotación y/o producción. En España particularmente, con una gran atomización y con presencia numerosa de PYMES, esta diferenciación se acentúa por el gran número de empresas existente.

Debido a las particularidades de la situación actual, el sector agroalimentario español tiene que afrontar estos retos como oportunidades. La globalización favorece la competencia pero también supone mayores riesgos en la seguridad alimentaria y calidad. Este contexto coincide con la presión de los mercados, administraciones y legislaciones sobre el sector, los cuales demandan una intensificación de los procesos de control y la mejora de la calidad, la seguridad alimentaria y la trazabilidad del alimento a lo largo de la cadena de producción. Esta combinación de necesidades no puede ser satisfecha por cada empresa de forma individual (agricultores, productores, distribuidores) sino que se requiere de dependencias estrechas a todos los niveles de la producción, de iniciativas conjuntas y nuevos enfoques de cooperación e integración de la cadena alimentaria.

El concepto cadena alimentaria se compone de una red en la que las industrias agrícola, ganadera y pesquera en primer lugar y alimentaria en segundo son los principales eslabones. Pero existen otras empresas que establecen una relación lateral, por ejemplo suministradores de productos y servicios como proveedores de envases, fármacos y aditivos, consultorías, organismos certificadores o laboratorios.

Los eslabones asociados al ámbito industrial del sector tienen dificultades en los volúmenes reducidos de producción, el suministro estacional, el carácter perecedero de las materias primas y su heterogeneidad. Estas últimas características tienen gran 
importancia en la gestión de la calidad y seguridad alimentaria, ya que obstaculizan el suministro continuo de niveles de calidad homogéneos. La etapa de distribución comercial en la que se ubican el transporte, almacenamiento, venta y manipulación de alimentos, tiene una importancia esencial y su objetivo es mantener al menos los niveles de calidad alcanzados en fases anteriores. Para productos refrigerados y congelados, el mantenimiento de la cadena de frío es absolutamente necesario en este eslabón previo al consumidor.

\section{Seguridad alimentaria}

La complejidad de la cadena alimentaria y los posibles riesgos sanitarios existentes resaltan la necesidad de implantar sistemas de trazabilidad, es decir, sistemas que permitan conocer las etapas seguidas por las materias primas desde su producción o cosecha y el destino final de los productos, y que estén integrados como herramienta de gestión en el sistema de Análisis de Peligros y Puntos Críticos de Control (APPCC o HACCP en inglés). La trazabilidad se emplea como mecanismo de control de la procedencia y destino de los alimentos y sirve para identificar y retirar productos no conformes. Trazabilidad es "la posibilidad de encontrar y seguir el rastro, a través de todas las etapas de producción, transformación y distribución, de un alimento, un pienso, un animal destinado a la producción de alimentos o una sustancia destinados a ser incorporados en alimentos o piensos o con probabilidad de serlo" (Art. 3 del Reglamento 178/2002). Otra definición la podemos ver en el Codex Alimentarius; según éste trazabilidad es "la capacidad para seguir el movimiento de un alimento a través de los pasos específicos de la producción, transformación y distribución". También es "la capacidad de reconstruir la historia, aplicación o localización de un producto mediante identificaciones registradas" (UNE 66.901-92). Esta definición está más vinculada a la necesidad de disponer de sistemas de información que posibiliten recibir la información de proveedores y transmitirla a clientes y controlar los lotes en el proceso productivo u operativa de almacén y de expedición. 
Dado que el ámbito de la trazabilidad es el de la cadena de suministros global y no el de un actor individual de la cadena, para poder llevar a cabo una iniciativa de trazabilidad, se considera necesaria la intervención y colaboración entre todos los agentes de la cadena. La solución de trazabilidad aplicada debe ser estándar y entendible por todos los agentes de dicha cadena de suministro. Al mismo tiempo, y con el ánimo de conseguir la máxima eficiencia, debe facilitar la automatización de los procesos de captura, registro y transmisión de la información necesaria. La identificación registrada se suele referir al concepto de lote que se entiende como el conjunto de unidades de un producto alimentario elaborado, fabricado o envasado en circunstancias prácticamente idénticas. Por tanto, la trazabilidad agrupa procedimientos que permiten conocer la historia, ubicación y recorrido de un producto o lote a lo largo de la cadena de suministros en cualquier momento.

La trazabilidad es descendente si permite localizar los lotes a lo largo de la cadena de suministros. A este proceso se le conoce como tracking; es ascendente cuando persigue conocer el origen de la mercancía y los procesos por los que ha pasado antes de llegar al punto final, y es de utilidad para distribuidores. A este proceso se le conoce como tracing. En cuanto a los niveles de trazabilidad existe una trazabilidad interna o de procesos y otra externa o de cadena. La trazabilidad interna comprende la capacidad de rastrear a lo largo del proceso de producción en cuanto que la empresa realiza un control y registro de cómo los ingredientes recibidos y las materias primas entran a su proceso de producción y se obtienen los productos terminados, sabiendo quién ha suministrado las materias primas unitarias y a quién se ha vendido cada unidad de producto terminado. La trazabilidad de cadena se refiere a cómo las unidades comercializadas son intercambiadas entre los participantes de la cadena. Un sistema capaz de proveer servicios para la trazabilidad de cadena necesita ser capaz de trazar a lo largo y a través de cada uno de los eslabones de la cadena y vincular las unidades cuando fluyen de una etapa a la siguiente en dicha cadena.

Los beneficios para la industria, el consumidor y la administración son claros, ya que se favorece la gestión de la calidad del alimento al reducir productos no conformes, se 
permite la diferenciación de los productos alimentarios, se mejora la gestión y logística de inventarios, y la seguridad alimentaria se ve reforzada al permitir la retirada de productos mediante el empleo adecuado de los sistemas de alerta.

\section{Gestión y certificación de la calidad}

Para la industria agroalimentaria es importante definir los atributos de calidad más valorados por cada grupo de consumidores, su importancia relativa y cómo se evalúan. Un alimento es de calidad cuando se adapta a las necesidades del consumidor, y las demandas del consumidor europeo y español son: seguridad alimentaria, calidad nutricional y saludable (en el conjunto de la dieta), características organolépticas deseables, y otros atributos de valor (respeto al medio ambiente, desarrollo sostenible, transparencia e información).

Una vez definidos, la principal preocupación de la empresa es conseguir la producción y el suministro continuo de un producto con niveles de calidad en continua mejora. La industria de alimentos ha generado normas y sistemas que permiten controlar y gestionar la calidad como el análisis de peligro y puntos críticos de control ya mencionados, las Buenas Prácticas de Producción (BPM o GMP) o ha adaptado los modelos desarrollados inicialmente para otros sectores industriales (normas ISO). Los sistemas ISO y APPCC son preventivos y dado que el control se plasma en un conjunto de documentos es posible hacer auditorías y homologar las industrias. El sistema APPCC gestiona fundamentalmente los riesgos sanitarios, mientras que las normas ISO engloban todas las facetas de la calidad. Existe ya una norma específica (ISO 22000:2005) que detalla los requisitos y permite la operación y mantenimiento de sistemas de gestión de la seguridad alimentaria general en la industria.

El sistema APPCC se usa para identificar y evaluar los peligros, y controlar en un proceso de fabricación los puntos clave que afectarían a la inocuidad del alimento. Por otra parte, existen normas creadas por grandes cadenas de distribución que establecen 
sus propios parámetros de seguridad y calidad, por ejemplo Eurep-gap, British Retail Consortium, norma UNE 155000, IFS (International Food Standard) y SQF (Safe Quality Food).

En otro orden de cosas, los productores buscan la diferenciación y el valor añadido de sus productos mediante el empleo de denominaciones de origen y marcas de calidad, a través de organizaciones que persiguen el respeto a un pliego de condiciones y la verificación de su cumplimiento por organismos certificadores acreditados por entes públicos. La legislación europea permite tres tipos de certificaciones: la Denominación de Origen Protegida (DOP) designa el nombre de un producto cuya producción, transformación y elaboración se realiza en una zona geográfica determinada, con unos conocimientos específicos reconocidos y comprobados; la Indicación Geográfica Protegida (IGP), donde el vínculo con el medio geográfico sigue presente en al menos una de las etapas de la producción, de la transformación o de la elaboración; y la Especialidad Tradicional Garantizada (ETG), que busca destacar una composición tradicional del producto o un modo de producción tradicional (Gómez-Cruz et al., 2004).

El control de calidad en la propia industria no garantiza la seguridad del producto final, ya que éste puede estar expuesto a modificaciones externas, por ejemplo, en productos refrigerados el mantenimiento de la cadena de frío es fundamental para preservar la estabilidad microbiológica. Esto resalta que las operaciones de distribución y transporte son fundamentales en la industria agroalimentaria y tienen impacto en la calidad y seguridad del producto

\section{Heterogeneidad de los productos alimentarios}

Ya hemos comentado la heterogeneidad de los productos en la industria agroalimentaria. Esta heterogeneidad representa un problema para la gestión de la 
calidad y seguridad alimentaria, problema que otros sectores no tiene un efecto menor al tener una producción más homogénea en términos de variedad de producto.

Las características físicas, químicas y microbiológicas (e incluso organolépticas) de cada tipología de producto (cárnico, lácteo, etc. ) son variables en función del tipo de alimento y se modifican durante el procesamiento por las transformaciones a lo largo de la cadena productiva. Un alimento es un sistema dinámico de comportamiento variable en el tiempo, cuyas causas de variación pueden ser múltiples (estacionales/climáticas, geográficas, debidas a especie, raza, variedad, sexo, manejo, alimentación, etc.). Su vida útil o periodo de caducidad dependerá de múltiples factores. La homogeneización de las condiciones de producción y distribución pretende disminuir dicha variabilidad, intentado ofrecer un producto de calidad uniforme. Sin embargo persiste una variación intrínseca entre lotes producidos en las mismas condiciones. Los alimentos elaborados tienen una composición final diversa, producto de la mezcla de materias primas, y conforman una matriz compleja. Cada constituyente tiene su propio comportamiento y propiedades, y precisa de técnicas de análisis propias. Por otra parte, las características de calidad, para su análisis y gestión, deben traducirse a lenguaje matemático; una determinada característica (p.ej., peso, color, terneza) debe expresarse numéricamente para describir una población/lote/muestra mediante términos estadísticos (distribuciones estadísticas, valores medios, y desviaciones). Desde un punto de vista matemático se puede decir que la calidad de un producto permanecerá constante mientras no se modifique la distribución estadística de sus características de calidad.

Algunos atributos sensoriales tienen un carácter subjetivo y son evaluados por paneles de catadores. Para ello se cuida especialmente la selección y entrenamiento de los paneles, el diseño de las hojas de cata, la metodología y el análisis estadístico de la información obtenida. Algunos atributos de calidad pueden ser valorados por el consumidor únicamente en el momento de la compra o el consumo (denominados atributos 'experiencia') mientras que otros solo lo serán mediante análisis por personal especializado, no consumidores, siendo atributos 'creencia'. Para paliar este inconveniente, este último grupo es presentado al consumidor mediante información en 
etiqueta, por ejemplo mediante marcas de calidad que, como se ha visto, certifican la adhesión del productor a estándares de calidad.

\section{Importancia de las etapas de producción en la cadena alimentaria}

Para garantizar la seguridad alimentaria, la necesidad de prestar especial atención a las fases de producción animal y vegetal está reconocida en el Libro Blanco de la Seguridad Alimentaria (CE, 2000) y en la legislación europea (CE, 2002). Durante mucho tiempo se consideró que un único control a nivel de matadero era suficiente para producir carne en buenas condiciones higiénicas y libre de agentes zoonóticos. Las crisis alimentarias (BSE, dioxinas, etc.) demostraron la necesidad de integrar y controlar todos los eslabones de la cadena y solamente aquellos sistemas con gestión, cooperación e integración efectivas son capaces de conseguir la garantía con máximos estándares de calidad. La importancia de los sistemas de calidad integrados radica en que es preciso controlar toda la cadena ya que la producción animal representa su eslabón más débil. La alimentación y manejo de los animales de abasto tiene importancia decisiva en la calidad del producto final, de tal manera que errores cometidos en las primeras fases no pueden ser solucionados posteriormente. Esta importancia puede observarse en los atributos de calidad higiénico-sanitaria y bromatológica.

\section{Agentes de la cadena agroalimentaria}

Los actores genéricamente implicados en cada una de las etapas son (MartínezSimarro y Pinazo, 2011):

- Productor: Este operador se puede considerar como el primer eslabón de la cadena. Viene representado por el agricultor, ganadero o pescador que es el que pone a disposición del siguiente eslabón, el fabricante, el producto necesario 
para la fabricación y transformación del mismo en productos listos para envasar y comercializar.

- Fabricante: Este operador es el que recibe materias primas de uno o varios productores y las transforma en productos bien semielaborados que se introducen a otro fabricante, bien en productos terminados disponibles para su envasado y comercialización.

- Envasador: Este operador recibe el producto terminado listo para envasar y realiza el envasado según el formato de comercialización. Una vez envasado el producto es comercializado hacia los clientes a través de transporte hacia las plataformas de distribución.

- Centro de distribución: Este operador se encarga de distribuir y comercializar el producto terminado hacia los puntos de venta, pudiendo realizar operaciones de manipulación (preparación de picking), transporte y almacenamiento que pueden tener consecuencias en cuanto al seguimiento del producto y sus parámetros de calidad.

- Operador logístico/Transportista: En función del tamaño de su flota, este operador dispone de una serie de medios de transporte (camión, barco, avión, tren) para recoger la mercancía en los centros de distribución y entregarla en los puntos de venta. Es de especial importancia en caso de producto refrigerado o congelado.

- Cliente: Son los eslabones previos que disponen el producto a la venta para su adquisición por parte del consumidor. Pueden ser el canal tradicional HORECA o los supermercados pertenecientes a la gran distribución.

- Consumidor: Último eslabón de la cadena. Es el que exige garantías de calidad del producto que compra y demanda cada vez más atributos que certifiquen la seguridad y salubridad de los alimentos. 
La cadena de producción agroalimentaria no es cerrada sino que tiene interacciones con otros agentes que también intervienen en los procesos de transformación y que se ven envueltos en la gestión de la calidad y seguridad alimentaria:

- Proveedor de material auxiliar: Este operador abastece a los productores o y/o fabricantes de los materiales auxiliares necesarios para las operaciones de transformación y elaboración de producto. Muchos de estos materiales auxiliares se utilizan en puntos intermedios del proceso de producción y/o fabricación pero no pasan a formar parte del alimento. Son sustancias que no se consumen como ingredientes alimenticios o como alimentos, que se utilizan intencionadamente en la transformación de materias primas, de productos alimenticios o de sus ingredientes, para cumplir un objetivo tecnológico determinado durante el tratamiento o la transformación, y que pueden tener como resultado la presencia no intencionada, pero técnicamente inevitable, de residuos de dicha sustancia o de sus derivados en el producto acabado siempre que dichos residuos no presenten riesgo sanitario y no tengan efectos tecnológicos sobre el producto acabado. Los coadyuvantes tecnológicos no son ingredientes de los alimentos y, por tanto, no se incluyen en su etiquetado. Son por ejemplo tratamientos fitosanitarios, desinfectantes, antiespumantes, catalizadores.

- Proveedor de envases: En el seguimiento de la seguridad alimentaria es necesario contemplar la trazabilidad de los envases, especialmente aquellos en contacto directo con el alimento. Este operador es el que abastece de los materiales de los envases y embalajes, que no pueden quedar exento de control, visual y/o microbiológico para el envasado de producto terminado. Las etiquetas de identificación se pueden considerar también en este eslabón.

- Proveedor de servicios: En la cadena alimentaria ciertos operadores externos tienen un papel relevante. Por ejemplo, existen laboratorios que proveen de servicios de análisis y certificación de resultados de control de calidad, entidades 
de certificación que auditan el funcionamiento de algunos procesos según petición de otros operadores, la propia Administración, que puede hacer uso de la información bien a nivel estadístico bien para otros usos.

El escenario de cadena alimentaria se focaliza en la cooperación a lo largo de la cadena basada en la comunicación potencial de todos sus participantes, la cual debe estar vinculada al camino que sigue el producto.

\subsection{Método de investigación}

\subsubsection{Métodos cualitativos vs. cuantitativos}

Los métodos de investigación tratan de desarrollar el conocimiento científico mediante la formulación de preguntas sobre la realidad, basadas en la observación de esta realidad y las teorías ya existentes, proponiendo respuestas a estas preguntas y contrastándolas mediante la observación de los hechos, y su posterior clasificación y análisis (Brunet, Belzunegui y Pastor, 2000). El término "metodología”, según Taylor y Bogdan (2002) designa el modo en que se enfocan los problemas y se buscan respuestas. Des esta forma, el tipo de metodología elegida va a determinar en gran medida el diseño posterior de la misma.

Aunque el método científico puede presentar diversas modalidades, Sierra (1995) considera dos grandes grupos: los métodos cuantitativos y los métodos cualitativos. Los métodos cuantitativos se centran en la observación de muchos casos particulares. Estos métodos son predominantemente deductivos, buscando determinar las características generales de una población basándose en la observación de muchos casos individuales. Los métodos cuantitativos permiten conducir una ciencia positiva, llevando a cabo una recolección de datos clara, rigurosa y fiable, y permitiendo someter a prueba empírica las hipótesis planteadas de una forma 
consistente (Schwartz, 1984:22). Los métodos cualitativos, por el contrario, se centran en el estudio en profundidad y global de un número muy reducido de casos individuales. Su objetivo es la comprensión profunda de una entidad, fenómeno o situación determinada. En la tabla 3.5 se muestran las ventajas e inconvenientes de ambos métodos, cualitativo y cuantitativos, según Brunet, Belzunegui y Pastor (2000).

Dentro de la literatura TI existe un gran número de investigaciones que utiliza una metodología de estudio de casos con medidas cualitativas, donde se estudia los efectos particulares de un determinado sistema de información en el desempeño (Banker y Kauffman, 1991; Campbell-Kelly, 1996; DeSanctis y Poole, 1994). En estos estudios suele predominar un nivel de análisis de aplicación. Los trabajos cualitativos en este campo aportan una visión en profundidad de los fenómenos y procesos que ocurren en la implantación y el funcionamiento de los sistemas de información. Las investigaciones de este tipo han mejorado la comprensión de cómo actúan las distintas tecnologías y sistemas en las organizaciones y los cambios que producen. Estos avances han generado nuevas inquietudes entre los investigadores, puesto que comprender dónde reside el valor potencial que puede resultar de la inversión en TI tiene importantes consecuencias tanto académicas como prácticas.

Tabla 3.2. Ventajas e inconvenientes de los métodos cuantitativos y cualitativos

\begin{tabular}{|l|l|l||}
\hline \multicolumn{1}{|c|}{ MÉTODO } & \multicolumn{1}{|c|}{ Ventajas } & \multicolumn{1}{|c|}{ Inconvenientes } \\
\hline CUANTITATIVO & $\begin{array}{l}\text { Resultados cuantificables } \\
\text { Resultados extrapolables } \\
\text { Interpretación objetiva }\end{array}$ & $\begin{array}{l}\text { Lenta } \\
\text { Coste elevado } \\
\text { Solamente responde a previsto }\end{array}$ \\
\hline CUALITATIVO & $\begin{array}{l}\text { Obtención de la información } \\
\text { con elevado grado de detalle } \\
\text { Riqueza y profundidad de la }\end{array}$ & Resultados no cuantificables \\
\hline
\end{tabular}




\begin{tabular}{|l|l|l|}
\hline & $\begin{array}{l}\text { información } \\
\text { Posibilidad de aparición de } \\
\text { conceptos no previstos ex ante } \\
\text { Rapidez } \\
\text { Economía }\end{array}$ & Resultados no explorables \\
\hline
\end{tabular}

Fuente: Brunet, Belzunegui y Pastor (2000)

En cambio, dentro de los estudios empíricos desde el EBC con un nivel de análisis organizativo, existe un predominio de los métodos cuantitativos (ver tabla 3.3).

Tabla 3.3. Estudios empíricos sobre el efecto de las TI desde el EBC

\begin{tabular}{|l|l|}
\hline \multicolumn{1}{|c|}{ MÉTODO } & \multicolumn{1}{c|}{ Trabajos publicados } \\
\hline Powell y Dent-Micallef, 1997; \\
Dent-Micallef y Powell, 1998; \\
Armstrong y Sambamurthy, 1999; \\
Bharadwaj, 2000; \\
Ray, Barney y Muhanna, 2001; \\
Ravichandran y Lertwongsatien, 2002; \\
Santhanam y Hartono, 2003; \\
Tippins y Sohi, 2003; \\
Bruque, Vargas y Hernández, 2003 \\
Bhatt y Grover, 2005 \\
Bhatt et al. 2010 \\
Chen, 2012
\end{tabular}




\section{\begin{tabular}{l|l} 
CUALITATIVO & $\begin{array}{l}\text { Jarvenpaa y Leidner, } 1998 \\
\text { Doerthy y Terry, } 2009\end{array}$
\end{tabular}}

Fuente: elaboración propia

En este trabajo se ha optado por la utilización de métodos cuantitativos con el objetivo de asegurar la objetividad y la extrapolación (Henderson y Cockburn, 1994; McEvily y Chakravarthy, 2002). En concreto utilizaremos el método de la encuesta que pasamos a describir brevemente.

\subsubsection{La encuesta como instrumento de investigación}

La encuesta es uno de los instrumentos de investigación social más conocidos y utilizados. Este instrumento utiliza procedimientos estandarizados para interrogar a una muestra de sujetos representativos de un colectivo más amplio con el fin de obtener información acerca de determinados aspectos de la realidad y el comportamiento humano (Brunet, Bezunegui y Pastor, 2000).

García, Ibáñez y Alvira (1994) justifican la utilización de la encuesta por los siguientes motivos:

- Permite abarcar un amplio abanico de cuestiones en un mismo estudio.

- Facilita la comparación de resultados, ya que permite normalizar datos que después se podrán analizar estadísticamente.

- Pueden generalizarse los resultados del estudio a todo un grupo de población.

- Posibilita la obtención de información significativa.

- Permite recuperar información sobre hechos pasados. 
- Permite el estudio de conceptos no directamente observables, como puedan ser actitudes y valores de las personas o la evaluación del desempeño desde un punto de vista organizativo.

Estas ventajas se ven oscurecidas por una serie de limitaciones inherentes al método de la encuesta (García, Ibáñez y Alvira, 1994):

- Sólo se pregunta sobres aquello que se conoce.

- La información obtenida queda limitada por la estructura rígida del cuestionario y por el conocimiento del individuo que la contesta.

- Es un método complejo y, generalmente, necesita un presupuesto elevado para su administración.

En la investigación sobre Organización de Empresas es habitual encontrar la modalidad de encuesta autoadministrada, donde la propia persona encuestada rellena el cuestionario sin la presencia de un entrevistador. Según Brunet, Bezunegui y Pastor (2000), la encuesta autoadministrada resulta poco costosa y es adecuada cuando las personas que hayan de responder tengan un nivel cultural suficiente para entender y responder el cuestionario.

Aunque la encuesta autoadministrada supere el problema del coste, tiene una serie de problemas adicionales (Santarelli y Piergiovanni, 1996; Brunet, Bezunegui y Pastor, 2000).

- Las encuestas suponen una carga para las empresas y generalmente la tasa de respuesta es baja.

- No hay control sobre quién contesta el cuestionario. 
- Pueden existir problemas terminológicos o de confusión conceptual por parte de los encuestados.

- Se ha observado un cierto sesgo hacia respuestas extremas.

Las variables proxy se utilizan frecuentemente en los estudios cuantitativos y se definen por ser un instrumento eficaz a la hora de aproximarse a una realidad o a un fenómeno social. Si bien no entregan información exacta de lo medido, su función es la de aproximarnos a la realidad estudiada con valores objetivos. Una forma de evitar la utilización de la encuesta para la recogida de datos es recurrir a este tipo de variables a disposición de los investigadores en fuentes de información secundaria, como es el caso de muchos de los estudios publicados sobre el efecto de las TI en el desempeño (Brynjolfsson, 1996; Dewan, Michael y Min, 1998; Bharadwaj, 2000; Santhanam y Hartono, 2003). Por el contrario, para la medición de estrategias competitivas y estrategia TI, son escasos los trabajos que utilizan aproximaciones cuantitativas objetivas (Hamilton, Eskin y Michaels, 1998). En su lugar, la gran mayoría de investigadores ha optado por medirlas mediante una escala subjetiva de auto-clasificación (Kanungo et al. 2001; Cegielsky et al. 2005). Esto se debe a que en la medición de las TI, donde las variables son en muchos casos de carácter intangible, se requiere de una operativización más complicada (Rouse y Daellenbach, 1999). En este caso, los indicadores objetivos, en ocasiones, representan sólo una porción de la realidad.

Así pues, dada la naturaleza de las variables a medir, proponemos la encuesta autoadministrada como método de obtención de los datos necesarios para realizar el estudio, pues permite recoger todas las dimensiones de la realidad del objeto analizado. Los errores introducidos en los datos debido a las características inherentes al método de la encuesta pueden ser cuantificados con las técnicas estadísticas adecuadas (Bagozzi, 1982). 


\subsection{La medición de las variables}

\subsubsection{Desarrollo de las escalas de medida}

El desarrollo de instrumentos de medida que sean válidos, fiables y precisos es una tarea de importancia crucial en toda investigación. La escala de medición debe ser útil para recoger información sobre el concepto a evaluar y dicha información debe ser obtenida por el procedimiento más exacto y fiel posible. Por tanto, el diseño de instrumentos de medida para aquellas variables que no son directamente observables debe seguir un procedimiento riguroso que asegure su precisión (Churchill, 1979). Además, debe cumplir con una serie de propiedades sociométricas para su validación. A continuación revisamos las fases más relevantes del proceso de creación de una escala de medida.

En primer lugar, existe un amplio consenso en la literatura en que el proceso de medición del trabajo empírico científico debe descansar sobre fundamentos teóricos (Mackenzie et al., 2011). Los autores distinguen en el proceso global de operativización dos nociones fundamentales: la conceptuación y la medición. La primera hacer referencia al proceso teórico mediante el cual se clarifican las ideas o conceptos teóricos y se les otorga una definición de trabajo. La segunda consiste en el proceso general que vincula las operaciones físicas de medición con las operaciones matemáticas de asignar números a objetos.

\subsubsection{Medición de la estrategia competitiva}

Para examinar y medir la estrategia competitiva, en el presente estudio se ha fundamentado su medida en la tipología de Porter (1992), por ser una de las más ampliamente utilizadas (Govindarajan, 1986; Miller, 1986; Pelham y Wilson, 1996) $\mathrm{y}$, tal y como se deriva del segundo capítulo de este trabajo, permite vehicular el valor de las TI a la agrupación de las actividades donde más valor aportan. Éste 
distingue fundamentalmente entre liderazgo en costes, la diferenciación de productos o servicio y la segmentación. No obstante, considerando los trabajos de Miller (1987b, 1988), hemos establecido a su vez dos tipos de estrategia de diferenciación: las basadas en la innovación y las fundamentadas en prácticas intensivas en marketing e imagen de marca. Esta distinción de estrategias ha sido también considerada en trabajos como los de Lee y Miller (1996), Spanos y Lioukas (2001) o Spanos et al. (2004).

Sin embargo, en el presente estudio no se ha considerado la estrategia de segmentación por tratarse en realidad de un combinación de las estrategias de liderazgo en costes y diferenciación en distintos segmentos de mercado, de modo que, como el propio Porter (1992:62) argumenta, no se necesita ningún requisito organizativo específico para este tipo de estrategia, sino una combinación de los requisitos propios de las otras dos estrategias genéricas.

Tal y como apuntan otros estudios anteriores, (Miller, 1988; Spanos y Lioukas, 2001) en el presente trabajo se asume que las estrategias de liderazgo en costes y diferenciación por marketing o innovación no constituyen estrategias excluyentes entre sí, sino diferentes dimensiones que definen la estrategia de la empresa, por lo que cualquier empresa puede presentar un elevado o bajo grado de cada una de ellas, dando lugar a su propia combinación y posición estratégica.

Así mismo, conviene resaltar, tal y como se indica en el trabajo de Pertusa y Claver (2007), que por estrategia de liderazgo en costes no entenderemos a la posición única de la empresa que presenta el más bajo coste posible, constituyéndose en líder en costes, sino el grado en que las empresas se preocupan por el control y reducción de sus costes, para poder ofrecer productos y servicios de bajo precio, otorgando mayor importancia a estas cuestiones frente a las posibilidades de diferenciación.

Para la medida de estas estrategias se ha utilizado una escala de medición previamente validada y utilizada en trabajos como los de Rivard et al. (2006), 
Ravichandran y Lertwongsatien (2002), Spanos y Lioukas (2001), siendo ésta una escala derivada y adaptada de los trabajos de Dess y Davis (1984) y Miller (1988).

La estrategia de diferenciación por innovación se ha establecido a partir de una escala de medida subjetiva formada por cuatro ítems relacionados con la frecuencia con la que se realizan innovaciones de productos o procesos (preguntas 1 a 4 del cuestionario, ver Anexo I):

1) Gasto en I+D para el desarrollo de nuevos productos

2) Gasto en I+D para la innovación de procesos

3) Énfasis puesto en estar a la cabeza en cuanto a competitividad

4) Ratio de innovaciones de producto

La medida de la estrategia de diferenciación por marketing se ha medido a través de los siguientes cuatro ítems:

1) Innovaciones en técnicas de marketing

2) Énfasis en la organización del departamento de marketing

3) Gasto en publicidad

4) Énfasis en una fuerza de ventas fuerte

Finalmente, la estrategia de liderazgo en costes se ha medido a través de los siguientes tres ítems:

1) Énfasis puesto en la modernización y automatización de los procesos de producción

2) Esfuerzos puestos en conseguir economías de escala 
3) Utilización de la capacidad (ocupación de la estructura de la producción)

En todos los casos la escala de respuesta ofrecida consta de siete puntos con una valoración subjetiva en relación a los competidores.

\subsubsection{Medición de la estrategia TI}

La medición de la estrategia TI ha sido tradicionalmente un elemento controvertido en la literatura debido principalmente a las diferentes concepciones de dicho constructo. En términos generales, podemos afirmar que la principal fuente para el desarrollo metodológico de este concepto ha sido la literatura relacionada con la estrategia competitiva.

Para medir la estrategia TI de una organización, se han utilizado varias aproximaciones en función de la concepción de la estrategia SI/TI sobre la que el autor ha desarrollado el trabajo. Como mencionábamos en el epígrafe 2.5, a lo largo de la literatura se han utilizado un gran número de términos equivalentes para definir la estrategia TI de una organización.

De esta manera, tal y como argumenta Chen et al. (2010), y según se ha detallado en el capítulo 2 del presente trabajo, podemos distinguir tres concepciones de estrategia TI en la literatura: aquella que concibe que la estrategia TI es la utilización de las TI como soporte a la estrategia competitiva de la empresa, aquella que concibe la estrategia TI como el Plan Maestro de la función SI/TI en la organización y aquella que define la estrategia TI como una visión compartida del rol TI dentro de la organización.

En el presente trabajo adoptaremos la operativización del concepto estrategia TI desde la última perspectiva, puesto que representa un concepto de orden superior respecto a las dos primeras concepciones (Chen et al, 2010). Bajo esta perspectivas se han desarrollado diferentes trabajos que han tenido su fundamento en la literatura 
de la dirección estratégica (Grover et al, 1993; Venkatraman, 1994), puesto que en términos generales, existe una falta de literatura sustantiva en el ámbito de la estrategia SI/TI (Ragu-Nathan et al., 2001) y consecuentemente la categorización de estrategias tienden a reflejar la orientación de negocio más que tener su propia identidad (Kanungo et al., 2001).

Ha habido varios intentos de definir estrategias TI genéricas como los de Das et al. (1991) o Kim y Lee (1991). Sin embargo una de las categorizaciones que proporcionan un mayor detalle y cobertura en su clasificación es la de Parsons (1983), que clasifica las estrategias TI en seis estrategias genéricas enfocada a exclusivamente la tecnología:

- Planificada de forma centralizada: en una estrategia planificada de forma centralizada, la empresa busca la integración de su estrategia corporativa y su estrategia de sistemas de información. La firma se enfocará a los sistemas integrados para maximizar la utilización de la tecnología TI. Se utilizará una aproximación "top-down” para la planificación y existirá un departamento TI centralizado.

- Estrategia de vanguardia: esta estrategia implica que la empresa actualiza de manera continua su hardware y software con los últimos desarrollos disponibles en el mercado. En una estrategia de estas características, se adquiere continuamente lo último que existe en el mercado. Se anima a la experimentación con la esperanza de que los avances lideren mejoras en el desempeño de la organización y una ventaja competitiva sostenible.

- Mercado libre: una estrategia de mercado libre asume que el usuario es el mejor cualificado para determinar sus propias necesidades. En estas circunstancias, el usuario puede adquirir software, hardware o servicios al departamento TI o a cualquier vendedor externo. La única regla que se aplica de forma estricta es que obtenga los servicios SI a un precio razonable. 
- Monopolio: la estrategia de monopolio se asienta sobre el principio de que sólo debe haber una única fuente de servicios TI en la organización. El primer factor de éxito de esta estrategia es la satisfacción de usuario. Para asegurarlo, debe haber una adecuada capacidad en el departamento TI para garantizar el servicio en picos de demanda. Una de las mayores dificultades es en la implementación de esta estrategia es la medida de la satisfacción del usuario.

- Recurso escaso: la estrategia de recurso escaso se fundamenta en un control intensivo del dinero que se invierte en el departamento TI. Subyace la idea de que la administración TI es un coste improductivo y que la gestión o dirección debe minimizar todos los costes en esta dirección.

- Mal necesario: esta estrategia se basa en la creencia de que el uso de la tecnología TI debe ser evitada si es posible. Sólo las actividades que no pueden ser desarrolladas son el uso de ordenadores y que son adecuadamente justificadas son consideradas. Si invierte lo mínimo en hardware, software y personas. Como resultado las firmas que persiguen esta estrategia frecuentemente consiguen una elevada rotación de sus programadores, analistas y operadores.

Ragu-Nathan (2001) propone las siguientes dimensiones para conformar el constructor estrategia SI/TI:

- Promoción agresiva de TI: identifica la estrategia para promocionar los productos TI dentro de una organización entre los usuarios de las TI.

- Desarrollo basado en el análisis de las TI: esta dimensión se enfoca a medir la naturaleza de los procesos de gestión vinculados con la planificación, el control y la toma de decisiones en la función TI.

- Gestión defensiva de TI: Identifica la actitud de gestión del directivo TI hacia el "status quo", es decir, las acciones de gestión dirigidas a proteger las prácticas existentes, los procedimientos y configuraciones, su resistencia a los 
cambios que se producen alrededor de éste defendiendo generalmente su dominio.

- Desarrollo orientado a futuro de TI: Esta dimensión recoge la perspectiva de futuro adoptada en la gestión de las TI.

- Gestión proactiva de TI: Hace referencia a la gestión y actitud hacia los cambios evolutivos e inevitables que ocurren en el entorno de las Tecnologías de la Información.

- Gestión conservadora de TI: Cuando se desarrolla un proyecto de nuevo sistema o se implementa, la gestión de los procesos involucrados en ello incluye el reconocimiento de una serie de riesgos asociados a dichos sistemas.

Nolan y McFarlan (2005) clasifican las estrategias de acuerdo a dos cuestiones estratégicas: cuánto se fundamenta la empresa en unos sistemas de información de coste efectivo, fiables, seguros y bien operados (lo que denomina una TI defensiva) o por el contrario cuánto fundamenta su competitividad en unos sistemas de información que aporten servicios de valor añadido, nuevos productos y alta respuesta a clientes (lo que denomina TI ofensivas). En el primer caso, las TI se fundamentan en una fiabilidad operacional y en el segundo caso las iniciativas suelen ser más ambiciosas y arriesgadas porque frecuentemente suponen cambios organizacionales sustanciales: 
Tabla 3.4. Matriz de impacto estratégico de las TI

\begin{tabular}{|c|c|}
\hline TI Defensivas & TI ofensivas \\
\hline Modo factoría & Modo estratégico \\
\hline $\begin{array}{l}\text { Si los sistemas fallan durante un minuto o } \\
\text { más hay una pérdida inmediata de negocio. } \\
\text { Decremento de la respuesta en más de un } \\
\text { segundo supone consecuencias serias para } \\
\text { los usuarios internos y externos. } \\
\text { La mayor parte de las actividades "core" } \\
\text { del negocio son on-line. } \\
\text { La mayor parte de los trabajos asociados a } \\
\text { las TI son de mantenimiento. } \\
\text { Los trabajos en TI proporcionan escasa } \\
\text { diferenciación estratégica o reducción de } \\
\text { costes significativas. }\end{array}$ & $\begin{array}{l}\text { Si los sistemas fallan durante un minuto o } \\
\text { más hay una pérdida inmediata de negocio. } \\
\text { Decremento de la respuesta en más de un } \\
\text { segundo supone consecuencias serias para } \\
\text { los usuarios internos y externos. } \\
\text { Nuevos sistemas pueden suponer profundas } \\
\text { transformaciones en los procesos y los } \\
\text { servicios. } \\
\text { Nuevos sistemas prometen reducciones de } \\
\text { costes significativas. } \\
\text { Nuevos sistemas suponen mejorar la } \\
\text { posición competitiva o reducir la distancia } \\
\text { respecto a los competidores en coste, } \\
\text { servicio o desempeño de los procesos. }\end{array}$ \\
\hline Modo soporte & Modo cambio o respuesta \\
\hline $\begin{array}{l}\text { Incluso con interrupciones repetidas del } \\
\text { servicio de hasta } 12 \text { horas no suponen } \\
\text { consecuencias serias. }\end{array}$ & $\begin{array}{l}\text { Los nuevos sistemas prometen } \\
\text { transformaciones relevantes de procesos y } \\
\text { servicios. }\end{array}$ \\
\hline $\begin{array}{l}\text { El tiempo de respuesta de usuario puede ser } \\
\text { de hasta } 5 \text { segundos en transacciones on- } \\
\text { line. }\end{array}$ & $\begin{array}{l}\text { Los nuevos sistemas prometen reducciones } \\
\text { de costes significativas. }\end{array}$ \\
\hline $\begin{array}{l}\text { Los sistemas internos son casi invisibles } \\
\text { tanto para proveedores como para clientes. } \\
\text { No hay necesidad significativa de } \\
\text { capacidades de extranet } \\
\text { La empresa puede rápidamente volver a los } \\
\text { procesos manuales para el } 80 \% \text { de las } \\
\text { transacciones. }\end{array}$ & $\begin{array}{l}\text { Nuevos sistemas suponen mejorar la } \\
\text { posición competitiva o reducir la distancia } \\
\text { respecto a los competidores en coste, } \\
\text { servicio o desempeño de los procesos. } \\
\text { Las TI constituyen más del } 50 \% \text { de gasto } \\
\text { de capital. } \\
\text { Las TI suponen más del } 15 \% \text { del total de } \\
\text { gastos corporativos. }\end{array}$ \\
\hline $\begin{array}{l}\text { Los trabajos de sistemas son } \\
\text { mayoritariamente tareas de mantenimiento. }\end{array}$ & \\
\hline
\end{tabular}

Fuente: adaptado a partir de Nolan y McFarlan (2005) 
Para la medida de la estrategia TI seguiremos la tipología de estrategia desarrollada por Chen et al. (2010) para operativizar el constructo, según hemos indicado en el epígrafe 2.3. Esta tipología establece tres posibles estrategias a seguir por una organización: una estrategia TI innovadora, una estrategia TI conservadora y una estrategia TI indefinida.

La medición del desarrollo de una estrategia TI innovadora se medirá a través de los siguientes ítems:

1) Nuestra organización lidera la innovación en sistemas de información en nuestro sector.

2) Nuestra organización tiende a ser el primero en la industria en cuanto a desarrollar iniciativas TI incluso si no está demostrado que dichos esfuerzos sean altamente rentables.

3) Nuestra organización responde rápidamente a las señales tempranas relacionadas con oportunidades en el campo de las TI.

La medición del desarrollo de una estrategia TI conservadora se medirá a través de los siguientes ítems:

1) Nuestra organización persigue una aproximación segura y estable a la hora de desarrollar nuevas iniciativas en el campo de las TI

2) Nuestra organización adopta prometedoras innovaciones TI una vez que éstas han sido probadas en nuestro sector o por nuestros competidores

3) Nuestras innovaciones TI son examinadas cuidadosamente antes de ser seleccionadas

4) Mis sistemas de información están basados exclusivamente en herramientas estándares fácilmente obtenibles en el mercado 
Una estrategia indefinida vendrá determinada por:

1) Nuestra organización no tiene objetivos TI a largo plazo

2) Nuestra organización no tiene una estrategia TI articulada

3) Nuestra organización no tiene un patrón consistente de comportamiento respecto a las TI

\subsubsection{Diseño del instrumento de medida del desempeño}

La medida del desempeño se ha considerado siempre como un elemento clave en la dirección estratégica (Lingle y Schieman, 1996). Pese a esta importancia, la conceptuación, operativización y medición del concepto Desempeño organizativo se mantiene aún como una cuestión académicamente conflictiva y pendiente de resolución satisfactoria (Camisón, 1999b). Para este autor, existen dos puntos críticos que deben resolverse: la amplitud de intereses que los resultados deben medir y la naturaleza de los indicadores (medidas objetivas versus subjetivas).

\section{Dimensiones de desempeño}

Respecto a los resultados que se deben medir, en la literatura no existe consenso en cuanto a cuáles son las principales dimensiones del desempeño, apareciendo distintas aproximaciones parciales a la misma (Smith, Guthrie y Chen, 1989; Camisón, 1997). Así, Kaplan y Norton (1993) proponen medir el desempeño a través del balanced scorecard, que identifican como un conjunto equilibrado de medidas financieras y no financieras. Por el contrario, Liebowitz y Beckman (1998) apuntan que, en general, no existen unas métricas lo suficientemente desarrolladas para medir las actividades relacionadas con los activos intangibles que considera una parte fundamental del 
desempeño. Provost y Leddick (1993) consideran que la evaluación del desempeño de una organización necesita de una familia de medidas de impacto de los cambios en todos los stakeholders de una organización: clientes, empleados, finanzas, operaciones y entorno. Camisón (1999b) sintetiza las distintas dimensiones propuestas desde diferentes ámbitos y propone estos seis aspectos que deben ser considerados en la medida del Desempeño organizativo:

- Satisfacción de los clientes

- Satisfacción de los empleados

- Resultados financieros

- Eficiencia operativa

- Impacto social

- Capacidad para competir

Esta propuesta es parecida a la escala subjetiva de Tanaka (1987). Esta escala recoge los siguientes elementos:

- La calidad del producto o servicio

- El éxito de nuevos productos o servicios

- La tasa de retención de clientes

- El nivel de ventas

- El retorno sobre capital

- El margen bruto de utilidad

- El retorno sobre inversión

Respecto a las medidas de desempeño organizativas utilizadas en las investigaciones sobre TI, normalmente se suele considerar que la aplicación de las TI a los procesos suele tener un impacto directo en la productividad de éstos. Este hecho ha producido 
que la productividad haya sido una de las variables más estudiadas para ver el efecto de las TI y sus aplicaciones en el desempeño organizativo (Brynjolfsson y Hitt, 1996). También se suele aceptar que los SI deberían afectar tanto a los beneficios como a la productividad. Sin embargo, Thatcher y Oliver (2001) consideran que la productividad no refleja enteramente los beneficios proporcionados por las TI en las empresas. Las mejoras en la productividad se producen cuando las inversiones en tecnología permiten a la empresa producir un servicio o un producto dado con menores recursos. Ejemplos de este tipo de inversiones serían aquellas tecnologías que automatizan tareas administrativas tradicionales, sistemas de reserva electrónico, herramientas de comercio electrónico y otras herramientas que permiten la distribución de un producto determinado. También se incluirían herramientas para diseño de prototipos, $\mathrm{CAD}$, etc.

Cuando se implantan aplicaciones que reducen los costes generales se incrementan los beneficios y se mejora la productividad. Sin embargo, la calidad del producto y las decisiones sobre precios no tienen por qué verse afectadas. Las aplicaciones que reducen los costes variables de diseño, desarrollo, y producción del producto, mejoran la calidad del producto y permiten aumentar los precios de éste. Aunque este ajuste permite aumentar los beneficios, también hace aumentar los costes de producción, y por tanto, bajo ciertas condiciones, reducir la productividad de la organización. Las mejoras en la calidad se producirían cuando la inversión en tecnologías de la información lleva a la creación de nuevos productos o la mejora de los actuales. Entre los ejemplos de sistemas que mejoran la calidad están los sistemas de seguimiento de pacientes en los hospitales, herramientas de Data Mining, DSS y DGS, que permiten el aumento de las capacidades en la toma de decisiones. Por esta razón, Thatcher y Oliver (2001) abogan por una aproximación diferente para medir el desempeño organizativo relacionado con las TI. Dentro de este enfoque propuesto, Mahmood y Mann (1993) seleccionaron seis medidas directas de desempeño organizativo estratégico y económico; ROI, ROS, crecimiento en rentas, ventas sobre activos, ventas por empleado y valor de mercado respecto al contable. 
Por último, algunos autores consideran que ha habido un exceso de confianza en los datos financieros con respecto al efecto de las TI y sus aplicaciones en el desempeño (Brynjolfsson y Hitt; 1998). Rai (1997) destaca que las mejoras producidas por las TI pueden no reflejarse en el desempeño financiero de las empresas porque los beneficios pueden redistribuirse a través de las empresas o pasar a los consumidores.

Por lo tanto, se deben considerar cuatro dimensiones como mínimo en el desempeño: la productividad, los resultados financieros, la satisfacción del cliente y la capacidad para competir.

\section{$\underline{\text { Medidas subjetivas frente a objetivas }}$}

Aunque la medida objetiva del desempeño siempre es difícil de rebatir frente a las subjetivas, existen trabajos en la literatura que refuerzan el uso de escalas subjetivas, sosteniendo que la medición de resultados utilizando un procedimiento subjetivo ofrece evaluaciones consistentes con medidas de resultado objetivas (Venkatraman y Ramanujam, 1986; Smith, Guthrie y Chen, 1989). Camisón (1999a) considera que la utilización de escalas subjetivas basadas en la autoevaluación de los directivos en comparación con los competidores es un procedimiento fiable y válido para la estimación de los resultados. Para ello suponemos que los directivos conocen de manera profunda el comportamiento interno de sus competidores.

Aunque las medidas basadas en percepciones están ampliamente aceptadas en el área de Organización de Empresas (Lawrence y Lorsch, 1986), este tipo de medidas no han empezado a aparecer en la literatura de los SI hasta hace bien poco. Por ejemplo, DeLone yMcLean (1992) argumentan que los directivos están posicionados de manera ideal para actuar como informadores clave en las evaluaciones cualitativas del impacto de las TI en sus empresas. Esta afirmación está basada en dos argumentos: en primer lugar, como consumidores directos de las TI, los directivos pueden confiar en su experiencia personal cuando conforman su percepción de las TI 
y su impacto, y segundo, a medida que los directivos se involucran cada vez más en las decisiones de inversiones en TI, su evaluación de los beneficios es más precisa (Watson, 1990).

Las investigaciones respaldan algunas de estas proposiciones mostrando que las medidas basadas en la percepción del desempeño de las organizaciones están correladas de manera elevada con medidas objetivas más tradicionales. Por ejemplo, en el estudio de Venkatraman y Ramanujam (1987) se preguntó a los altos directivos que evaluaran el desempeño en relación con su mayor competidor utilizando un número diferente de criterios de desempeño que incluían el crecimiento en ventas, el crecimiento de ingresos netos y el ROI. La correlación elevada entre las medidas de desempeño objetivas y subjetivas han llevado a los autores a concluir que los datos perceptivos provenientes de los altos directivos pueden considerarse operativizaciones aceptables del desempeño económico. Adicionalmente, se ha demostrado que las percepciones de los ejecutivos sobre las TI y sus beneficios están correladas con medidas de desempeño económicas tradiconales como los beneficios netos, los ingresos y la productividad (Tallon, Kraemer y Gurbaxani, 2000).

Considerando los puntos debatidos, y teniendo en cuenta que el objetivo de esta tesis es estudiar la moderación de la estrategia TI en la relación entre estrategias competitivas y desempeño, hemos optado por la utilización de indicadores objetivos. Esto evitará problemas relacionados con el sesgo derivado de la evaluación de todas las escalas por un mismo sujeto (common method bias) y dará más solidez a los resultados. Los indicadores que se han barajado son aquellos disponibles en la base de datos SABI (Sistema de Análisis de Balances Ibéricos, datos consultados en enero de 2012.). De entre ellos se ha decidido medir la fortaleza de la posición competitiva de la empresa con dos indicadores financieros clásicos, (en inglés según como aparecen en la base de datos SABI) Rentabilidad sobre activos (Return on Total Assets, ROA) y margen de beneficios (\%) (Profit Margin, PM) la rentabilidad (eg., Tippins y Sohi, 2003; Tam, 1998; Rai, Patnayakuni y Patnayakuni, 1997; Hitt y 
Brynjolfsson, 1996; Barua, Kriebel y Mukhopadhya, 1995; Brown, Gatian y Hicks, 1995; Mahmood y Mann, 1993). Otro indicador relacionado con la productividad seleccionado es el beneficio por empleado en miles de euros (Profit per employee, PpE) (e.g., Francalanci y Galal, 1998; Rai, Patnayakuni y Patnayakuni, 1997; Hitt y Brynjolfsson, 1996; Brown, Gatian y Hicks, 1995; Brynjolfsson, 1993).

\subsection{Recogida de datos y trabajo de campo}

\subsubsection{El cuestionario}

La no disponibilidad de información relativa a las variables que hemos considerado en el estudio nos obliga a utilizar como fuente de información primaria la encuesta.

El cuestionario definitivo se ajustó para conseguir una extensión de una única página (con el objetivo de mejorar la tasa de respuesta) y se cumplimentó por parte de gerentes y directivos de pequeñas y medianas empresas del sector. El método fue el envío de la encuesta por correo electrónico.

La encuesta estaba compuesta por tres bloques de preguntas, cada uno de ellos dirigidos a medir cada una de las variables objeto de la investigación. Se han añadido aparte de estas variables algunas cuestiones generales como el número de empleados y la antigüedad de la empresa. Adicionalmente, en aras a minimizar posibles reticencias a contestar a las cuestiones, se garantizó la confidencialidad de la información expresada en el cuestionario.

Para medir las variables se ha utilizado una escala likert de 7 puntos, comparando la organización respecto a la competencia. Así, una puntuación de 7 quiere decir que la empresa está mucho mejor que la competencia en ese ítem, mientras que una puntuación de 1 indica que la empresa está mucho peor que la competencia. 
Camisón (1999) sostiene que la utilización de escalas subjetivas basadas en la autoevaluación de los directivos en comparación con los competidores es un procedimiento fiable y válido para la estimación de los resultados. Para ello suponemos que los directivos conocen de alguna manera el comportamiento interno de sus competidores.

Otros datos importantes respecto al cuestionario utilizado son los siguientes:

- El cuestionario fue dirigido a la dirección general y/ cualquier directivo de la empresa, puesto que se consideró que cualquier directivo tiene suficiente visión general como para dar una visión fiable a las cuestiones planteadas.

- El cuestionario estaba formado por 4 partes. Estas cuatro partes agrupan cuestiones correspondientes a las variables genéricas ya mencionadas (número de empleados y antigüedad de la empresa), la estrategia TI, la estrategia competitiva y el desempeño.

Una vez desarrollado el cuestionario se procedió a seleccionar la muestra sobre la que se iba a desarrollar el estudio. En el próximo epígrafe describiremos la selección del universo objeto del estudio.

\subsubsection{Recogida de datos}

La población de empresas del sector agroalimentario en España en el 2011 según FIAB (Federación de Industrias de Alimentación y Bebidas) es de 29.334, por lo que se puede considerar una muestra infinita (Miquel et al., 1997). El número total de cuestionarios recibidos fue de 184. Algunas de estas respuestas fueron desechadas por aparecer algunas anomalías, como indicadores sin contestar e inconsistencias entre respuestas. El número de respuestas eliminadas fue 18, quedando una muestra final de 166 respuestas. Las características de la muestra se recogen en el tabla 3.4. 
Tabla 3.5. Ficha técnica del estudio empírico

\begin{tabular}{|l|l|}
\hline UNIVERSO & Sector agroalimentario \\
\hline ÁMBITO & Nacional \\
\hline TIPO DE ENTREVISTA & $\begin{array}{l}\text { Por correo electrónico mediante cuestionario } \\
\text { estructurado }\end{array}$ \\
\hline $\begin{array}{l}\text { MARGEN DE ERROR } \\
\text { ESTADÍSTICO }\end{array}$ & $\begin{array}{l} \pm 7,6 \text { (para un nivel de confianza del } 95 \% \text { para } \\
\text { el caso más desfavorable: } \mathrm{p}=\mathrm{q}=0.5)\end{array}$ \\
\hline POBLACIÓN & 29.334 \\
\hline TAMAÑO MUESTRA & 166 \\
\hline UNIDAD DE ANÁLISIS & Empresa \\
\hline $\begin{array}{l}\text { PERSONA A QUIEN SE DIRIGE } \\
\text { LA ENCUESTA }\end{array}$ & Gerente y directivos \\
\hline $\begin{array}{l}\text { FECHA DEL TRABAJO DE } \\
\text { CAMPO }\end{array}$ & Enero-Junio 2011 \\
\hline \hline
\end{tabular}

El método seleccionado para la recolección de los datos fue el correo electrónico.

Con el fin de corregir los problemas que se le atribuyen a este método de recolección de datos, y persiguiendo elevar la tasa de respuesta y la calidad de los cuestionarios, se emplearon un conjunto de procedimientos sugeridos para la investigación mediante encuestas que son una versión modificada del "método de diseño total" de Dillman (1978). Estos procedimientos han sido utilizados por otros autores (Conant, Mokwa y Varadarajan, 1990).

El primer envío a la población de empresas incluía: una carta de presentación explicando los diversos objetivos que se pretenden en la investigación, el cuestionario junto con una lista de instrucciones para rellenarlo adecuadamente y un sobre franqueado para la devolución del cuestionario. 
Transcurridos 20 días desde el primer envío, se realizó una llamada telefónica preguntando si deseaba contestar la encuesta por correo ordinario o por correo electrónico. Adicionalmente, y con el mismo fin de elevar la tasa de respuesta, se incentivaba al encuestado con el compromiso de facilitarle los resultados del estudio si éste lo solicitaba expresamente.

El cuestionario estaba dirigido al director general de la empresa o a otros directivos en su defecto, ya que es la persona con mayor visión global de la organización y además dispone de la información necesaria para responder al cuestionario que hemos diseñado.

Una vez recogidos los datos, es necesario determinar si los instrumentos de medida seleccionados para evaluar los conceptos teóricos que aparecen en nuestro modelo son adecuados. Para resolver esto utilizaremos los modelos de ecuaciones estructurales que, además, permitirán contrastar el modelo teórico que hemos elaborado. En el siguiente epígrafe vamos a describir de forma breve las características de los modelos de ecuaciones estructurales.

\subsection{La metodología de los modelos de ecuaciones estructurales}

\subsubsection{Características de los modelos de ecuaciones estructurales}

Los modelos de ecuaciones estructurales se consideran como una conjunción de dos enfoques: una perspectiva econométrica que se centra en la predicción, y un énfasis psicométrico que modela conceptos como variables latentes (no observadas) que se infieren de forma indirecta a partir de múltiples medidas observadas (es decir, indicadores o variables manifiestas). También se le denomina "análisis de la estructura de covarianzas" y es una técnica confirmatoria que trata principalmente de comprobar si un cierto modelo teórico es válido. Constituye una herramienta útil para el estudio de relaciones causales de tipo lineal sobre conceptos. Algunos los 
describen como un ejemplo de "una segunda generación de análisis multivariante" (Fornell y Larcker, 1987).

Para Hair et al. (1999) las técnicas de ecuaciones estructurales se distinguen por dos características:

- La estimación de relaciones de dependencia múltiples y cruzadas: esto implica que algunas de las variables dependientes se convierten en variables independientes en relaciones ulteriores, dando lugar a la naturaleza interdependiente del modelo estructural. El modelo estructural expresa estas relaciones entre variables dependientes e independientes, incluso cuando una variable dependiente se convierte en variable independiente en otras relaciones.

- La capacidad de representar conceptos no observados en estas relaciones y tener en cuenta el error de medida en el proceso de estimación: los modelos de ecuaciones estructurales pueden incorporar variables latentes al análisis. Una variable latente es un concepto teórico supuesto y no observado que sólo puede ser aproximado mediante variables observables o manifiestas. Además, se parte de la idea de que no se puede medir perfectamente un concepto y que siempre hay algún grado de error de medida.

La primera característica de esta metodología supone que se pueden considerar ecuaciones simultáneas con varias variables endógenas. Las ecuaciones estructurales proporcionan estimaciones de la fuerza de las relaciones establecidas entre todas las variables, ofreciendo información sobre el impacto directo de una variable sobre otra así como sobre el impacto vía otras variables mediadoras.

La segunda característica expuesta es relevante para este estudio puesto que los conceptos que hemos expuesto en el modelo teórico son conceptos latentes que se miden a través de los instrumentos de medida que hemos desarrollado o 
seleccionado. Esto obliga, previamente a la contrastación de las hipótesis, a comprobar que estas escalas de medida son válidas y fiables. Los modelos de ecuaciones estructurales permiten comprobar si las escalas de medida utilizadas son adecuadas para medir los conceptos teóricos y si aparecen relaciones causales en el modelo teórico. A diferencia de la mayoría de métodos econométricos, las ecuaciones estructurales permiten errores de medida en las variables exógenas y endógenas y se obtienen indicadores múltiples de conceptos latentes y de los errores de medida. También se dispone de la estimación de la fiabilidad y la validez de las escalas de medida.

Estas características han convertido a los modelos de ecuaciones estructurales en una de las herramientas más potentes en las ciencias sociales para el estudio de relaciones causales sobre datos no experimentales (Batista y Coenders, 2000). Estos autores distinguen cinco razones por las que los modelos de ecuaciones estructurales son cada vez más utilizados:

- Permiten trabajar con variables latentes, que se miden a través de indicadores, y evaluar la calidad de la medición.

- Permiten incorporar múltiples variables tanto endógenas como exógenas.

- Consideran conjuntamente medida y predicción, análisis factorial y efectos de variables latentes entre sí, sin contaminación debida al error de medida.

- Permiten introducir la perspectiva confirmatoria en el modelado estadístico, facilitando la introducción del conocimiento teórico en la especificación del modelo antes de la estimación.

- Permiten descomponer la covarianza, además de la varianza en los análisis de interdependencia. 
Los modelos de ecuaciones estructurales son utilizados para estudiar relaciones causales teóricamente justificadas (Barrio y Luque, 2000). Así, dentro de la investigación del efecto de las TI sobre el desempeño, debido a que la causalidad no puede establecerse mediante técnicas estadísticas convencionales, Mahomood (2000) recomienda la utilización de métodos multivariantes (análisis de correlación canónica) y no paramétricos que permitan inferir causalidad y salvar este obstáculo. De la misma manera, dentro del EBC, Bruque, Vargas y Hernández (2003) reconocen que con análisis de correlaciones sólo es posible certificar que existen relaciones de asociación entre variables, pero no causalidad, recomendando otros métodos que lo consigan.

Todas estas características hacen de las ecuaciones estructurales una metodología apropiada para el contraste de las hipótesis propuestas.

\subsubsection{Etapas para el desarrollo de un modelo de ecuaciones estructurales}

Según Barrio y Luque (2000), un modelo de ecuaciones estructurales se debe desarrollar siguiendo cuatro grandes fases: la especificación, la identificación, la estimación y la evaluación e interpretación de dicho modelo. A continuación pasamos a describir brevemente cada una de ellas.

\subsubsection{Especificación del modelo}

En esta fase el investigador aplica sus conocimientos teóricos del fenómeno estudiado al planteamiento de las ecuaciones matemáticas relativas a los efectos causales de las variables latentes y a las expresiones que las relacionan con los indicadores o variables observables. La especificación del modelo establece las relaciones de dependencia entre las diversas variables que se consideran relevantes en la explicación de un determinado fenómeno (Barrio y Luque, 2000). El conjunto de hipótesis que se plantean en el modelo teórico se expresan mediante un conjunto 
de ecuaciones. Estas ecuaciones se suelen representar mediante diagramas de paso. Esto presupone la existencia de relaciones causales lineales.

La claridad del modelo viene determinada por el grado de conocimiento teórico que posea el investigador sobre el tema de estudio. La literatura recomienda modelos teóricos concisos y parsimoniosos (Hair et al. 1999). Por razones operativas y de interpretación debe incluirse el menor número posible de variables y de relaciones causales, sin dejar de incluir, obviamente, una variable o relación que tenga suficiente justificación.

El modelo causal, una vez justificadas teóricamente las variables utilizadas y sus relaciones, se representa mediante un diagrama de secuencias o de pasos (path diagram) a partir del cual se establece un sistema de ecuaciones estructurales que describen las relaciones entre variables. El diagrama de pasos permite representar las relaciones predictivas (variable exógena - variable endógena) y de asociación (correlaciones) entre conceptos. Finalmente, estas relaciones se trasladan a un conjunto de relaciones lineales que definen las relaciones entre los conceptos (modelo estructural), la medida de tales conceptos a través de las variables observadas (modelo de medida), y las posibles correlaciones entre las diferentes variables (Barrio y Luque, 2000).

\subsubsection{Identificación del modelo}

La identificación del modelo consiste en evaluar si la información suministrada por los datos de la encuesta es suficiente para obtener estimaciones únicas de los parámetros no conocidos. En función de las condiciones de identificación, Batista y Coenders (2000) clasifican los modelos estructurales en tres grupos:

- Modelo infraidentificado: el número de parámetros a estimar es superior al número de ecuaciones, en cuyo caso no existe solución. 
- Modelo identificado: en este caso el número de parámetros coincide con el número de ecuaciones, por lo que el modelo tiene una solución única.

- Modelo sobreidentificado: este modelo obtiene soluciones múltiples, ya que el número de ecuaciones es superior al número de parámetros.

Se debe trabajar con modelos "sobre estimados" (Barrio y Luque, 2000) en los que hay más valores conocidos que parámetros a estimar. Una condición necesaria para que el modelo esté identificado es que los grados de libertad del modelo sean iguales o superiores a cero o bien se cumpla la siguiente condición:

$$
\mathrm{p}<=1 / 2(\mathrm{q}+\mathrm{r})(\mathrm{q}+\mathrm{r}+1)
$$

siendo:

$$
\begin{aligned}
& \mathrm{p}=\text { número de parámetros a estimar } \\
& \mathrm{q}=\text { número de indicadores exógenos } \\
& \mathrm{r}=\text { número de indicadores endógenos }
\end{aligned}
$$

El programa informático que hemos utilizado evalúa automáticamente la identificación al estimar un modelo (Bentler, 1995).

\subsubsection{Estimación del modelo}

La estimación del modelo consiste en obtener los estimadores de los parámetros libres del conjunto de datos, que son los coeficientes que representan las relaciones entre las varianzas. La estimación del modelo se hace mediante un proceso iterativo que finaliza cuando los elementos de la matriz residual no se pueden minimizar más. 
Los métodos (criterios) de estimación más habituales son (Batista y Coenders, 2000):

- Mínimos cuadrados no ponderados (LS): en el programa estadístico Lisrel se conoce también como ULS.

- Mínimos cuadrados ponderados bajo normalidad (NT-WLS): este método es asintóticamente eficiente bajo el supuesto de normalidad multivariante.

- Máxima verosimilitud (ML): es asintóticamente eficiente bajo el supuesto de normalidad multivariante. En nuestra investigación hemos seguido el método ML con estimadores robustos.

- Método asintóticamente libre de distribución (ADF): este método es menos restrictivo, ya que es asintóticamente eficiente para cualquier distribución de las variables observables.

\subsubsection{Interpretación del modelo}

Se trata de evaluar si los datos obtenidos se ajustan al modelo propuesto. Barrio y Luque (2000) sostienen que la evaluación debe realizarse a tres niveles: evaluación del ajuste del modelo global, evaluación del ajuste del modelo de medida y evaluación del ajuste del modelo estructural. A continuación pasamos a describir brevemente cada uno de ellos:

- Ajuste global del modelo: este ajuste indica la correspondencia entre la matriz del modelo y la de las observaciones. Existen medidas de ajuste absolutas, incrementales y de parsimonia.

- Ajuste del modelo de medida: en este ajuste se comprueba la significación de las cargas, la fiabilidad de cada uno de los indicadores y la fiabilidad compuesta del concepto. 
- Ajuste del modelo estructural: implica el análisis de la significación alcanzada por los coeficientes estimados (para un nivel de significación de $0,05$ el valor t toma el valor de 1,96$)$. Un parámetro no significativo indicaría que la relación propuesta no tiene ningún efecto sustancial.

El software utilizado para modelar las ecuaciones estructurales ha sido el EQS 6.0, puesto que dispone de todas las funcionalidades necesarias para evaluar las escalas de medida y contrastar las hipótesis.

Para contrastar las hipótesis de moderación se realizó el test $\mathrm{z}$ de Fisher con submuestras utilizando el programa SPSS. 
Pág. 202 de 329 


\section{ANÁLISIS DE RESULTADOS Y CONTRASTE DE HIPÓTESIS}


Pág. 204 de 329 


\section{ANÁLISIS DE RESULTADOS Y CONTRASTE DE HIPÓTESIS}

\subsection{Objetivos y contenidos del capítulo}

Este capítulo se centra en el análisis y exposición de los resultados obtenidos tras el desarrollo empírico con el fin de validar los modelos teóricos expuesto anteriormente y contrastar las hipótesis planteadas.

Primeramente (epígrafe 4.2), se describen brevemente las propiedades que deben cumplir las escalas de medida en las ciencias sociales y los indicadores utilizados para su comprobación.

En los siguientes epígrafes (epígrafe 4.3 - 4.5), se analiza si los instrumentos de medida para evaluar los conceptos teóricos son válidos. Esto nos permitirá asegurar que las herramientas de medida propuestas recogen la información del concepto que se pretenden evaluar. (DeVellis, 1991:10).

Los cuatro siguientes epígrafes evalúan las escalas utilizadas y ya validadas en otros estudios.

Una vez comprobado que las escalas utilizadas son adecuadas para la medición del concepto teórico, el siguiente paso (epígrafe 4.6) es contrastar el modelo teórico elaborado, observando la metodología de ecuaciones estructurales expuesta en el capítulo precedente.

En el último epígrafe se contrastan las hipótesis de moderación mediante el test Z de Fisher. 


\subsection{Propiedades de las escalas e indicadores utilizados en el desarrollo empírico}

Una vez que el modelo ha sido identificado y estimado, se debe evaluar el ajuste de los datos al modelo (Barrio y Luque, 2000). La evaluación de las escalas propuestas para medir los diferentes conceptos implicados en el modelo exige comprobar sus propiedades sociométricas y confirmar de esta manera que es una escala rigurosa y válida. Para ello, comprobaremos tres características: la dimensionalidad, la fiabilidad y finalmente la validez, esta última tanto discriminante, como convergente y de contenido (Hair et al. 1999).

\subsubsection{Dimensionalidad}

Para la comprobación de las hipótesis, debemos garantizar que la escala de medida o modelo estructural está basado en una definición teórica sólida que refleje el concepto o las relaciones que se pretenden medir. Por lo tanto, previamente, debemos realizar un análisis de la dimensionalidad o unidimensionalidad de la escala para comprobar la existencia de un único concepto o característica subyacente en el conjunto de indicadores con los que se mide el concepto (Anderson y Gerbing, 1988). Para ello hemos utilizado las técnicas de Análisis Factorial Confirmatorio. En este análisis se debe observar la calidad del ajuste de los datos al modelo planteado, tanto de la escala como de los modelos estructurales que se verán más adelante. Por lo tanto, antes de la interpretación de los resultados es necesario determinar hasta qué punto los modelos asumidos se ajustan a los datos muestrales.

El proceso comienza con la comprobación de la existencia de los suficientes grados de libertad (g.l.) para obtener modelos sobreidentificados. Una vez comprobada la identificación, en las ecuaciones estructurales se distinguen tres tipos de medidas de ajuste global: medidas absolutas de ajuste, medidas incrementales, y medidas de parsimonia (Hair et al. 1999). A continuación, pasamos a describirlas brevemente. 


\subsubsection{Medidas absolutas de ajuste}

Las medidas absolutas de ajuste determinan el grado en que el modelo global (modelo de medida y modelo estructural) predice la matriz de datos inicial. El estadístico $\chi^{2}$ (Chi-Square) es el más utilizado para realizar pruebas de significación para un diagnóstico global del modelo. Este instrumento es un test que mide la distancia existente entre la matriz de datos inicial y la matriz estimada por el modelo (Barrio y Luque, 2000). En nuestro caso, al utilizar un método robusto, usamos el estadístico Satorra Bentler Chi-Square. Aparte de éste, existen otros indicadores que pasamos a describir brevemente:

- Satorra Bentler Chi-Square: el estadístico Chi-Square o Chi-Cuadrado permite contrastar la hipótesis nula de que el modelo es correcto, es decir, que el modelo proporciona un ajuste aceptable de los datos observados. El nivel de significación tiene que ser mayor de 0,05 .

- GFI (LISREL Goodness Fit Index): es una medida de la variabilidad explicada por el modelo. Es menos sensible que la Chi-Square a las desviaciones de la normalidad. Este índice indica un buen ajuste de los datos observados si su valor es igual o superior a 0,9 .

- RMSR (Root Mean Square Residual): es el promedio de los residuos entre la matriz de observaciones inicial y la matriz estimada por el modelo. Cuando el valor se acerque a 0 el ajuste será bueno.

- RMSEA (Root Mean Square Error of Approximation): supera el inconveniente de la $\chi^{2}$ cuando la muestra no es lo suficientemente grande. Es parecido al RMSR pero con términos de población en lugar de muestra. Se considera que existe un buen ajuste del modelo cuando el RMSEA toma unos valores por debajo de 0,05 o incluso 0,08 .

Para comprobar el ajuste absoluto seleccionamos los índices Satorra Bentler Chi-Square y su significatividad (p), y el RMSR. 


\subsubsection{Medidas incrementales de ajuste}

Este tipo de medidas se utilizan para comparar el modelo propuesto con un modelo nulo o básico que se toma como referencia y que, tradicionalmente, suele ser aquel que estipula una falta absoluta de asociación entre las variables. Con esto se comprueba la superioridad del modelo propuesto frente a un modelo nulo que considera la ausencia de asociación entre los indicadores (Barrio y Luque, 2000). Entre los índices más comunes para comprobar el ajuste incremental se encuentran:

- AGFI (LISREL Adjusted Goodness Fit Index): representa el GFI ajustado por los grados de libertad del modelo propuesto y el modelo nulo, estadístico que posee la misma interpretación que el Adjusted R2 en regresión múltiple. Este índice indica un buen ajuste de los datos observados si su valor es igual o superior a 0,9 .

- BB-NFI (Bentler-Bonett Normed Fit Index): mide la disminución del estadístico Chi-Square del modelo propuesto con relación al modelo base. El índice de ajuste normalizado (acotado entre 0 y 1 ) evalúa la disminución del estadístico Chi-Square del modelo con respecto del modelo base. Valores iguales o superiores a 0,9 indican un buen ajuste.

- BB-NNFI (Bentler-Bonett Non Normed Fit Index): al igual que el parámetro anterior, mide la disminución del estadístico Chi-Square del modelo propuesto. Su valor debe superar 0,9 .

- IFI (Incremental Fit Index): excluye parte de los inconvenientes del NFI respecto al sobreajuste como consecuencia del número de parámetros. Los valores aceptables de esta medida de ajuste incremental son los cercanos a la unidad, si bien su valor puede ser superior a la unidad en determinadas ocasiones.

Para comprobar el ajuste incremental seleccionamos los índices BB-NNFI e IFI. 


\subsubsection{Medidas de parsimonia}

La parsimonia de un modelo se refiere al grado en que se alcanza el ajuste para cada coeficiente o parámetro estimado, evitando el sobreajuste del modelo con coeficientes innecesarios. Jöreskog (1969) propuso para esta medida el valor estadístico $\chi 2$ divido por los grados de libertad, o NC (Normed Chi-Square). Otro indicador utilizado es el AIC (Akaike Information Criterion), aunque éste se utiliza más para comparar modelos.

En la tabla 4.1 se presenta una síntesis de todos los indicadores presentados y que serán utilizados.

Tabla 4.1. Medidas de bondad del ajuste del modelo de medida

\begin{tabular}{||c|c||}
\hline MEDIDAS ABSOLUTAS DE AJUSTE & $\begin{array}{c}\text { NIVELES DE ACEPTACIÓN } \\
\text { RECOMENDADOS }\end{array}$ \\
\hline$\chi^{2}$ Satorra-Bentler y nivel de significación & Nivel de significación mayor de 0,05 \\
\hline GFI & Valores superiores a 0,90 \\
\hline RMSR & Valores inferiores a 0,08 \\
\hline RMSEA & Valores inferiores a 0,08 \\
\hline Medidas incrementales de ajuste & Valores superiores a 0,90 \\
\hline AGFI & Valores superiores a 0,90 \\
\hline BB NFI & Valores superiores a 0,90 \\
\hline BB NNFI & Valores próximos a 1 \\
\hline IFI & Valores entre 1 y 2, llegando a 5 con \\
menos exigencia
\end{tabular}

Fuente: Barrio y Luque (2000) 


\subsubsection{Fiabilidad}

Evaluar la fiabilidad de una escala equivale a determinar que las mediciones están libres de las desviaciones producidas por los errores casuales. Por lo tanto, la fiabilidad nos asegura una determinada calidad de los instrumentos de medida, en el sentido de que la estructura de las escalas creadas esté correctamente diseñada y existe una coherencia en la medida (Hayes, 1992:50). Esto nos permite asegurar que las conclusiones derivadas de la interpretación de los resultados son fiables.

La fiabilidad de una escala implica dos dimensiones, la consistencia interna y la estabilidad. La consistencia o equivalencia interna hace referencia a que el conjunto de variables operativas observadas mida el mismo concepto subyacente. La estabilidad es la capacidad de la escala para generar resultados constantes para una misma medición.

Las fuentes de error sistemático no tienen ningún impacto negativo sobre la fiabilidad de la escala, dado que afectan a la medición de forma constante. Sin embargo, el error aleatorio sí que puede producir inconsistencias, dando como resultado una fiabilidad de la escala menor. Por tanto, la fiabilidad puede también definirse como el grado en que la medición está libre de error aleatorio. No obstante, el hecho de que una escala sea fiable no significa que sea válida, pues la validez implica que la medida está libre tanto de errores aleatorios como sistemáticos.

El estadístico a utilizar para medir la fiabilidad depende del enfoque de la investigación y de la propia naturaleza de los datos. El coeficiente más común es el $\alpha$ de Cronbach, que analiza la consistencia interna de la escala a través de la correlación media de un ítem con todos los demás ítems de la misma. Sin embargo, este coeficiente ha recibido severas críticas relativas al uso de asunciones demasiado restrictivas, como ponderar igualmente a todos los indicadores, por lo que el valor del estadístico puede estar sesgado.

Barrio y Luque (2000:523) recomiendan comprobar la fiabilidad de cada uno de los indicadores, así como la fiabilidad compuesta del concepto. La fiabilidad de los 
indicadores es la proporción de varianza que tiene en común con el concepto (la parte de la varianza que no se debe al término error). Bollen (1989) y Mueller (1996) sugieren estimar la fiabilidad de una medida mediante el cuadrado del coeficiente de correlación múltiple de cada indicador (R2). Este valor debe ser superior a 0,5. La fiabilidad compuesta (Fornell y Larcker, 1981) se puede calcular a partir de las cargas estandarizadas y los errores de medida mediante la siguiente fórmula:

$$
\text { Fiabilidad compuesta }=\frac{(\Sigma \text { cargas estandarizadas })^{2}}{(\Sigma \text { cargas estandarizadas })^{2}+(\Sigma \text { errores de medida })}
$$

Aunque no existe un consenso establecido sobre el valor mínimo de la fiabilidad compuesta, se suele utilizar como cota mínima de fiabilidad 0,7.

\subsubsection{Validez}

La validez refleja la bondad de medición de la variable objeto de estudio por medio de la escala de medida. Esto supone que las diferencias en los valores observados reflejan diferencias reales en la variable objeto de medida, y no en otros factores. La validez implica que la medida está libre tanto de errores sistemáticos como aleatorios (Churchill, 1979).

La validez de una medida no puede estimarse directamente ni estadísticamente, sino que únicamente puede inferirse a partir de la manera en que ha sido creada la escala, de su relación con las medidas de otras variables y de su habilidad para predecir cuestiones específicas. Hay tres tipos básicos de validez que se corresponden con esas tres formas de determinarla. Así pues, distinguimos la validez de contenido, la validez de criterio, la validez convergente y la validez discriminante (Hair et al. 1999). 


\subsubsection{Validez de contenido}

La validez de contenido indica si el conjunto de indicadores que forman la escala es adecuado para la medición de la variable. Cuando lo que se trata de medir son actitudes, creencias o predisposiciones, resulta muy complejo evaluar la validez, puesto que es difícil determinar exactamente cuál es el abanico de ítems que debería recoger la escala. Generalmente, al aumentar el número de ítems en las escalas, aumenta la validez de contenido de éstas (Grapentine, 1994), por lo que muchos autores (Churchill, 1979) recomiendan la utilización de escalas multi-ítem, puesto que con ellas se reducen los errores de medición y se aumenta la fiabilidad de los mismos. Pese a esta recomendación, no existe un criterio objetivo para evaluar el grado de validez de contenido de una escala, ya que se trata de un concepto cualitativo que depende en gran medida del criterio subjetivo de los investigadores. Es por esto que se recurre a la evaluación del procedimiento seguido para la creación del instrumento de medida para comprobar la validez de contenido (Peter y Churchill, 1986:1; Grapentine, 1994). Este proceso de creación de la escala debe observar con cuidado la metodología y las técnicas en la construcción de las escalas.

\subsubsection{2. $\quad$ Validez de criterio}

La validez de criterio, nomológica o externa, implica que un ítem o una escala es útil para predecir otros conceptos o criterios. Es por esta causa que también se la conoce como validez predictiva. Esta validez se puede contrastar si se observa una validez en los modelos planteados.

\subsubsection{Validez convergente}

Un concepto tiene validez convergente cuando la medida que se evalúa tiene una elevada correlación con otras medidas que evalúan el mismo concepto (Churchill, 1979:70). También se puede comprobar la validez convergente empleando la misma escala sobre diferentes poblaciones. 
Esta validez se puede evaluar a través del análisis factorial mediante los siguientes indicadores:

- Coeficiente AGFI: un valor de este estadístico superior a 0,9 demuestra la existencia de validez convergente.

- Coeficiente de Bentler-Bonett Non Normed Fit Index (Bentler y Bonett, 1980): un valor de este estadístico superior a 0,9 demuestra la existencia de validez convergente.

- La magnitud de las cargas factoriales: Bollen (1989) sugiere estimar la validez de un indicador a partir de la magnitud de las cargas factoriales. Estos coeficientes deben superar idealmente el valor de 0,4 (Hair et al., 1999).

- Coeficientes de los valores t: Anderson y Gerbing (1982) analizan la existencia de validez convergente a partir de la significación estadística de cada carga obtenida entre el indicador y la variable latente (valores de t superiores a 1,96 para $\alpha=0,05)$.

\subsubsection{Validez discriminante}

La validez discriminante indica en qué grado dos escalas de medida desarrolladas para medir conceptos similares, pero conceptualmente diferentes, están relacionadas. Esta validez nos permite comprobar si es un concepto diferente o un reflejo de otras variables (Camisón, 1998).

Para determinar la validez discriminante de las diferentes escalas examinaremos la matriz de correlaciones entre escalas. En caso de una alta correlación, superior al 0.7 , implicaría que dos escalas están aportando la misma información, por lo que hay un solapamiento de conceptos y se está incurriendo en una tautología (Barrio y Luque, 2000). 


\subsection{Evaluación de la escala de medida de la estrategia TI}

En este epígrafe se intentará validar las escalas de medida del concepto estrategia en TI. Tal como se ha definido en el capítulo anterior, y dada su relativa independencia, se han utilizado tres escalas de estrategia en TI: Estrategia innovadora en TI, estrategia conservadora en TI, y Sin estrategia en TI. Las escalas de medida utilizadas están ya validadas por Chen et al. (2010), y suponen que las diferentes estrategias en TI es un factor de primer orden, implementados con los indicadores propuestos, cuyas medias y desviaciones típicas de los datos obtenidos se muestra en el tabla 4.2. Los indicadores se consideran que tienen una única carga factorial positiva en el factor que miden. También se supone que los errores de medida de la escala no están correlacionados.

Figura 4.1a. Modelo para medir la estrategia innovadora en TI

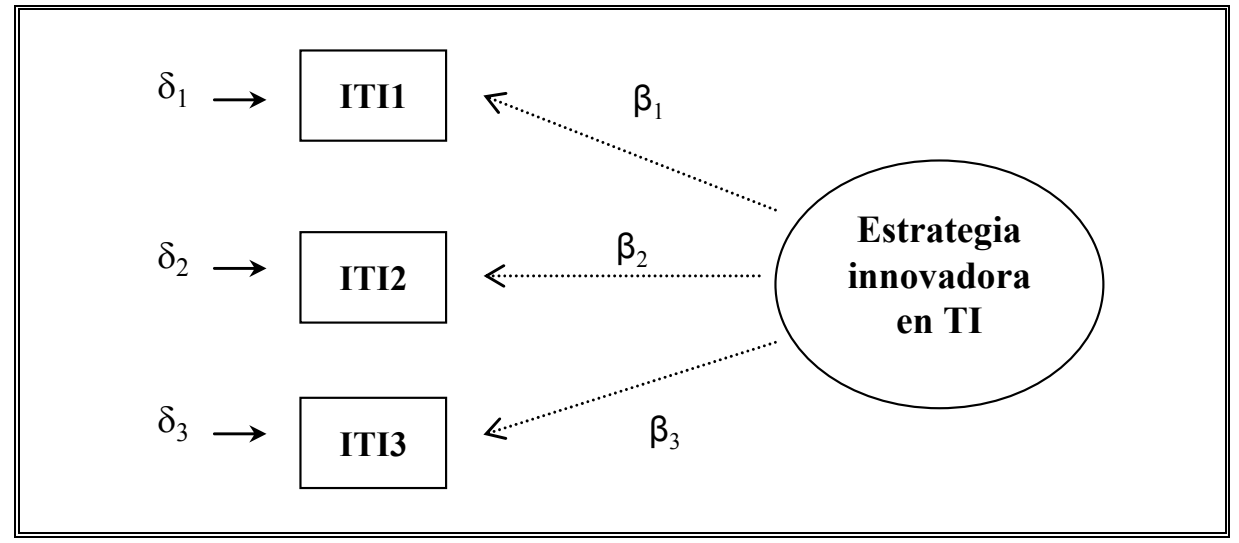

Donde:

$\beta=$ Cargas factoriales de los indicadores

$\delta=$ Errores de medida 
Figura 4.1b Modelo para medir la estrategia conservadora en TI

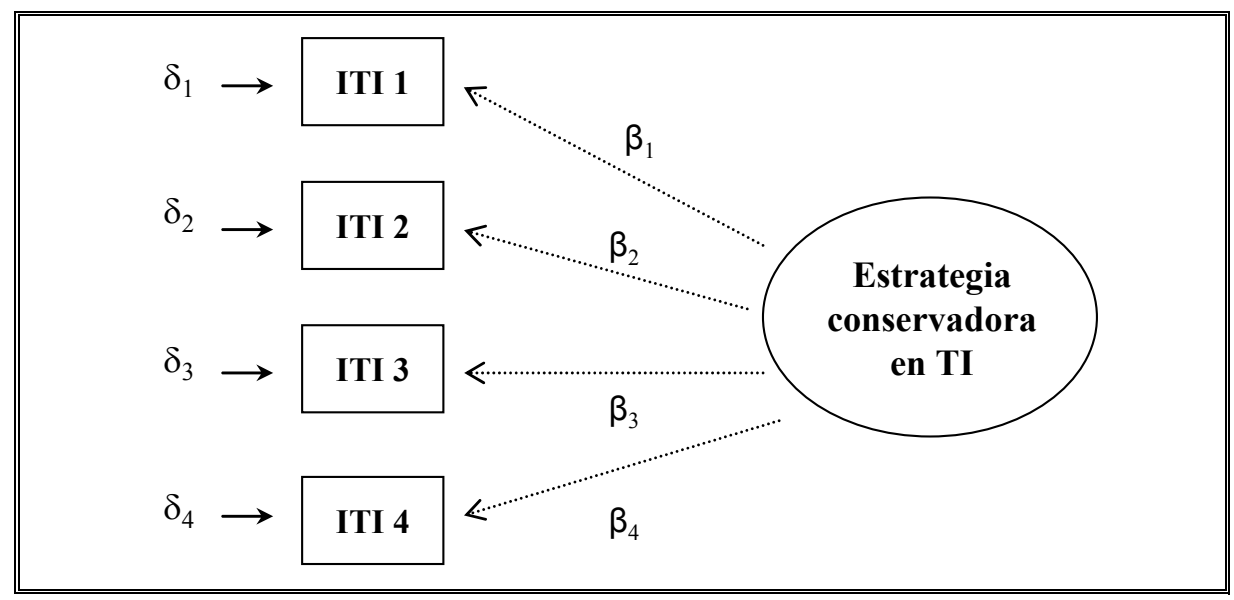

Donde:

$\beta=$ Cargas factoriales de los indicadores

$\delta=$ Errores de medida

Figura 4.1c Modelo para medir la falta de estrategia en TI

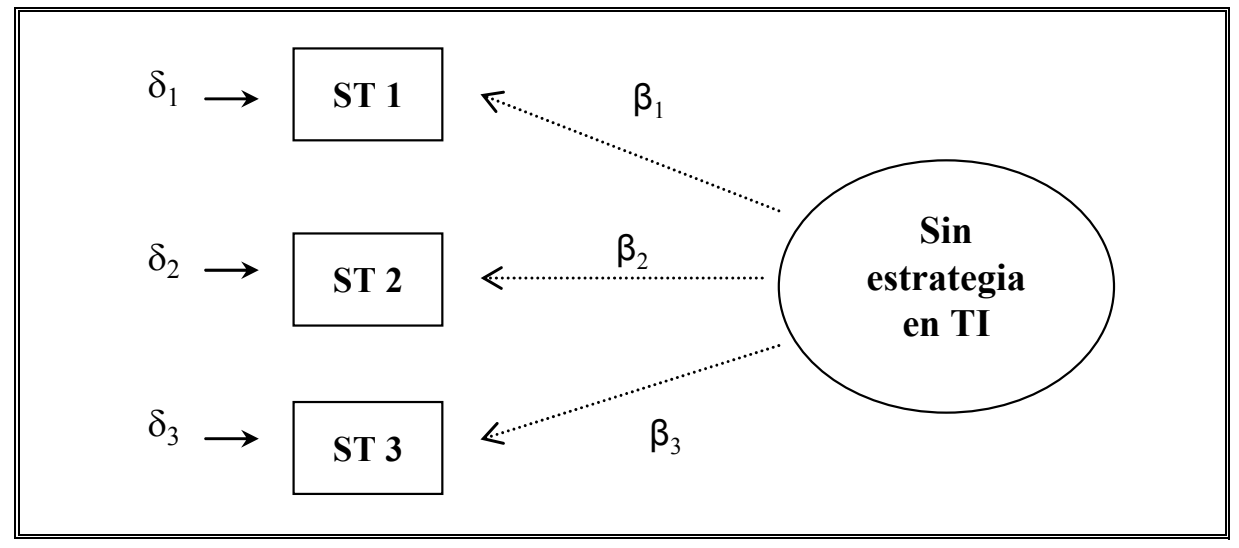

Donde:

$\beta=$ Cargas factoriales de los indicadores

$\delta=$ Errores de medida

Las medias, desviaciones típicas y máximos y mínimos de cada uno de los ítems de las escalas se muestran a continuación. 
Tabla 4.2a. Medias y desviaciones típicas de los ítems de Estrategia innovadora en TI

\begin{tabular}{|c|l|c|c|c|c|}
\hline $\mathbf{N}^{\mathbf{a}}$ & \multicolumn{1}{|c|}{ Ítem } & $\mathbf{m}$ & $\mathbf{\sigma}$ & Min & Max \\
\hline ITI1 & $\begin{array}{l}\text { Nuestra organización lidera la innovación en sistemas } \\
\text { de información en nuestro sector }\end{array}$ & 3,46 & 1,605 & 1 & 7 \\
\hline ITI2 & $\begin{array}{l}\text { Nuestra organización tiende a ser el primero en la } \\
\text { industria en cuanto a desarrollar iniciativas TIC } \\
\text { incluso si no está demostrado que dichos esfuerzos } \\
\text { sean altamente rentables }\end{array}$ & 3,43 & 1,703 & 1 & 7 \\
\hline ITI3 & $\begin{array}{l}\text { Nuestra organización responde rápidamente a las } \\
\text { señales tempranas relacionadas con oportunidades en } \\
\text { el campo de las TIC }\end{array}$ & 3,46 & 1,741 & 1 & 7 \\
\hline
\end{tabular}

\section{Donde:}

$m=$ Media (entre 1 y 7 )

$\sigma=$ Desviación típica

$n=166$

Tabla 4.2b. Medias y desviaciones típicas de los ítems de Estrategia conservadora en TI $(n=166)$

\begin{tabular}{|c|l|c|c|c|c|}
\hline $\mathbf{N}^{\mathbf{a}}$ & \multicolumn{1}{|c|}{ Ítem } & $\mathbf{6}$ & Min & Max \\
\hline CTI1 & $\begin{array}{l}\text { Nuestra organización persigue una aproximación } \\
\text { segura y estable a la hora de desarrollar nuevas } \\
\text { iniciativas en el campo de las TIC }\end{array}$ & 4,45 & 1,276 & 1 & 7 \\
\hline CTI2 & $\begin{array}{l}\text { Nuestra organización adopta prometedoras } \\
\text { innovaciones TIC una vez que estas indicativas han } \\
\text { sido probadas en nuestro sector o por nuestros } \\
\text { competidores }\end{array}$ & 4,43 & 1,515 & 1 & 7 \\
\hline CTI3 & $\begin{array}{l}\text { Nuestras innovaciones en TIC son examinadas } \\
\text { cuidadosamente antes de ser seleccionadas }\end{array}$ & 4,67 & 1,428 & 1 & 7 \\
\hline CTI4 & $\begin{array}{l}\text { Los sistemas de información de mi organización están } \\
\text { basados exclusivamente en herramientas estándares y } \\
\text { de mercado en el sector }\end{array}$ & 4,74 & 1,489 & 1 & 7 \\
\hline
\end{tabular}

\section{Donde:}

$m=$ Media (entre 1 y 7 )

$\sigma=$ Desviación típica

$n=166$ 
Tabla 4.2c. Medias y desviaciones típicas de los ítems de la falta de estrategia en TI

\begin{tabular}{|c|l|c|c|c|c|}
\hline $\mathbf{N}^{\mathbf{a}}$ & \multicolumn{1}{|c|}{ Ítem } & $\mathbf{m}$ & $\boldsymbol{\sigma}$ & Min & Max \\
\hline STI1 & $\begin{array}{l}\text { Nuestra organización no tiene objetivos TIC a largo } \\
\text { plazo }\end{array}$ & 2,96 & 1,815 & 1 & 7 \\
\hline STI2 & $\begin{array}{l}\text { Nuestra organización no tiene una estrategia TIC } \\
\text { articulada }\end{array}$ & 3,17 & 1,840 & 1 & 7 \\
\hline STI3 & $\begin{array}{l}\text { Nuestra organización no tiene un patrón consistente de } \\
\text { comportamiento respecto a las TIC }\end{array}$ & 3,17 & 2,037 & 1 & 7 \\
\hline $\begin{array}{l}\text { Donde: } \\
m=\text { Media (entre 1 y 7) } \\
\begin{array}{l}\sigma=\text { Desviación típica } \\
n=166\end{array}\end{array}$
\end{tabular}

\subsubsection{Relación entre ítems de las escalas de estrategia en TI}

Aunque las tres escalas de estrategia en TI son conceptuadas como de un solo orden e independientes una de otra, es necesario comprobar que miden conceptos diferentes. Especialmente relevante para este estudio es comprobar que la estrategia innovadora en TI y la inversa de la estrategia conservadora en TI no son conceptualmente el mismo constructo. Para comprobarlo, analizaremos las tres escalas de estrategia propuestas (innovadora en TI, conservadora en TI, y sin estrategia en TI) de manera conjunta, realizando un análisis factorial exploratorio con todos los ítems. Este análisis nos permitirá evaluar si los indicadores propuestos para medir las diferentes posibles estrategias son válidos y son una expresión de los conceptos que intentan medir. Para realizar el análisis exploratorio utilizamos el programa informático SPSS, utilizando el método de extracción de componentes principales y el método de rotación Varimax con Kaiser. La escala de conservador en TI se ha invertido, para comprobar que no mide la inversa de la innovación. Los resultados se muestran en la siguiente tabla. 
Tabla 4.3. Análisis factorial exploratorio de los ítems de innovación en TI

Matriz de componentes rotados

\begin{tabular}{||c|c|c|c||}
\hline \multirow{2}{*}{ Items } & \multicolumn{3}{|c|}{ Factores } \\
\cline { 2 - 4 } & 1 & 2 & 3 \\
\hline ITI1 &,- 062 & $\mathbf{9 1 5}$ &, 160 \\
\hline ITI2 &,- 049 & $\mathbf{9 4 2}$ &, 032 \\
\hline ITI3 &,- 103 &, $\mathbf{9 0 8}$ &, 010 \\
\hline CTI1* &, 176 &,- 222 & $\mathbf{, 8 2 9}$ \\
\hline CTI2* &, 201 &, 082 &, $\mathbf{8 2 7}$ \\
\hline CTI3* &, 269 &, 124 &, $\mathbf{7 4 9}$ \\
\hline CTI4* &,- 047 &, 203 &, $\mathbf{7 0 9}$ \\
\hline STI1 & $\mathbf{8 9 4}$ &,- 080 &, 102 \\
\hline STI2 & $\mathbf{, 9 4 3}$ &,- 052 &, 172 \\
\hline STI3 & $\mathbf{9 2 2}$ &,- 099 &, 216 \\
\hline
\end{tabular}

*Ítem invertido

$$
n=166
$$




\section{Varianza total explicada}

\begin{tabular}{|c|c|c|c|c|c|c|c|c|c|}
\hline \multirow{2}{*}{ Componente } & \multicolumn{3}{|c|}{ Autovalores iniciales } & \multicolumn{3}{|c|}{$\begin{array}{l}\text { Sumas de las saturaciones al } \\
\text { cuadrado de la extracción }\end{array}$} & \multicolumn{3}{|c|}{$\begin{array}{l}\text { Suma de las saturaciones } \\
\text { al cuadrado de la rotación }\end{array}$} \\
\hline & Total & $\begin{array}{c}\% \text { de la } \\
\text { varianza }\end{array}$ & $\begin{array}{c}\% \\
\text { acumulado }\end{array}$ & Total & $\begin{array}{c}\% \text { de la } \\
\text { varianza }\end{array}$ & $\begin{array}{c}\% \\
\text { acumulado }\end{array}$ & Total & $\begin{array}{c}\% \text { de la } \\
\text { varianza }\end{array}$ & $\begin{array}{c}\% \\
\text { acumulado }\end{array}$ \\
\hline 1 & 3,567 & 35,669 & 35,669 & 3,567 & 35,669 & 35,669 & 2,701 & 27,012 & 27,012 \\
\hline 2 & 2,854 & 28,537 & 64,206 & 2,854 & 28,537 & 64,206 & 2,680 & 26,799 & 53,811 \\
\hline 3 & 1,508 & 15,082 & 79,288 & 1,508 & 15,082 & 79,288 & 2,548 & 25,476 & 79,288 \\
\hline 4 & ,644 & 6,436 & 85,724 & & & & & & \\
\hline 5 & ,444 & 4,439 & 90,163 & & & & & & \\
\hline 6 & ,360 & 3,601 & 93,765 & & & & & & \\
\hline 7 & ,219 & 2,191 & 95,955 & & & & & & \\
\hline 8 & ,177 & 1,765 & 97,720 & & & & & & \\
\hline 9 & , 130 & 1,297 & 99,018 & & & & & & \\
\hline 10 & ,098 & ,982 & 100,000 & & & & & & \\
\hline
\end{tabular}

La observación de los resultados nos indica la extracción de tres factores claramente independientes, correspondientes a las tres estrategias en TI propuestas para este estudio. Las cargas factoriales para todos los ítems en su respectivo factor superan el 0.7 , no siendo nunca superior a 0.3 su carga en un factor ajeno para ningún ítem. Por lo tanto, podemos asumir que los modelos de medida de las tres estrategias son independientes y miden estrategias distintas. 


\subsubsection{Fiabilidad}

Pasamos a continuación a comprobar la fiabilidad de las escalas. Para ello realizamos un análisis factorial confirmatorio con el programa informático EQS 6.0. Este programa plantea posibles explicaciones sobre los motivos del desajuste entre el modelo teórico y el modelo generado por los datos procesados. Así, siguiendo los resultados del Lagrange Multipler Test que ofrece el EQS, se pueden eliminar los ítems que no aportan información relevante por estar altamente correlados con otros ítems.

Hay que comentar que tanto la escala de estrategia innovadora en TI como la escala para medir la falta de estrategia en TI tienen únicamente 3 ítems, con lo que el modelo está saturado ( 0 grados de libertad) y no permite calcular indicadores de ajusta. Esta limitación obliga a evaluar la fiabilidad mediante coeficientes de fiabilidad como el Alpha de Cronbach o el RHO de Sperman y el análisis de los pesos y $\mathrm{R}^{2}$ de los ítems.

Los resultados del análisis factorial confirmatorio para cada una de las tres escalas de estrategia en TI se muestra a continuación.

\subsubsection{1. $\quad$ Escala estrategia innovadora en TI}

El análisis factorial confirmatorio para esta escala muestra los siguientes resultados:

Tabla 4.4. Análisis factorial confirmatorio de la escala estrategia innovadora en TI

\begin{tabular}{|c|c|c|c|c|}
\hline \hline Ítem & $\boldsymbol{\beta}$ & $\mathbf{t}$ & Errores $(\boldsymbol{\delta})$ & $\mathbf{R}^{\mathbf{2}}$ \\
\hline ITI1 & .901 & 3.491 & .433 & .813 \\
\hline ITI2 & .932 & 2.419 & .362 & .869 \\
\hline ITI3 & .863 & 6.032 & .505 & .745 \\
\hline
\end{tabular}

\begin{tabular}{|c|c|c|c|}
\hline g.l. & $\begin{array}{c}\text { Alpha de } \\
\text { Cronbach }\end{array}$ & $\begin{array}{c}\text { RHO de } \\
\text { Spearman }\end{array}$ & $\begin{array}{c}\text { Fiabilidad } \\
\text { compuesta }\end{array}$ \\
\hline 0 & .926 & .926 & .848 \\
\hline
\end{tabular}

$n=166$ 
Para la escala de estrategia innovadora en TI, por lo que respecta a la fiabilidad individual de los indicadores, todos superan el valor mínimo recomendado de 0,4 para la $\mathrm{R}^{2}$. Todos los pesos $(\beta)$ son elevados, por encima de 0.7 , y con una alta significatividad $(\mathrm{p}<0.001)$. Además, el Alpha de Cronbach y el RHO superan el 0.9. Con todo ello podemos decir que esta escala cumple los requisitos de fiabilidad exigidos. La fiabilidad compuesta es mayor que 0.7 .

\subsubsection{Escala estrategia conservador en TI}

Para la escala de estrategia conservadora en TI, los resultados del análisis factorial confirmatorio se muestran en la siguiente tabla.

Tabla 4.5. Análisis factorial confirmatorio de la escala estrategia conservadora en TI

\begin{tabular}{|l|c|c|c|c|}
\hline Ítem & $\boldsymbol{\beta}$ & $\mathbf{t}$ & Errores $(\delta)$ & $\mathbf{R}^{\mathbf{2}}$ \\
\hline CTI1 & .795 & 5.208 & .607 & .631 \\
\hline CTI2 & .833 & 5.029 & .553 & .694 \\
\hline CTI3 & .721 & 4.981 & .693 & .520 \\
\hline CTI4 & .558 & 6.644 & .830 & .311 \\
\hline
\end{tabular}

\begin{tabular}{|c|c|c|c|c|c|c|}
\hline g.l. & $\begin{array}{c}\text { Alpha de } \\
\text { Cronbach }\end{array}$ & $\begin{array}{c}\text { RHO de } \\
\text { Spearman }\end{array}$ & RMSEA & $\begin{array}{c}\text { Fiabilidad } \\
\text { compuesta }\end{array}$ & BB NFI & IFI \\
\hline 2 & .813 & .818 & .000 & .759 & .999 & 1.010 \\
\hline
\end{tabular}

$$
n=166
$$

Los indicadores muestran un buen ajuste, con valores muy por encima del 0.9 recomendado en en BBNNFI y el IFI, y por debajo del 0.08 en el RMSEA. Los pesos de los ítems son todos excelentes excepto para el CTI4, que no llega a 0.6. Pese a ello se mantiene el ítem en la escala, pues sus valores son aceptables y la escala tiene muy bien Alpha de Cronbach (0.813). La fiabilidad compuesta es mayor que 0.7.

Podemos concluir que la escala es perfectamente fiable. 


\subsubsection{Escala falta de estrategia en TI}

Por último, para la escala para medir la falta de estrategia en TI de una organización, el análisis confirmatorio se presenta en la siguiente tabla (X.6) . Como en el caso de la escala de estrategia innovadora el modelo es saturado por contar sólo con tres ítems. Los resultados en esta escala también son excelentes. Tanto los pesos individuales de los ítems como sus $\mathrm{R}^{2}$ muy elevadas. Además, los indicadores de fiabilidad superan con creces el 0.7. La fiabilidad compuesta es mayor que 0.7 .

Tabla 4.6. Análisis factorial confirmatorio de la escala falta de estrategia en TI

\begin{tabular}{|l|c|c|c|c|}
\hline Ítem & $\boldsymbol{\beta}$ & $\mathbf{t}$ & Errores $(\boldsymbol{\delta})$ & $\mathbf{R}^{\mathbf{2}}$ \\
\hline STI1 & .836 & 3.870 & .549 & .698 \\
\hline STI2 & .963 & 3.555 & .270 & .927 \\
\hline STI3 & .934 & 4.364 & .356 & .873 \\
\hline
\end{tabular}

\begin{tabular}{|c|c|c|c||}
\hline \hline g.l. & $\begin{array}{c}\text { Alpha de } \\
\text { Cronbach }\end{array}$ & $\begin{array}{c}\text { RHO de } \\
\text { Spearman }\end{array}$ & $\begin{array}{c}\text { Fiabilidad } \\
\text { compuesta }\end{array}$ \\
\hline 0 & .934 & .939 & .864 \\
\hline
\end{tabular}

$n=166$

Podemos concluir que la escala es perfectamente fiable.

\subsubsection{Validez}

\subsubsection{Validez de contenido}

Se considera que una escala de medida tiene validez de contenido si cumple dos condiciones. La primera es que la generación de los ítems que la forman se basen en argumentaciones teóricas, escalas y estudios empíricos previos existentes en la literatura. Los ítems fueron extraídos de la literatura de sistemas de información, de escalas ya validadas, por lo que se puede considerar que la escala cumple la primera condición. 
La segunda condición es que la escala haya sido elaborada de acuerdo con procedimientos aceptados en literatura. En este caso, la escala propuesta por Chen et al. (2010), se realizó siguiendo el método de encuesta entre para la recogida de datos y su posterior validación estadística.

\subsubsection{Validez de criterio}

La validez de criterio se verificará al comprobar el ajuste del modelo causal y las hipótesis planteadas.

\subsubsection{Validez convergente}

La bondad del los indicadores y la magnitud de las cargas factoriales (ver tablas 4.4, 4.5 y 4.6 ) aseguran la validez convergente.

\subsubsection{Validez discriminante}

La validez discriminante la evaluamos mediante la matriz de correlaciones entre diferentes tipos de estrategias (tabla 4.7). Todos los valores son menores que 0,9, negativos y estadísticamente significativos, por lo que podemos asegurar la validez discriminante de las distintos tipos de estrategia.

Tabla 4.7. Matriz de correlaciones entre estrategias en TI

\begin{tabular}{|c|c|c|c|}
\hline ESTRATEGIAS EN TI & Innovador & Conservador & Sin estrategia \\
\hline Innovador & 1 & & \\
\hline Conservador & $-0,102$ & 1 & \\
\hline Sin estrategia & $-0,139$ & $-0,437$ & 1 \\
\hline \multicolumn{4}{|c}{$n=166$}
\end{tabular}

Todos los coeficientes de correlación son estadísticamente significativos $(\mathrm{p} \leq 0,01)$

Una vez comprobada la dimensionalidad, fiabilidad y validez de las tres escalas propuestas para medir la estrategia en TI, podemos concluir que cumplen todas las 
propiedades sociométricas que se les exigen a las escalas de medición en las ciencias sociales.

\subsection{Evaluación de las escalas de medida de la Estrategia Competitiva}

En este epígrafe se analiza la escala de medida utilizada para la evaluación de las estrategias competitivas. Este instrumento ya validado (Dess y David, 1984; Miller, 1988; Spanos y Lioukas, 2001; Rivard et al. (2006)), considera tres tipos de estrategias, y presenta tres escalas independientes para cada estrategia: en innovación, en marketing y en costes. Las tres escalas se consideran un factor de un solo orden. Los indicadores se consideran que tienen una única carga factorial positiva en el factor que miden. También se supone que los errores de medida de la escala no están correlacionados.

La siguiente figura representa los tres modelos de medida con sus ítems.

Figura 4.2a. Modelo para medir la estrategia competitiva en innovación

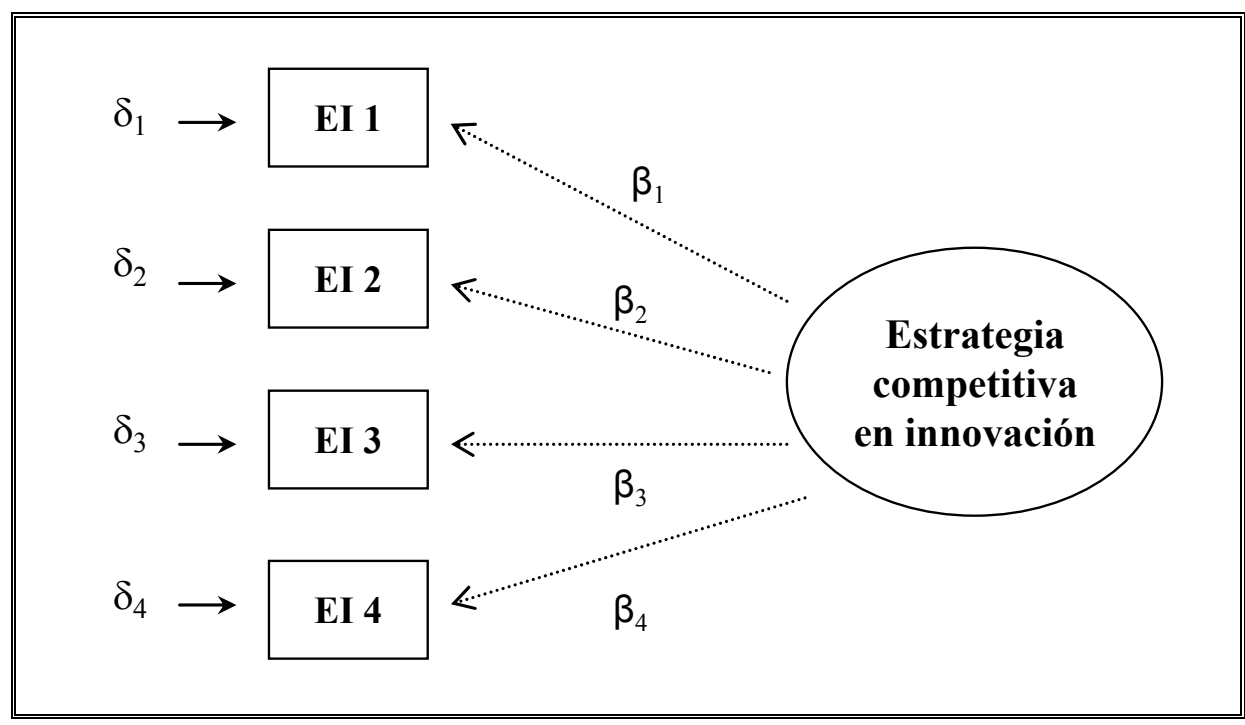

Donde:

$\beta=$ Cargas factoriales de los indicadores

$\delta=$ Errores de medida 
Figura 4.2b. Modelo para medir la estrategia competitiva en marketing

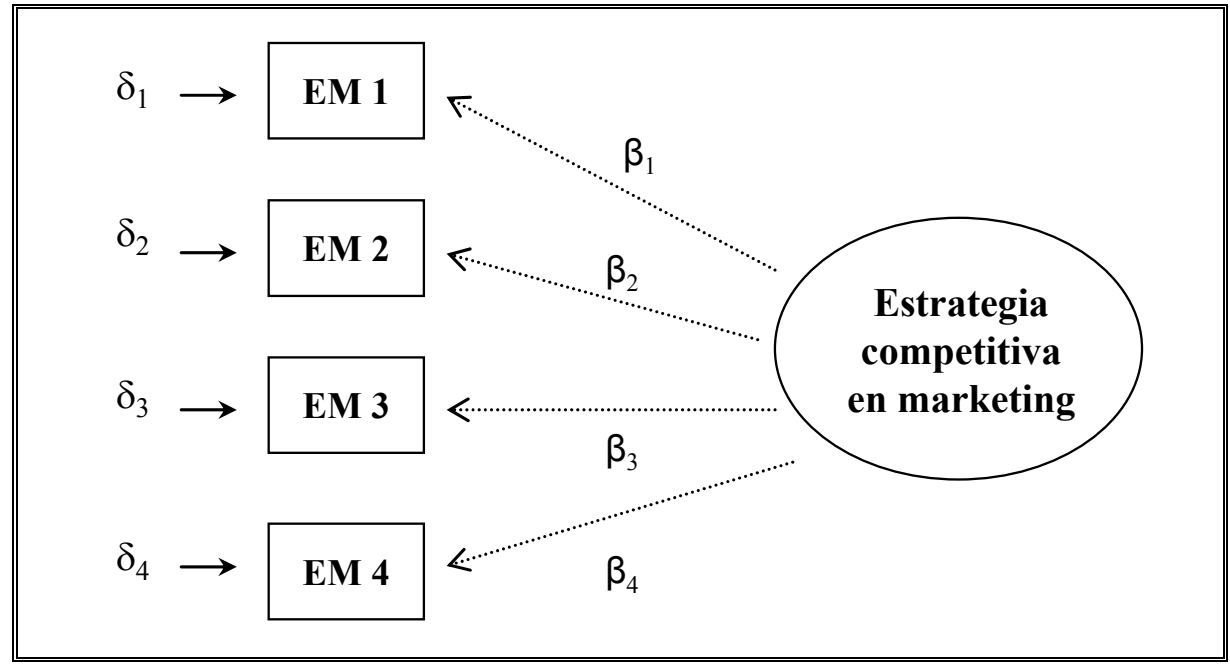

Donde:

$\beta=$ Cargas factoriales de los indicadores

$\delta=$ Errores de medida

Figura 4.2c. Modelo para medir la estrategia competitiva en costes

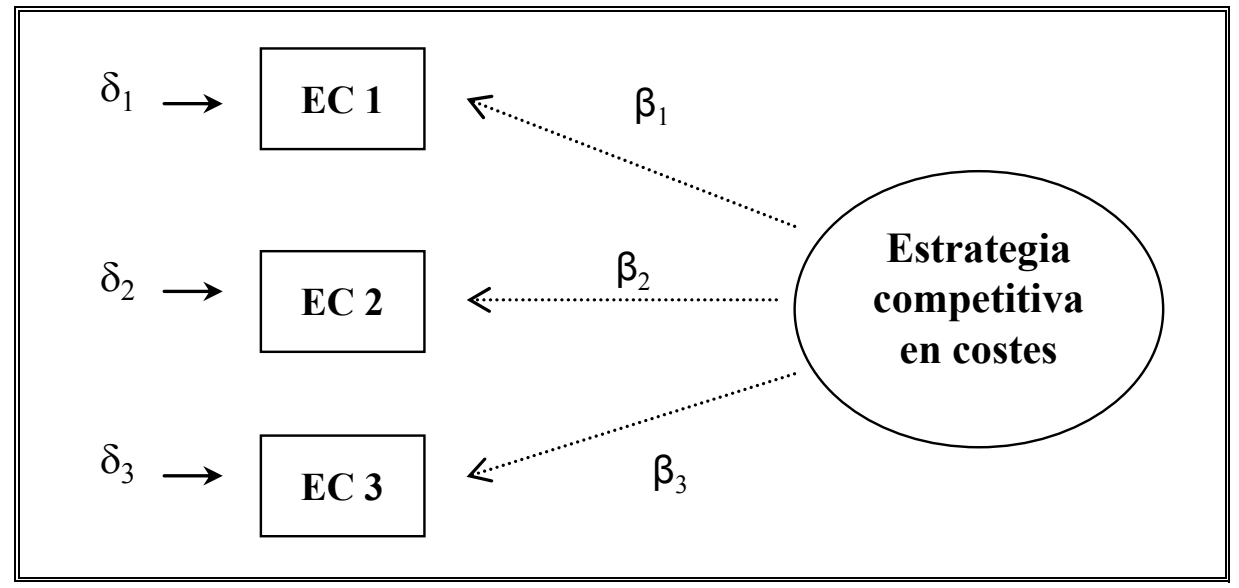

Donde:

$\beta=$ Cargas factoriales de los indicadores

$\delta=$ Errores de medida

Las medias, desviaciones típicas y máximos y mínimos de cada uno de los ítems de las escalas se muestran a continuación. 
Tabla 4.8a. Medias y desviaciones típicas ítems de Estrategia competitiva en innovación

\begin{tabular}{|c|l|c|c|c|c|}
\hline $\mathbf{N}^{\mathbf{1}}$ & \multicolumn{1}{|c|}{ Ítem } & $\mathbf{m}$ & $\boldsymbol{\sigma}$ & Mín & Max \\
\hline EI1 & Gasto en I+D para el desarrollo de nuevos productos & 5,08 & 1,433 & 1 & 7 \\
\hline EI2 & Gasto en I+D para innovaciones de proceso & 5,15 & 1,391 & 2 & 7 \\
\hline EI3 & $\begin{array}{l}\text { Énfasis puesto en estar a la cabeza en cuanto a } \\
\text { competitividad }\end{array}$ & 5,08 & 1,504 & 1 & 7 \\
\hline EI4 & Ratio de innovaciones de producto & 4,90 & 1,547 & 1 & 7 \\
\hline \hline
\end{tabular}

Donde:

$$
\begin{aligned}
& m=\text { Media (entre } 1 \text { y } 7) \\
& \sigma=\text { Desviación típica } \\
& n=166
\end{aligned}
$$

Tabla 4.8b. Medias y desviaciones típicas ítems de Estrategia competitiva en marketing

\begin{tabular}{|c|l|c|c|c|c||}
\hline \hline $\mathbf{N}^{\mathbf{1}}$ & \multicolumn{1}{|c|}{ Ítem } & $\mathbf{m}$ & $\boldsymbol{\sigma}$ & Mín & Max \\
\hline EM1 & Innovaciones en técnicas de marketing & 4,75 & 1,488 & 1 & 7 \\
\hline EM2 & $\begin{array}{l}\text { Énfasis en la organización del departamento de } \\
\text { marketing }\end{array}$ & 4,74 & 1,522 & 1 & 7 \\
\hline EM3 & Gasto en publicidad & 4,64 & 1,607 & 1 & 7 \\
\hline EM4 & Énfasis en una fuerza de ventas fuerte & 4,94 & 1,537 & 1 & 7 \\
\hline
\end{tabular}

Donde:

$m=$ Media (entre 1 y 7 )

$\sigma=$ Desviación típica

\begin{tabular}{|c|c|c|c|c|c|}
\hline $\mathbf{N}^{\mathbf{0}}$ & Ítem & m & $\boldsymbol{\sigma}$ & Mín & Max \\
\hline $\mathrm{EC} 1$ & $\begin{array}{l}\text { Modernización y automatización de los procesos de } \\
\text { producción }\end{array}$ & 5,22 & 1,346 & 1 & 7 \\
\hline $\mathrm{EC} 2$ & Esfuerzos en conseguir economías de escala & 5,18 & 1,388 & 1 & 7 \\
\hline EC3 & $\begin{array}{l}\text { Utilización de la capacidad (ocupación de la estructura } \\
\text { de producción) }\end{array}$ & 5,30 & 1,359 & 1 & 7 \\
\hline
\end{tabular}

$n=166$

Tabla 4.8c. Medias y desviaciones típicas de ítems de de Estrategia competitiva en costes

Donde:

$m=$ Media (entre 1 y 7 )

$\sigma=$ Desviación típica

$n=166$ 


\subsubsection{Relación entre ítems de las escalas de estrategia competitiva}

Aunque las tres escalas de estrategia competitiva son conceptualmente diferenciadas, conviene comprobar su independencia, especialmente entre las estrategias de innovación y costes, pues esta última tiene un ítem de automatización y modernización de procesos que puede implicar cierta innovación en procesos. Para comprobarlo, analizaremos las tres escalas de estrategia propuestas (en innovación, en marketing, y en costes) de manera conjunta, realizando un análisis factorial exploratorio con todos los ítems tal como se hizo para las escalas de estrategia en TI. Los resultados se muestran en la siguiente tabla.

Tabla 4.9. Análisis factorial exploratorio de los ítems de estrategia competitiva

Matriz de componentes rotados

\begin{tabular}{|c|c|c|}
\hline \multirow{2}{*}{ Items } & \multicolumn{2}{|c|}{ Factores } \\
\cline { 2 - 3 } & 1 & 2 \\
\hline EI1 & $\mathbf{, 6 0 0}$ &, 503 \\
\hline EI2 & $\mathbf{, 7 0 5}$ &, 462 \\
\hline EI3 & $\mathbf{, 7 7 9}$ &, 327 \\
\hline EI4 &, 469 & $\mathbf{, 6 6 7}$ \\
\hline EM1 &, 319 & $\mathbf{, 7 9 5}$ \\
\hline EM2 &, 334 & $\mathbf{, 7 7 9}$ \\
\hline EM3 &, 145 & $\mathbf{8 3 7}$ \\
\hline EM4 &, 357 & $\mathbf{8 1 3}$ \\
\hline EC1 & $\mathbf{, 8 0 3}$ &, 241 \\
\hline EC2 & $\mathbf{, 8 2 9}$ &, 230 \\
\hline EC3 & $\mathbf{, 6 0 0}$ &, 503 \\
\hline
\end{tabular}

$n=166$ 


\section{Varianza total explicada}

\begin{tabular}{|c|c|c|c|c|c|c|c|c|c|}
\hline \multirow{2}{*}{ Componente } & \multicolumn{3}{|c|}{ Autovalores iniciales } & \multicolumn{3}{|c|}{$\begin{array}{l}\text { Sumas de las saturaciones al } \\
\text { cuadrado de la extracción }\end{array}$} & \multicolumn{3}{|c|}{$\begin{array}{l}\text { Suma de las saturaciones } \\
\text { al cuadrado de la rotación }\end{array}$} \\
\hline & Total & $\begin{array}{c}\% \text { de la } \\
\text { varianza }\end{array}$ & $\begin{array}{c}\% \\
\text { acumulado }\end{array}$ & Total & $\begin{array}{c}\% \text { de la } \\
\text { varianza }\end{array}$ & $\begin{array}{c}\% \\
\text { acumulado } \\
\end{array}$ & Total & $\begin{array}{c}\% \text { de la } \\
\text { varianza }\end{array}$ & $\begin{array}{c}\% \\
\text { acumulado } \\
\end{array}$ \\
\hline 1 & 6,701 & 60,916 & 60,916 & 6,701 & 60,916 & 60,916 & 4,103 & 37,300 & 37,300 \\
\hline 2 & 1,209 & 10,990 & 71,906 & 1,209 & 10,990 & 71,906 & 3,807 & 34,606 & 71,906 \\
\hline 3 & ,658 & 5,977 & 77,884 & & & & & & \\
\hline 4 & ,498 & 4,526 & 82,410 & & & & & & \\
\hline 5 & ,403 & 3,660 & 86,070 & & & & & & \\
\hline 6 & ,331 & 3,008 & 89,078 & & & & & & \\
\hline 7 & ,290 & 2,632 & 91,710 & & & & & & \\
\hline 8 & ,268 & 2,438 & 94,149 & & & & & & \\
\hline 9 & ,243 & 2,206 & 96,355 & & & & & & \\
\hline 10 & ,215 & 1,956 & 98,311 & & & & & & \\
\hline 11 & , 186 & 1,689 & 100,000 & & & & & & \\
\hline
\end{tabular}

La observación de los resultados nos indica la extracción de dos factores, donde los ítems de estrategia de innovación y costes son agrupados en un único factor, exceptuando el ítem de innovación de productos (EI4), que tiene una carga mayor en el factor donde cargan los ítems de estrategia en marketing. Hay que señalar que el ítem EI4 carga de manera muy alta también en el primer factor. La teoría y la definición de los ítems sin embargo justifican la separación en tres factores. Para comprobar esto, se ha realizado un análisis factorial exploratorio forzando la división en tres factores. Los resultados se muestran en la siguiente tabla. 
Tabla 4.10. Análisis factorial exploratorio ítems de estrategia negocio con tres factores

Matriz de componentes rotados

\begin{tabular}{|c|c|c|c|}
\hline \multirow{2}{*}{ Items } & \multicolumn{3}{|c|}{ Factores } \\
\cline { 2 - 4 } & 1 & 2 & 3 \\
\hline EI1 &, 358 &, 243 & $\mathbf{, 8 1 9}$ \\
\hline EI2 &, 343 &, 401 & $\mathbf{, 7 5 1}$ \\
\hline EI3 &, 242 &, 553 & $\mathbf{, 6 2 7}$ \\
\hline EI4 & $\mathbf{, 6 3 4}$ &, 367 & $\mathbf{3 5 7}$ \\
\hline EM1 & $\mathbf{, 8 0 7}$ &, 321 &, 149 \\
\hline EM2 & $\mathbf{, 7 7 2}$ &, 292 &, 228 \\
\hline EM3 & $\mathbf{, 7 9 8}$ &, 037 &, 294 \\
\hline EM4 & $\mathbf{, 8 0 3}$ &, 309 &, 247 \\
\hline EC1 &, 261 & $\mathbf{8 1 5}$ &, 215 \\
\hline EC2 &, 246 & $\mathbf{8 2 8}$ &, 242 \\
\hline EC3 &, 270 & $\mathbf{, 7 9 7}$ &, 344 \\
\hline
\end{tabular}

$$
n=166
$$




\section{Varianza total explicada}

\begin{tabular}{|c|c|c|c|c|c|c|c|c|c|}
\hline \multirow{2}{*}{ Componente } & \multicolumn{3}{|c|}{ Autovalores iniciales } & \multicolumn{3}{|c|}{$\begin{array}{l}\text { Sumas de las saturaciones al } \\
\text { cuadrado de la extracción }\end{array}$} & \multicolumn{3}{|c|}{$\begin{array}{l}\text { Suma de las saturaciones } \\
\text { al cuadrado de la rotación }\end{array}$} \\
\hline & Total & $\begin{array}{c}\% \text { de la } \\
\text { varianza }\end{array}$ & $\begin{array}{c}\% \\
\text { acumulado }\end{array}$ & Total & $\begin{array}{l}\% \text { de la } \\
\text { varianza }\end{array}$ & $\begin{array}{c}\% \\
\text { acumulado } \\
\end{array}$ & Total & $\begin{array}{c}\% \text { de la } \\
\text { varianza }\end{array}$ & $\begin{array}{c}\% \\
\text { acumulado } \\
\end{array}$ \\
\hline 1 & 6,701 & 60,916 & 60,916 & 6,701 & 60,916 & 60,916 & 3,437 & 31,249 & 31,249 \\
\hline 2 & 1,209 & 10,990 & 71,906 & 1,209 & 10,990 & 71,906 & 2,931 & 26,641 & 57,890 \\
\hline 3 & ,658 & 5,977 & 77,884 & ,658 & 5,977 & 77,884 & 2,199 & 19,994 & 77,884 \\
\hline 4 & ,498 & 4,526 & 82,410 & & & & & & \\
\hline 5 & ,403 & 3,660 & 86,070 & & & & & & \\
\hline 6 & ,331 & 3,008 & 89,078 & & & & & & \\
\hline 7 & ,290 & 2,632 & 91,710 & & & & & & \\
\hline 8 & ,268 & 2,438 & 94,149 & & & & & & \\
\hline 9 & ,243 & 2,206 & 96,355 & & & & & & \\
\hline 10 & ,215 & 1,956 & 98,311 & & & & & & \\
\hline 11 & , 186 & 1,689 & 100,000 & & & & & & \\
\hline
\end{tabular}

Los resultados de la tabla 4.10 muestran como las cargas de los ítems se distribuyen en los tres factores como lo esperado según la teoría, exceptuando el ítem EI4, que carga también, y de forma más alta, sobre el factor de marketing. Hay que resaltar que este ítem es que tiene meno carga sobre el factor de marketing, y mantiene una carga cercana a 0.4 sobre el factor de innovación. La ambigüedad de este ítem nos permitiría situarlo en ambas estrategias, pero dado que no afecta al buen ajuste de la escala de estrategia competitiva en innovación, como se verá más en el siguiente epígrafe, se ha decidido mantenerlo en esta escala. 


\subsubsection{Fiabilidad}

Pasamos a continuación a comprobar la fiabilidad de las escalas de estrategia competitiva como en el caso de las escalas de estrategia en TI.

En este caso la única escala saturado ( 3 ítmes), es la de estrategia competitiva en costes, por lo que su fiabilidad será evaluada con el Alpha de Cronbach y el RHO de Sperman y el análisis de los pesos y $\mathrm{R}^{2}$ de los ítems.

Los resultados del análisis factorial confirmatorio para cada una de las tres escalas de estrategia competitiva se muestra a continuación.

\subsubsection{Escala estrategia competitiva en innovación}

El análisis factorial confirmatorio para esta escala muestra los siguientes resultados:

Tabla 4.11. Análisis factorial confirmatorio de la escala estrategia competitiva en innovación

\begin{tabular}{|c|c|c|c|c|}
\hline Ítem & $\boldsymbol{\beta}$ & $\mathbf{t}$ & Errores $(\delta)$ & $\mathbf{R}^{\mathbf{2}}$ \\
\hline EI1 & .854 & 4.381 & .521 & .729 \\
\hline EI2 & .892 & 4.024 & .452 & .796 \\
\hline EI3 & .770 & 5.237 & .638 & .593 \\
\hline EI4 & .692 & 6.746 & .722 & .478 \\
\hline
\end{tabular}

\begin{tabular}{|c|c|c|c|c|c|c||}
\hline g.l. & $\begin{array}{c}\text { Alpha de } \\
\text { Cronbach }\end{array}$ & $\begin{array}{c}\text { RHO de } \\
\text { Spearman }\end{array}$ & RMSEA & $\begin{array}{c}\text { Fiabilidad } \\
\text { compuesta }\end{array}$ & BB NFI & IFI \\
\hline 2 & .875 & .875 & .000 & .815 & .995 & 1.004 \\
\hline
\end{tabular}

$n=166$

Como era de esperar por los resultados del análisis factorial exploratorio, el ítem EI4 tiene una carga baja, pero superior a 0.5. Aún así los índices de ajuste son buenos, lo que permite mantener el ítem sin perjudicar el buen comportamiento de la escala. El resto de ítems tienen unos peso elevados, y los coeficientes de fiabilidad de Conbrach 
(0.875) y Spearman (0.875) son elevados. Todo esto nos permite asegurar la fiabilidad de la escala tal como está propuesta, sin necesidad de eliminar el ítem EI4.

\subsubsection{Escala estrategia competitiva en marketing}

Para la escala de estrategia competitiva en marketing, los resultados del análisis factorial confirmatorio se muestran en la siguiente tabla.

Tabla 4.12. Análisis factorial confirmatorio de la escala estrategia competitiva en marketing

\begin{tabular}{|c|c|c|c|c|}
\hline Ítem & $\boldsymbol{\beta}$ & $\mathbf{t}$ & Errores $(\boldsymbol{\delta})$ & $\mathbf{R}^{\mathbf{2}}$ \\
\hline EM1 & .834 & 7.829 & .552 & .695 \\
\hline EM2 & .806 & 6.536 & .592 & .649 \\
\hline EM3 & .747 & 7.012 & .665 & .558 \\
\hline EM4 & .854 & 5.053 & .521 & .729 \\
\hline
\end{tabular}

\begin{tabular}{|c|c|c|c|c|c|c|}
\hline \hline g.l. & $\begin{array}{c}\text { Alpha de } \\
\text { Cronbach }\end{array}$ & $\begin{array}{c}\text { RHO de } \\
\text { Spearman }\end{array}$ & RMSEA & $\begin{array}{c}\text { Fiabilidad } \\
\text { compuesta }\end{array}$ & BB NFI & IFI \\
\hline 2 & .883 & .884 & .148 & 0,818 & .971 & .978 \\
\hline
\end{tabular}

$n=166$

Por lo que respecta a la fiabilidad individual de los indicadores, todos superan el valor mínimo recomendado de 0,4 , (ver tabla 4.12) para la $\mathrm{R}^{2}$. Todos los pesos $(\beta)$ son elevados, por encima de 0.7 , y con una alta significatividad $(\mathrm{p}<0.001)$. Además, el Alpha de Cronbach y el RHO superan el 0.8. La fiabilidad compuesta es mayor que 0.7.

Los indicadores muestran un buen ajuste, con valores muy por encima del 0.9 recomendado en el BBNFI y el IFI, aunque elevado en el RMSEA. Los pesos de los ítems son todos excelentes, por encima de 0.7. La escala tiene muy alto el Alpha de Cronbach (0.883).

Podemos concluir que la escala es perfectamente fiable, podemos decir que esta escala cumple los requisitos de fiabilidad exigidos. 


\subsubsection{Escala estrategia competitiva en costes}

Por último, para la escala para medir la estrategia competitiva en costes, el análisis confirmatorio se presenta en la siguiente tabla. El modelo es saturado por contar sólo con tres ítems. Los resultados en esta escala también son excelentes. Tanto los pesos individuales de los ítems como sus $\mathrm{R}^{2}$ muy elevadas. Además, los indicadores de fiabilidad superan con creces el 0.7 recomendado. La fiabilidad compuesta es mayor que 0.7 .

Tabla 4.13. Análisis factorial confirmatorio de la escala de estrategia competitiva en costes

\begin{tabular}{|c|c|c|c|c|}
\hline Ítem & $\boldsymbol{\beta}$ & $\mathbf{t}$ & Errores $(\boldsymbol{\delta})$ & $\mathbf{R}^{\mathbf{2}}$ \\
\hline EC1 & .803 & 5.231 & .596 & .644 \\
\hline EC2 & .843 & 4.550 & .538 & .710 \\
\hline EC3 & .892 & 3.690 & .451 & .796 \\
\hline
\end{tabular}

\begin{tabular}{|c|c|c|c||}
\hline g.l. & $\begin{array}{c}\text { Alpha de } \\
\text { Cronbach }\end{array}$ & $\begin{array}{c}\text { RHO de } \\
\text { Spearman }\end{array}$ & $\begin{array}{c}\text { Fiabilidad } \\
\text { compuesta }\end{array}$ \\
\hline 0 & .883 & .884 & .803 \\
\hline
\end{tabular}

$n=166$

Tanto la fiabilidad compuesta como el Alpha de Cronbach son elevados, así como las cargas factoriales.

\subsubsection{Validez}

\subsubsection{Validez de contenido}

Los ítems fueron extraídos de la literatura de "Management", de escalas ya validadas, por lo que se puede considerar que la escala cumple la primera y segunda condición de validez de contenido. 


\subsubsection{Validez de criterio}

La validez de criterio se verificará al comprobar el ajuste del modelo causal y las hipótesis planteadas.

\subsubsection{Validez convergente}

La bondad del indicador BB-NNFI y la magnitud de las cargas factoriales (ver tablas $4.11,4.12$ y 4.13 ) aseguran la validez convergente.

\subsubsection{Validez discriminante}

La validez discriminante la evaluamos mediante la matriz de correlaciones entre diferentes tipos de estrategias competitiva (tabla 4.14). Todos los valores son menores que 0,9 y estadísticamente significativos, por lo que podemos asegurar la validez discriminante de las distintos tipos de estrategia.

Tabla 4.14. Matriz de correlaciones entre estrategias competitiva

\begin{tabular}{|c|c|c|c|}
\hline $\begin{array}{c}\text { Estrategias } \\
\text { competitiva }\end{array}$ & Innovación & Marketing & Costes \\
\hline Innovación & 1 & & \\
\hline Marketing & .733 & 1 & \\
\hline Costes & .759 & .592 & 1 \\
\hline
\end{tabular}

$n=166$

Todos los coeficientes de correlación son estadísticamente significativos $(\mathrm{p} \leq 0,01)$

Una vez comprobada la dimensionalidad, fiabilidad y validez de las tres escalas propuestas para medir las estrategias competitivas, podemos concluir que cumplen todas las propiedades sociométricas que se les exigen a las escalas de medición en las ciencias sociales. 


\subsection{Evaluación de las escala de medida del desempeño}

En este epígrafe se analiza el instrumento utilizado para la medición del Desempeño organizativo. Las medidas propuestas para esta escala son objetivas, utilizando los datos disponibles en la base de datos SABI. Dada la complejidad de poder construir una escala que cumpla los criterios de validez convergente con datos económicos dispares como son el beneficio económico, el beneficio financiero, productividad, etc., se optó por analizar aquellas variables más relacionadas, en este caso las de beneficio (\%). Las indicadores seleccionados son los siguientes (en inglés según como aparecen en la base de datos SABI): Rentabilidad sobre activos (Return on Total Assets, ROA), Margen de Beneficios (\%) (Profit Margin, PM) y Beneficio por empleado en miles de euros (Profit per employee, $\mathrm{PpE})$.

Los indicadores se consideran que tienen una única carga factorial positiva en el factor que miden. También se supone que los errores de medida de la escala no están correlacionados.

La siguiente figura representa el modelo de medida con sus ítems.

Figura 4.3. Modelo para medir el desempeño organizativo

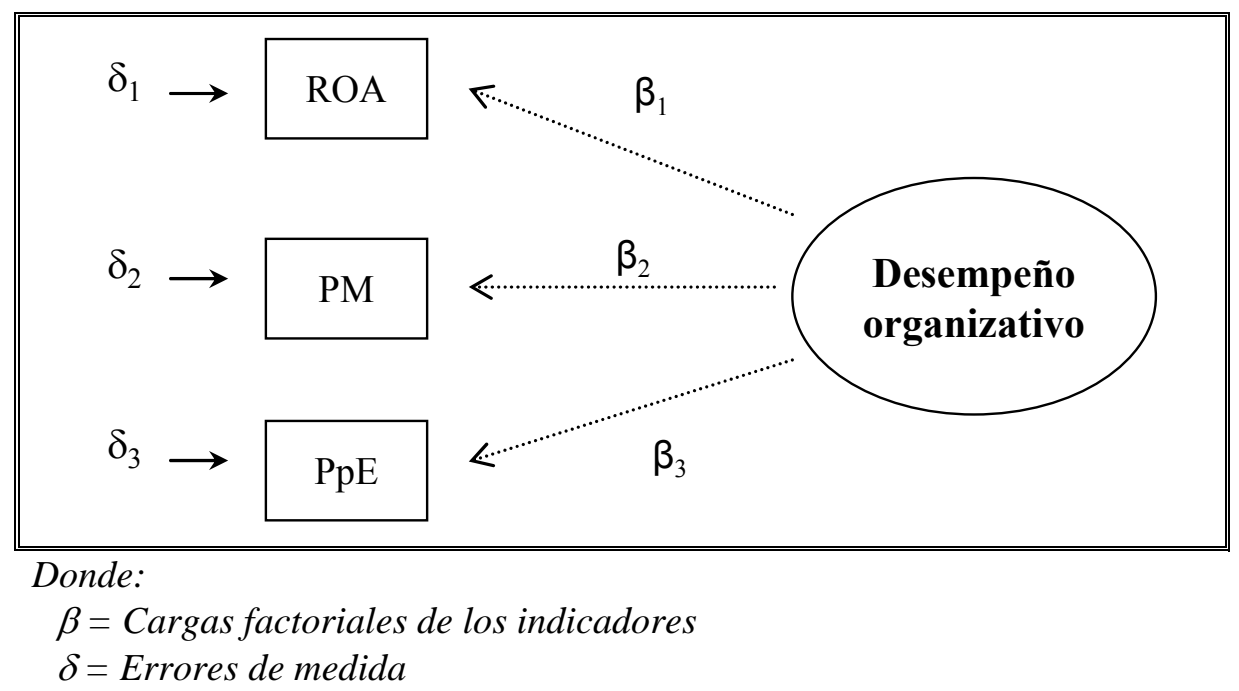

Las medias, desviaciones típicas y máximos y mínimos de cada uno de los parámetros objetivos de la escala se muestran a continuación. 
Tabla 4.15. Medias y desviaciones típicas de medidas objetivas del desempeño

\begin{tabular}{|c|l|c|c|c|c||}
\hline $\mathbf{N}^{\mathbf{0}}$ & \multicolumn{1}{|c|}{ Ítem } & $\mathbf{m}$ & $\boldsymbol{\sigma}$ & \multicolumn{1}{|c|}{ Min } & Max \\
\hline ROA & Rentabilidad sobre activos (Return on Total Assets) & $-1,10$ & 11,61 & $-45,24$ & 26,82 \\
\hline PM & Margen de Beneficios (\%) (Profit Margin) & $-2,24$ & 24,57 & -151 & 151 \\
\hline PpE & $\begin{array}{l}\text { Beneficio por empleado en miles de euros (Profit per } \\
\text { employee, PpE) }\end{array}$ &,- 58 & 28,21 & -98 & 220 \\
\hline
\end{tabular}

Donde:

$$
\begin{aligned}
& m=\text { Media } \\
& \sigma=\text { Desviación típica } \\
& n=166
\end{aligned}
$$

\subsubsection{Fiabilidad}

Pasamos a continuación a comprobar la fiabilidad de la escala de desempeño. La escala está saturada, con sólo tres ítems, por lo que su fiabilidad será evaluada con el Alpha de Cronbach y el RHO de Sperman y el análisis de los pesos y $\mathrm{R}^{2}$ de los indicadores.

Los resultados del análisis factorial confirmatorio se muestra a continuación:

Tabla 4.16. Análisis factorial confirmatorio de la escala de estrategia competitiva en costes

\begin{tabular}{|c|c|c|c|c|}
\hline Ítem & $\boldsymbol{\beta}$ & $\mathbf{t}$ & Errores $(\boldsymbol{\delta})$ & $\mathbf{R}^{\mathbf{2}}$ \\
\hline $\mathrm{ROA}$ & .879 & 1.116 & .476 & .773 \\
\hline $\mathrm{PM}$ & .944 & .857 & .330 & .891 \\
\hline $\mathrm{PpE}$ & .746 & 1.568 & .665 & .557 \\
\hline
\end{tabular}

\begin{tabular}{|c|c|c|c||}
\hline g.l. & $\begin{array}{c}\text { Alpha de } \\
\text { Cronbach }\end{array}$ & $\begin{array}{c}\text { RHO de } \\
\text { Spearman }\end{array}$ & $\begin{array}{c}\text { Fiabilidad } \\
\text { compuesta }\end{array}$ \\
\hline 0 & .896 & .897 & .818 \\
\hline
\end{tabular}

$$
n=166
$$

Como se puede observar, los indicadores de fiabilidad son excelentes, así como los pesos y los $\mathrm{R}^{2}$. Como era de esperar, la significatividad de los pesos desciende, especialmente en el margen de beneficios, aunque tiene un significatividad cercana al 
$80 \%$. Esta escala objetiva conjunta de tres indicadores económicos da gran solidez a los resultados que se puedan obtener. La fiabilidad compuesta es mayor que 0.7.

\subsubsection{Validez}

\subsubsection{Validez convergente}

La bondad de los indicadores y de fiabilidad y la magnitud de las cargas factoriales (ver tablas 4.16) aseguran la validez convergente.

\subsection{Contraste de las hipótesis}

\subsubsection{Criterios de evaluación de las hipótesis}

Las hipótesis teóricas planteadas en el trabajo suponen que las estrategias en TI moderan la relación entre estrategias competitiva y el desempeño organizativo. Es decir, analiza si una determinada estrategia en TI favorece la consecución de los objetivos de las diferentes estrategias competitivas. Para contrastar estas hipótesis, planteamos un modelo estructural por cada relación y comprobaremos su ajuste y sus relaciones estructurales. Para poder analizar la relación de moderación de las estrategias en TI, dividiremos la muestra en dos, de manera que se pueda contrastar la relación estrategia competitiva y desempeño para la muestra alta en una determinada estrategia en TI y la baja. Además de esta contrastación de las hipótesis planteadas, se realizará un examen previo, relacionada con las hipótesis nulas implícitas en el trabajo, donde se revisará la relación entre las distintas estrategias competitiva y el desempeño, y las distintas estrategias en TI y el desempeño. Todos estos análisis se realizarán con ecuaciones estructurales.

Para la evaluación del ajuste de los datos a los modelos propuestos utilizaremos tres análisis: el ajuste del modelo global, el ajuste del modelo de medida y el ajuste del modelo estructural. 


\subsubsection{Ajuste global del modelo}

Para comprobar el ajuste global del modelo examinamos los principales indicadores ya comentado en el apartado 4.1 y que se muestran en el tabla 4.1. La bondad de estos indicadores demostraría que el modelo considerado es una representación adecuada del conjunto de relaciones causales entre las variables estudiadas.

\subsubsection{2. $\quad$ Ajuste del modelo de medida}

Aunque hemos validado y el resto de variables utilizadas en las hipótesis, cuando se trabaja con modelos estructurales puede darse el caso de que un indicador que sea válido para medir un concepto, no lo sea cuando se incluye en el modelo causal. Por ello, es necesario estimar los diferentes parámetros, tanto exógenos como endógenos, en el modelo de medida de las hipótesis. Además, todas las cargas factoriales deben superan el valor de 0,6 para mostrar un buen ajuste, o en todo caso superar el mínimo de 0,4 , y además deben ser estadísticamente significativas al $95 \%(\mathrm{t} \geq 1,96)$.

Una vez analizadas las cargas, hay que observar los indicadores utilizados para medir los factores latentes. Para ello estudiaremos individualmente la fiabilidad de cada indicador y la fiabilidad compuesta de cada factor involucrado en el modelo. El valor de la fiabilidad compuesta tiene que ser superior a 0,7. Asimismo, los indicadores deben superan el valor mínimo de aceptación de 0,5 . Con esto se comprueba que el modelo de medida para los conceptos involucrados dispone de indicadores fiables y válidos para su medición.

\subsubsection{Ajuste del modelo estructural}

Para comprobar el ajuste del modelo estructural hay que verificar que los coeficientes estimados tienen significación. En caso de no ser significativos, el modelo no tendría validez positiva. Para ello se evaluarán los coeficientes $\beta$ (coeficiente de relación entra variables latentes) en las ecuaciones de los modelo y se comprobará que el coeficiente es estadísticamente significativo (t mayor que 1,96). Para analizar la fiabilidad de las ecuaciones estructurales comprobaremos el coeficiente $\mathrm{R}^{2}$ de los coeficientes $\beta$. Este coeficiente indica en qué porcentaje la varianza de una variable endógena queda 
explicada por la varianza de la variable exógena. Este valor debe ser significativo y teóricamente congruente, lo que indicaría que los resultados son en este aspecto fiables.

A continuación pasamos a analizar cada una de las hipótesis planteadas siguiendo estos criterios generales, pero antes analizaremos la relación entres las estrategias competitiva y el desempeño, y las estrategias en TI y el desempeño, para establecer las hipótesis nulas.

\subsubsection{Relación entre las estrategias en TI y el desempeño organizativo.}

Como ya se ha comentado en el desarrollo teórico, la relación entre estrategias en TI y desempeño es una relación compleja y ambigua. Los estudios muestran diferentes resultados empíricos. Nuestro posicionamiento teórico considera que la eficacia de las diferentes estrategias en TI depende del valor de los procesos a los que se aplique y la capacidad de replicabilidad del sistema final por parte de los competidores. Por tanto, a priori, una determinada estrategia sin considerar las actividades competitivas donde se aplique tiene que tener unos resultados poco determinantes en el desempeño. Esta hipótesis nula, representa la hipótesis que mantendremos a no ser que los datos indiquen su falsedad. Pasaremos a analizar esta hipótesis para cada una de las estrategias.

\subsubsection{Relación estrategia innovadora en TI y desempeño organizativo}

Para analizar la relación estrategia innovadora en TI y desempeño organizativo planteamos el modelo estructural de la figura 4.4. 
Figura 4.4. Modelo Estrategia Innovadora en TI - Desempeño Organizativo

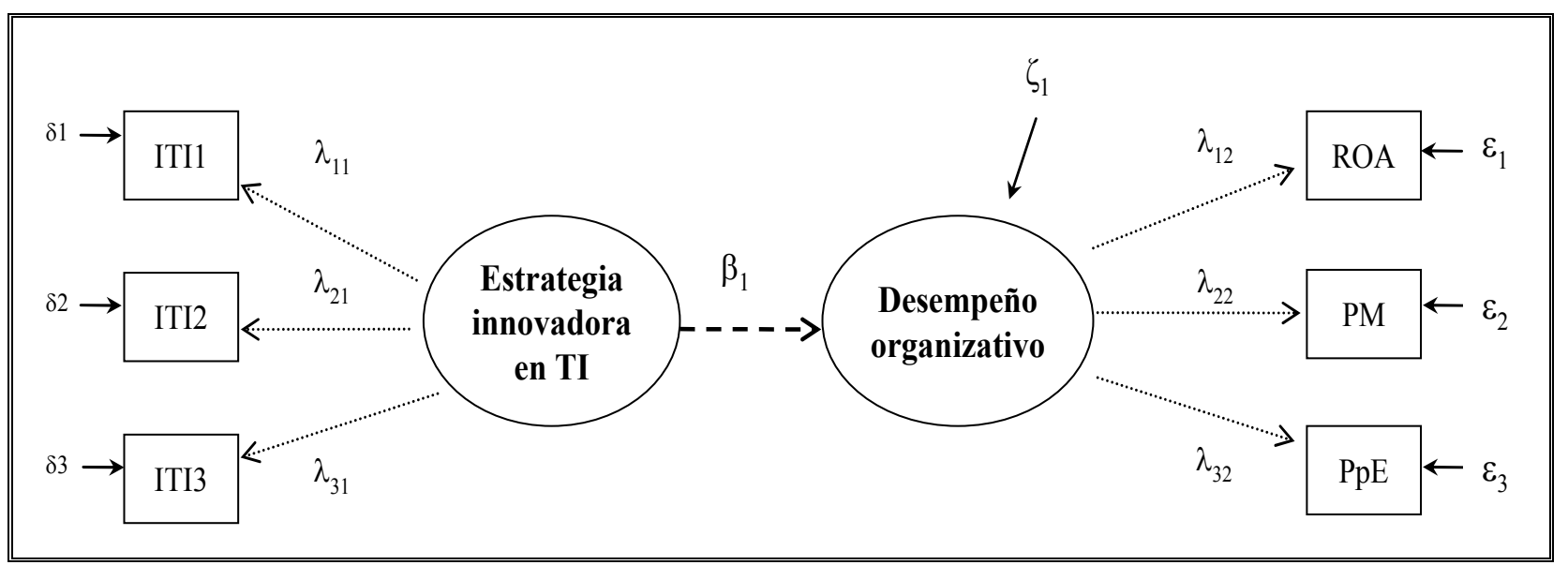

El modelo estructural está formado por una variable latente exógena ITI (Estrategia innovadora en TI) y una variable latente endógena DES (Desempeño organizativo). La variable de Desempeño está compuesta por tres indicadores, el ROA, el margen de beneficios (PM) y los Beneficios por Empleados $(\mathrm{PpE})$ en miles de euros. La estrategia innovador en TI está compuesta por 3 indicadores.

Las ecuaciones estructurales relacionan las variables de la siguiente manera:

$$
\begin{aligned}
& I T I=I T I \lambda_{11}+\delta_{1} \\
& I T I 2=I T I \lambda_{21}+\delta_{2} \\
& I T I 3=I T I \lambda_{31}+\delta_{3} \\
& \text { ROA =DES } \lambda_{12}+\varepsilon_{1} \\
& P M=D E S \lambda_{22}+\varepsilon_{2} \\
& P p E=D E S \lambda_{32}+\varepsilon_{3} \\
& D E S=I T I \beta_{1}+\zeta_{1}
\end{aligned}
$$

Siendo: $\quad \delta$ y $\varepsilon=$ errores de medida

$$
\zeta=\text { perturbación aleatoria }
$$

\subsection{Ajuste global del modelo}

Los índices presentados en la tabla 4.17 evidencian un muy buen ajuste global, por lo que podemos afirmar que el modelo considerado es una representación adecuada de la relación causal entre las variables latentes estudiadas. 
Tabla 4.17. Índices de ajuste del modelo innovador en TI-Desempeño

\begin{tabular}{|c|c|c|c|c|c|}
\hline g.l. & $\begin{array}{c}\text { Chi }^{2} \\
\text { Satorra-Bentler }\end{array}$ & RMSEA & BB NNFI & IFI & NC \\
\hline 8 & 8.7471 & .032 & .970 & .997 & 1.09 \\
\hline
\end{tabular}

$$
n=166
$$

Las medidas absolutas de ajuste son excelentes. Las medidas incrementales de ajuste también presentan niveles muy satisfactorios, situándose el BB NNFI muy cerca de la unidad. El índice IFI está muy por encima de su umbral de aceptación de 0,9. Finalmente, la medida de ajuste de parsimonia se sitúa entre 1 y 2.

\subsection{Ajuste del modelo de medida}

En la tabla 4.18 podemos observar que los parámetros estructurales del modelo exógeno y endógeno son satisfactorios. Todas las cargas factoriales son elevadas y significativas, exceptuando PM.

Tabla 4.18. Cargas factoriales y errores del modelo innovador en TI - Desempeño

\begin{tabular}{|c|c|c|c|c|}
\hline Modelo & ITI & DES & \multirow{2}{*}{ Errores } & \multirow{2}{*}{$\mathbf{R}^{2}$} \\
\hline Indicador & $\lambda_{\mathrm{x} 1}$ & $\lambda_{\mathrm{x} 2}$ & & \\
\hline ITI1 & $.888 *$ & & .459 & .789 \\
\hline ITI2 & .933 & & .360 & .871 \\
\hline ITI3 & .865 & & .502 & .748 \\
\hline ROA & & $.868 *$ & .496 & .754 \\
\hline $\mathrm{PM}$ & & .961 & .277 & .923 \\
\hline $\mathrm{PpE}$ & & .592 & .806 & .351 \\
\hline Fiabilidad compuesta & .845 & .788 & & \\
\hline
\end{tabular}

Los parámetros señalados con * se han igualado a 1 con el fin de fijar la escala de la variable latente. Todos los parámetros estimados son estadísticamente significativos al $95 \%(t>1,96)$

Las medidas de fiabilidad compuesta superan el umbral de 0,7 , por lo que podemos concluir que la fiabilidad del modelo es correcta. 


\subsection{Ajuste del modelo estructural}

En la tabla 4.19 podemos comprobar la relación entre los dos constructos del modelo. El coeficiente $\beta$ de la ecuación estructural no es significativo $(\mathrm{t}=-1.098)$ y la fiabilidad de la ecuación estructural $\left(\mathrm{R}^{2}\right)$ es muy reducida.

Tabla 4.19. Carga e índice de fiabilidad en el modelo innovador en TI - Desempeño

\begin{tabular}{|l|c|c|c|}
\hline Relación & $\boldsymbol{\beta}_{\mathbf{1}}$ & $\zeta_{\mathbf{1}}$ & $\mathbf{R}^{\mathbf{2}}$ \\
\hline Innovador en TI $\rightarrow \beta_{1} \rightarrow$ Desempeño & -.110 & .994 & .012 \\
\hline
\end{tabular}

NO es estadísticamente significativo al $95 \%(t>1,96)$

$$
n=166
$$

Tras estos análisis podemos afirmar que la prueba empírica realizada sugiere que ser innovador en TI de manera genérica no tiene impacto sobre el desempeño organizativo. Este resultado es acorde con la revisión de la literatura sintetizada en el epígrafe 2.5

\subsubsection{Relación estrategia conservadora en TI y desempeño organizativo}

Para analizar la relación estrategia conservadora en TI y desempeño organizativo planteamos el modelo estructural de la figura 4.5.

Figura 4.5. Modelo estrategia conservadora en TI - desempeño organizativo

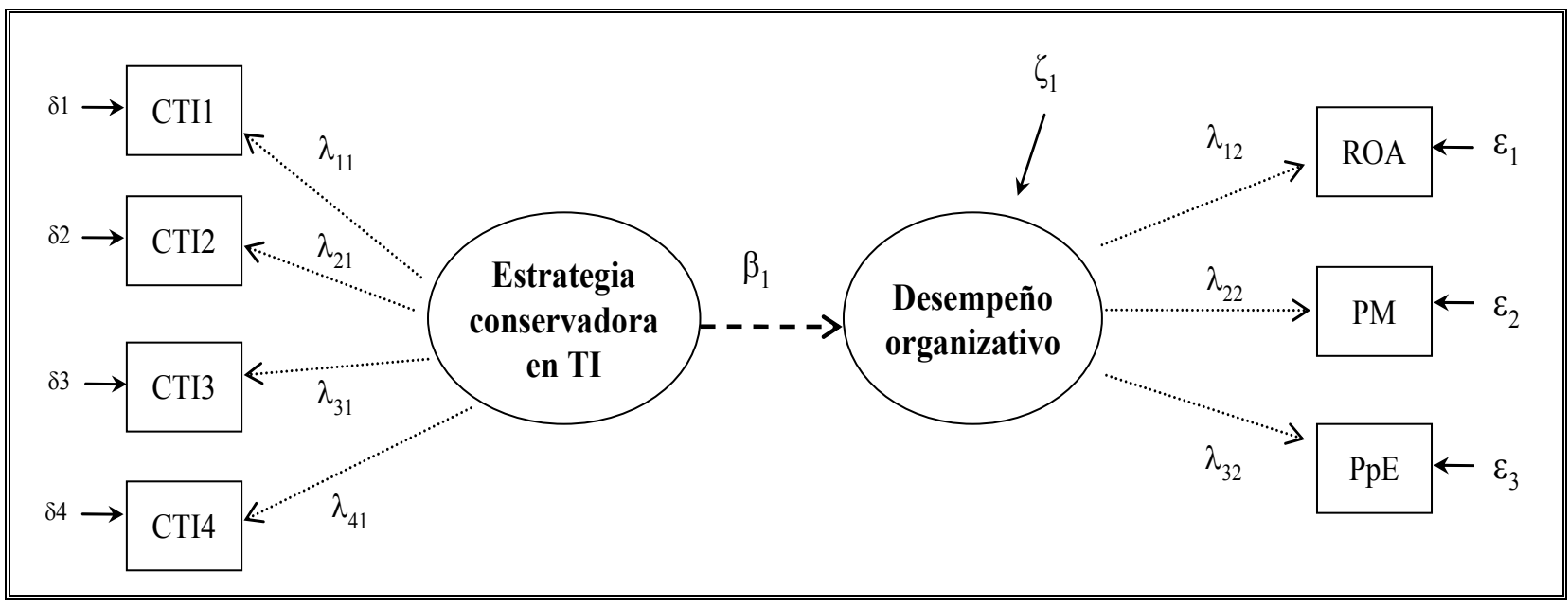


El modelo estructural está formado por una variable latente exógena CTI (Estrategia conservadora en TI) y una variable latente endógena DES (Desempeño organizativo). La variable de Desempeño está compuesta por tres indicadores, el ROA, el margen de beneficios $(\mathrm{PM})$ y los Beneficios por Empleados $(\mathrm{PpE})$ en miles de euros. La estrategia conservadora en TI está compuesta por 4 indicadores.

Las ecuaciones estructurales relacionan las variables de la siguiente manera:

$$
\begin{aligned}
& C T I 1=C T I \lambda_{11}+\delta_{1} \\
& C T I 2=C T I \lambda_{21}+\delta_{2} \\
& C T I 3=C T I \lambda_{31}+\delta_{3} \\
& C T I 4=C T I \lambda_{41}+\delta_{4} \\
& \text { ROA = DES } \lambda_{12}+\varepsilon_{1} \\
& \text { PM =DES } \lambda_{22}+\varepsilon_{2} \\
& \text { PPE =DES } \lambda_{32}+\varepsilon_{3} \\
& D E S=C T I \beta_{1}+\zeta_{1}
\end{aligned}
$$

Siendo: $\quad \delta$ y $\varepsilon=$ errores de medida

$$
\zeta=\text { perturbación aleatoria }
$$

\subsection{Ajuste global del modelo}

Los índices presentados en la tabla 4.20 evidencian un muy buen ajuste global, por lo que podemos afirmar que el modelo considerado es una representación adecuada de la relación causal entre las variables latentes estudiadas.

Tabla 4.20. Índices de ajuste del modelo conservador en TI-Desempeño

\begin{tabular}{|c|c|c|c|c|c|}
\hline g.l. & $\begin{array}{c}\text { Chi }^{2} \\
\text { Satorra-Bentler }\end{array}$ & RMSEA & BB NNFI & IFI & NC \\
\hline 13 & 11.0779 & .000 & 1.018 & 1.010 & .90 \\
\hline
\end{tabular}

$$
n=166
$$

Las medidas absolutas de ajuste son buenas. 


\subsection{Ajuste del modelo de medida}

En la tabla 4.21 podemos observar que los parámetros estructurales del modelo exógeno y endógeno son satisfactorios. Todas las cargas factoriales son elevadas y significativas, exceptuando PM.

Tabla 4.21. Cargas factoriales y errores del modelo conservador en TI - Desempeño

\begin{tabular}{|l|c|c|c|c||}
\hline Modelo & CTI & DES & \multirow{2}{*}{ Errores } & \multirow{2}{*}{$\mathbf{R}^{2}$} \\
\cline { 1 - 2 } Indicador & $\lambda_{\mathbf{x} 1}$ & $\lambda_{\mathbf{x} 2}$ & & .538 \\
\hline CTI1 & $.733^{*}$ & & .680 & .788 \\
\hline CTI2 & .888 & & .460 & .420 \\
\hline CTI3 & .648 & & .761 & .193 \\
\hline CTI4 & .440 & & .898 & .767 \\
\hline POA & & $.876^{*}$ & .483 & .907 \\
\hline PpE & & .952 & .305 & .355 \\
\hline Fiabilidad compuesta & .724 & .596 & .803 & \\
\hline
\end{tabular}

Los parámetros señalados con * se han igualado a 1 con el fin de fijar la escala de la variable latente.

Todos los parámetros estimados son estadísticamente significativos al $95 \%(t>1,96)$

Las medidas de fiabilidad compuesta superan el umbral de 0,7 , por lo que podemos concluir que la fiabilidad del modelo es correcta.

\subsection{Ajuste del modelo estructural}

En la tabla 4.22 podemos comprobar la relación entre los dos constructos del modelo. El coeficiente $\beta$ de la ecuación estructural no es significativo $(\mathrm{t}=.074)$ y la fiabilidad de la ecuación estructural (R2) es muy reducida. 
Tabla 4.22. Carga e índice de fiabilidad en el modelo conservador en TI - Desempeño

\begin{tabular}{|l|c|c|c|}
\hline Relación & $\boldsymbol{\beta}_{\mathbf{1}}$ & $\zeta_{\mathbf{1}}$ & $\mathbf{R}^{\mathbf{2}}$ \\
\hline Conservador en TI $\rightarrow \beta_{1} \rightarrow$ Desempeño & .008 & 1.000 & .000 \\
\hline
\end{tabular}

$$
n=166
$$

NO es estadísticamente significativo al $95 \%(t>1,96)$

En este caso, una estrategia conservadora tiene mucha menos significatividad, en el desempeño que una estrategia innovadora, aunque este último caso negativa, aunque sin llegar a ser significativa al 95\%.

\subsubsection{Relación "sin estrategia en TI" y desempeño organizativo}

Para analizar la relación entre la falta de estrategia en TI y desempeño organizativo planteamos el modelo estructural de la figura 4.6.

Figura 4.6. Modelo sin estrategia en TI - Desempeño Organizativo

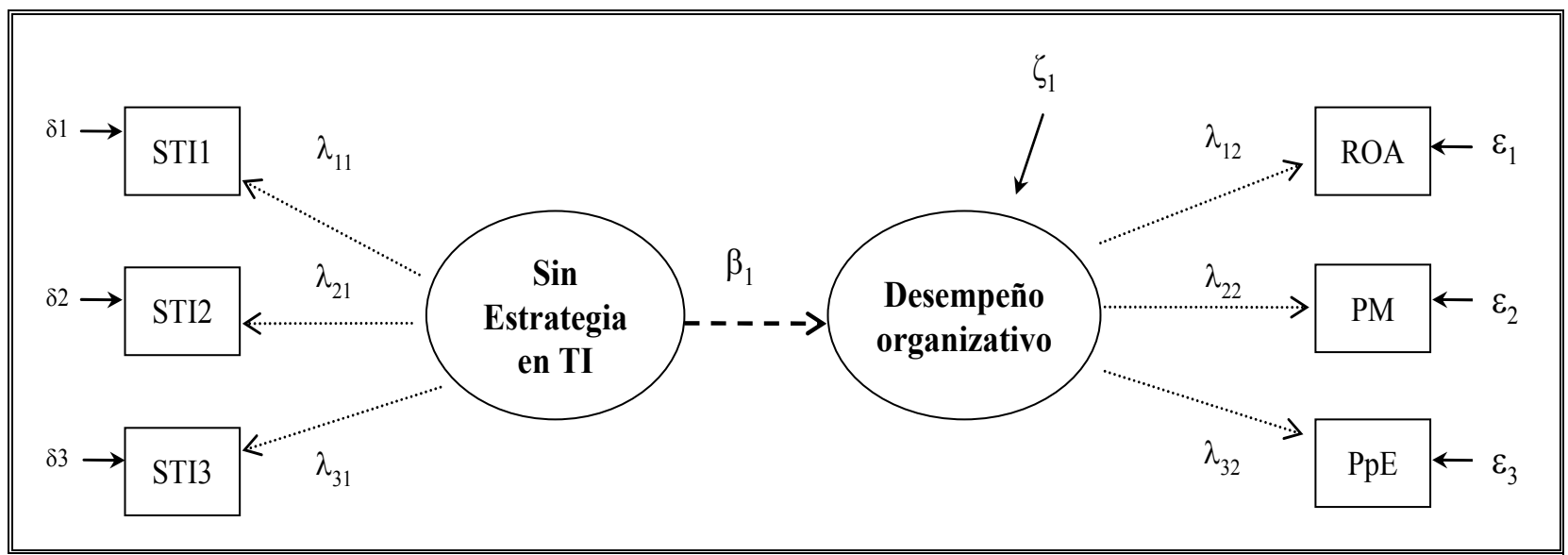

El modelo estructural está formado por una variable latente exógena STI (Sin estrategia en TI) y una variable latente endógena DES (Desempeño organizativo). La variable de Desempeño está compuesta por tres indicadores, el ROA, el margen de beneficios (PM) 
y los Beneficios por Empleados (PpE) en miles de euros. La estrategia conservadora en TI está compuesta por 3 indicadores.

Las ecuaciones estructurales relacionan las variables de la siguiente manera:

$$
\begin{aligned}
& S T I 1=S T I \lambda_{11}+\delta_{1} \\
& S T I 2=S T I \lambda_{21}+\delta_{2} \\
& S T I 3=S T I \lambda_{31}+\delta_{3} \\
& R O A=D E S \lambda_{12}+\varepsilon_{1} \\
& P M=D E S \lambda_{22}+\varepsilon_{2} \\
& P P E=D E S \lambda_{32}+\varepsilon_{3} \\
& D E S=C T I \beta_{1}+\zeta_{1}
\end{aligned}
$$

Siendo: $\quad \delta$ y $\varepsilon=$ errores de medida

$$
\zeta=\text { perturbación aleatoria }
$$

\subsection{Ajuste global del modelo}

Los índices presentados en la tabla 4.23 evidencian un muy buen ajuste global, por lo que podemos afirmar que el modelo considerado es una representación adecuada de la relación causal entre las variables latentes estudiadas.

Tabla 4.23. Índices de ajuste del modelo "sin estrategia en TI"-Desempeño

\begin{tabular}{|c|c|c|c|c|c|}
\hline g.l. & $\begin{array}{c}\text { Chi }^{2} \\
\text { Satorra-Bentler }\end{array}$ & RMSEA & BB NNFI & IFI & NC \\
\hline 8 & 9.4182 & .043 & .990 & .995 & 1.18 \\
\hline
\end{tabular}

$$
n=166
$$

Las medidas absolutas de ajuste son buenas.

4.6.2.3.2 Ajuste del modelo de medida 
En la tabla 4.24 podemos observar que los parámetros estructurales del modelo exógeno y endógeno son satisfactorios. Todas las cargas factoriales son elevadas y significativas, exceptuando PM.

Tabla 4.24. Cargas factoriales y errores del modelo sin estrategia en TI - Desempeño

\begin{tabular}{|l|c|c|c|c||}
\hline Modelo & STI & DES & \multirow{2}{*}{ Errores } & \multirow{2}{*}{$\mathbf{R}^{\mathbf{2}}$} \\
\cline { 1 - 3 } Indicador & $\lambda_{\mathbf{x} 1}$ & $\lambda_{\mathbf{x} 2}$ & & .669 \\
\hline STI1 & .818 & & .575 & .946 \\
\hline STI2 & .973 & & .232 & .851 \\
\hline STI3 & .922 & & .386 & .765 \\
\hline ROA & & .875 & .485 & .911 \\
\hline PM & & .954 & .298 & .353 \\
\hline PpE & & .594 & .804 & \\
\hline Fiabilidad compuesta & .86 & .79 & & \\
\hline
\end{tabular}

$$
n=166
$$

Los parámetros señalados con * se han igualado a 1 con el fin de fijar la escala de la variable latente. Todos los parámetros estimados son estadísticamente significativos al $95 \%(t>1,96)$

Las medidas de fiabilidad compuesta superan el umbral de 0,7 , por lo que podemos concluir que la fiabilidad del modelo es correcta.

\subsection{Ajuste del modelo estructural}

En la tabla 4.25 podemos comprobar la relación entre los dos constructos del modelo. El coeficiente $\beta$ de la ecuación estructural no es significativo $(\mathrm{t}=-0.834)$ y la fiabilidad de la ecuación estructural $\left(\mathrm{R}^{2}\right)$ es muy reducida.

Tabla 4.25. Carga e índice de fiabilidad en el modelo sin estrategia en TI - Desempeño

\begin{tabular}{|l|c|c|c|}
\hline Relación & $\boldsymbol{\beta}_{\mathbf{1}}$ & $\zeta_{\mathbf{1}}$ & $\mathbf{R}^{\mathbf{2}}$ \\
\hline Sin estrategia en TI $\rightarrow \beta_{1} \rightarrow$ Desempeño & -.078 & .997 & .006 \\
\hline \hline
\end{tabular}

$$
n=166
$$

NO es estadísticamente significativo al $95 \%(t>1,96)$ 
Tras estos análisis podemos afirmar que la prueba empírica realizada sugiere que no tener una estrategia en TI no tiene impacto negativo significativo sobre el desempeño organizativo.

\subsubsection{Relación entre las estrategias competitivas y el desempeño organizativo.}

Aunque la relación directa entre estrategias competitivas y desempeño organizativo no es el objeto de este trabajo, es necesario ver su comportamiento antes de estudiar la mediación de la estrategia en TI en esta relación. Por esta razón se muestran los resultados de manera conjunta, reducida y gráfica.

Al igual que para las estrategias en TI, se recorrió a modelos estructurales. Los resultados se muestran de manera sinóptica a continuación:

\subsubsection{Estrategia competitiva basada en innovación}

Tabla 4.26. Índices de ajuste del modelo E. $N$ basada en innovación -Desempeño

\begin{tabular}{|c|c|c|c|c|c|}
\hline g.l. & $\begin{array}{c}\text { Chi }^{\mathbf{2}} \\
\text { Satorra-Bentler }\end{array}$ & RMSEA & BB NNFI & IFI & NC \\
\hline 13 & 12.54 & .000 & 1.00 & 1.002 & .964 \\
\hline
\end{tabular}

$$
n=166
$$


Tabla 4.27. Cargas factoriales y errores del modelo E.N. basado en innovación-Desempeño

\begin{tabular}{|l|c|c|c|c||}
\hline Modelo & $\begin{array}{c}\text { E.N. } \\
\text { Innovación }\end{array}$ & DES & \multirow{2}{*}{ Errores } & \multirow{2}{*}{$\mathbf{R}^{\mathbf{2}}$} \\
\cline { 1 - 2 } Indicador & $\lambda_{\mathbf{x} 1}$ & $\lambda_{\mathbf{x} 2}$ & & \\
\hline EI1 & .838 & & .546 & .702 \\
\hline EI2 & .913 & & .408 & .834 \\
\hline EI3 & .753 & & .658 & .567 \\
\hline EI4 & .678 & & .736 & .459 \\
\hline ROA & & .916 & .401 & .839 \\
\hline PM & & .910 & .414 & .828 \\
\hline PpE & .81 & .478 & .878 & .228 \\
\hline Fiabilidad compuesta & & & & \\
\hline
\end{tabular}

$$
n=166
$$

Los parámetros señalados con * se han igualado a 1 con el fin de fijar la escala de la variable latente.

Tabla 4.28. Carga e índice de fiabilidad en el modelo E.N. basado en innovación -Desempeño

\begin{tabular}{|l|c|c|c||}
\hline Relación & $\beta_{1}$ & $\zeta_{1}$ & $\mathbf{R}^{2}$ \\
\hline E.N Innovación $\rightarrow \beta_{1} \rightarrow$ Desempeño & $.184 *$ & .983 & .034 \\
\hline
\end{tabular}

$$
n=166
$$

$* \mathrm{t}=1.43$ (no significativo)

\subsubsection{2. $\quad$ Estrategia competitiva basada en marketing}

Tabla 4.29. Índices de ajuste del modelo E.N basada en marketing-Desempeño

\begin{tabular}{|c|c|c|c|c|c|}
\hline g.l. & $\begin{array}{c}\text { Chi }^{2} \\
\text { Satorra-Bentler }\end{array}$ & RMSEA & BB NNFI & IFI & NC \\
\hline 13 & 13.89 & .027 & .994 & .996 & 1.07 \\
\hline
\end{tabular}

$$
n=166
$$


Tabla 4.30. Cargas factoriales y errores del modelo E.N. basada en marketing - Desempeño

\begin{tabular}{|l|c|c|c|c||}
\hline Modelo & $\begin{array}{c}\text { E.N. } \\
\text { marketing }\end{array}$ & DES & \multirow{2}{*}{ Errores } & \multirow{2}{*}{$\mathbf{R}^{\mathbf{2}}$} \\
\cline { 1 - 2 } Indicador & $\lambda_{\mathbf{x} 1}$ & $\lambda_{\mathbf{x} 2}$ & & \\
\hline EM1 & .840 & & .543 & .705 \\
\hline EM2 & .794 & & .608 & .630 \\
\hline EM3 & .785 & & .619 & .617 \\
\hline EM4 & .865 & & .502 & .748 \\
\hline ROA & & .875 & .484 & .766 \\
\hline PM & & .954 & .299 & .911 \\
\hline PpE & & .594 & .805 & .352 \\
\hline Fiabilidad compuesta & .83 & .79 & & \\
\hline
\end{tabular}

$$
n=166
$$

Los parámetros señalados con * se han igualado a 1 con el fin de fijar la escala de la variable latente.

Tabla 4.31. Carga e índice de fiabilidad en el modelo E.N. basado en marketing -Desempeño

\begin{tabular}{|l|c|c|c||}
\hline Relación & $\beta_{1}$ & $\zeta_{1}$ & $\mathbf{R}^{2}$ \\
\hline E.N Marketing $\rightarrow \beta_{1} \rightarrow$ Desempeño & $.125^{*}$ & .992 & .016 \\
\hline
\end{tabular}

$$
n=166
$$

$* \mathrm{t}=1.287$ (no significativo)

\subsubsection{Estrategia competitiva basada en costes}

Tabla 4.32. Índices de ajuste del modelo E. $N$ basada en costes -Desempeño

\begin{tabular}{|c|c|c|c|c|c|}
\hline g.l. & $\begin{array}{c}\text { Chi }^{2} \\
\text { Satorra-Bentler }\end{array}$ & RMSEA & BB NNFI & IFI & NC \\
\hline 8 & 4.5833 & .000 & 1.040 & 1.02 & .57 \\
\hline
\end{tabular}

$$
\mathrm{n}=166
$$


Tabla 4.33. Cargas factoriales y errores del modelo E.N. basada en costes - Desempeño

\begin{tabular}{|l|c|c|c|c||}
\hline Modelo & E.N. Costes & DES & \multirow{2}{*}{ Errores } & \multirow{2}{*}{$\mathbf{R}^{2}$} \\
\cline { 1 - 3 } Indicador & $\lambda_{\mathbf{x} 1}$ & $\lambda_{\mathbf{x} 2}$ & .432 & .814 \\
\hline EC1 & .902 & & .596 & .644 \\
\hline EC2 & .803 & & .580 & .663 \\
\hline EC3 & .815 & & .415 & .827 \\
\hline ROA & & .910 & .401 & .839 \\
\hline PM & & .916 & .876 & .232 \\
\hline PpE & & .482 & & \\
\hline Fiabilidad compuesta & & .76 & & \\
\hline
\end{tabular}

$$
n=166
$$

Los parámetros señalados con * se han igualado a 1 con el fin de fijar la escala de la variable latente.

Tabla 4.34. Carga e índice de fiabilidad en el modelo E.N. basado en costes -Desempeño

\begin{tabular}{|l|c|c|c|}
\hline Relación & $\beta_{1}$ & $\zeta_{1}$ & $\mathbf{R}^{2}$ \\
\hline E.N costes $\rightarrow \beta_{1} \rightarrow$ Desempeño & $.112 *$ & .994 & .013 \\
\hline
\end{tabular}

$n=166$

$*_{\mathrm{t}}=.848$ (no significativo)

\subsubsection{Estadísticos descriptivos de las variables y correlaciones}

Los estadísticos descriptivos de las variables del modelo se muestran a continuación. En este caso se ha considerado los constructos como simple media de sus ítems. Además se han introducido dos variables de control que pueden afectar tanto al desempeño organizativo como a la estrategia en TI. Estas variables de control son el tamaño de la organización, medido como el número de empleados, y la antigüedad de ésta, medida en años. El tamaño es una característica importante de la organización y puede ser determinante para conseguir ventajas competitivas basadas en economías de escala 
(referencia) y para determinar la factibilidad económica de la estrategia en TI basada en innovación (Ray et al., 2005). La antigüedad puede resultar importante a la hora de establecer una imagen reconocible y conseguir una base fiel de clientes. También puede afectar en términos del desarrollo de competencias, aunque también puede afectar negativamente si existe una estructura demasiado anticuada y unas capacidades desfasadas o poco actualizadas por parte del departamento de sistemas de información.

Las medias de las variables y sus desviaciones típicas, junto con las variables de control se muestran en la siguiente tabla.

Tabla 4.35. Medias y desviaciones típicas de las variables

\begin{tabular}{|l|c|c|c|c||}
\hline Variable & Media & $\begin{array}{c}\text { Desviación } \\
\text { Típica }\end{array}$ & Mínimo & Máximo \\
\hline Innovador en TI & 3,4606 & 1,56757 & 1,00 & 7,00 \\
\hline Conservador en TI & 4,5482 & 1,16869 & 1,50 & 7,00 \\
\hline Sin estrategia en TI & 3,0833 & 1,77515 & 1,00 & 7,00 \\
\hline E. negocio basada en innovación & 5,0306 & 1,25373 & 1,50 & 7,00 \\
\hline E. negocio basada en marketing & 4,7712 & 1,32270 & 1,50 & 7,00 \\
\hline E. negocio basada en costes & 5,2154 & 1,24893 & 1,00 & 7,00 \\
\hline Tamaño & 190,34 & 598,837 & 1 & 3828 \\
\hline Antigüedad & 17,3458 & 17,82996 &, 00 & 125,00 \\
\hline Desempeño organizativo & $-4,6967$ & 45,43481 & $-186,42$ & 242,12 \\
\hline
\end{tabular}

$$
n=166
$$

Las variables latentes se han calculado como media de sus indicadores. Las correlaciones entre variables se muestran en la siguiente tabla. 


\section{Tabla 4.36. Correlaciones de las variables}

\begin{tabular}{|c|c|c|c|c|c|c|c|c|}
\hline Variable & 1 & 2 & 3 & 4 & 5 & 6 & 7 & 8 \\
\hline \multicolumn{9}{|l|}{ 1. Innovador en TI } \\
\hline 2. Conservador en TI &,- 027 & & & & & & & \\
\hline 3. Sin estrategia en TI &,$- 193 *$ &,$- 386^{* *}$ & & & & & & \\
\hline 4. E. negocio basada en innovación &, $336 * *$ &, $394 * *$ &,$- 563 * *$ & & & & & \\
\hline 5. E. negocio basada en marketing &, $301 * *$ &, $427 * *$ &,$- 669 * *$ &, $733 * *$ & & & & \\
\hline 6. E. negocio basada en costes &, $287 * *$ &, $426^{* *}$ &,$- 499 * *$ &, $759 * *$ &, $592 * *$ & & & \\
\hline 7. Antigüedad &,- 092 &,- 121 &, 121 &,- 117 &,- 133 &,$- 245^{*}$ & & \\
\hline 8. Tamaño & ,099 & ,096 &, 064 &, 150 &, 151 &, 054 &,- 014 & \\
\hline 9. Desempeño organizativo &,- 065 &, 037 &,- 025 &, 054 &,- 005 &, 134 &, 058 &,- 096 \\
\hline
\end{tabular}




\subsubsection{Moderación de una estrategia en TI sobre el efecto de las estrategias competitiva sobre el desempeño: verificación de las hipótesis.}

Para analizar la validez de las hipótesis se plantearon varias posibles estrategias. Una de las posibles estrategias es mediante un análisis de regresión moderada (Aiken and West 1991). Creando términos de interacción mediante la multiplicación de la variable independiente y la moderadora, y realizando diferentes modelos de regresión, los términos de interacción deben ser significativos para demostrar la interacción. Sin embargo, para el caso que nos ocupa, y tras el examen de la relación directa entre las estrategias en TI y el desempeño (punto 4.5.2) y las estrategias competitivas y el desempeño (punto 4.5.3), es de esperar que el término de interacción obtenga valores poco significativos. Es por ello que se opta no tanto por ver la significatividad de una determina estrategia competitiva sobre el desempeño, si no en observar la significatividad relativa de una determinada estrategia competitiva soportada o no con por una específica estrategia en TI. Para Baron y Kenny (1986, p. 1174) un moderador es una variable, ya sea cualitativas (e.g., sexo, raza, etc.) o cuantitativa que afecta a la dirección y la fuerza de la relación entre una variable independiente o predictora y una variable dependiente. Específicamente, en un contexto de análisis de correlaciones, un moderador es una tercera variable que afecta la correlación de orden cero entre otras dos variables. Así, la significatividad de la diferencia entre dos correlaciones de las mismas variables, evaluadas usando el test $\mathrm{Z}$ de Fisher, es un test directo de la moderación entre las dos muestras independientes.

Para analizar la moderación se dividió la muestra en pares de submuestras y se realizó un análisis de subgrupo. Para el caso del análisis de la estrategia innovadora en TI, por ejemplo, se dividió en dos muestras marcadas como "Alto innovador en TI" y "Bajo innovador en TI" (ver tabla 4.37), con 86 y 80 casos respectivamente. Se realizaron tests $\mathrm{Z}$ de Fisher y ANOVA para comprobar que se pueden considerar muestras aleatorias de una población común como se muestra en las siguientes tablas: 
Tabla 4.37. ANOVA para las variables de control para las dos submuestras alto y bajo innovador en TI

\begin{tabular}{||l|l|l|l|l|l|l||}
\hline \multicolumn{2}{|c|}{ Variable de control } & \multicolumn{1}{|c|}{$\begin{array}{c}\text { Suma de } \\
\text { cuadrados }\end{array}$} & \multicolumn{1}{|c|}{ gl } & $\begin{array}{c}\text { Media } \\
\text { cuadrática }\end{array}$ & \multicolumn{1}{c|}{ F } & \multicolumn{1}{c|}{ Sig. } \\
\hline \multirow{3}{*}{ Antigüedad } & Inter-grupos & 355,015 & 1 & 355,015 & 1,989 &, 161 \\
\cline { 2 - 8 } & Intra-grupos & 20529,617 & 115 & 178,518 & & \\
\cline { 2 - 8 } & Total & 20884,632 & 116 & &, 468 &, 496 \\
\hline \multirow{3}{*}{ No Empleados $^{*}$} & Inter-grupos & 168768,947 & 1 & 168768,947 & & \\
\cline { 2 - 8 } & Intra-grupos & 34616016,941 & 96 & 360583,510 & & \\
\cline { 2 - 8 } & Total & 34784785,888 & 97 & & & \\
\hline
\end{tabular}

Tabla 4.38. ANOVA para las variables de control para las dos submuestras alto y bajo conservador en TI

\begin{tabular}{|c|l|l|l|l|l|l||}
\hline \multicolumn{2}{|c|}{ Variable de control } & \multicolumn{1}{|c|}{$\begin{array}{c}\text { Suma de } \\
\text { cuadrados }\end{array}$} & \multicolumn{1}{|c|}{ gl } & $\begin{array}{c}\text { Media } \\
\text { cuadrática }\end{array}$ & F & Sig. \\
\hline \multirow{4}{*}{ Antigüedad } & Inter-grupos & 396,422 & 1 & 396,422 & 1,331 &, 251 \\
\cline { 2 - 8 } & Intra-grupos & 34538,866 & 116 & 297,749 & & \\
\cline { 2 - 8 } & Total & 34935,288 & 117 & & & \\
\hline \multirow{3}{*}{$N^{o}$ Empleados } & Inter-grupos & 286733,398 & 1 & 286733,398 &, 798 &, 374 \\
\cline { 2 - 8 } & Intra-grupos & 34498052,490 & 96 & 359354,713 & & \\
\cline { 2 - 8 } & Total & 34784785,888 & 97 & & & \\
\hline
\end{tabular}

Tabla 4.39. ANOVA para las variables de control para las dos submuestras alto y bajo sin estrategia en TI

\begin{tabular}{|c|l|l|l|l|l|l|}
\hline \multicolumn{2}{|c|}{ Variable de control } & $\begin{array}{c}\text { Suma de } \\
\text { cuadrados }\end{array}$ & \multicolumn{1}{c|}{ gl } & $\begin{array}{c}\text { Media } \\
\text { cuadrática }\end{array}$ & F & \multicolumn{1}{c|}{ Sig. } \\
\hline \multirow{4}{*}{ Antigüedad } & Inter-grupos & 163118,658 & 1 & 163118,658 & 1,845 &, 177 \\
\cline { 2 - 8 } & Intra-grupos & 9549502,697 & 108 & 88421,321 & & \\
\cline { 2 - 8 } & Total & 9712621,355 & 109 & & & \\
\hline \multirow{3}{*}{$\mathrm{N}^{\text {o Empleados }}$} & Inter-grupos & 96945,595 & 1 & 96945,595 &, 268 &, 606 \\
\cline { 2 - 8 } & Intra-grupos & 34687840,293 & 96 & 361331,670 & & \\
\cline { 2 - 8 } & Total & 34784785,888 & 97 & & & \\
\hline
\end{tabular}

$$
n=166
$$


La media de las variables de control no fue estadísticamente diferente entre las diferentes muestras agrupadas por pares (alto-bajo innovador en TI; alto-bajo conservador en TI; alto-bajo; alto-bajo sin estrategia en TI).

Los análisis de correlaciones se muestran en las siguientes tablas, junto con la significatividad de la diferencia entre submuestras mediante en test $\mathrm{z}$ de Fisher.

Tabla 4.40. Correlaciones y test z de Fisher entre las estrategias competitivas y el desempeño para las submuestras Alto y Bajo innovador en TI

\begin{tabular}{|c|c|c|c|c|}
\hline $\begin{array}{c}\text { Estrategia } \\
\text { competitiva }\end{array}$ & $\begin{array}{c}\text { Alto innovador } \\
\text { en TI }\end{array}$ & $\begin{array}{c}\text { Bajo innovador } \\
\text { en TI }\end{array}$ & Fisher $\mathbf{z}$ & p (one tailed) \\
\hline En Innovación &,- 097 &, 296 & $-2,388$ & 0,0054 \\
\hline En Marketing &,- 117 &, 269 & $-2,334$ & 0,0065 \\
\hline En Costes &, 203 &, 045 & 0,954 & 0,155 \\
\hline
\end{tabular}

Alto innovador en TI $n=86$; Bajo innovador en TI $n=; 80$

Como se puede observar, la diferencia entre submuestras es significativa para innovación y marketing, mostrando que una estrategia innovadora en TI es perjudicial para las actividades de innovación y marketing. Esto confirma las hipótesis uno y tres. La relación se invierte para una estrategia competitiva en costes, mostrando unos resultados peores la muestra bajo innovadora en TI, sin embargo su significatividad es baja, siendo $\mathrm{p}=.155$, por lo que no se puede confirmar que se valida la tercera hipótesis, aunque el cambio de sentido de la relación, además de la diferencia entre los valores de las correlaciones (.203 para un alto innovador en TI y .045 par un bajo innovador) es considerable.

En la siguiente tabla (4.41) se examinan las relaciones para las tres estrategias competitivas consideradas y el desempeño, en las dos submuestras "Alto conservador en TI" y "Bajo conservador en TI". Para a estrategia competitiva en innovación no existe diferencia entre la dos submuestras (.054 y .049 respectivamente). Para la estrategia basada en marketing, una estrategia alta conservadora en TI da mejores resultados, aunque la significatividad es baja $(\mathrm{p}=.125)$. Sin embargo, una estrategia conservadora en TI en costes resulta contraproducente de manera significativa $(p=.0159)$. 
Tabla 4.41. Correlaciones y test z de Fisher entre las estrategias competitivas y el desempeño para las submuestras Alto y Bajo conservador en TI

\begin{tabular}{|c|c|c|c|c|}
\hline $\begin{array}{c}\text { Estrategia } \\
\text { competitiva }\end{array}$ & $\begin{array}{c}\text { Alto conservador } \\
\text { en TI }\end{array}$ & $\begin{array}{c}\text { Bajo conservador } \\
\text { en TI }\end{array}$ & Fisher $\mathbf{z}$ & p (one tailed) \\
\hline En Innovación &, 054 &, 049 & 0,030 & 0,488 \\
\hline En Marketing &, 137 &,- 056 & 1,150 & 0,125 \\
\hline En Costes &,- 167 &, 191 & $-2,146$ & 0,0159 \\
\hline
\end{tabular}

Alto conservador en TI $n=85$; Bajo conservador en TI $n=; 81$

Por último, la tabla 4.42 muestra las correlaciones entre las tres estrategias competitivas consideradas y el desempeño para las dos submuestras "Alto sin estrategia TI" y "Bajo sin estrategia TI". En este caso se ve que las organizaciones con una falta de estrategia en TI obtienen peores resultados, aunque apenas significativo par una estrategia basada en innovación, con una significatividad $\mathrm{p}<0.01$ para costes, $\mathrm{y} \mathrm{p}<0.05$ para marketing.

Tabla 4.42. Correlaciones y test z de Fisher entre las estrategias competitivas y el desempeño para las submuestras Alto y Bajo sin estrategia en TI

\begin{tabular}{|c|c|c|c|c|}
\hline $\begin{array}{c}\text { Estrategia } \\
\text { competitiva }\end{array}$ & $\begin{array}{c}\text { Alto sin estrategia } \\
\text { en TI }\end{array}$ & $\begin{array}{c}\text { Bajo sin estrategia } \\
\text { en TI }\end{array}$ & Fisher $\mathbf{z}$ & p (one tailed) \\
\hline en innovación &, 053 &, 146 & $-0,553$ & 0,290 \\
\hline en marketing &,- 126 &, 180 & $-1,816$ & 0,0347 \\
\hline en costes &,- 227 &, 011 & 1,294 & 0,0978 \\
\hline
\end{tabular}

Alto innovador en TI $n=86$; Bajo innovador en TI $n=; 80$

Para finalizar, la siguiente tabla muestra un resumen de los resultados, donde se muestra la diferencia para cada una de las estrategias entre el valor de la correlación con el desempeño de la muestra "alta" y "baja" de cada una de las estrategias en TI.

Tabla 4.43. Tabla resumen. Diferencia entre correlaciones de las dos submuestras.

\begin{tabular}{|c|c|c|c|}
\hline Estrategia competitiva & $\begin{array}{c}\text { Innovador } \\
\text { en TI }\end{array}$ & Conservador en TI & Sin estrategia en TI \\
\hline en innovación & $-0,393^{* *}$ & 0,005 & $-0,093$ \\
\hline en marketing & $-0,386^{* *}$ & 0,193 & $-0,306^{* *}$ \\
\hline en costes & 0,158 & $-0,358^{* *}$ & $-0,238^{*}$ \\
\hline
\end{tabular}


Pág. 258 de 329 


\section{CONCLUSIONES Y LIINEAS FUTURAS DE INVESTIGACIÓN}


Pág. 260 de 329 


\section{CONCLUSIONES Y LÍNEAS FUTURAS DE INVESTIGACIÓN}

\subsection{Conclusiones}

El objetivo general del presente trabajo ha sido mejorar el conocimiento de las TI como soporte e impulso de la estrategia competitiva de una organización, así como su contribución al desempeño empresarial y la mejora del posicionamiento competitivo. Más concretamente, el objetivo ha sido determinar cómo la elección de una estrategia TI determinada afecta al desempeño empresarial en función de la estrategia genérica adoptada por una organización y si existe alguna combinación de estrategia TI y estrategia de negocio que arroje mejores resultados que otra en términos de desempeño. Puesto que las TI tienen diferentes características desde un punto de vista de replicabilidad y facilidad de imitación dependiendo de la actividad donde se aplica, determinar el valor de las TI y la mejor estrategia en TI desde un punto de vista genérico es ambiguo y poco concluyente.

Una manera de abordar el problema con la menor pérdida de generalidad posible es analizar de la forma más global factible las actividades donde la integración de las TI con las actividades de negocio y la combinación con otros activos estratégicos supongan una barrera para su imitabilidad por parte de los competidores. La decisión de qué estrategia seguir en TI vendría determinada por el valor estratégico que estas actividades suponen para la organización. En el caso de darles un valor alto, una estrategia de innovación en TI podría suponer una fuente de ventaja competitiva sostenible.

La contribución del presente trabajo por tanto ha sido extender la comprensión de la aportación de valor de las TI al negocio como elemento clave y como fuente de ventaja competitiva, así como profundizar en la relación entre estrategia TI y la estrategia de negocio de las organizaciones.

Con este fin, el trabajo se ha dividido en dos partes claramente diferenciadas. La primera parte, de carácter teórico, ha constituído los capítulos 1 y 2 . En el capítulo 1 
se ha realizado una revisión de la literatura sobre el Enfoque Basado en las Competencias con la intención de concretar aquellas características de los recursos, capacidades y competencias que pueden generar y sostener la ventaja competitiva, así como los diferentes tipos de recursos y competencias TI que han sido identificadas en la literatura. Este primer capítulo asienta las bases teóricas con las que abordar los tres objetivos fundamentales del trabajo (ver epígrafe 0.3 ):

- Realizar una revisión del marco teórico que más ha influido en la literatura TI, es decir, el enfoque basado en competencias. Revisar qué recursos, competencias y capacidades TI pueden ser fuente de ventaja competitiva y mejorar el desempeño.

- Establecer un modelo teórico que vincule la estrategia TI como elemento moderador entre la estrategia competitiva y el desempeño.

- Validar empíricamente el modelo en el sector agroalimentario por su importancia económica en España y la escasez de trabajos de esta naturaleza desarrollados en este sector.

El estudio y clasificación de los recursos y competencias realizada en este primer capítulo nos ha permitido analizar, ya en el capítulo 2, el valor que las TI aportan a los organizaciones como elemento generador de ventajas competitivas sostenibles. En función de la consideración de las TI como fuente de ventaja competitiva o no da lugar a un posicionamiento estratégico respecto a éstas por parte de la organización, por lo que es necesario analizar qué estrategias seguir en TI. En este segundo capítulo también se aborda el siguiente objetivo de este trabajo, postulando un modelo que vincula la estrategia TI con la estrategia competitiva y desempeño.

La segunda parte, de carácter empírica, ha pretendido aplicar los conceptos desarrollados previamente. Esta parte está compuesta por el tercer y cuarto capítulo. En el capítulo 3, se han tratado las cuestiones relacionadas con el diseño de la investigación empírica, destacando especialmente los aspectos de carácter metodológico empleados. Así, se han desarrollado todas las cuestiones relativas a la descripción del objeto, la selección de las técnicas de observación y de tratamiento 
de los datos. En este mismo capítulo se han revisado y seleccionado los instrumentos de medida que nos permitieron evaluar las variables involucradas en las hipótesis de trabajo.

Finalmente, en el capítulo 4 se han recogido los resultados que se han obtenido en el estudio empírico, dando respuesta a las hipótesis planteadas. Aplicando la técnica de modelos de ecuaciones estructurales, se ha estimado la importancia de las relaciones de moderación de la estrategia TI entre la estrategia competitiva y el desempeño.

A continuación se presentan las conclusiones sobre los principales puntos de interés que hemos planteado en los objetivos, siguiendo el mismo orden expositivo que se ha seguido a lo largo del trabajo.

\subsubsection{Conclusiones sobre los aspectos teóricos}

El objetivo de la revisión teórica inicial fue realizar un análisis desde el EBC que nos permitiera conocer cuáles eran las características de los recursos, competencias y capacidades que los dotaban de posibilidad de ser fuente de ventajas competitivas sostenibles y consecuentemente mejorar el desempeño organizativo. Una vez desarrollada esta revisión, se profundizó en el análisis de aquellos recursos TI que pueden cumplir dicha función. Consecuentemente, uno de los aspectos teóricos más relevantes del presente trabajo ha sido la realización de una revisión de los recursos, competencias y capacidades TI que son susceptibles de ser valiosos para la organización en términos de ventaja competitiva y desempeño.

Se ha desarrollado una revisión de uno de los aspectos controvertidos que se han dado en la literatura TI desde el enfoque basado en competencias: determinar qué recursos, capacidades y competencias TI deben ser consideradas en el análisis estratégico de una organización, ya que muy pocas han sido claramente definidas y examinadas en detalle (Bhatt y Grover, 2005). Como se ha podido constatar, aunque se han publicado numerosos trabajos con el objetivo de desarrollar un listado de 
recursos, competencias y capacidades TI, estos marcos teóricos no convergen entre sí.

Cuando el concepto de recurso TI es considerado únicamente como equipamiento y software (recursos tangibles), los resultados muestran un poco significativo efecto en el desempeño. Sin embargo, cuando el concepto de recurso TI se amplia a recurso o competencia TI, donde se incluye los recursos intangibles como las habilidades del personal TI, las competencias de los directivos TI o incluso recursos funcionales complementarios habilitados gracias a las TI, los resultados confirman una relación positiva entre las capacidades TI y el desempeño empresarial. Los estudios desde el enfoque basado en competencias de forma recurrente enfatizan el valor de los recursos organizativos complementarios que contribuyen a la integración de las TI en las actividades de negocio.

El segundo elemento teórico básico para esta investigación ha sido la revisión del valor que los diferentes trabajos han otorgado a los recursos, capacidades y competencias TI. Basándonos en la literatura revisada, hemos clasificado los recursos, competencias y capacidades en infraestructura TI, recursos humanos TI y recursos organizativos complementarios.

Respecto a la infraestructura TI, si ésta es considerada en su concepto más restringido y de forma aislada, como los avances y las innovaciones de estas tecnologías son completamente exógenas respecto a las organizaciones fuera de la industria del software y la electrónica están más cerca del concepto "commodity" que de un recurso estratégico. Sin embargo, es posible explicar su valor a través del soporte a capacidades y competencias funcionales (variables mediadoras) como el aprendizaje organizativo, gestión del conocimiento $\mathrm{u}$ otras competencias clave. En estos casos, la integración de la infraestructura TI en distintas funciones de negocio se desarrolla a lo largo del tiempo a través de una serie de decisiones estratégicas enlazadas sobre inversión en TI embebidas con los procesos organizativos, lo que dificulta su imitación y consecuentemente aporta valor en términos de ventaja competitiva o desempeño. 
Respecto a los recursos humanos TI (tanto de carácter técnico como directivo), la revisión manifiesta que las habilidades técnicas o la existencia de un departamento TI simplemente o un programa de formación en TI podrían originar una ventaja competitiva, pero sólo de carácter temporal debido a la posible movilidad de la mano de obra o bien por la externalización de labores tanto técnicas como directivas a empresas especializadas (el llamado "outsourcing"). Consecuentemente si una ventaja competitiva se sustenta sobre la existencia de un departamento TI no sería sostenible debido a las posibilidades de imitación. Sin embargo, aquellos recursos específicos de la empresa con un alto grado de complejidad social, como puede ser el conocimiento compartido entre el área TI y las unidades de atención al cliente por ejemplo, sí pueden ser objeto de ventaja competitiva sostenible. La mejora del desempeño basada en las TI se basará en aquellos activos y capacidades que son desarrollados de forma específica dentro de la empresa y sobre las efectivas relaciones entre las TI y los gestores de otras áreas de negocio.

Los recursos organizativos complementarios incluyen los recursos físicos no TI, recursos humanos no $\mathrm{TI}$, estructura organizativa, políticas y reglas, cultura, etc. Destacan la capacidad de rediseño de procesos en función de las TI, la habilidad para gestionar las relaciones con los agentes relativos a la TI, la capacidad para desarrollar sinergias entre los distintos activos TI y entre los mismos activos y otras áreas de negocio o la existencia de comunicaciones abiertas y consenso organizativo. Los estudios desde el EBC señalan de forma recurrente el valor de estos recursos que contribuyen a la integración de las TI en las actividades de negocio.

Un tercer elemento teórico del presente trabajo es el análisis del concepto estrategia TI en la literatura. Se han identificado tres grandes concepciones: la estrategia TI como soporte a la estrategia competitiva, la estrategia TI como plan maestro de la función SI/TI y la estrategia TI como visión compartida del rol que los sistemas de información juegan en la organización (Chan et al. 2010). En el presente trabajo se ha asumido esta última concepción. En esta concepción, la estrategia TI es vista desde una perspectiva organizativa (Mintzberg, 1978) que guía el futuro de las decisiones y actividades de negocio relacionadas con los Sistemas de Información más que un plan concreto. Esta concepción de estrategia TI nos ha permitido 
independizar la estrategia TI de la estrategia competitiva elegida por la empresa (asumiendo que en ocasiones apoya y en otras guía a la segunda).

\subsubsection{Conclusiones sobre las hipótesis}

Todas las hipótesis planteadas han sido contrastadas empíricamente. Para cada hipótesis se ha planteado un modelo estructural acorde y se ha comprobado su ajuste y sus relaciones estructurales. En términos generales, podemos decir que las hipótesis con las que construimos nuestro modelo teórico han recibido una considerable evidencia empírica. Los innovadores en TI necesitan desarrollar sus capacidades en TI, mientras que un conservador en TI no. Aunque esto no implica explícitamente que las capacidades en TI de un conservador sean más limitadas que un TI innovador, sí permite al conservador en TI confiar exclusivamente en profesionales externos y en productos del mercado para sus implantaciones.

A continuación pasamos a describir detalladamente los resultados obtenidos en cada una de ellas.

\section{Estrategia competitiva de diferenciación por innovación: hipótesis 1 y 2}

La estrategia de diferenciación por producto o proceso está vinculada a la generación de un producto superior a lo existente en el mercado o "único", bien sea en términos de calidad o de imagen. Miller y Friesen (1986) miden esta estrategia en términos de producto o servicio de calidad superior, imagen de producto y ratio de nuevos productos lanzados.

La primera hipótesis mantiene una relación de moderación negativa en relación a asumir una estrategia TI innovadora cuando la organización adopta una estrategia 
competitiva de diferenciación por innovación. De los resultados obtenidos podemos ver que esta hipótesis se verifica de manera significativa $(p<0,05)$. Este resultado debemos interpretarlo desde la perspectiva de lo que supone una estrategia TI innovadora en términos de riesgo e imitabilidad de estas iniciativas con la moderación que supone el sector donde se ha desarrollado el trabajo de campo.

Como decíamos en el segundo capítulo del presente trabajo, en un sector donde las TI funcionan como soporte a las actividades de I+D y no como núcleo central de la innovación, una estrategia innovadora aumenta los riesgos y la incertidumbre de los resultados. El hecho es que, a una actividad de $\mathrm{I}+\mathrm{D}$ con un riesgo inherente sumamos una estrategia (la estrategia TI) que también supone la asunción de riesgos. Una organización que desarrolle una estrategia TI innovadora necesita asegurar que puede desarrollarla con éxito puesto que de otro modo será poco probable que le suponga una ventaja respecto a sus competidores (He y Wong, 2004). Aunque el objetivo es ganar una ventaja competitiva a través de innovar con las TI, los riesgos de fracaso que supone puede revertir en resultados adversos en términos financieros y organizativos (Leidner y Mackay, 2007) o bien tendría un efecto nulo o destructor sobre los recursos de I+D (Black y Boal, 1994).

El sector en el que se ha desarrollado el trabajo empírico de contraste de hipótesis es un sector no intensivo en conocimiento. Tal y como afirman Lim y Stratopoulos (2008), mientras que para unos sectores (como pueden ser el de las telecomunicaciones, o el financiero, sectores intensivos en conocimiento) las TI son la base de su estrategia de $\mathrm{I}+\mathrm{D}$, en otros es posible considerar las TI como una necesidad estratégica. El sector agroalimentario se ubica en este segundo grupo.

En un sector donde las TI no son un elemento competitivo clave y no se integran en el producto resultante (como ocurre en términos generales en el sector agroalimentario), los elementos de soporte a estas actividades son más fácilmente replicables, puesto que al no integrarse con recursos organizativos complementarios no elevan su ambigüedad causal y no cumplen las condiciones de recurso estratégico (valioso, escaso, imperfectamente imitable y no sustituible). Los recursos TI no tienen efectos sinérgicos con otras capacidades organizativas ni supone la creación de recursos coespecializados. Por otra parte, no está sujeto a acumulación de stock de 
existencias (Piccoly e Ives, 2005). Una estrategia en TI innovadora y arriesgada vinculada con estos procesos puede, consecuentemente, arrojar resultados que no compensen en términos de desempeño a la organización

Sin embargo en el caso de adoptar una estrategia TI conservadora, cuando buscamos desarrollar una estrategia competitiva de diferenciación por innovación, se cumple la hipótesis de ausencia de moderación. Hemos definido la estrategia TI conservadora como aquella que persigue una aproximación segura y estable a la hora de desarrollar nuevas iniciativas TI, adoptar innovaciones TI una vez que han sido probadas en el sector o por los competidores y básicamente adopta herramientas estándares fácilmente adquiribles en el mercado.

Esta aproximación desde el punto de vista del EBC supone utilizar las TI como una "commodity" o como necesidad estratégica. Una aproximación de esta naturaleza convierte a las TI en un recurso no estratégico, puesto que son elementos que se pueden obtener fácilmente en el mercado de factores. Esta aproximación no aportará ventajas competitivas a las empresas que la implementen, pero tampoco asumirán riesgos más allá que los derivados de sus procesos de I+D. Es interesante resaltar que aquellos más conservadores en TI, la correlación de la submuestra más conservadora apenas tiene significatividad la relación de estrategia competitiva en innovación y desempeño, mientras que la muestra menos conservadora en TI tiene una correlación negativa bastante significativa.

En todo caso, la influencia de desarrollar una estrategia TI segura no tendrá influencia en relación a otros factores organizativos que serán más relevantes en términos de desempeño.

\section{Estrategia competitiva de diferenciación por marketing: hipótesis 3 y 4}

Para una estrategia competitiva basada en diferenciación por marketing, una estrategia innovadora TI arroja resultados negativos respecto a seguir una estrategia poco innovadora en TI. La estrategia basada en la diferenciación por marketing se 
basa en establecer un mayor vínculo con el cliente, estableciendo con éste relaciones más ricas y complejas. Estas interacciones posibilitan una mayor satisfacción del cliente al mismo tiempo que para la empresa es una fórmula de recopilación de información de éste en aras a mejorar su orientación al mercado. Consecuentemente, una organización que opte por una estrategia competitiva de este tipo, debe desarrollar habilidades para orientarse al cliente, entender sus necesidades y consolidar relaciones a largo plazo.

Las TI en este ámbito incluyen tecnologías para dar soporte a todas las funciones del marketing, incluyendo la gestión de la relación con el cliente, la actividad de ventas, el soporte al cliente o la planificación e investigación de mercados. Una estrategia TI innovadora supone ser el líder de innovación en el sector, en ser el primero en desarrollar iniciativas TI incluso si no está demostrado que dichos esfuerzos sean altamente rentables o responder rápidamente a las señales tempranas relacionadas con las oportunidades en el campo de las TI.

Las iniciativas TI en este ámbito son visibles por los competidores, por lo que no supone una barrera para la imitación por parte de éstos. Por otra parte, el primer competidor en desarrollar una acción en este ámbito asume los riesgos, lo cual puede suponer un grave perjuicio, en caso de fracasar, puesto que los activos de marca, imagen, etc, son difíciles de reconstruir y requiere de tiempo contrarrestar una mala imagen.

Sin embargo, una aproximación estable y segura hace que la organización pueda aprender de los fracasos de los competidores y no perder valor en términos de marca y percepción del cliente. Una estrategia TI conservadora permitirá calibrar mejor los movimientos a realizar, desarrollando capacidades orientadas a mejorar la operación de los sistemas existentes, mejorando de esta manera el nivel de satisfacción del cliente, obteniendo de esta manera mejores resultados en términos de desempeño. En este sentido, el desarrollo de recursos TI tecnológicos, humanos y organizativos orientados a conseguir una mejor explotación de los recursos TI existentes supone una capacidad valiosa, heterogénea y distribuída que aporta una ventaja competitiva respecto a la permanente exploración de nuevos sistemas. Como se ha demostrado en trabajos como 
el de Bharadwaj et al. (2009), los clientes asumen mejor los fallos en los sistemas existentes que un fallo en un nuevo sistema.

Al igual que en las hipótesis anteriores, el hecho de que el trabajo empírico se haya desarrollado en un sector no intensivo en conocimiento, donde el producto que adquiere el cliente no incorpora de forma intensiva las TI, como puede ser el sector bancario o empresas de Internet, modera claramente los resultados obtenidos.

Es importante resaltar que la correlación es negativa en el caso de alto innovador en TI tanto en estrategias competitivas en innovación como en marketing. Por el contrario, estas dos últimas estrategias competitivas tienen una relación positiva con el desempeño cuando se trata de bajos innovadores en TI. Esto implica una fuerte penalización para los innovadores en TI, incluso dentro de la muestra más innovadora (ver tabla 4.40). Por el contrario, la muestra "poco innovador en TI" en la estrategia competitiva en costes no tiene ninguna significatividad, mientras que premia con una significatividad de $\mathrm{p}>0.1$ a los innovadores en TI, incluso dentro de la misma submuestra de "alto innovador en TI".

\section{Estrategia competitiva de liderazgo en costes: hipótesis 5 y 6}

Como hemos comentado previamente, una estrategia de liderazgo en costes persigue la máxima eficiencia en las operaciones, mediante economías de escala, economías de experiencia y de aprendizaje, optimizando la capacidad, con bajos costes laborales o el acceso favorable a materias primas. Esta estrategia requiere de la construcción de un mercado vía precios agresivos para la maximización de dichas economías de escala, el diseño de productos de fácil manufactura, la utilización de equipamiento moderno y la inversión en I+D tecnológico asociado a la producción. Esta estrategia supone un elevado riesgo, siendo el mayor riesgo la caída en un círculo vicioso de bajada de precios y rotura de márgenes. Las firmas que persiguen esta estrategia tienden a centrarse en actividades de producción en masa y estandarización que pueden ser fácilmente imitables. Los clientes son muy sensibles al precio y tienen bajos niveles de lealtad a la marca. Las variables consideradas como paradigmáticas son la diferencia de precio (el líder en costes puede cargar precios más bajos que sus 
competidores), la integración vertical, la novedad de la planta productiva y su equipamiento, la utilización de la capacidad, los costes directos y los procesos de $\mathrm{I}+\mathrm{D}$ o de valor añadido.

La revisión realizada de la literatura en este caso, nos indica que el mayor valor que aportan las TI están en los procesos relacionados con las relaciones con proveedores, la producción y las operaciones. Siendo relevante la incorporación de las TI a estas actividades para mejorar la eficiencia del procesamiento de la información y permitir un intercambio de información más rápido con los colaboradores de la organización.

Adoptar una estrategia TI innovadora asociada a estas actividades modera positivamente la relación con el desempeño. Cuando las TI se aplican a procesos como los mencionados, estas actuaciones son difíciles de replicar por parte de los competidores.

Las iniciativas TI en este ámbito son poco visibles, lo que supone una dificultad para la imitación por parte de los competidores. En términos generales, son actuaciones que requieren de inversiones tangibles e intangibles co-especializadas, lo que dificulta sensiblemente su replicabilidad, no siendo sencillo adquirirlas en el mercado de factores. La integración de una infraestructura TI con otro equipamiento productivo y la generación de redes de colaboración con otros integrantes de la cadena de valor hace que además estas inversiones o iniciativas estén sujetas a la acumulación de existencias de activo, sean dependiente del camino seguido, exista ambigüedad causal y complejidad social. Su singularidad hace que la movilidad sea imperfecta.

Por otra parte, estas estrategias generan unas ventajas de prioridad por ser el primero en incorporarlas. Así, ejemplos como tecnologías que permiten integrar la cadena de valor pueden generar costes de conexión (Piccoli e Ives, 2005) que supone una barrera para los competidores.

Otro elemento que dificulta la replicabilidad y que permite explicar la moderación positiva de una estrategia TI innovadora es la ambigüedad causal: las TI en las actividades ligadas a la cadena de valor, la producción y las operaciones se 
entrelazan con otras capacidades y hace que su imitabilidad sea imperfecta, lo que dificulta sensiblemente la posibilidad de movilidad perfecta de los recursos resultantes.

Teniendo en cuenta que únicamente un competidor puede ser líder en costes en una industria, apostar por una estrategia TI conservadora, orientada a seguir al líder en sus iniciativas TI y mejorar la explotación de su infraestructura es una tarea compleja. La escasa visibilidad de las iniciativas y la ambigüedad causal dificulta la generación de recursos, capacidades y competencias que puedan implementar satisfactoriamente una estrategia de estas características.

Pese a la relativamente baja significatividad entre la diferencia entre los altos innovadores en TI y bajos innovadores en su relación entre estrategia competitiva en costes y desempeño, el cambio de tendencia respecto a las otras estrategias es importante. Los innovadores en TI gozan de un mejor desempeño, mientras que aquellos que son menos innovadores la relación apenas es significativa. En este caso las TI si que están funcionando como fuente de ventaja competitiva. Una situación parecida, pero invertida, aparece entre los altos conservadores en TI y bajos conservadores en $\mathrm{TI}$.

Es importante resaltar esta diferencia, aunque no estrictamente significativa, entre los innovadores y no innovadores en TI en una estrategia basada en costes. Por lo general los investigadores han tenido dificultades en relacionar las capacidades en TI dentro de la empresa capaces de generar innovaciones es difícil y el desempeño organizativo. Esta ambigüedad ha sido reconocida en muchos de los estudios que analizan la ventaja competitiva a través de las TI mediante el enfoque basado en recursos y capacidades. Para romper esta ambigüedad, como es el caso en las actividades de las actividades relacionadas con operaciones, y sobre todo aquellas relacionadas con la reducción de costes, la mayoría de los investigadores recurren a analizar cómo los recursos en TI y las capacidades directivas en TI se interrelacionan con otros factores de la empresa. En estos casos, mediante la mediación de variables que facilitan la integración de las TI en los negocios como son las capacidades organizativas o una cultura organizativa facilitadora de la innovaciones, los 
resultados suelen mostrar una relación positiva de una actitud innovadora en TI con el desempeño, como muestra el estudio de Jeffers et al. (2008).

Esta conclusión es importante para aquellas empresas cuya estrategia competitiva esté basada en costes, como pueden ser los proveedores de logística, sobre todo en la gestión de la cadena de valor en un mercado internacional, con una presencia creciente (Fujun et al., 2008). Para estas empresas proveedoras de logística, la inversión en capacidades en TI para desarrollar sus propios sistemas e integrarlos con sus clientes se ha mostrado positiva reduciendo costes, proporcionando servicios innovadores y personalizados, y mejorando la calidad del servicio.

Así pues, que la inversión en TI arroje resultados no siempre está garantizado. Esto tiene implicaciones importantes para los gerentes en la asignación de recursos en las TI. A la misma conclusión, pero de manera inversa, llegan Mithas, Tafti y Bardhan (2012). Estos autores comprueban que los proyectos basados en TI, sin tener en cuenta la capacidad en TI de la empresa, simplemente invirtiendo dinero en TI estándares, tiene mejores resultados para aquellas actividades relacionadas con la publicidad e I+D. Por el contrario, no muestran retorno en actividades que permiten el ahorro en costes.

Por último conviene resaltar que en aquellos casos en que no hay una política definida en TI (estrategia indefinida), para todas las estrategias competitivas supone una peor situación respecto a aquellos que sí tienen una estrategia TI definida. El caso más claro por su significatividad se produce en la estrategia competitiva en marketing. En este caso, debido a la exposición a los clientes del mal funcionamiento que una decisión puntual innovadora en TI puede suponer un deterioro de la imagen difícilmente compensable con otros éxitos de innovaciones basadas en TI. 


\subsection{Limitaciones del trabajo}

Las limitaciones presentes en este trabajo son de diferente naturaleza, tanto en lo que respecta a la metodología del desarrollo empírico de la investigación, como a los planteamientos teóricos y el ámbito.

En primer lugar, hay que comentar las limitaciones del trabajo debidas a la utilización de la encuesta como método para generar la base de datos del estudio empírico. Esto implica una serie de inconvenientes como son la aparición de sesgos, problemas terminológicos o de confusión conceptual por parte de la persona que contesta la encuesta, o problemas de control sobre quién contesta el cuestionario. Sin embargo, el método utilizado para llevar a cabo la encuesta (ver epígrafe 3.6.), hace suponer que estos inconvenientes están minimizados al máximo posible.

También hay que hacer mención como posible limitación del trabajo que el estudio está centrado exclusivamente en un sector, y por lo tanto, se corre el riesgo de no poder generalizar las conclusiones (Dess, Ireland y Hitt, 1990). Sin embargo, hay que constatar que en el EBC existe una gran cantidad de trabajos empíricos de carácter sectorial. Además, en nuestro caso, el sector bajo estudio es de especial interés por la importancia de la información en sus procesos productivos. A pesar de ello, como argumenta Lim y Stratopoulos (2008), el impacto que tendrá el desarrollo de una estrategia u otra dependerá de la industria en la que se aplique, porque mientras en un sector puede ser menos relevantes, en otros será el principal elemento competitivo. Como ejemplo de esta cuestión se puede tomar el estudio de $\mathrm{Wu}$ et al. (2006), realizado en varios sectores, en la que se comprueba que las capacidad en TI generadas en la cadena de suministros son específicas a la empresa.

El estudio realizado es transversal, observándose tanto las variables dependientes como independientes en un único momento del tiempo. Ello se traduce en un análisis limitado de la relación dinámica entre los diversos conceptos que forman el modelo teórico. La implementación de una estrategia TI y su efecto en el desempeño supone un cierto tiempo o retardo en sus efectos. En temas tanto de estrategia TI como en 
estrategia de negocio un estudio transversal está sujeto al retardo de su manifestación en el desempeño puesto que hay un retardo en su repercusión en esta variable.

Además, no podemos deducir con absoluta seguridad el orden causal entre las variables, ya que tal como señala Bagozzi (1994), conocer la causalidad requiere medir la temporalidad, cosa que no se puede obtener en modelos de corte transversal. Aunque, por lo general, la implementación de ambas estrategias (de negocio y de TI) aparecerá reflejada en el desempeño, siempre puede haber un desfase temporal que reduciría la precisión de los resultados. Este descenso de precisión, sin embargo, es difícil de corregir, aún realizando estudios longitudinales.

Por último, cabe destacar que en el estudio no se ha tenido en cuenta otras variables que, tal y como apuntó Melville et a. (2004), pueden influir en el impacto que las TI pueden tener en el desempeño, como puede ser los socios y partners de las organizaciones o las características y contexto del país. Futuras investigaciones deberán ahondar en estas cuestiones.

Otra de las limitaciones del presente estudio es la no integración de otros factores organizativos que pueden mediar o moderar los resultados en el desempeño, como puede ser la cultura, la estructura o la política de la empresa, que pueden influir en el efecto moderador de la estrategia TI. Por ejemplo, en el estudio de Tian et al. (2010). se analiza, también desde el enfoque de los recursos y capacidades, el efecto de la alineación entre estrategia de negocios y estrategia en TI sobre la ventaja competitiva, comprobando que esta relación está mediada por la flexibilidad en TI (capacidad en TI) de la empresa y el grado de integración de las TI en el negocio.

\subsection{Propuestas para investigaciones futuras}

Las investigaciones futuras deben ir dirigidas a mejorar las limitaciones comentadas en el punto anterior y a ampliar el ámbito de estudio incorporando nuevos elementos, así como los diversos avances que se produzcan en el campo. 
La primera propuesta planteada es desarrollar un estudio similar en una industria intensiva en conocimiento. Aunque los resultados alcanzados se pueden considerar extrapolables a las industrias manufactureras españolas por su similitud, el efecto moderador del ámbito empírico del estudio entre empresas de servicios o intensivas en conocimiento puede arrojar resultados distintos.

Un elemento de interés para su profundización es el desarrollo de un estudio similar con escalas más complejas, que permitan medir diferentes dimensiones de las estrategias en TI. También una diferenciación de las diferentes actividades clave de las estrategias competitivas permitiría discernir aquellas que son más susceptibles de defender las innovaciones en TI.

Otra cuestión importante es la limitación que supone centrarse en un único sector. Cada sector tiene sus actividades bien definidas, y podría ser un error mezclar distintos sectores, en una relación ya de por sí difícil de establecer. Por esto, una réplica de este estudio en otros sectores, con sus actividades específicas, permitiría ahondar más en esta relación entre estrategias TI y de negocio.

También sería recomendable utilizar muestras mayores, permitiendo hacer más divisiones de la muestra, y ver las diferencias entre los primeros cuartiles y últimos cuartiles (el limitado número de casos aconsejaba no subdividir más la muestra). Esto realzaría los resultados y marcaría los riesgos de cada una de las estrategias en TI con mayor claridad.

El modelo propuesto por esta tesis podría aplicarse a estudios, dentro del EBC, que analizan las interacciones de las competencias en TI con otros activos organizativos en la consecución de ventajas competitivas. La focalización de estos estudios a actividades específicas y estratégicas para las empresas podría esclarecer los mecanismos de aislamiento frente a la réplica de los competidores en las innovaciones en TI, y en consecuencia, adoptar la estrategia TI correspondiente. 


\section{BIBLIOGRAFÍA}


Pág. 278 de 329 


\section{BIBLIOGRAFÍA}

ADLER, P.S.; McDONALD, D.W.; McDONALD, F. "Strategic management of technical functions”. Sloan Management Review, 1992, vol. 33, num. 2, pp. 19-37

AETIC-EVERIS. Las tecnologías de la sociedad de la información en la empresa española 2008. Madrid: Everis, 2008.

AETIC-EVERIS. Las tecnologías de la información y las comunicaciones en la empresa española 2009. Madrid: Everis, 2009.

AGARWAL, R.; SAMBAMURTHY, V. "Principles and models for organizing IT functions" MIS quarterly executive. 2002. Vol. 1, num.1, p. 1-16.

AIKEN, L. S., AND WEST, S. G. Multiple Regression:Testing and Interpreting Interactions. Newbury Park, CA: Sage Publications, 1991.

ALPAR, P.; KIM, M. "A microeconomic approach to the measurement of information technology value". Journal of management information systems. 1990. Vol. 7, num. 2, p. $55-69$

ALLEN, D.K.; WILSON, T.D. "Information strategies in UK Higher Education Institutions". International Journal of Information Management. 1996, vol. 4, num. 16, pp. 239-251

AMBROSINI, V.; BOWMAN, C. "What are dynamic capabilities and are they useful construct in strategic management?". International journal of management review, 2009, vol. 11 , num. 1 p. $29-49$

AMERICAN PRODUCTIVITY \& QUALITY CENTER (APQC). Process Classification Framework. Houston, Texas: American Productivity \& Quality Center, 2004.

AMIT, R., SCHOEMAKER, P. "Strategic assets and organizational rent". Strategic Management Journal. 1993, vol. 14, pp. 33-46. 
ANASTASSOPOULOS, J.P., RAMANANTSOA, B. "Le segment est mort, place au metier”. Revue Française de Gestion, 1982, nº. 2, pp. 82-88.

ANDERSON, J.C., GERBING, D.W. "Some methods for respecifying measurement models to obtain unidimensional constructs measures". Journal of Marketing Research, 1982, vol. 19, pp. 453-460.

ANDREWS, K. R. The Concept of Corporate Strategy. Homewood: Dow-Jones-Irwin, 1971

ANSOFF, H.I. Corporate Strategy. New York: McGraw-Hill, 1965

APPLEGATE, L.M. Making the case for networked business. NuevaYork: Mc Graw Hill. 2003.

ARMSTRONG, C.P; SAMBAMURTHY, V. "Information technology assimilation in firms: the influence of senior leadership and IT infrastructures", Information Systems Research, 1999, Vol. 10 No. 4, pp. 304-27.

ATKINS, M.H. "Information technology and information systems perspectives on business strategies”. Journal of Strategic Information Systems. 1994, vol. 3, num. 2, pp. $123-135$

BAILY, M. "What has happened to productivity growth?”. Science. 1986, vol. 234, pp. $443-451$

BALDWIN E.; CURLEY, M. Managing IT innovation for Business Value: practiced strategies fort IT and business managers. Santa Clara, CA: Intel Press, 2007

BANKER, R.D., KAUFMANN, R.J. "Strategic contributions of information technology: An empirical study of ATM networks". En: Proceedings of the Ninth International Conference on Information Systems. Minneapolis, MN: 1988, pp. 141150.

BARNEY, J. B. "Strategic factor markets. Expectations, luck and business strategy". Management Science, 1986, vol. 32, nº 10, pp. 1231-1241. 
BARNEY, J.B. "Firm resources and sustained competitive advantage", Journal of management. 1991. Vol. 17, num. 1, p. 99-120

BARNEY, J. B. "Bringing managers back in: a Resource-Based Analysis of the role of managers in creating and sustaining competitive advantages for firms". En Barney, J. B. (Ed.). Does management matter? Institute of Economic Research, Lund University, 1994, pp. 3-36.

BARNEY,J.; GRIFFIN, R. The management of organizations: strategy, structure, and behaviour. Boston, MA: Hoghton Mifflin, 1992

BARNEY, J., WRIGHT, M., KETCHEN, D.J. "The resource-based view of the firm: Ten years after 1991”. Journal of Management, 2001, vol. 27, nº 6, pp. 625-646.

BARNEY,J.; ZAJAC, E. "Competitive organizational behaviour: toward an organizationally-based theory of competitive advantage". Strategic Management Journal, Winter special issue, 1994, vol. 15, num. 5, pp. 5-9

BARON, R. M., AND KENNY, D. A. “The Moderator Mediator Variable Distinction in Social Psychological Research: Conceptual, Strategic, and Statistical Considerations," Journal of Personality and Social Psychology, 1986, vol. 521, pp.1173-1182.

BARRIO, S., LUQUE, T. “Análisis de ecuaciones estructurales”. En: Luque, T. (coord). Técnicas de análisis de datos en investigación de mercados. Madrid: Editorial Pirámide, 2000.

BARTON, P.S.; PETERS, D.H.; "The ASB Bank: an IT case study in sustained competitive advantage". Journal of strategic information systems. 1992. Vol. 1, num. 3, p. $165-170$.

BARUA, A; SOPHIE, C.; WHINSTON, A.;"The calculus of engineering”. Information systems research. 1996. Vol. 7, num. 4, p. 409-428 
BARUA, A., KRIEBEL, C.H., MUKHOPADHYAY, T. "Information Technologies and Business Value: An Analytic and Empirical Investigation”. Information Systems Research, 1995, Vol. 6 Issue 1, pp. 3-18.

BASSELLIER, G., REICH, B.H., BENBASAT, I. "Information Technology Competence of Business Managers: A Definition and Research Model”. Journal of Management Information Systems, 2001, vol. 17, nº 4, pp. 159-182.

BASSELLIER, G., BENBASAT, I., REICH, B.H. "The Influence of Business Managers' IT Competence on Championing IT”. Information Systems Research, 2003, vol. $14, n^{\circ} 4$, pp. 317-336.

BATISTA, J.M., COENDERS, G. Modelos de ecuaciones estructurales. Madrid: La Muralla / Hespérides, 2000

BAUER, C.; COLGAN, J. "Planning for electronic commerce strategy: an explanatory study from the financial services sector". Logistics Information Management, 201, vol. 14, num. 1, pp.24-32

BENDER, D. "Financial impact of information processing". Journal of management information systems. 1986, vol. 3, num. 2, p. 22-32.

BENJAMIN, R.I; LEVINSON E. “A framework for managing it-enabled change”. sloan management review. 1993, vol. 34, num. 4, p. 23-33

BENTLER, P.M. EQS: Structural Equations Program Manual. Los Angeles: BDMP Statistical Software, 1995

BENTLER, P.M., BONETT, D.G. "Significance tests and goodness-of-fit in the analysis of covariance structures”. Psychological Bulletin, 1980, vol. 88, pp. 588-606.

BERTHOFF, A. “Differentiation II” Computer Dealer news, 2002, vol. 18, pp. 20

BHATT, G.D; GROVER, V. "Types of information technology capabilities and their role in competitive advantage: an empricial study". Journal of Management Information Systems. 2005, vol. 22, nº 22, pp.253-277 
BHARADWAJ, A.S.; SAMBAMURTHY V; ZMUD, R.W. "IT capabilities theoretical perspectives and empirical operationalization", En: Hirscheim R; Newman, M.; Degross, J.I (Eds). Proceedings of the $19^{\text {th }}$ International Conference on Information Systems: Helsinki, Finland, 1998, pp. 378-385.

BHARADWAJ, A., BHARADWAJ, S., KONSYNSKI, B. (1999). "Information Technology Effects on Firm Performance as Measured by Tobin's q". Management Science. 1999, vol. 45, nº 7, pp. 1008-1024.

BHARADWAJ, D.H. "A resource-based perspective on information technology capability and firm performance: an empirical investigation”. MIS Quaterly. 2000. Vol. 24, num. 1, p. 169-196

BHARADWAJ, A.; KEIL, M.; MÄHRING, M. "Effects of information technology failures on the market value of firms". Journal of strategic information systems. 2009. Vol. 18 , p. 66-79

BHARDAN, I.; MITHAS, S.; LIN, S. "Performance impacts of strategy, information technology applications, and business process outsourcing in U.S. manufacturing plants". Production and Operation Management, 2007, vol. 16, num. 6, pp. 747-762

BHASKARAN, S. "Incremental innovation and business performance: small and medium-sized food enterprises in a concentrated industry environment". Journal of small business management. 2006. Vol. 44, num. 1, p. 64-80

BHATT G.D; EMDAD, A.; ROBERTS, N; GROVER, V. "Building and leveraging information in dynamic environments: the role of IT infrastructure flexibility as enabler of organizational responsiveness and competitive advantage". Information \& Management. 2010, vol. 47, pp. 341-349

BHATT, G. D. ; GROVER, V. "Types of Information Technology Capabilities and Their Role in Competitive Advantage: An Empirical Study". Journal of Management Information Systems, 2005, Vol.22, num. 2, pp.253-277

BENJAMIN, R., LEVISON, E. “A framework for managing IT-enabled change”. Sloan Management Review. 1993, vol. 34, nº 4, pp. 23-33. 
BITAR, J.; HAFSI, T. "Strategizing through the capability lens: sources and outcomes of integration", Management Decision, 2007, Vol. 45, num. 3, p.403 - 419

BLACK, J.A., BOAL, K.B. "Strategic resources: traits, configurations and paths to sustainable competitive advantage“. Strategic Management Journal, Summer Special Issue, 1994, vol. 15, pp. 131-148.

BLACKLER, F. "Knowledge, knowledge work and organizations: An overview and interpretation". Journal of Management Studies, 1993, vol. 30, nº 6, pp. 863-884.

BLUMENTRITT, T.; DANIS W.M. "Business strategy types and innovative practices”. Journal of managerial issues. 2006. Vol. 18, p. 274-291.

BOMMENSATH, M. Manager l'intelligence de votre entreprise. Paris: Les Éditions d'Organisation, 1987

BONNICI, T.S., SARKIS, J. "Performance measurement systems development in a telecommunication company". Production \& Inventory Management Journal, 2001, vol. $42, \mathrm{n}^{\circ} 1$, pp. 19-24.

BOLLEN, K.A. Structural equations with latent variables. New York: John Wiley \& Sons, 1989

BRADY, M.; MICHAEL, S.; NIKOLAOS, T. "Integrating information technology into marketing practice. The IT reality of contemporary marketing practice". Jounrnal of Marketing Management, 2002, vol. 18, num. 5, pp.555-578

BRADY, T.; CAMERON, R.; TARGETT, D.; BEAUMONT, C. "Strategic IT issues: the views of some major IT investors". Journal of Strategic Information Systems, 1992, vol. 1, num. 4, pp. 183-189

BRADY, T.; TARGETT, D. "Strategic information systems in the Banking sector: Holy Grail or poison Chalice”. Technology Analysis \& Strategic Management. 1995, vol. 7, num. 4, pp 387-406 
BROADBENT, M., WEILL, P. "Management by maxim: how business and IT managers can create IT infrastructures". Sloan Management Review. 1997, vol. 38, $\mathrm{n}^{\circ} 3$ pp. $77-92$.

BRODIE, R.J.; WINKHOLFER, H; COIELLO, N.E.; JOHNSTON, W.J. "Is emarketing coming on age? An examination of the penetration of e-marketing and firm performance”. Journal of interactive marketing. 2007. Vol. 21, num. 1, p. 2-21.

BROWN, I.T.J. "Testing and extending theory in strategic information systems planning through literature analysis”. Information Resources Management Journal. 2004, vol. 17 , num. 4 , pp. $20-48$

BROWN, J.S. Y DUGUID, P. “Organizating knowledge“. California Management Review, 1998, vol. 40, nº 3, pp. 90-111.

BRUQUE, S., VARGAS, A., HERNÁNDEZ, M.J. “Organizational determinants of IT adoption in the pharmaceutical distribution sector". European Journal of Information Systems. 2004, vol. 13, nº 2, pp.133-146.

BRYNJOLFSSON, E. "The productivity paradox of information technology". Communications of the ACM. 1993. Vol. 36, num. 12, p. 66-77.

BRYNJOLFSSON, E; HITT, L. "Information technology as a factor of production: the role of differences among firms". Economics of Innovation and New Technology. 1995, vol. 3, num. 4, pp. 183-200

BRYNJOLFSSON, E; HITT, L. "Paradox lost? Firm-level evidence on the returns to information systems spending”. Management science. 1996. Vol. 42, num. 4, p. 541558.

BRYNJOLFSSON, E; HITT, L. "Beyond computation: information technology, organizational transformation and business performance". Journal of economic perspective. 2000. Vol. 14, num. 4, p. 23-48.

BRYNJOLFSSON, E. "The productivity paradox of information technology". Communications of the ACM. 1996. Vol. 36, num. 12, p. 66-77. 
BRYNJOLFSSON, E; HITT, L. "Paradox lost? Firm-level evidence on the returns to information systems spending”. Management science. 1996. Vol. 42, num. 4, p. 541558.

BRYNJOLFSSON, E., HITT, L. M. "Beyond the productivity paradox". Communications of the ACM, 1998, vol. $41 \mathrm{n}^{\circ} 8$, pp. 49-55.

BRYNJOLFSSON, E; HITT, L. YANG, S. "Intangible assets: computers and organizational capital”. Brookings papers on economic activity. 2002, vol. 1, p. 137181.

BRYNJOLFSSON，E.; MALONE，T.; GURBAXANI，V.;KAMBIL，A.; "Does information technology lead to smaller firms?”. Management sciences. 1994. Vol. 40, num. 12, p. 1628-1628.

BRUNET, I., BEZUNEGUI, A., PASTOR, I. Les tècniques d'investigació social i la seva aplicació. Tarragona: Universitat Rovira i Virgili 2000.

BYRD, T.A.; DAVIDSON, N.W. "Examining possible antecedents of IT impact on the supply chain and its effect on firm performance". Information \& Management. 2003, vol. 41, num. 2, pp. 243-255

BYRD, T.A., TURNER, D.E. "Measuring the flexibility of information technology infrastructure: Exploratory analysis of construct”. Journal of Management Information Systems. 2000. vol. 17, $\mathrm{n}^{\mathrm{o}}$ 1, pp. 167-208.

CALDEIRA, M.M.; WARD, J.M. "Using resource-based theory to interpret the successful adoption and use of information systems and technology in manufacturing small and medium enterprises". European journal of information systems. 2003. Vol. 12, num. 2, p. 125-139.

CAMPBELL-HUNT, C. "What have we learnt about generic competitive strategy? A meta-analysis”. Strategic Management Journal, 2000, vol. 21, num.2, pp. 127-154

CAMISÓN, C. La competitividad de la PYME industrial española: estrategia y competencias distintivas. Madrid: Civitas, 1997 
CAMISÓN, C. "Sobre cómo medir las competencias distintivas. Un examen empírico de la fiabilidad y validez de los modelos multi-ítem para la medición de los activos intangibles“. En: The Iberoamerican Academy of Management, First International Conference, Madrid, 1999a.

CAMISÓN, C. "La medición de los resultados empresariales desde una óptica estratégica: Construcción de un instrumento a partir de un estudio delphi y aplicación a la empresa industrial española en el período 1983-96”. Estudios financieros, 1999b, vol. 62, pp. 201-265.

CAMISÓN, C. "Competencias distintivas basadas en activos intangibles“. En: Nuevas claves para la dirección estratégica. Madrid: Ariel Economía, 2002a, pp. 117-153.

CAMISÓN, C. "On the relevance of industry, competitive scope, strategic group, size and distinctive competences construct on explaining of organizational performance". Working Paper 1-02. Castellón: Universitat Jaume I, Grupo de investigación en estrategia, gestión del conocimiento y aprendizaje organizacional, $2002 b$.

CARR, N.G. “IT Doesn't Matter”. Harvard Business Review. 2003, vol. 81, n 5, pp. 41-49.

CE. Libro blanco de la seguridad alimentaria. Diario oficial de las comunidades europeas, 12 de enero de 2000.

CE. Reglamento 178/2002, de 28 de enero. Diario oficial de las comunidades europeas, 31 de enero de 2002.

CEGIELSKY, C.G; REITHEL, B.J; REBMAN, C.M. "Developing a timely TI strategy". Communication of the ACM. 2005. Vol. 48, num. 8

CHAN, Y.E.; HUFF, S.L. "Strategy: an information systems research perspective". Journal of Strategic Information Systems. 1992, vol. 1, num. 4, pp.191-204

CHAN, Y.E.; HUFF, S.L.; COPELAND, D.G.; BARCLAY, D.W. "Business strategic orientation, information systems strategic orientation and strategic alignment". Infrmation systems research. 1997, vol. 8, num. 2, pp. 125-150 
CHAN, Y.E.; REICH, B.H. "IT alignment: what have we learned?". Journal of Information Technology. 2007, vol. 22, pp. 297-315

CHAN, Y.E.; SABHERWAL, R; THATCHER, J.B. “Antecedents and outcomes of strategic IS alignment: an empirical investigation”. IEEE Transactions on Engineering Management. 2006, vol. 11, pp. 191-206

CHEN, D.Q; MOCKER, M.; PRESTON D.S. "Information systems strategy: reconceptualization, measurement and implications". MIS Quaterly. 2010. Vol. 34, num. 2, p.233-259

CHEN, J.L. "The synergistic effects of IT-enabled resources on organizational capabilities and firm performance”. Information \& Management, 2012, Vol. 49, n 3-4, pp. $142-150$

CHI, T. "Trading in Strategic Resources: Necessary Conditions, Transactions, Transaction Costs Problems and Choice of Exchange Structure“. Strategic Management Journal, 1994, vol. 15, pp. 271-290.

CHRISMAN, J.; HOFER, C.; BOLTON, W. "Toward a system for classifying business strategies". Academy of Management Review. 1988, vol. 13, pp. 413-428

CHURCHILL, G.A. "A Paradigm for Developing Better Measures of Marketing Constructs”. Journal of Marketing Research, 1979, vol. 16, nº 1, pp. 64-73.

CLEMONS, E.K. "Information systems for sustainable competitive advantage". Information \& Management. 1991, vol. 11, num. 3, p. 131-136.

CLEMONS, E.K., ROW, M.C. "Sustaining IT advantage. The role of structural differences”. MIS Quarterly. 1991, pp. 275-292.

COLLIS, D.J. "Research Note: How Valuable are Organizational Capabilities?“. Strategic Management Journal, 1994, vol. 15, pp. 143-152.

COLLIS, D.J., MONTGOMERY, C.A. "Competing on resources: Strategy in the 1990s“. Harvard Business Review, 1995, vol. 73, n 4, pp. 118-128. 
CONNER, K.R. "A historical comparison of resource-based theory and five schools of thought within industrial organization economics: Do we have a new theory of the firm?”. Journal of Management, 1991, vol. 17, nº 1, pp. 121-154.

CONRATH, D.W.; ANG, J.K.; MATTAY, S. "Strategic planning for information systems: a survey of Canadian organizations". Infor, 2000, vol. 30, num. 4, pp. 364378

COMPUTER SCIENCE CORPORATION, Critical issues of information system management [en línea]. California, 2001. [citado 20 septiembre 2010] Disponible en World wide web: http://assets1.csc.com/newsroom/downloads/2503 1.pdf

CONANT, J.S., MOKWA, M.P., VARADARAJAN, P.R. "Strategic types, distinctive marketing competencies and organizational performance: A multiple measures-based study”. Strategic Management Journal, 1990, vol. 11, nº 5, pp. 365-383.

COOK, S., YANOW, D. “Culture and organizational learning”. En Cohen, M.; Sproull, L. (Eds.). Organizational Learning. California: Sage Publications, 1996

COOPER, B.L.; WATSON, H.J.; WIXON, B.H.; GOODHUE, D.L.; "Data warehousing supports corporate strategy at first American corporation”. MIS Quarterly. 2000, vol. 24, num. 4, p. 547-567.

COOPER, R.G. "The dimension of industrial new product success and failure". Journal of Marketing. 1979, vol. 43, num.3, pp. 93-103

CRON, W.; SOBOL, M. "The relationship between computerization and performance: a strategy for maximizing the economic benefits of computerization". Information and management. 1983, vol. 6, num. 3, p. 171-181.

CROSS, L. "Strategy drives marketing success". Graphic Arts Monthly, 1999, vol. 71, num. 2, pp. 96

CROTEAU, A.M.; BERGUERON, F. “An information technology trilogy: business strategy, technological deployment and organizational performance". Journal of strategic information systems. 2001. Vol. 10, p. 77-99. 
CRUZ-GÓMEZ, J.C, et al. "Sistemas de certificación de la calidad en el sector agroalimentario español”. Distribución y consumo. 2004. Num. 4, p. 23-39

CUERVO, A. La dirección estratégica de la empresa. . Madrid: Civitas, 1995

DAS, S.R.; ZAHRA, S.A.; WARKETIN, M.E.'Integrating the content and process of strategic MIS Planning with corporate strategy”. Decision Sciences, 1991, vol. 22, num. 5, pp. 953-984

D'AVENI, R. A., GUNTHER, R. Hypercompetition. Managing the dynamics of strategic maneuvering. New York: The Free Press, 1994

DAVENPORT, T.H. "Human-centered information management". En: Harvard Business Review: Harvard Business Review on the Business Value of IT. Boston: Harvard Business School Press, 1993, pp.1-33.

DAVID, F. Strategic management concept and cases. Englewood liffs, NJ: PrenticeHall, 2000

DAVIDSON, S. "Seizing the competitive advantage", Community Banker, 2001, vol. 10 , num. 8 , pp. $32-34$

DEHNING, B.; STRATOPOULOS, T. "Determinants of a sustainable competitive advantage due to an IT-enabled strategy". Journal of Strategic Information Systems. 2003, vol. 12 , num. 1, pp. 7-28

DELONE, W. H., MCLEAN, E. R. "Information Systems Success: The Quest for the Dependent Variable”. Information Systems Research, 1992, vol. 3, n 1, pp. 60-75.

DENT-MICALLEF, A., POWELL, T. “Technologies de l'information: nécessités stratégiques ou sources d'avantage concurrentiel? Une étude empirique dans le secteur de la distribution aux Etats-Unis“. Revue canadienne des sciences de l'administration, 1998, vol. 15, no 1, pp. 39-64. 
DESANCTIS, G., POOLE, M.S. "Capturing the Complexity in Advanced Technology Use: Adaptive Structuration Theory”. Organization Science, 1994, vol. 5, n² 2, pp. 121147.

DESS, G.G.; DAVIS, P.S. "Porter's (1980) generic strategies as determinants of strategic group membership and organizational performance". Academy of Management Journal, 1984, vol. 27, num. 3, pp. 467-488

DESS, G.G., IRELAND, R.D., HITT, M.A. "Industry effects and strategic management research”. Journal of Management, 1990, vol. 16, No 1, pp. 7-27.

DESS, G.G.; MILLER, A. Strategic Management. New York: McGraw-Hill, 1993

DEVARAJ, S; KHOLI, R. "Information technology payoff in the heath-care industry", Journal of management information systems. 2000. vol. 16, num. 4, p 41-67

DEVARAJ, S; KHOLI, R. "Performance impacts of information technology: is actual usage the missing link?”. Management Sciences. 2003, vol. 49, num. 3, pp.273-289

DEVECE, CARAÑANA, C.A."Efectos de la gestión de la información en el desempeño organizativo. Un enfoque basado en competencias". Tesis Doctoral. Directores: César Camisón y Rafael Lapiedra. Universitat Jaume I de Castellón, Departamento de Gestión Empresarial, 2004.

DEVELLIS, R. F. Scale Development. Theory and Applicationes. Newbury Park, California: Sage Publications, 1991

DEWAN, S.; MIN, C.; "The substitution of information technology for other factor of production: a firm level analysis”. Management science. 1997, vol. 43, num. 12, p. $1660-1675$.

DEWAN, S; KRAEMER, K.L. "Information technology and productivity: evidence form country-level data”. Management science, 2000, vol. 46, num. 4, p. 548-562 
DIBRELL, C; DAVID, P.S; CRAIG, J. "Fueling innovation through information technology in SMEs". Journal of small business management. 2008. Vol. 46, num. 2, p. $203-218$

DIERICKX, I.; COOL, K. “Asset stock accumulation and sustainability of competitive advantage". Management sciences. 1989. Vol. 6, num. 3, p. 241-259.

DILLMAN, D.A. Mail and telephone surveys: The total design method. John Nueva York: Wiley \& Sons, 1978

DOHERTY, N.F; TERRY, M. "The role of IS capabilities in delivering sustainable improvements to competitive positioning". Journal of Strategic Information Systems. 2009, vol. 18, pp. 100-116

DOSI, G.; FREEMAN, C.; NELSON, R.R., SILVERBERG, G., SOETE, L. Technical change and Economic theory. London: Printer Publishers, 1988.

DOSI, G.; TEECE, D.J., WINTER, S. Towards a theory of corporate coherence. preliminary remarks. En: Dosi, G.; Giannetti, R.; Toninelli, P.A. (Ed) , Oxford: Clarendon Press, 1992.

DRUCKER, P.F., The effective executive, New York: Harper and Row, 1966

DUHAN, S.; LEVY, M.; POWELL, P. "Information systems strategies in knowledge-based SME's: the role of core competences". European Journal of Information Systems. 2001, vol. 10, n um. 1, pp. 25-40

DUNCAN, N. B. “Capturing Flexibility of Information Technology Infrastructure: A Study of Resource Characteristics and Their Measure”. Journal of Management Information Systems. 1995, vol. 12, nº 2, pp. 37-56.

DURMUSOGLU, S.; CALANTONE, R.J.; SAMBAMURTHY, V. "Is more information technology better for new product development?". 2006. Journal of product \& brand management. Vol. 15, num. 7, p. 435-441 
DURMUSOGLU, S. “The role of top management team's information technology (IT) infrastructure view onnew product development: conceptualizing IT infrastructure capability as a mediator". 2009. European journal of innovation management. Vol. 12. num. 3, p. 364-385

EARL, M.J. Management Strategies for Information Technology. Englewood Cliffs, NJ: Prentice Hall, 1989

EARL, M.J. "Experiences in strategic information systems planning". MIS Quarterly. 1993, vol. 17, num. 1, pp. 1-25

EIN-DOR, P.; SEGEV, E. "Strategic planning for Management information Systems”. Management Sciences, 1979, vol. 24, num. 15, pp. 1631-1641

EISENHART, K.M., MARTIN, J.A. "Dynamic Capabilities. What are they?". Strategic Management Journal. 2000, vol. 21, n 10/11, pp. 1105-1121.

ELGAZZAR, S. H. ; TIPI, N. S. ; HUBBARD, N. J. ; LEACH, D. Z. "Linking supply chain processes' performance to a company's financial strategic objectives", European Journal of Operational Research, 2012, Vol.223, num. 1, p.276-290

ESCRIG, A. B. "Efectos de la Dirección de Calidad en los resultados. El papel mediador de las competencias distintivas". Tesis Doctoral. Directores: César Camisón y Juan Carlos Bou. Universidad Jaume I de Castellón. Departamento de Administración de Empresas y Marketing, 2001.

FEENY, D.F.; WILLCOCKS, L.P. "Core IS capabilities for exploiting information technology”. Sloan Management Review, 1998, vol. 39, nº 3, pp. 9-21.

FERNÁNDEZ, Z., SUÁREZ, I. "La estrategia de la empresa desde una perspectiva basada en los recursos“. Revista Europea de Dirección y Economía de la Empresa, 1996, vol. 5, no 3, pp. 73-92.

FIELDER, K.D., GROVER, V., TENG, J.T.C. “An Empirical Study of Information Technology Enabled Business Process Redesign and Corporate Competitive Strategy". European Journal of Information Systems. 1995, vol. 4, nº 1, pp. 17-30 
FIOL, C.M. "Revisiting an identity-based view of sustainable competitive advantage”. Journal of Management, 2001, vol. 6, pp. 691-699.

FLOWER, A. "Operations management and systemic modeling as frameworks for BPR". International Journal of Operations and Production Management, 1998, vol. 18, num. 9, pp. 1028-1056

FOOD AND AGRICULTURE ORGANIZATION. Codex Alimentarius. Roma: FAO, 1963.

FORNELL, C., LARCKER, D.F. "Evaluating structural equations models with unobservable variables and measurement error". Journal of Marketing Research, 1981, vol. 18 , pp. 39-50.

FOSS, N. J. Introduction. the emerging competence perspective. En: Foss, N.J. y Knudsen, C. (Ed.). Towards a Competence Theory of the Firm. Londres y Nueva York: Routledge, 1996

FRANCALACI, C.; GALAL, H. "Information Technology and worker composition: determinants of productivity in the life insurance industry”. MIS Quarterly, 1998, vol. 22, num. 2, pp. 227-241

FRISHAMMAR, J.; HÖRTE, S.A. "Managing external information in manufacturing firms: the impact on innovation performance”. Journal of product innovation management. 2005. Vol. 22, p. 251-266

FUNDACIÓN ORANGE. eEspaña 2008: Informe anual sobre el desarrollo de la sociedad de la información 2008. Madrid: Fundación Orange, 2008.

FUNDETEC. Informe ePYME 2010. Madrid: Ministerio de Industria, Energía y Turismo, 2010

FUNDETEC. Informe ePYME 2011. Madrid: Ministerio de Industria, Energía y Turismo, 2011 
FUJUN LAI, F., LI, D., Wang, Q., Zhao, X. "The information technology capability of third-party logistics providers: a resource-based view and empirical evidence from china”. Journal of supply chain management. 2008, vol. 44, no 3, pp. 22-38.

GALBREATH, J., GALVIN, P. "Which resources matter? A fine grained test of the resource based view of the firm". Academy of Management Proceedings, 2004, pp. $1-6$.

GALBREATH, J. "Which resources matter the most to firm success? An exploratory study of resource-based theory". Technovation. 2005, vol. 25, nº 9, pp. 979-987.

GALLIERS, R.D. "Strategic information systems planning: myths, reality and guidelines for successful implementation”. European journal of Information Systems. 1991, vol. 1, num. 1, pp. 55-64

GALLIERS, R.D. "IT Strategies: beyond competitive advantage". Journal of Strategic Information Systems. 1993, vol. 2, num. 4, pp. 283-291

GALLIERS, R.D. Reorienting information systems strategy: integrating information systems into the business. En: F.A. Stowell (ed.). Information systems provision: the contribution of soft system methodology. London, UK: McGraw-Hill, 1995, pp. 5174

GALLIERS, R.D. Reflections on information systems strategizing. En: C. Avgerou, C. Ciborra y F. Lan (ed). The social study of Information and Communications Technology: Innovation, Actors and Contexts. Oxford, UK: Oxford University Press. 2004, pp. 231-262

GALLIERS, R.D. "On confronting some of the common myths of information strategy discourse". En: The Oxford handbook of Information and Communication Technology. Oxford, UK: Oxford University Press, 2006, pp. 225-243

GARCÍA, F., ORTIZ DE URBINA, M., VARGAS, P. "Conceptualización y clasificación de las capacidades empresariales desde una perspectiva dinámica”. En: XI Congreso Nacional de ACEDE, Zaragoza, 2001. 
GARCÍA, M., IBAÑEZ, M., ALVIRA, F. (1994). El análisis de la realidad social. Métodos y técnicas de investigación social. Madrid: Alianza, 1994

GARTNER. [en línea] Stamford, Connecticut. [ref. agosto 2012] Disponible en web http://www.gartner.com/it/page.jsp?id=1888514

GHEMAWAT, P. Commitment the dynamic of strategy. Free Press, 1991

GOTTSCHALK, P. "Implementation predictors of strategic information systems plans”. Information \& Management, 1999a, vol. 36, num. 2 pp. 77-91

GOTTSCHALK, P. "Strategic information systems planning: the IT strategy implementation matrix”. European journal of information systems. 1999b, vol. 8, num. 2 pp. 107-118

GOVINDARAJAN, V. "Decentralization, strategy and effectiveness of strategic business units in multibusiness organizations". Academy of Management Review, 1986, vol. 11, num. 4, pp. $844-856$

GRANT, R.M. "The Resource-Based Theory of Competitive Advantages. Implications for Strategy Formulation“. California Management Review, 1991, vol. 33, no 3 , pp. 114-135.

GRANT, R.M. "The Resource-Based Theory of Competitive Advantages. Implications for Strategy Formulation“. California Management Review. 1993, vol. 33, no 3 , pp. 114-135.

GRANT, R.M. "Prospering in Dynamically-Competitive Environments. Organizational Capability as Knowledge Integration“. Organizational Science, 1996a, vol. 7, no 4, pp. 375-388.

GRANT, R.M. "Toward a knowledge-based theory of the firm". Strategic Management Journal, 1996b, vol. 17, pp. 109-122.

GRAPENTINE, T. "Problematic scales. When measuring quality, expectations scales exhibit several drawbacks”. Marketing Research, 1996, vol. 6, n 4, pp. 8-12. 
GROVER, V.; JEONG, S.R.; KETTINGER, W.J.; LEE, C.C. "The Chief Information Officer: a study of managerial roles". Journal of Management Information Systems, 1993, vol. 10, num. 2, pp. 107-130

GUPTA, A. "A stakeholder analysis approach for interorganizational systems". industrial management and stat systems. 1995, vol. 95, num. 6, pp. 3-7

HACKETT, G. "Investments in technology - The service sector sinkhole?". Sloan Management Review. 1990, vol. 31, nº 2, pp. 97-103.

HAIR, H.F., ANDERSON R.E., TATHAM, R.L., BLACK, W.C. Análisis Multivariante. Madrid: Prentice Hall, 1991

HALL, R.H. "The strategic analysis of intangible resources". Strategic Management Journal, 1992, vol. 13, n 2, pp. 135-144.

HAMEL, G.; PRAHALAD, C.K. "To revitalize corporate performance, we need a whole new model for strategy. Strategic intent”. Harvard Business Review. 1985, vol. 67 , num. 3 , pp. 63-76

HAMEL, G., PRAHALAD, C.K. Competing for the future. Boston: Harvard Business School Press, 1993

HAMILTON, R.D., ESKIN, E.D., MICHAELS, M.P. ”Assessing Competitors: the Gap between Strategic Intent and Core Capability”. Long Range Planning, 1998, vol. 31, $\mathrm{n}^{\mathbf{o}}$ 3, pp. 406-417

HARRIS, S.; KATZ, J. "Organizational performance and information technology investment intensity in the insurance industry". Organization science. 1991, vol. 2, num. 3, p. 263-295.

HART S. L., DOWELL, G. A. "Natural-Resource-Based View of the Firm: Fifteen Years After”. Journal of Management September. 2011, vol. 37, no. 5, pp. 1464-1479.

HATTEN, M.L.; HATTEN, K.J "Information Systems strategy: long overdue and still not here”. Long Range Planning. 1997, vol. 30, num 2, pp. 254-266 
HAYES, B. Measuring customer satisfaction. Development and use of questionnaires. Milwaukee: The Quality Press, 1992

HAYWARD, R.G. "Developing an information systems strategy". Long Range Planning, 1987, vol. 20, num. 2, pp. 100-113

HE, Z.L.; WONG, P.K. "Exploration vs. explotation: an empirical test of the ambidexterity hypothesis”. Organization Science, 2004, vol. 15, num. 4, pp. 481-494

HEDLUND, G. "A model of knowledge management and the N-form corporation". Strategic Management Journal, 1994, vol. 15, pp. 73-90.

HEENE, A., SÁNCHEZ, R. (eds.). Competence-Based Strategic Management. The Strategic Management Society Series, Chichester: John Wiley \& Sons, 1997

HELFAT, C.E.; PETERAF, M.A. “The dynamic resource-based view: capability lifecycles. (Why is there a resource-based view? Toward a theory of competitive heterogeneity). Strategic Management journal, 2003, vol. 24, num. 10, pp. 997-1010

HELFAT, C. E., FINKELSTEIN, S., MITCHELl, W., PETERAF, M. A., SINGH, H., TEECE, D. J., et al. Dynamic capabilities: Understanding strategic change in organisations. Massachussets: Blackwell Publishing, 2007

HELMS, M.M; CLAY, D.; PETER, W. "Competitive strategies and business performance: evidence from the adhesives and sealants industry". Management Decision, 1997, vol. 35, num. 9, pp. 689-703

HENDERSON, R., COCKBURN, I. "Measuring competence? Exploring firm effects in pharmaceutical research". Strategic Managament Journal, 1994, vol. 15, pp. 63-84.

HENDERSON, J.C.: VENKATRAMAN, N. "Strategic alignment: leveraging information technology for transforming organizations". IBM Systems Journal, 1999, vol. 38, Num. 2, pp. 472-485. 
HENDERSON, J.C., LENTZ, C. M.A. "Learning, working, and innovation: A case study in the insurance industry". Journal of Management Information Systems. 1996, vol. $12, \mathrm{n}^{\mathrm{o}} 3$, pp. $43-64$.

HIDDING, G.J. "Sustaining strategic IT advantage in the information age: how strategy paradigms differ by speed". journal of strategic information systems. 2001, vol. 10, num. 3, pp. 201-222

HITT, M.A., BIERMAN, L., SHIMIZU, K., KOCHHAR, R. "Direct and moderating effects of human capital on strategy and performance in professional service firms: A resource-based perspective". Academy of Management Journal, 2001, vol. 44, $\mathrm{n}^{\circ}$, pp. 13-28.

HITT, L.M., BRYNJOLFSSON, E. "Productivity, Business Profitability, and Consumer Surplus: Three Different Measures of Information Technology Value." MIS Quarterly, 1996, vol 20, nº 2, pp. 121-142.

HITT, L.; WU, D.J.; ZHOU, X. "Investment in enterprise resource planning: business impact and productivity measures". Journal of Management Information Systems. 2002, vol. 19, num.1, pp. 71-98

HLAVACKA, S.;LJUBA, B.; VIERA, R.; ROBERT, W. "Performance implications of porter's generic strategies in slovak hospitals". journal of management in medicine. 2001, vol. 15, num. 1, pp. 44-66

HOEY, A. "Inside the RUC: information technology and policing in nothern ireland". international reiew of law, computers \& technology, 1998, vol. 12, num. 1, pp. $15-26$

HOFER, C.W., SCHENDEL, D. Strategy formulation: Analytical concepts. St. Paul, MN: West series in business policy and planning, 1978.

HOLLAND, C., LOCKETT, G., BLACKMAN, I. "Planning for electronic data interchange”. Strategic Management Journal. 1992, vol. 13, nº 7, pp. 539-550. 
HUNTON, J.E.; BEELER, J.O. "Effects of user participation in systems development: A longitudinal field experiment”. MIS Quarterly. 1997, vol. 21, n 4, pp. 359-388.

HYATT, L. “A simple guide to strategy”, Nursing Homes,, 2001, vol. 50, num. 1, pp. $12-13$

ISO. Sistema de gestión de la seguridad alimentaria. 22.000. Ginebra: ISO, 2005.

ITAMI, H. Mobilizing Invisible Assets. Cambridge: Harvard University Press, 1987

JARVENPAA, S.L; LEIDNER, D.E. “An information company in Mexico: extending the resource-based view of the firm to a developing country context". Information systems research. 1998, vol. 9, num. 4, pp. 17-39

JAVIDAN, M. "Core competence. what does it mean in practice?". Long Range Planning, 1998, vol. 31, no 1, pp. 60-71.

JEFFERS, P. I.; MUHANNA, W.A.; NAULT, B.R. "Information Technology and Process Performance: An Empirical Investigation of the Interaction Between IT and Non-IT Resources”. 2008. Decision Sciences, Vol. 39, nº 4, pp. 703-735.

JÖRESKOG, K.G. “An approach to confirmatory maximum likelihood factor analysis”. Psychometrica, 1969, vol. 34, pp. 183-202.

JOSHI, K. “A model of users' perspective on change: The case of information systems technology implementation”. MIS Quarterly. 1991, vol. 15, nº 2, pp. 229-242.

KANUNGO S.; SADDAVARTI, S; SRINIVAS, Y; "Relating IT strategy and orgnaizational culture: an empirical study of public sector units in India”. Journal of Strategic Information Systems, 2001. Vol. 10, p. 29.57

KAPLAN, R.S., NORTON, D.P. "Putting the balanced scorecard to work". Harvard Business Review, 1993, vol. 71, nº 5, pp. 71-79.

KARNANI, A.; Generic competitive strategies: an analytical approach”. Strategic Management Journal, 1984, vol. 5, num. 4, pp. 367-380 
KEEN, P.G.W. Shaping the future: business design through information technology. Boston: Harvard business school press. 1991.

KEEN, P.W. "Information technology and the management difference: A fusion map". IBM systems journal. 1993, vol. 32, nº 1, pp. 17-39.

KETTINGER, W.J. GROVER, V., GUHA, S., SEGARS, A. "Strategic information systems revisited; A study in sustainability and performance”. MIS Quarterly, 1994, vol. $18, \mathrm{n}^{\mathrm{o}} 1$, pp. 31-58.

KIM, L.; LIM, Y. "Environment, generic strategies and performance in a rapidly developing country: a taxonomic approach". Academy of management journal, 1988, vol.31, pp. 802-827

KING, W.R. "Strategic planning for management information systems". MIS Quarterly, 1978, vol. 2, num. 1, pp. 27-38

KING, S. F., AND T. F. BURGESS "Beyond Critical Success Factors: A Dynamic Model of Enterprise System Innovation," International Journal of Information Management, 2006, vol. 26, pp 59-69.

KING A.W, ZEITHAML, CARL P. "Competencies and firm performance: examining the causal ambiguity paradox". Strategic Management Journal. 2001, Vol. $22, n^{\circ} 1$, pp. $75-99$

KINNEAR, T.C., TAYLOR, J.R. Investigación de Mercados: Un enfoque aplicado. Nueva York: McGraw-Hill Interamericana, 1998.

KOGUT, B., ZANDER, U. "Knowledge of the firm, combinative capabilities and the replication of technology”. Organization Science, 1992, vol. 3, n 3, pp. 383-397.

KRAAIJENBRINK, J. “The Resource-Based View: A Review and Assessment of Its Critiques”. Journal of Management, 2010, vol. 36 num. 1, pp. 349-372. 
KRELL, K.; MATOOK, S. "Competitive advantage from mandatory investments: an empirical study of Australian firms". Journal of Strategic Information Systems, 2009, vol. 18 , num. 1 , pp. $31-45$

KUMAR, K.; SUBRAMANIAN, R.; YAUNGER, C. "Puer versus hibryd: performance implications of Porter's generic strategies". Health Care Management Review, 1997, vol. 22, num. 4, pp. 47-60

LAVE, J., WENGER, E. Situated learning: Legitimate peripheral participation. New York: Cambridge University Press, 1991

LAWRENCE, P.R., LORSCH, J.W. Organization and Environment: Managing Differentiation and Integration. Boston: Harvard Business School Press, 1986

LEDERER, A.L.; SALMELA, H. "Toward a theory of strategic information systems planning", journal of strategic information systems, 1996, vol. 5, num. 3, pp. 237253

LEE, D.M.S., TRAUTH, E.M., FARWELL, D. "Critical skills and knowledge requirements of IS professionals: A joint academic/industry investigation”. MIS Quarterly. 1995, vol. 19, nº 3, pp. 313-340.

LEE, J.; MILER; D. "Strategy, environment and performance in two technological contexts: contingency theory in Korea". Organizaion Studies, 1996, vol. 17, num. 5, pp. $729-750$

LEI, D., HITT, M.A., BETTIS, R. "Dynamic core competences through metalearning and strategic context”. Journal of Management, 1996, vol. 22, no 4, pp. 549569.

LEIDNER, D.E.; LO, J.; PRESTON, D. "An empirical investigation of the relationship of IS strategy with firm performance". Journal of Strategic Information Systems, 2011, vol. 20, p. 419-437

LEIDNER, D.E. MACKAY, J.M. "How incoming CIOs transition into their new jobs”. MIS Quarterly Executive, 2007, vol. 6, num1, pp. 17-28 
LI, Y.; TAN, C.H.; TEO, H.H.; TAN, B.C.Y. "Innovative usage of Information Technology in Singapore Organizations: do CIOs characteristics make the difference?”. IEEE Transactions on Engineering Management. 2006, vol. 53, num. 2, pp. $177-190$

LICHTENBERG, F. "The output contributions of computer equipment and personnel: a firm-level analysis". Economics of innovation and new technology. 1995. Vol. 3, num. 3, p. 201-218.

LIEBOWITZ, J., BECKMAN, T. Knowledge Organizations: What Every Manager Should Know. Boca Raton: St. Luci press, 1998.

LIM, J.H.; STRATOPOULOS, T.C. "IT innovation capability and returns on IT innovation persistence”. En: AMCIS 2008 Proceedings, 2008, paper 247

LIPPMAN, S.A., RUMELT, R.P. "Uncertain imitability. an analysis of interfirm differences in efficiency under competition”. Bell Journal of Economics, 1982, vol. 23, pp. 418-438.

LOCKETT, A., THOMPSON, S., MORGENSTERN, U. "The development of the resource-based view of the firm: A critical appraisal". International Journal of Management Review. 2009, vol. 11, nº 1, pp. 9-28.

LOVEMAN, G. An assessment of the productivity impact of information technologies. En: Allen, T.J. y Scott, M., (ed)., Information technology and the corporation of the 1990’s:. Massachussets: MIT Press. 1994. p. 84-110.

LUO, J.; FAN, M.; ZHANG, H. "Information technology and organizational capabilities: a longitudinal study of the apparel industry”. Decision Support Systems, 2012, vol. 53, num. 1, p. 186-194

MACKENZIE, S.S.; PODSAKOFF, P.M.; PODSAKOFF, N.P. "Construct measurement and validation procedures in MIS and behavioural research: integrating new and existing techniques”. MIS Quarterly, 2011, vol. 35, num. 2, pp. 293-334 
MAHMOOD, M,A., MANN, G.J. "Measuring the organizational impact of information technology investment: An exploratory study". Journal of Management Information Systems, 1993, vol. 10, nº 1, pp. 97-122.

MAHONEY, J., PANDIAN, J.R. "The resource-based view within the conversation of strategic management”. Strategic Management Journal, 1992, vol. 13, n 5, pp. 363-380.

MAKADOK, R. "Toward a synthesis of the resource-based and dynamic-capability views of rent creation”. Strategic Management Journal, 2001, vol. 22, pp. 387-401.

MALBURG, C. “Competing on costs”. Industry Week, 2000, vol. 249, num. 17, p. 31

MALONE, T. "Is empowerment just a fad?. Control, decision making and IT.". Sloan management review. 1997. Vol. 38, num. 2, p. 23-25.

MALONE, T.W.; CROWSTON, K; LEE, J.; PENTLAND, B.;. "Tools for inventing organisations: towards a handbook for organisational processes". Management Science, 1999, vol. 45, num. 3, pp. 425-441

MARTÍNEZ-SIMARRO, D.; PINAZO-SÁNCHEZ, J.M.; ALMARCHA-VELA, R. "Gaps to fill between theoretical interoperable quality and food safety environment and enterprise implementations”. En: Popplewell, K., Harding, J. Poler, R., Chalmeta, R. (Eds.). Enterprise Interoperability IV. Lonres: Springer, 2010, pp.377-386

MATA, F.J.; FUERST, W.L.; BARNEY, J.B. "Information technology and sustained competitive advantage: a resourced-based analysis”. MIS quarterly. 1995. Vol. 19, num. 4, p. 487-505.

McAFEE, A.; BRYNJOLFSSON, E. "Investing In the IT that makes a competitive difference”. Harvard Business Review, 2008, vol. 86, num.7, pp. 98-107

McCRAKEN, L. "Differentiation: win new business with less effort". Principal's Report, vol. 2, pp. 283-295 
McEVILY, S., CHAKRAVARTHY, B. "The persistence of knowledge-based advantage: An empirical test for product performance and technological knowledge". Strategic Management Journal, 2002, vol. 23, pp. 285-305.

McFARLAN, E.W.; McKENNEY, J.L.; PYBURN, P. "The information archipielago, ploating a course”. Harvard Business Review, vol. 1, num. 1, pp. 145-156

McKENNEY, J. L., D. COPELAND, ASSOCIATES. Waves of Change: Business Evolution through Information Technology. Cambridge, MA: Harvard Business School Press 1995

MELVILLE, N.; KRAEMER, K.; GURBAXANI, V. "Information technology and organizational performance: an integrative model of IT business value". MIS Quarterly. 2004. Vol. 28, num. 2, p. 283-322.

MILES, R.E.; SNOW, C.C. Organizational strategy, structure and process. Nueva York: McGraw-Hill, 1978

MILLER, A. Strategic Management. 3ª Ed. Nueva York: McGraw-Hill, 1998

MILLER, A.; DESS, G. “Assessing Porter's (1980) model in terms of its generalizability, accuracy and simplicity”. Journal of Management Studies, 1993, vol. 30 , pp. 553-585

MILLER, D. "Configurations of strategy and structure: towards a synthesis”.Strategic Management Journal, 1986, vol. 7, num. 3, pp. 233-249

MILLER, D. “The genesis of configuration”. Academy of Management Review, vol. 12, num. 1, pp. 686-701

MILLER, D. "Relating Porter's business strategies to environment and structure analysis and performance implications". Academy of Management Journal. 1988, vol. 31, num. 2, pp-280-308 
MILLER, D.; FRIESEN, P.H. "Porter's (1980) generic strategies and performance: an empirical examination with American data. Part I: testing Porter". Journal of Management Studies, 1988, vol. 7, p. 37-55

MINTZBERG, H. Structuring of organizations. New Jersey: Prentice Hall 1979.

MINTZBERG, H. “The strategy concept I: five Ps for strategy”. California management review. 1987. Vol. 30, num 1, p.11-24.

MINTZBERG, H.; WATERS, J.A. "Of strategies, deliberate and emergent". Strategic Management Journal. 1985, vol. 6, num. 3, pp. 257-272

MIQUEL, S.; BIGNÉ, E.; LÉVY, J-P.; CUENCA, A.C. Y MIQUEL, Mª .Investigación de mercados. Madrid: McGraw Hill, 1997

MITHAS, S.; KRISHNAN, M.S.; FORNELL, C. "Why do customer relationship management applications affect customer satisfaction?” Journal of Marketing, 2005, vol. 69 , num. 4, pp. 201-209

MITHAS, S., TAFTI, A., BARDHAN, I., et al. "Information technology and firm profitability: Mechanism and empirical evidence". MIS Quarterly, 2012, Vol. 36, $\mathrm{n}^{\circ}$ 1, pp. 205-224.

MITRA, S., CHAYAM, A.K. "Analyzing cost-effectiveness of organizations: The impact of information technology spending”. Journal of Management Information Systems. 1996, vol. 13, num. 2, pp. 29-57.

MONTGOMERY, C.A. Resource-based and Evolutionary Theories of the Firm: Towards a Synthesis. Massachussetts: Kluwer Academic Publishers, 1995.

MORCILLO, P., RODRÍGUEZ, J.M., FERNÁNDEZ, F., RODRÍGUEZ, J. "El oficio de la empresa como base de la estrategia”. En: Morcillo, P., Fernández, J. Nuevas claves para la dirección estratégica. Barcelona: Ariel Economía, 2002, pp. 261-288. 
MOSAKOWSKI, E. "Strategy making under causal ambiguity: Conceptual issues and empirical evidence”. Organization Science, 1997, vol. 8, n 4, pp. 414-442

MUELLER, R.O. Basic principles of structural equation modeling. An introduction to LISREL and EQS. New York: Springer Texts in Statistics, 1996

NATH, P; NACHIAPPAN, S.; RAMANATHAN, R. "The impact of marketing capability, operations capability and diversification strategy on performance: A resource-based view". Industrial Marketing Management, 2010, vol. 39 num. 2, pp. $317-329$

NELSON, R.R. "Why do firms differ and how does it matter?". Strategic Management Journal, 1991, vol. 12, pp. 61-74.

NELSON, R.R. "Recent evolutionary theorizing about economic change". Journal of Economic Literature, 1995, vol. 33, pp. 48-90.

NELSON, R.R., WINTER, S.G. An Evolutionary Theory of Economic Change. Cambridge: Harvard University Press, 1982

NEO, B.S. "Factors facilitating the use of information technology for competitive advantage: An exploratory study". Information and Management. 1988, vol. 15, pp. 191-201.

NEWBERT; S.L. "value, rareness, competitive advantage and performance: a conceptual-level emprirical investigation of the resourced-based view of the firm". Strategic Management Journal, 2008, vol. 29, p. 745-768

NOLAN, R.; MCFARLAN, F.W. "Information technology and the board of directors”. Harvard Business Review, 2005, vol. 86, num.10, pp. 96-106

NONAKA, I. "A dynamic theory of organizational knowledge creation". Organization Science, 1994, vol. 5, $\mathrm{n}^{\mathrm{o}}$ 1, pp. 14-37.

NONAKA, I., KONNO, N. "The concept of 'Ba': Building a foundation for knowledge creation”. California Management Review, 1998, vol. 40, nº 3, pp. 40-54. 
NONAKA, I., TAKEUCHI, H. The knowledge-Creating Company. How Japanese Companies Create the Dynamics of Innovation. New York: Oxford University Press, 1995

OCDE. Good Governance for Digital Policies: How to Get the Most Out of ICT. The Case of Spain's Plan Avanza. New York: OCDE publishing. 2010.

OH, W.; PINSONNEAULT, A. "On the assessment of the strategic value of information technologies: conceptual and analytical approaches". MIS Quarterly, 2007 vol. 31 , num.2, pp.239-265

OLINER, S., SICHEL, D. "The resurgence of growth in the late 1990s: Is information technology the story?". Journal of Economic Perspective. 2000, vol. 14, $\mathrm{n}^{\mathrm{o}} 4, \mathrm{pp} 3-22$.

ORLIKOWSKI, W.J. "Improvising Organizational Transformation Over Time: A Situated Change Perspective”. Information Systems Research. 1996, vol. 7, nº 1, pp. 63-92.

ORLIKOWSKI, J; LACONO, C.S. "Desperately seeking the IT in IT research. A call to theorizing the IT artefact”. Information system research. 2001, Vol 12, num. 2, p. 121134

PALACIOS, D. “La creación de competencias distintivas dinámicas mediante la gestión del conocimiento y su efecto sobre el desempeño. Análisis empírico en las industrias de biotecnología y telecomunicaciones". Tesis Doctoral. Director: César Camisón. Universidad Jaume I, Facultad de Ciencias Jurídicas y Económicas, Departamento de Administración de Empresas y Marketing, 2002

PANDYA, K.V.; KARLSSON, A.; SEGA, C.; CARRIE, A. "Towards the manufacturing enterprise of the future". International Journal of Operations and Production Management, 1997, vol.17 num. 5, pp. 502-521

PANKO, R. “Is office productivity stagnant?”. MIS Quarterly, vol. 15. 1991, no 2, pp. 191-203. 
PARSONS, G.L. Fitting information systems technology to corporate needs: the linking strategy. Harvard business school: 1993. Teaching note 9-183-176.

PELHAM, A.M.; WILSON, D.T. "A longitudinal study of the impact of market structure, firm structure, strategy, and market orientation culture on dimensions of small-firms performance”. Journal of the Academy of Marketing Science, 1996, vol. 24, num. 1, pp. 27-43

PENROSE, E.T. The theory of growth of the firm. New York: Wiley, 1959

PEPPARD, J ; WARD, J. "Beyond strategic information systems. Towards an IS capability”. Journal of Strategic Information Systems, 2004, vol. 13, pp. 167-194

PETER, J.P. Y CHURCHILL, G.A. "Relationship among research design choices and psychometric properties of rating scales. A Meta-analysis". Journal of Marketing Research, 1996, vol. 23, pp. 1-10.

PETERAF, M.A. "The Cornerstone of Competitive Advantage. A Resource-Based View”. Strategic Management Journal, 1993, vol. 14, pp. 179-191.

PETERS, T.J., WATERMAN, R.H. In search of excellence: Lessons from America's best-run companies. Nueva York: Harper \& Row Publishers, 1982

PICCOLI, G.; YVES, B. "Review: IT dependent strategic iniciatives and sustained competitive advantage: a review and synthesis of the literature”. MIS Quarterly. 2005. Vol. 29, num. 4. p. 747-776

PORTER, M.E. "How competitive forces shape strategy", Harvard Business Review, 1979, Marzo/Abril, pp. 137-145

PORTER, M.E. Competitive Strategy. New York: The free press 1980

PORTER, M.E. Competitive advantage creating and sustaining superior performance. New York: The free press 1985

PORTER, M.E. "From competitive advantage to corporate strategy". Harvard Business Review. 1987, vol.65, num. 3, pp. 43-59 
PORTER, M.E. "What is strategy". Harvard Business Review. 1996, Vol. 74, num. 6, pp. $61-78$

PORTER M.E.; MILLAR, V.E. "How information gives you competitive advantage". Hardvard business review. 1985. Vol. 79, num. 3, p. 149-160.

POWELL, T.C.; DENT-MICALLEF, A. "Information technology as competitive advantage: the role of human, business and technology resources". Strategic management journal. 1997. Vol. 8, num. 5, p. 375-405.

PRAHALAD C.K.; HAMEL, G. "The core competence of the organization". Harvard business review. 1990. Vol. 68, num. 3, p. 79.93

PRAHALAD, C.K., HAMEL, G. "Strategy as a field of study. Why search for a new paradigm?”. Strategic Management Journal, 1994, vol. 15, pp. 5-16.

PRASAD, B.; HARKER, P. "Examining the contribution of information technology toward productivity and profitability in US retail banking". The Wharton financial institutions center working papers. 1997.

PRESTON, D.S.; KARAHANNA, E. "How to develop a shared vision, the key of strategic alignment”. MIS Quarterly Executive. 2009, vol. 8, num. 1, pp 1-8

PRIEM, R. L., BUTLER, J. E. "Tautology in the Resource-based View and the Implications of Externally Determined Resource Value: Further Comments.” Academy of Management Review, 2001, vol. 26, pp. 57-66.

PROVOST, L., LEDDICK, S. "Kow to take multiple measures to get a complete picture of organizational performance”. National Productivity Review, 1993, pp. 477-490.

PYBURN, P.J. "Linking the MIS plan with corporate strategy: an exploratory study". MIS Quarterly, 1983, vol. 7, num. 2, pp. 1-14

RAGU-NATHAN, B.; RAU-NATHAN, T.S.; TU, Q.; SHI, Z. "Information management (IM) strategy: the construct and its measurement". Journal of Strategic Information Systems, 2001, vol. 10, num. 4, pp. 265-289 
RAI, A., PATNAYAKUNI, R., PATNAYAKUNI, N., "Technology investment and business performance". Communications of the ACM, 1997, vol. $40 \mathrm{n}^{\circ}$ 7, pp. 89-97.

RAI, A.; PATNAYAKUNI, R.; SETH, N. "Firm performance impactc of digitally enabled supply chain integration capabilities”. MIS Quarterly, 2006, vol. 30, num.2, pp. $225-246$

RAMASUBBU, N.; MITHAS, S.; KRISHNAN, M.S. "High tech, high touch: the effect of employee skills and customer heterogeneity on customer satisfaction with enterprise system support services”. Decision support systems, 2008, vol. 44, num. 2, pp. 509-523

RAVICHANDRAN, T., LERTWONGSATIEN, C. "Impact of information systems resources and capabilities on firm performance: A resource-based perspective“. En: L. Applegate, R. Galliers, J.I. DeGross (eds.). Proceedings of 23rd international conference on information systems., Barcelona, 2002, pp. 577-582.

RAVICHANDRAN, T., LERTWONGSATIEN, C. "Effect of information systems resources and capabilities on firm performance: a resource-based perspective“. Journal of management information systems. 2005, vol. 21, num. 4, pp. 237-276

RAY, G.; MUHANNA, W.; BARNEY, J.B. "Information technology and the performance of the customer service process: a resource-based analysis". MIS Quarterly. 2005, vol. 29, num. 4, pp. 625-652

REED, R., DEFILLIPPI, R.J.“Causal ambigüity, barriers to imitation, and sustainable competitive advantage”. Academy of Management Review, 1990, vol. 15, nº 1, pp. 88102.

REILLY, T. "Be a champion of the solution”. Industrial Distribution, 2002, vol. 91, num.5, pp. 61-78

REPONEN, T. "Organizational information management strategies". Information Systems Journal, 1994, vol. 4, num. 4, pp. 27-44 
RICHARDSON, O.; DENNIS, C.; "UK vineyards sector case study: analysis of retail activities using exemplar strategic marketing tools”. British Food Journal, 2003, vol. 105, num.9, pp. 634

RIVARD, S.; RAYMOND, L.; VERREAULT, D. "Resource-based view and competitive strategy: an intended model of the contribution of the information technology to firm performance". Journal of strategic information system. 2006, Vol. 15 , p. $29-50$

ROACH, S. America's technology dilemma: a profile of the information economy. Nueva York: Morgan Stanley. 1987.

ROACH, S. "Services under siege, the restructuring imperative". Harvard business review. 1991, vol. 69, num. 5, p. 82-91.

ROSS, J.W.; BEATH, C.M.; GOODHUE, D.L. "Develop long-term competitiveness through IT assets”. Sloan management review. 1996. Vol. 38, num. 1, p. 31-42.

ROUSE, M.J., DAELLENBACH, U.S. "Rethinking research methods for the resourcebased perspective: Isolating sources of sustainable competitive advantage". Strategic Management Journal, 1999, vol. 20, nº 5, pp. 487-494.

RUMELT, R.P. "How much does industry matter?". Strategic Management Journal, 1991, vol. 12, nº 3, pp. 167-185.

SABHERWAL, R.; CHAN, Y.E. "Alignment between business and IS strategies: a study of prospectors, analyzers and defenders". Information systems research. 2001, vol. 12, num. 1, pp. 11-33

SALUNKE, S; WEERAWARDENA, J ; MCCOLL-KENNEDY, J. R. "Towards a model of dynamic capabilities in innovation-based competitive strategy: Insights from project-oriented service firms". Industrial Marketing Management, 2011, Vol.40(8), pp.1251-1263 
SAMBAMURTHY, V., ZMUD, R.W. (1994). IT Management Competency Assessment: A Tool for Creating Business Value Through IT. Morristown, New York: Financial Executives Research Foundation.

SAMBAMURTHY, V., ZMUD, R.W. “Arrangements for Information Technology Governance: A Theory of Multiple Contingencies”. MIS Quarterly. 1999, vol. 23, num. 2, pp. 261-290.

SAMBAMURTHY, V.; BHARADWAJ, A.; GROVER, V. "Shaping agility through digital options: reconceptualizing the role of information technology in contemporary firms”. MIS quarterly. 2003. Vol. 27, num. 2, p. 237-263

SÁNCHEZ, R., HEENE, A., THOMAS, H. Dynamics of Competence-Based Competition. Theory and Practice in the New Strategic Management. Oxford: Elsevier Science Publishers, 1996

SANTARELLI, E., PIERGIOVANNI, R. "Analysing literature-based output indicators: the Italian experience”, Research Policy, 1996, vol. 25, pp. 689-711.

SANTHANAM, R.; HARTONO, E. "Issues in linking information technology capability to firm performance". MIS Quarterly. 2003. Vol. 27, num. 1, p. 125-153

SCHEIN, E.H. "The role of the CEO in the management of change: the case of Information Technology". En : T. Kochan y M. Unseem (eds.). Transforming Organizations. New York: Oxford University Press, 1992, pp. 80-96

SCHOEMAKER, P. Y AMIT, R.H. "Investment in Strategic Assets. Industry and Firm-Level Perspectives”. En Shirivastava, P.; Huff, A.; Dutton, J. (eds.), 1994, pp. $3-33$.

SCHUMPETER J.A. The theory of economic development. Cambridge, MA: Harvard Business Press, 1934

SCHUMPETER J.A. Capitalism, Socialism and Democracy. New York: Harper, 1975 
SELZNICK, P. Leadership in Administration. A Social Interpretation. Nueva York: Harper \& Row, 1957

SENGE, P.M. The fifth Discipline: The Age and Practice of the Learning Organization. London: Century Business, 1990

SETHI, V.; KING, W.R., "Development of measures to assess the extent to which an information technology application provides competitive advantage", Management sciences, 1994, vol. 40, num. 12, p. 1601-1628

SHER, P.J; LEE, V.C. "Information technology as facilitator for enhancing dynamic capabilities trough knowledge management”. Information \& Management. 2004, vol. 41, num. 8, pp. 933-945

SIERRA, R. Técnicas de investigación social. 10ª ed. Madrid: Paraninfo, 1995.

SIMON, F.; TELLIER, A. "How do actors shape social networks during the process of new product development?”. European Management Journal, 2011, vol. 29, num. 5 , p. $414-430$

SIMONIN, B. "Ambiguity and the process of knowledge transfer in strategic alliances”. Strategic Management Journal, 1999, vol. 20, pp. 595-623.

SIQUEIRA, A. C.; COSH, D.C. "Effects of product innovation and organizational capabilities on competitive advantage: evidence from UK small and medium manufacturing enterprises". International Journal of Innovation Management, 2004, vol. 12, num. 2, p. 113-137

SMITH, K.G., GUTHRIE, J.P., CHEN, M.J. "Strategy, size and performance". Organization Studies, 1989, vol. 10, nº 1, pp. 63-81.

SMITS, M.T.; VAN DER POEL, K.G.; RIBBERS, P.M.A. "Assessments of information strategies in insurance companies in the Netherlands". Journal of Strategic Information Systems, 1997, vol. 6, num. 2, pp. 129-148 
SMITH, W.K.; TUSHMAN, M.L. "Managing strategic contradictions: a top management model for managing innovation streams". Organization Sciences, 2005 vol. 16 , num. 5, pp. 522-536

SOH, C.; MARKUS, M.L. "How IT creates business value: a process theory synthesis”. En: J.I. DeGross, G. Ariav, C. Beath, R. Hoyer, C. Kemerer (Eds). Proceedings of the $16^{\text {th }}$ International Conference on Information Systems. Amsterdam, Holanda: 1995, pp. 29-41

SOHAL, A.; MOSS, S.; Ng, L. "Comparing IT success in manufacturing and service industries". International journal of operations and production management. 2001. Vol. 21, num. 1, p.30-45.

SONG, L.Z.; SONG, M. "the role of information technologies in enhancing R\&DMarketing integration: an empirical investigation". Journal of Product Innovation Management, 2010, vol. 27, pp. 382-401

SONG, M.; VAN DER BIJ, H.; WEGGEMAN, M. "Determinants of the level of knowledge application: a knowledge-based ad information-processing perspective". Journal of product information management. 2005. Vol. 22, num. 5, p. 430-444.

SPANOS, Y.E.; LIOUKAS, S.; "An examination into de causal logic of rent generation: contrasting Porter's competitive strategy framework and the resourcebased perspective". Strategic management journal. 2001, Vol. 22, Num. 10, pp. 907934

SPANOS, Y.E.; ZARALIS, G.;LIOUKAS, S. "Strategy and industry effects on profitability: evidence from Greece". Strategic Management Journal. 2004, vol. 25, num. 2, p. 139

SPENDER, J.C., GRANT, R. M. "Knowledge and the firm: Overview". Strategic Management Journal, 1996, vol. 17, pp. 5-9.

SPRAGGON, M.; BODOLICA, V. "A multidimensional taxonomy of intra-firm knowledge transfer processes”. Journal of Business Research, 2012, vol. 65, num. 9, p. $1273-1282$ 
STALK, G., EVANS, P., SHULMAN, L.E. (1992). "Competing on capabilities. The rules of corporate strategy". Harvard Business Review, vol. 70, nº 2, pp. 57-69.

STRASSMANN, P.A. The squandered computer: Evaluating the business alignment of information technologies. New Canaan, CT: Information Economics Press, 1997

STRATOPOULOS, T.C.;LIM, J.H.'IT Innovation persistence: an oxymoron?" Communications of the ACM, 2010, vol. 53, num. 5, pp. 142-146

SZULANSKI, G. "Exploring internal stickiness: Impediments to the transfer of best practice within the firm". Strategic Management Journal, 1996, Winter Special Issue, vol. 17, pp. 27-44.

TAI, L.A.; PHELPS, R. "CEO and CIO perceptions of information systems strategy: evidence from Hong Kong”. European Journal of Information Systems, 2000, vol. 9, num. 3, pp. 163-172

TALLON, P.P. "Does IT pay to focus? An analysis o IT business value under single and multi-focused business strategies". Journal of Strategic Information systems. 2007, vol. 16, pp. 278-300

TALLON, P.P.; KRAEMER, K.L.; GURBAXANI, V. “Executives' perceptions of the business value of information technology: a process-oriented approach". Journal of Management Information Systems. 2000, vol. 16, num. 4, pp. 145-173

TAM, K.Y. "The Impact of Information Technology Investments on Firm Performance and Evaluation: Evidence from Newly Industrialized Economies". Information Systems Research, 1998, vol. 9,nº 1, pp. 85-98.

TANRIVERDI, H. "Performance effects on Information Technology synergies in multibusiness firms”. MIS Quarterly. 2006, vol. 30, num. 1, pp. 57-77

TARAFDAR, M; GORDON, S.R. "Understanding the influence of information systems competences on process innovation: a resorce-based view". Strategic Information systems. 2007, vol 16, p. 353-392. 
TEECE, D.J., PISANO, G. “The Dynamic capabilities of the firm. An introduction”. En Dosi, G., Teece, D. y Chytry, J. (Ed.). Technology, Organization and Competitiveness. Perspectives on Industrial and Corporate change. Oxford University Press, Oxford, 1998, pp. 193-212.

TEECE, D.J., PISANO, G., SHUEN, A. "Dynamic capabilities and strategic management”. Strategic Management Journal. 1997, vol. 18, nº 7, pp. 509-533.

TEECE, D.J., RUMELT, R., DOSI, G., WINTER, S. "Understanding corporate coherence. Theory and evidence". Journal of Economic Behaviour and Organization. 1994, vol. 23, pp. 1-30.

TEO, T.S.H.; ANG, J.S.K. "How useful are strategic plans for information systems?”. Behaviour \& Information Technology, 2000, vol. 19, num. 4, pp. 275-282

TEO, T.S.H.; RANGANATHAN, C. "Leveraging IT resources and capabilities at the housing and development board”. Journal of Strategic Information Systems. 2003, vol. 12, num. 3, pp. 229-249

TEUBNER, R.A. "Strategic information systems planning: a case study from the financial services industry". Journal of strategic information systems, 2007, vol. 16, num. 1, pp. 105-125

THATCHER, M. E., OLIVER, J.R. "The impact of technology investments on a firm's production efficiency, product quality, and productivity". Journal of Management Information Systems, 2001, vol. 18 nº 2, pp. 17-45.

THOMPSON, A.;STRICKLAND, A. Crafting and implementing strategy. Nueva York: Irving McGraw-Hill , 1998

TIAN, JUN; WANG, KANLIANG; CHEN, YAN; ET AL. "From IT deployment capabilities to competitive advantage: An exploratory study in China". Information Systems Frontiers". Information systems, 2010, Vol.12, n 3, pp. 239-255 
TIPPINS M.J.; SOHI, R.S. "IT competency and firm performance: Is organizational learning a missing link?”. Strategic Management Journal, 2003, vol. 24, nº 8, pp. 745761.

TRAINOR K.J.; RAPP, A.; BEITELSPACHER, L.S; SCHILLEWAERT, N. "Integrating information technology and marketing: an examination of the drivers and outcomes of e-marketing capability” . Industrial Marketing Management. 2011, Vol 40, p. 162-174.

VENKATESH, V. "Creation of Favorable User Perceptions: Exploring the Role of Intrinsic Motivation”. MIS Quarterly. 1999, vol. 23, nº 2, pp. 239-250.

VENKATESH, V.; MORRIS, M.G.; DAVIS, G.B.; DAVID, F.D. “User acceptance of Information Technology: Toward a Unified View”. MIS Quarterly, 2003, vol. 27, num. 3, pp. $425-478$

VENKATRAMAN, N. "IT-induced business reconfiguration. En M.S. Scott Morton (Ed.). The corporation of the 1990s. New York: Oxford University Press, 1991, (pp. 122-159)

VENKATRAMAN, N. "IT-enabled business transformation: From automation to business scope redefinition”. Sloan Management Review, 1994, vol. 35, n 2, pp. 73 87.

VENKATRAMAN, N., RAMANUJAM, V. "Measurement of business economic performance in strategic research: A comparison of approaches". Academy of Management Review, 1986, vol. 11, nº 4, pp. 801-814.

VON HIPPEL, E. “' 'Sticky information' and the locus of problem solving. Implications for innovation”, Management Science, 1994, vol. 40, nº 4, pp. 429-439.

WADE, M., HULLAND, J. "Review: The Resource-Based view and information systems research: Review, extension, and suggestions for future research”. MIS Quarterly. 2004, vol. 28, nº1, pp. 107-142. 
WANG, S., RAYMOND, A.N. "Knowledge sharing: A review and directions for future research". Human Resource Management Review. 2010, vol. 20, no 2, pp. $115-131$.

WARD, J.M. "Integrating information systems into business strategies". Long Range Planning, 1987, vol. 20, num. 3, pp. 19-29

WATSON, R.T. "Influences on the IS manager's perceptions of key issues: information scanning and the relationship with the CEO". MIS Quarterly, 1990, vol. 14, no 2, pp. 217-231.

WEILL, P. "The relationship between investment in information technology and firm performance: a study of valve manufacturing sector". Information systems research. 1992. Vol. 3, num. 4, p. 307-331.

WERNERFELT, B. "A resource-based view of the firm". Strategic Management Journal. 1984, vol. 5, nº 2, pp. 171-180.

WEXELBLAT, R.L.; SRINIVASAN, N. "Planning for information technology in a federated organization”. Information \& Management, 1999, vol. 35, pp. 265-282

WHELLEN, T.L.; HUNGER, J.D. Strategic management and business policy. Upper saddle river, NJ: Pearson Prentice hall, 2006

WHITAKER, J.S.; MITHAS, M.S.; KRISHNAN, M.S. "A field study of RFID deployment and return expectations". Production and Operations Management, 2007, vol. 16, num. 5, pp. 1493-1509

WHITE, R.E. “Generic business strategies, organizational context, and performance: an empirical investigation”. Strategic Management Journal, 1986, vol. 7, num. 2, pp. 217-231

WHITTINGTON, R. What is strategy, and does it matter? London: Routledge, 1993 
WINTER, S.G. Four R's of profitability. rents, resources, routines and replication. Resource-based and evolutionary theories of the firm: towards a synthesis. C.A. Montgomery, 1995.

WOOLFE, R. "The path to strategic alignment". Information Strategy: The Executive's Journal. 1993, vol. 9, nº 2, pp. 13-23.

WORLD ECONOMIC FORUM. Global information technology report 2008-2009. Nueva York: WEF, 2009.

WORTHEN, B. "The IT factor: tech staff 's bigger role”. Wall street journal. 2007, December, 4.

WRIGHT, P.M., DUNFORD, B.B., SNELL, S.A. "Human resources and the resource based view of the firm". Journal of Management, 2001, vol. 27, $\mathrm{n}^{\circ}$ 6, pp. 701-721.

WU., F., YENIYURT S., KIM, D., CAVUSGIL, S. T. The impact of information technology on supply chain capabilities and firm performance: A resource-based view. Industrial Marketing Management, 2006, Vol. 35, nº 4, pp. 493-504.

YEH, C.; LEE, G.; PAI, J. "How information system capability affects e-business information technology strategy implementation: An empirical study in Taiwan", Business Process Management Journal, 2012, Vol. 18 num. 2 pp. 197 - 218

ZOLLO, M.; WINTER, S. "Deliberate Learning and the Evolution of Dynamic Capabilities”. Organization Science, 2002, vol. 13, nº 3, pp. 339-351. 
Pág. 322 de 329 


\section{ANEXO I. CUESTIONARIO DE CAMPO}

Nombre de la empresa:

$N^{0}$ de empleados:

ESTRATEGIA EN TIC

Indique el grado de acuerdo o desacuerdo con las siguientes afirmaciones con respecto a la media de sus competidores. e-mail contacto:

Antigüedad empresa (en años):

\begin{tabular}{|c|c|c|c|c|c|c|c|}
\hline & \multicolumn{4}{|c|}{ Parcialmente en desacuerdo } & & \\
\hline & \multicolumn{4}{|c|}{ Bastante en desacuerdo } & & & \\
\hline & & & & & & & \\
\hline $\begin{array}{l}\text { Nuestra organización lidera la innovación en sistemas de información en } \\
\text { nuestro sector }\end{array}$ & 1 & 2 & 3 & 4 & 5 & 6 & 7 \\
\hline $\begin{array}{l}\text { Nuestra organización tiende a ser el primero en la industria en cuanto a } \\
\text { desarrollar iniciativas TIC incluso si no está demostrado que dichos esfuerzos } \\
\text { sean altamente rentables }\end{array}$ & 1 & 2 & 3 & 4 & 5 & 6 & 7 \\
\hline $\begin{array}{l}\text { Nuestra organización responde rápidamente a las señales tempranas } \\
\text { relacionadas con oportunidades en el campo de las TIC }\end{array}$ & 1 & 2 & 3 & 4 & 5 & 6 & 7 \\
\hline $\begin{array}{l}\text { Nuestra organización persigue una aproximación segura y estable a la hora de } \\
\text { desarrollar nuevas iniciativas en el campo de las TIC }\end{array}$ & 1 & 2 & 3 & 4 & 5 & 6 & 7 \\
\hline $\begin{array}{l}\text { Nuestra organización adopta prometedoras innovaciones TIC una vez que } \\
\text { estas indicativas han sido probadas en nuestro sector o por nuestros } \\
\text { competidores }\end{array}$ & 1 & 2 & 3 & 4 & 5 & 6 & 7 \\
\hline $\begin{array}{l}\text { Nuestras innovaciones en TIC son examinadas cuidadosamente antes de ser } \\
\text { seleccionadas }\end{array}$ & 1 & 2 & 3 & 4 & 5 & 6 & 7 \\
\hline $\begin{array}{l}\text { Los sistemas de información de mi organización están basados } \\
\text { exclusivamente en herramientas estándares fácilmente obtenibles en el } \\
\text { mercado }\end{array}$ & 1 & 2 & 3 & 4 & 5 & 6 & 7 \\
\hline Nuestra organización no tiene objetivos TIC a largo plazo & 1 & 2 & 3 & 4 & 5 & 6 & 7 \\
\hline Nuestra organización no tiene una estrategia TIC articulada & 1 & 2 & 3 & 4 & 5 & 6 & 7 \\
\hline $\begin{array}{l}\text { Nuestra organización no tiene un patrón consistente de comportamiento } \\
\text { respecto a las TIC }\end{array}$ & 1 & 2 & 3 & 4 & 5 & 6 & 7 \\
\hline
\end{tabular}




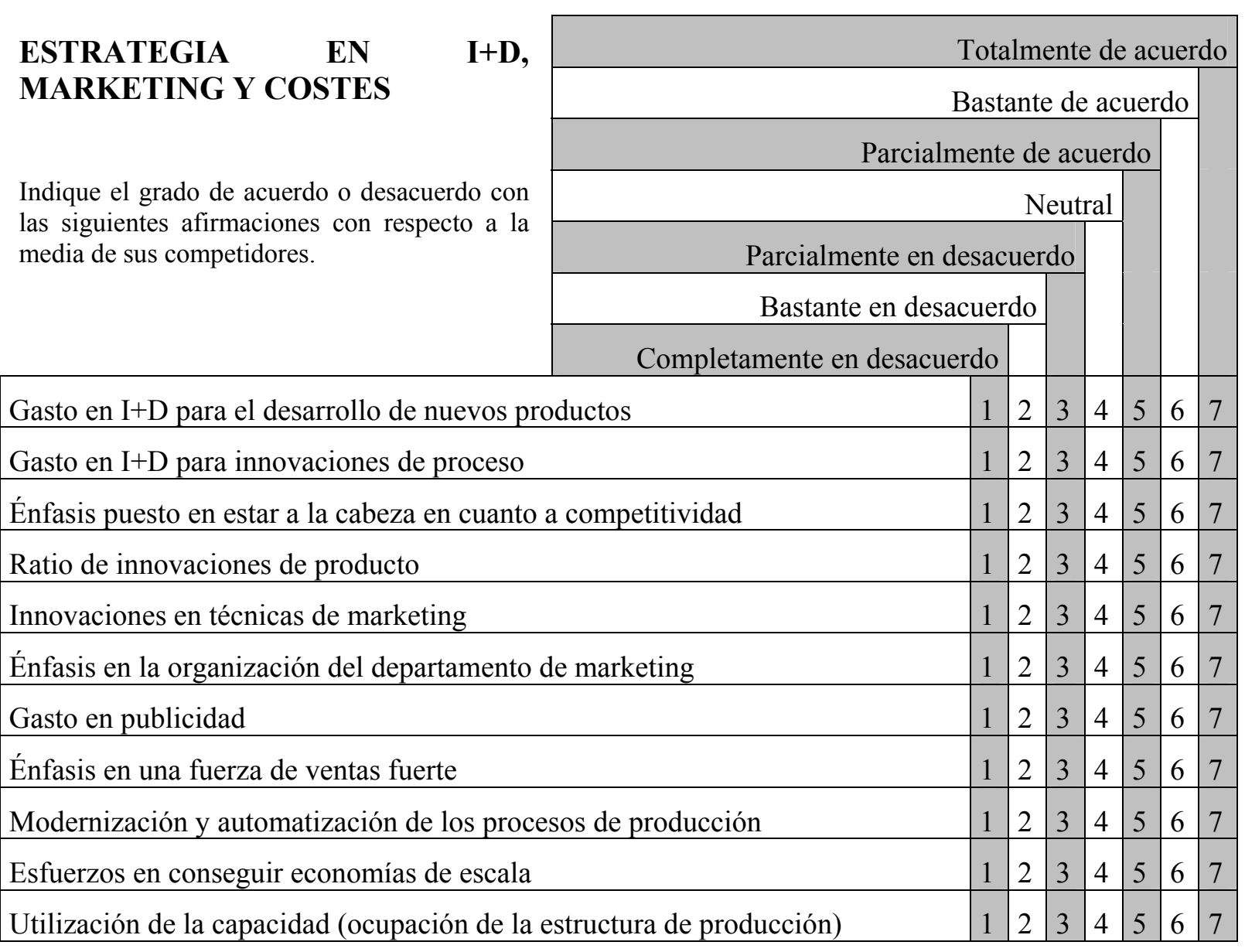

\section{RESULTADOS}

Indique el grado de acuerdo o desacuerdo con las siguientes afirmaciones con respecto a la media de sus competidores.
Totalmente de acuerdo

Bastante de acuerdo Parcialmente de acuerdo

\section{Neutral}

Parcialmente en desacuerdo

Bastante en desacuerdo

Completamente en desacuerdo

\begin{tabular}{|c|c|c|c|c|c|c|c|}
\hline La calidad del producto o servicio & 1 & 2 & 3 & 4 & 5 & 6 & 7 \\
\hline El éxito de nuevos productos o servicios & 1 & 2 & 3 & 4 & 5 & 6 & 7 \\
\hline La tasa de retención de clientes & 1 & 2 & 3 & 4 & 5 & 6 & 7 \\
\hline El nivel de Ventas & 1 & 2 & 3 & 4 & 5 & 6 & 7 \\
\hline El retorno sobre capital & 1 & 2 & 3 & 4 & 5 & 6 & 7 \\
\hline El margen Bruto de utilidad & 1 & 2 & 3 & 4 & 5 & 6 & 7 \\
\hline El retorno sobre inversión & 1 & 2 & 3 & 4 & 5 & 6 & 7 \\
\hline
\end{tabular}




\section{ANEXO II. ÍNDICE DE TABLAS}

Tabla 1.1 Corrientes teóricas en el Enfoque Basado en las Competencias....... 52

Tabla $1.2 \quad$ Clasificación de los recursos................................. 61

Tabla 1.3 Requisitos de los activos estratégicos para ser fuente de ventaja 81 competitiva.

Tabla 1.4 Recursos TI

Tabla 2.1. Definiciones de estrategia TI y términos relacionados en la literatura................................................. 118

Tabla 2.2. Visión de los roles TI en la organización.......................... 126

Tabla 2.3. Revisión de estudios desde el EBC que examinan el impacto de las TI en la ventaja competitiva.

Tabla 2.4. Taxonomía genérica de procesos de negocio...................... 133

Tabla 3.1. Magnitudes económicas del Sector Agroalimentario............... 161

Tabla 3.2. Ventajas e inconvenientes de los métodos cuantitativos y cualitativos............................................... 172

Tabla 3.3. Estudios empíricos sobre el efecto de las TI desde el EBC.......... 173

Tabla 3.4. Matriz de impacto estratégico de las TI......................... 184

Tabla 3.5. Ficha técnica del estudio empírico............................. 193

Tabla 4.1. Medidas de bondad del ajuste del modelo de medida............... 209

Tabla 4.2a. Medias y desviaciones típicas de los ítems de Estrategia innovadora en TI......................................................... 216

Tabla 4.2b. Medias y desviaciones típicas de los ítems de Estrategia conservadora en TI........................................ 216

Tabla 4.2c. Medias y desviaciones típicas de los ítems de la falta de estrategia en TI....................................................... 217

Tabla 4.3. Análisis factorial exploratorio de los ítems de innovación en TI..... 218

Tabla 4.4. Análisis factorial confirmatorio de la escala estrategia innovadora en TI.........................................................

Tabla 4.5. Análisis factorial confirmatorio de la escala estrategia conservadora en TI...........................................................

Tabla 4.6. Análisis factorial confirmatorio de la escala falta de estrategia en TI...................................................... 222

Tabla 4.7. Matriz de correlaciones entre estrategias en TI................... 223

Tabla 4.8a. Medias y desviaciones típicas ítems de Estrategia competitiva en innovación 
Tabla 4.8b. Medias y desviaciones típicas ítems de Estrategia competitiva en marketing....

Tabla 4.8c. Medias y desviaciones típicas de ítems de de Estrategia competitiva en costes...

Tabla 4.9. Análisis factorial exploratorio de los ítems de estrategia competitiva.

Tabla 4.10. Análisis factorial exploratorio ítems de estrategia negocio con tres factores.

Tabla 4.11. Análisis factorial confirmatorio de la escala estrategia competitiva en innovación.

Tabla 4.12. Análisis factorial confirmatorio de la escala estrategia competitiva en marketing.

Tabla 4.13. Análisis factorial confirmatorio de la escala de estrategia competitiva en costes.

Tabla 4.14. Matriz de correlaciones entre estrategias competitiva.................

Tabla 4.15. Medias y desviaciones típicas de medidas objetivas del desempeño

Tabla 4.16. Análisis factorial confirmatorio de la escala de estrategia competitiva en costes.

Tabla 4.17. Índices de ajuste del modelo innovador en TI-Desempeño.

Tabla 4.18. Cargas factoriales y errores del modelo innovador en TI Desempeño....................................................

Tabla 4.19. Carga e índice de fiabilidad en el modelo innovador en TI -

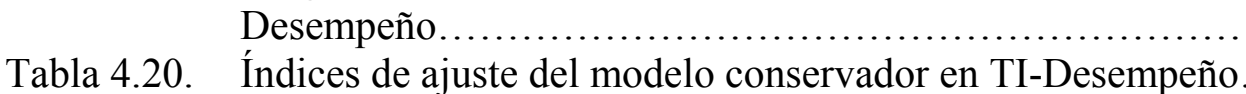

Indices de ajuste del modelo conservador en TI-Desempeño..........

Tabla 4.21. Cargas factoriales y errores del modelo conservador en TI Desempeño

Tabla 4.22. Carga e índice de fiabilidad en el modelo conservador en TI Desempeño................................................ 245

Tabla 4.23. Índices de ajuste del modelo "sin estrategia en TI"-Desempeño.....

Tabla 4.24. Cargas factoriales y errores del modelo sin estrategia en TI Desempeño.

Tabla 4.25. Carga e índice de fiabilidad en el modelo sin estrategia en TI Desempeño....................................................

Tabla 4.26. Índices de ajuste del modelo E.N basada en innovación Desempeño.

Tabla 4.27. Cargas factoriales y errores del modelo E.N. basado en innovaciónDesempeño................................................

Tabla 4.28. Carga e índice de fiabilidad en el modelo E.N. basado en innovación -Desempeño..................................... 249

Tabla 4.29. Índices de ajuste del modelo E.N basada en marketing -Desempeño

Tabla 4.30. Cargas factoriales y errores del modelo E.N. basada en marketing Desempeño. 
Tabla 4.31. Carga e índice de fiabilidad en el modelo E.N. basado en marketing -Desempeño.

Tabla 4.32. Índices de ajuste del modelo E.N basada en costes -Desempeño..... 250

Tabla 4.33. Cargas factoriales y errores del modelo E.N. basada en costes Desempeño.

Tabla 4.34. Carga e índice de fiabilidad en el modelo E.N. basado en costes Desempeño.............................................. 251

Tabla 4.35. Medias y desviaciones típicas de las variables................... 252

Tabla 4.36. Correlaciones de las variables.................................. 253

Tabla 4.37. ANOVA para las variables de control para las dos submuestras alto y bajo innovador en TI.........................................
ANOVA para las variables de control para las dos submuestras alto

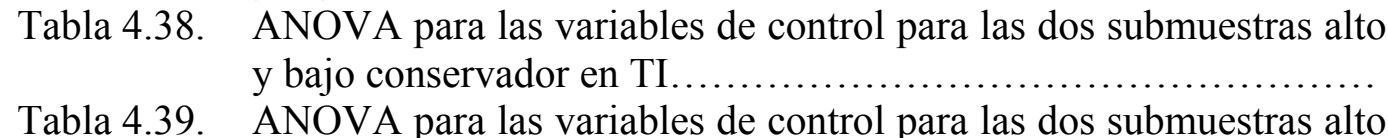
y bajo sin estrategia en TI................................ 255

Tabla 4.40. Correlaciones y test $\mathrm{z}$ de Fisher entre las estrategias competitivas y el desempeño para las submuestras Alto y Bajo innovador en TI..... 256

Tabla 4.41. Correlaciones y test $\mathrm{z}$ de Fisher entre las estrategias competitivas y el desempeño para las submuestras Alto y Bajo conservador en TI...

Tabla 4.42. Correlaciones y test $\mathrm{z}$ de Fisher entre las estrategias competitivas y el desempeño para las submuestras Alto y Bajo sin estrategia en TI. 257

Tabla 4.43. Tabla resumen. Diferencia entre correlaciones de las dos submuestras 
Pág. 328 de 329 


\section{ANEXO III. ÍNDICE DE FIGURAS}

Figura 1.1 Esquema teórico perspectiva basada en recursos................. 43

Figura 2.1 Modelo de valor de negocio de las TI....................... 115

Figura 4.1a Modelo para medir la estrategia innovadora en TI.............. 214

Figura 4.1b Modelo para medir la estrategia conservadora en TI............. 215

Figura 4.1c Modelo para medir la falta de estrategia en TI................. 215

Figura 4.2a. Modelo para medir la estrategia competitiva en innovación....... 224

Figura 4.2b. Modelo para medir la estrategia competitiva en marketing....... 225

Figura 4.2c. Modelo para medir la estrategia competitiva en costes.......... 225

Figura 4.3. Modelo para medir el desempeño organizativo................. 235

Figura 4.4. Modelo Estrategia Innovadora en TI - Desempeño Organizativo.. 240

Figura 4.5. Modelo estrategia conservadora en TI - desempeño organizativo. 242

Figura 4.6. Modelo sin estrategia en TI - Desempeño Organizativo.......... 245 